Chapman University

Chapman University Digital Commons

Educational Studies Dissertations

Spring 5-31-2017

\title{
Queer Teachers in Catholic Schools: Cosmic Perceptions of an Easter People
}

Kevin Stockbridge

Chapman University, kstock@chapman.edu

Follow this and additional works at: https://digitalcommons.chapman.edu/ces_dissertations

Part of the Curriculum and Social Inquiry Commons, and the Lesbian, Gay, Bisexual, and Transgender Studies Commons

\section{Recommended Citation}

Stockbridge, K. (2017). Queer teachers in Catholic schools: Cosmic perceptions of an Easter people (Doctoral dissertation). https://doi.org/10.36837/chapman.000032

This Dissertation is brought to you for free and open access by Chapman University Digital Commons. It has been accepted for inclusion in Educational Studies Dissertations by an authorized administrator of Chapman University Digital Commons. For more information, please contact laughtin@chapman.edu. 
Queer Teachers in Catholic Schools: Cosmic Perceptions of an Easter People

A Dissertation by

Kevin James Stockbridge

Chapman University

Orange, CA

College of Educational Studies

Submitted in Partial Fulfillment of the Requirements for the Degree of

Doctor of Philosophy in Education

Cultural and Curricular Studies

May 2017

Committee in Charge

Suzanne SooHoo, Ph.D., Chair

Peter McLaren, Ph.D., Chair

Kris DePedro, Ph.D.

Kevin Kumashiro, Ph.D. 
The dissertation of Kevin James Stockbridge is approved.

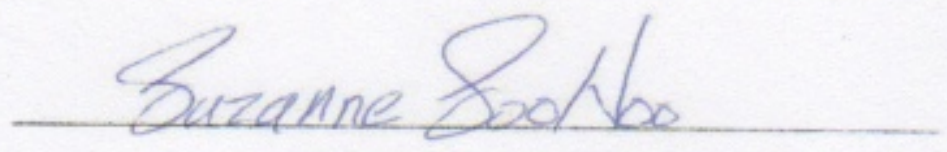

Suzanne BooHoo, PhD.. Chair
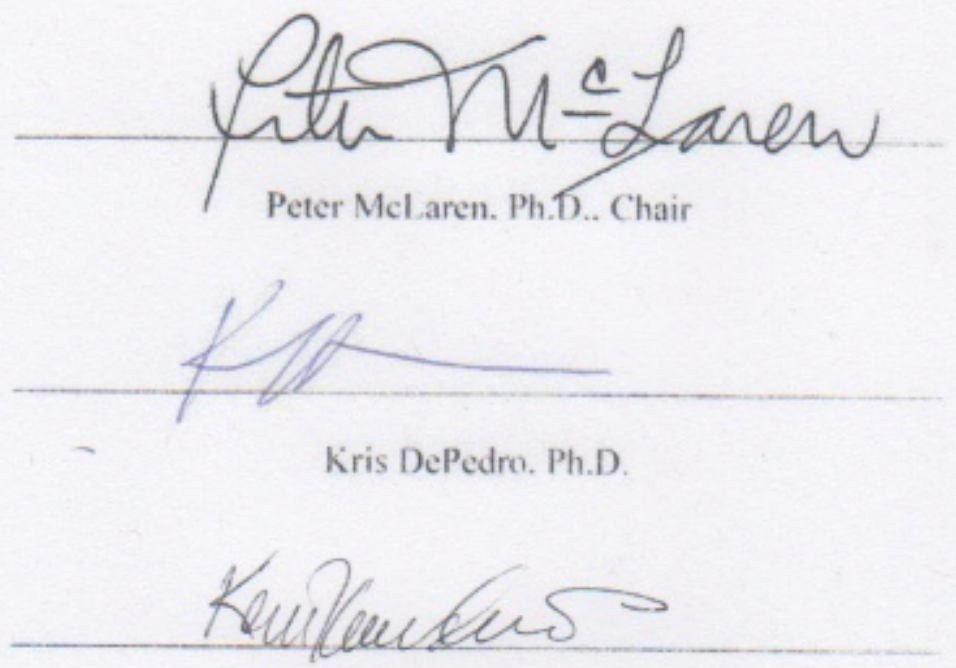

Kevin Kumashiro. Ph.D.

December 2016 
Queer Teachers in Catholic Schools: The Cosmic Story of an Easter People Copyright $(C 2016$

by Kevin James Stockbridge 


\section{DEDICATION}

Dedicated to my grandmother:

Fay Elizabeth Guidroz Stockbridge

She's swinging with the summer breeze

Her pupils on her lap and knees

Stories she tells to make us smile

Imaginations to beguile

She lights a spark in everyone

And, thus, my journey has begun 


\section{ACKNOWLEDGMENTS}

The dissertation before you has been a labor of love and joy. Although my name will be listed as the author, this research would never have come to fruition if I had done it alone. I would like to take a few lines to acknowledge the many people who have been a part of making this work a success.

First, I would like to thank the community of participants that shared the work of this study with me. Jae, Pablo, Gary, and Mateo (all pseudonyms), you are some of the bravest and most loving men that I have ever met in my life! Your joy and passion ignited my own resolve when writing got tedious. Your laughter and tears humanized the research process as we made this into something we never imagined, a vibrant and growing community of LGBTQ teachers in Catholic schools. You have forever changed me and become friends. Thank You!

My love for learning and commitment to justice were not innate attributes, but characteristics fostered in me by a loving family. To my grandmother, Fay, to whom this is dedicated, I owe the lighting of my imagination and academic mind. I am thankful for my loving mother and father, Ami and Jimmy Stockbridge, who have supported my work always. I also want to thank my sister, Stephanie Schadrack, for many conversations that have put me back on track and made me feel loved. I am thankful for the growing love of my family that has come from my brother-in-law, Chip Schadrack, and my twin niece and nephew, William and Rebecca. Family has a way of grounding the academic mind and filling it with wisdom.

Concretely, this research project could not have happened without many forms of support. I received help in the form of money, housing, food, retreat preparation, time, 
and many other forms of assistance. I list those who contributed here with a heart full of gratitude. I have chosen to set aside honorific titles to let the names of these wonderful people stand side by side without difference for they are all doctors of love. Thank you to: the Paulo Freire Democratic Project, the Teach Acceptance Organization, Ahmed Younis, Yasmine Abdel-Aal, Anat Herzog, Steven Stockbridge, Lilia Monzo, Elizabeth Zarkos, Suzanne SooHoo, Wang Yan, Peter McLaren, Charlotte Achieng-Evensen, Nancy Brink, Maria Cuca Perez, Barbara Tye, Tim Bolin, Kim Dieu, Alessandra WardGoldberg, Kevin Kumashiro, Jane Bleasdale, Ursula Aldana, Michael Duffy, Jamie Steponovich Fenton and all the others I surely have missed or who have asked to remain hidden.

Finishing a dissertation, as I have learned, requires a great deal of psycho-spiritual support. I was never lacking in this. These acknowledgements are particularly special to me. I would like to thank Anna Wilson, for patiently and knowingly seeing the queer scholar that came into her classroom still closeted but left far more liberated. I am eternally grateful to William Parham, a priest and best friend whose intelligence is unmatched and whose heart has held me through many broken moments in the light of hope. To the chosen family members who have been so important in helping me find my voice which is echoed in this dissertation. In particular, I say thank you to Sandra ‘Audaz' Arias, Preston Martin Lopez, Erin Pullin, and Jonathan Serrato. I am thankful for the love, support, and goodness that came from Ben, Akira, and Anthony in relationships which have blessed me in so many ways. To my committee, Suzanne SooHoo, Kevin Kumashiro, Peter McLaren, and Kris DePedro, I hope to be like you in the world, thank you for being honest, critical, encouraging, insightful, and unswerving. 
I am thankful for the inspiration and wisdom of great teachers and mentors like Ian Barnard and Rafael Luevano who have walked this journey with me. In a special way, I wish to acknowledge Barbara Tye, who never relented in encouragement during this process. Barbara's faith in me and my scholarship sometimes seemed far above what I thought was due to my work, but it inspired me to greatness. To such a brilliant scholar, I am thankful. Where I go with my work will be forever dedicated to you. For those who encouraged me to push through when I thought I should give up, such as mi familia de Padres Unidos, especially Patricia Huerta, Patty Huerta Meza, and Erika Perales, I acknowledge that this dissertation is complete because you spurred me on. Undying gratitude goes to Marie Painter, whose patience with me in the editing process was beyond heroic.

To my high school history teacher, Sally Hermsdorfer, I want you to know that you changed my life by being a great educator. I was going to give up on my dreams and you gave me enough room to let them breath and grow. All that is good in this work redounds to your good work in me. I will never cease to thank you!

Finally, I wish acknowledge three key players in the finishing of this dissertation. The first is Tim Bolin. In many ways, I gained a brother in this process. Hours of talks about so many projects that we shared over the years along with trips across this country for presentations allowed me to sharpen my mind against the brilliance of yours, Tim. Have no doubt that you were an essential piece in this project. You heard about most of my ideas before they ever hit the page in print. Second is Charlotte Achieng-Evensen. There is no doubt that this is my sister and fellow scholar in the academy. International travel, shared accommodations, late night dinners, oceans of coffee, and your unrelenting 
belief in me came together to make this dissertation a possibility. Thank you for pushing, laughing, questioning, waiting, and loving. You kept me accountable to good work and to myself. Finally, I want to say thank you to Suzanne SooHoo. This research project actually would not have happened if you had not asked the deepest question about subjectivity on the banks of a river in Aotearoa/New Zealand. You received more texts from about theoretical musings than you could have ever imagined as I was troubling through this research. Your ability to see my untapped potential led you to ask questions and challenge my work in ways that only proved to make me a stronger scholar. You have been my champion to others helping me to find graduate positions, explore new possibilities, and essentially focus on this study so that it could make an impact on the world. Thank you for helping me to become a colleague and for becoming a friend as well!

Thank you all. I hope this dissertation brings you pride! 


\begin{abstract}
Queer Teachers in Catholic Schools: The Cosmic Story of an Easter People

by Kevin James Stockbridge
\end{abstract}

Queer-teacher lives aren't easy! They experience isolation and bifurcation of their lives on a daily basis. How much more difficult must life be for these teachers in the theologically heteronormative context of the Catholic school? Yet, these teachers remain educators in these institutions, sensing goodness in what they are doing and in the future of these schools. Inspired by this interesting reality of tension, this study asks two important questions. First, how do queer teachers understand their identities as constructed in a Catholic school? Secondly, it wants to know what action teachers will take when they have come to an answer about their constructed identities. This dissertation incorporates queer studies, liberation theology, and critical pedagogy into a bricolage theory to fully address the intersectional lives of its participants. With a methodological approach informed by the ethics of culturally responsive research, this participatory action research begins from a moment of dialogical praxis towards the hope of social engagement. Crafted as a retreat in which queer educators share their stories of working in these institutions, this unique research incorporates the participants into the analysis process as essential actors in understanding the meaning of their own lives. The study reveals the perceptions of queer teachers about the ways that schools make meaning of their role in the educational environment as well as how they make meaning of their lives. Three major themes, "doing queer," "being queer," and "enforcing queer" show that these teachers are part of a complex reality in which their identities and performances in Catholic schools are dictated by the pull and push of fear enforced 
through many channels in the Catholic school. These themes also show that teachers are actively making new meaning about themselves and acting in ways that seek to dismantle oppression in their institutions. The study also reveals a vibrant spirituality which emerges from the daily experience of being queer in a Catholic school. Geared towards social justice, this spirituality invites us to reimagine that work for social justice may mean pushing into oppression through a paschal victimhood which transforms institutions fundamentally from within. 


\section{TABLE OF CONTENTS}

Chapter 1: "Twinkle, Twinkle Little Star. How I wonder What You Are!" .......................1

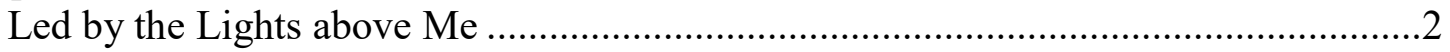

Stories of Other Star-lit Journeys..........................................................................

Shooting Stars Arc Towards Justice …………………...........................................

Walking out Into the Night ..................................................................................

Chapter 2: Building a Telescope: A Queer Theo-Critical Theory ......................................13

Lens One: Queer Theory ..................................................................................14

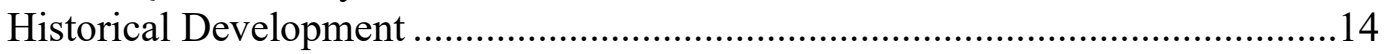

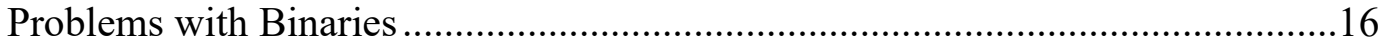

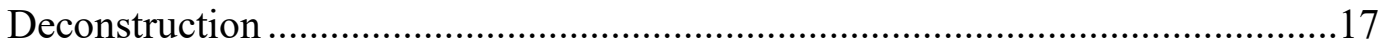

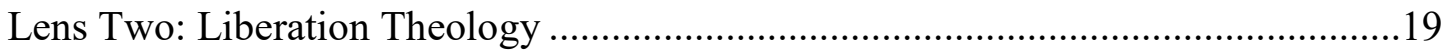

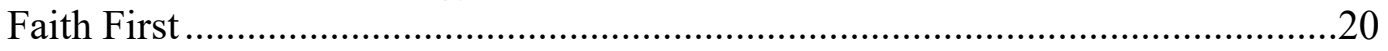

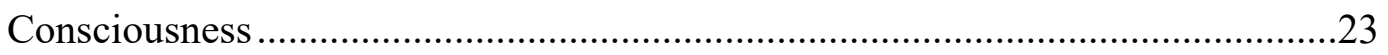

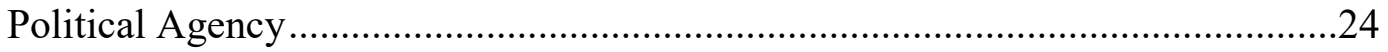

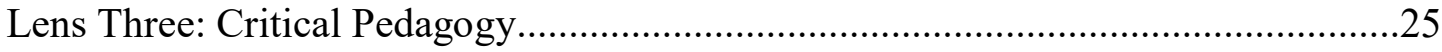

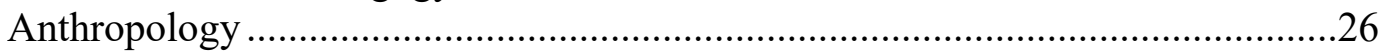

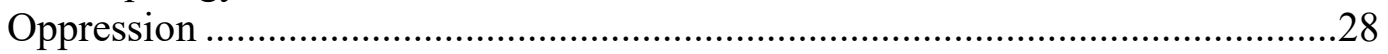

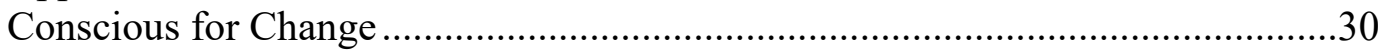

Our Telescope: A Bricolage Queer Theo-Critical Theory............................................31

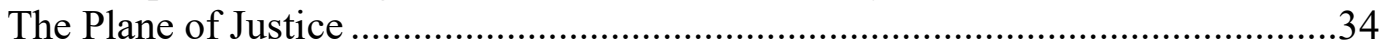

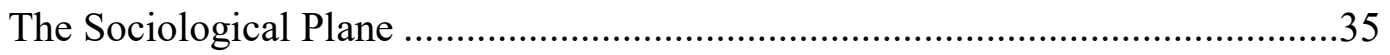

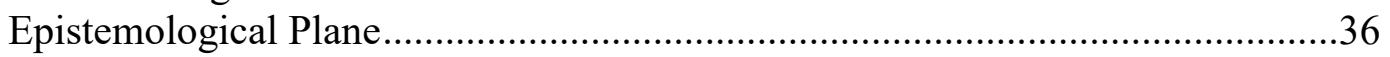

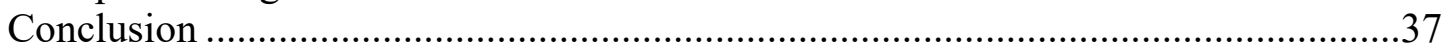

Chapter 3: Consulting the Star Maps: A Literature Review ...............................................39

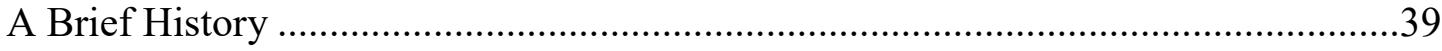

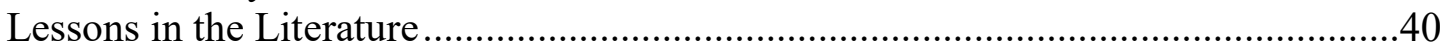

Negotiation of Public/Private Realities...................................................................4

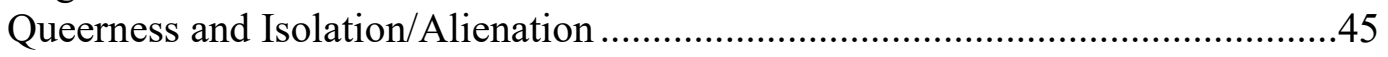

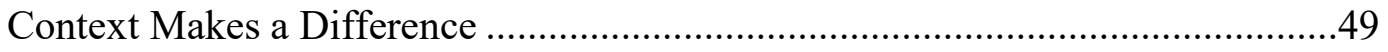

Importance of Narrative .................................................................................52

The Lacunae: Blank Spots on the Map ..................................................................5

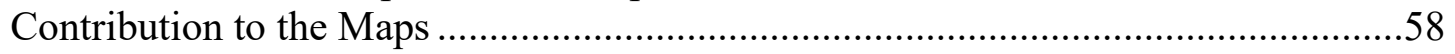

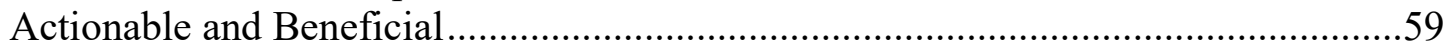

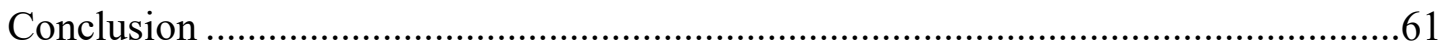

Chapter 4: Taking Time to Look Up: A Critical Ignatian Retreat .....................................62

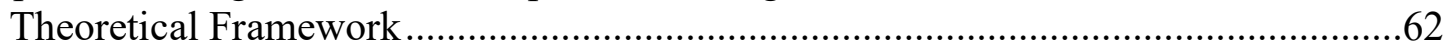

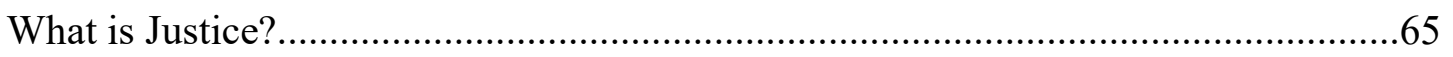

Philosophy of Method: Culturally Responsive Methodologies ......................................66

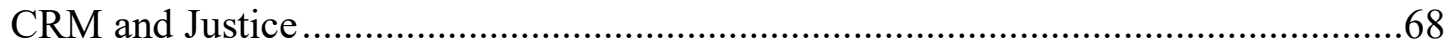

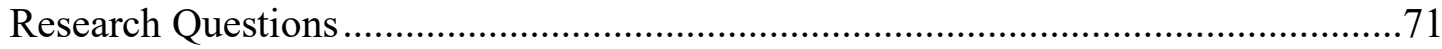

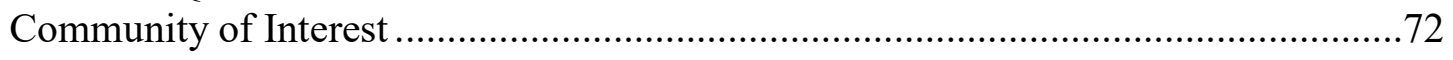


Homosexual Persons and the Universal Church................................................74

Homosexuality and the North American Church.................................................76

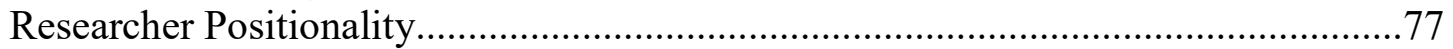

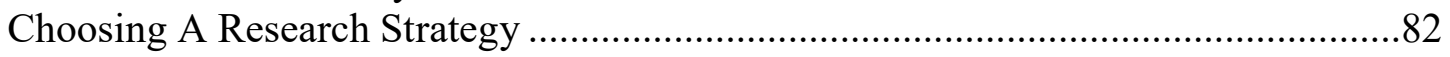

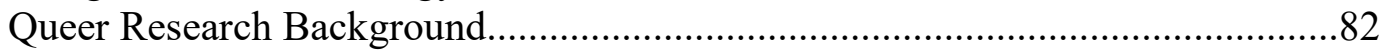

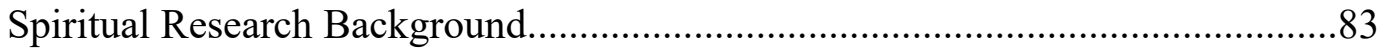

Existent Research with Queer Teachers ........................................................84

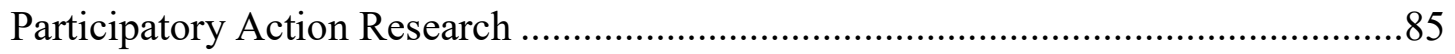

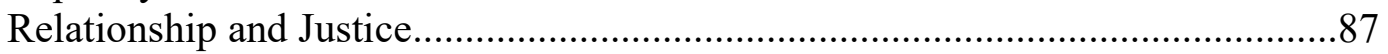

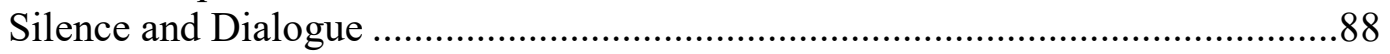

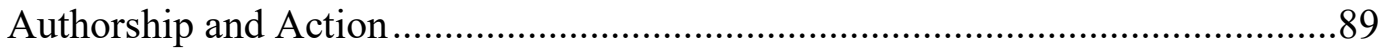

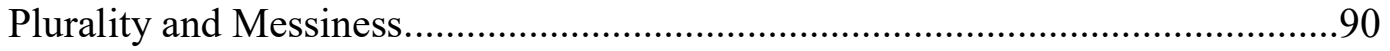

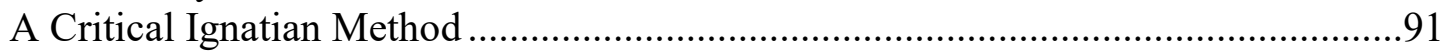

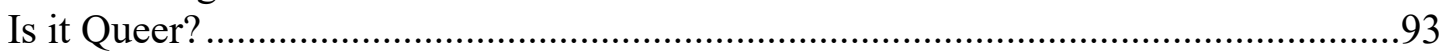

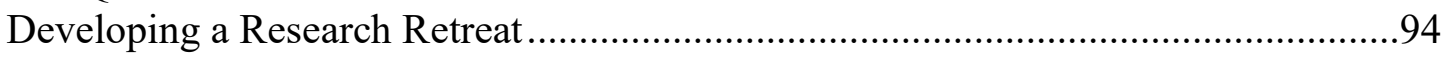

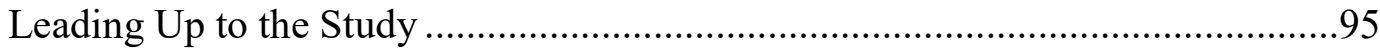

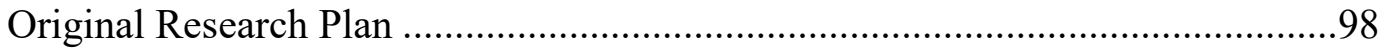

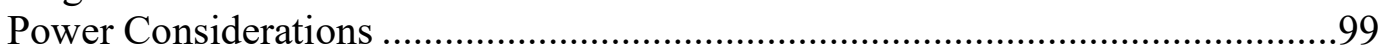

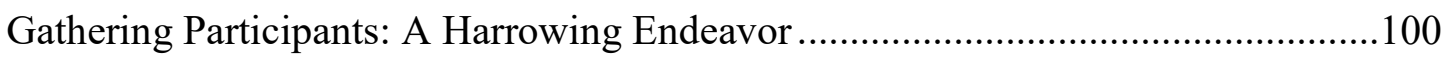

Lesson Learned about Queer-teacher Reality .................................................106

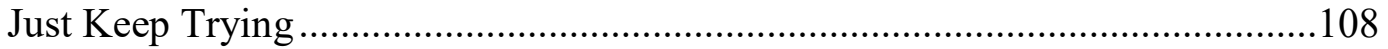

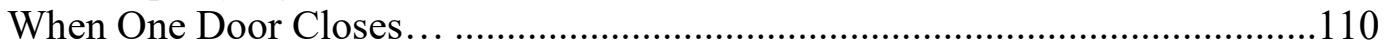

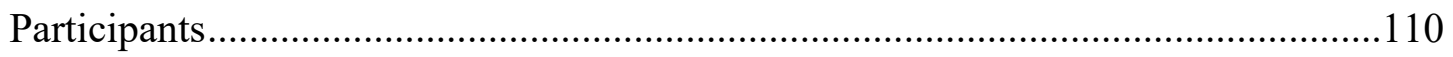

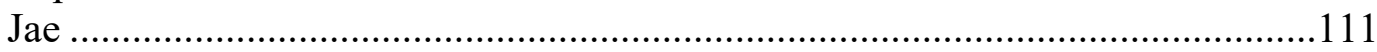

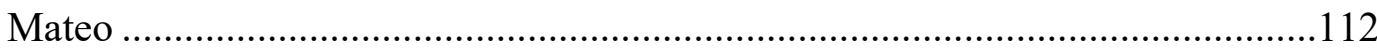

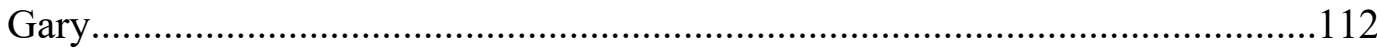

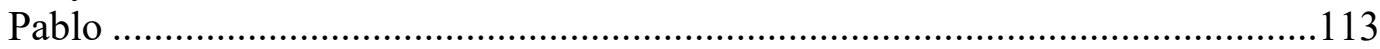

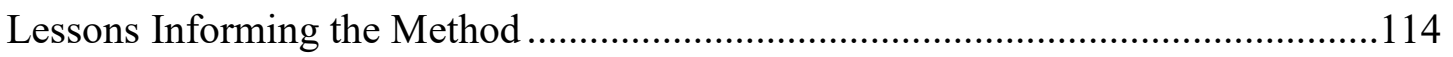

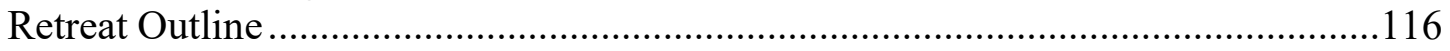

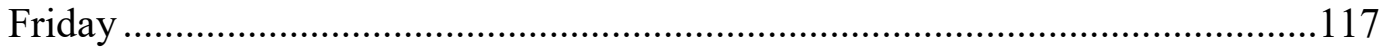

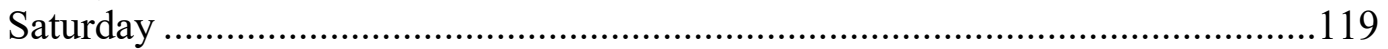

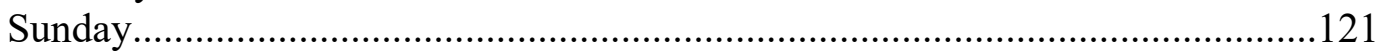

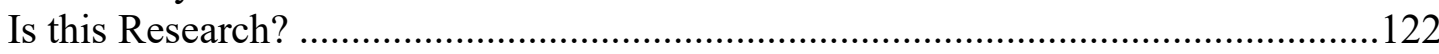

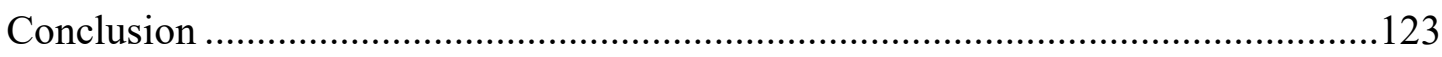

Chapter 5: Reflections on a Queer Catholic Cosmology Data and Analysis...................125

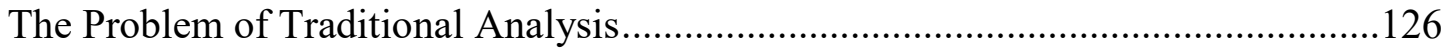

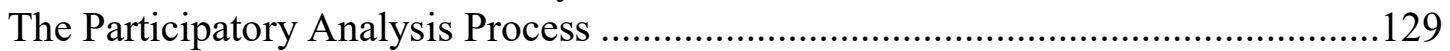

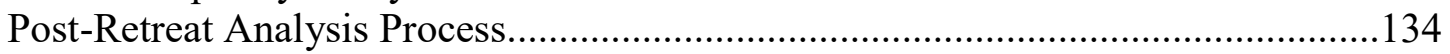

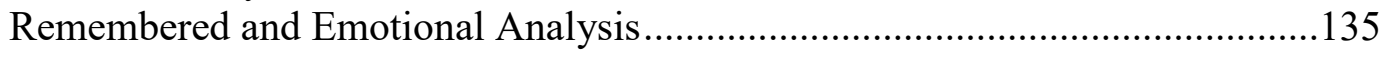

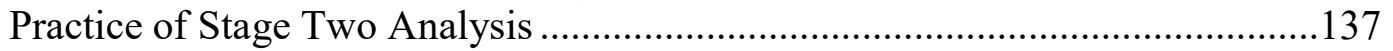

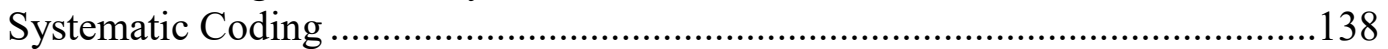

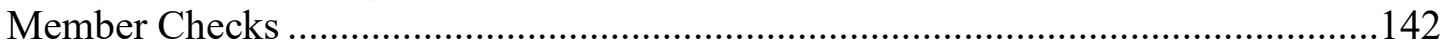

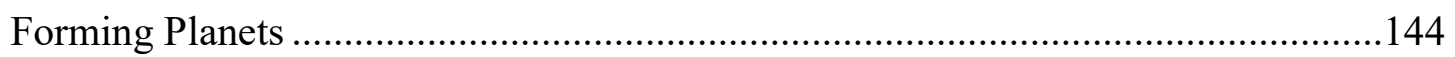

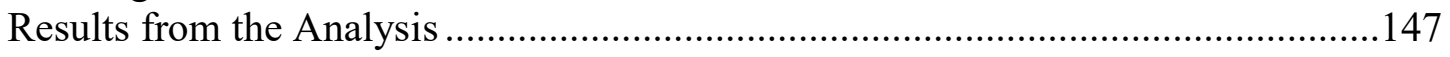

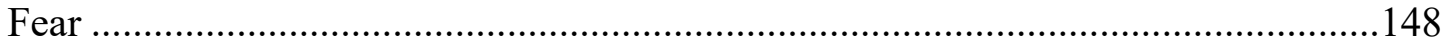

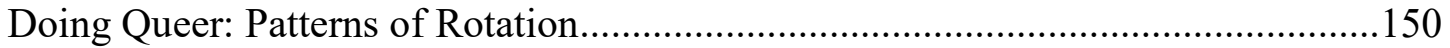




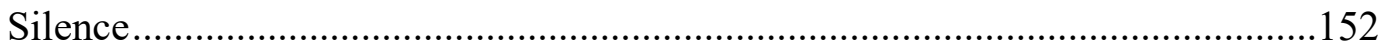

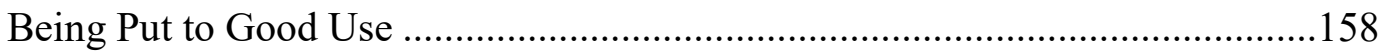

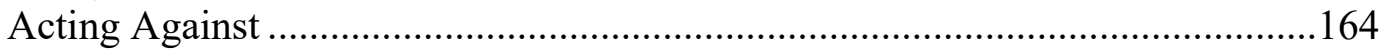

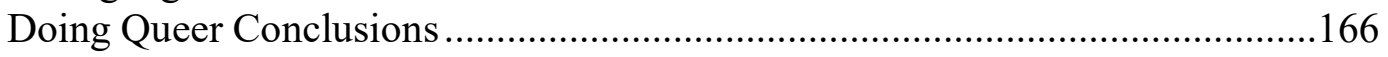

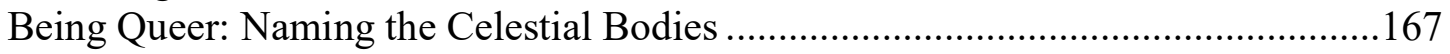

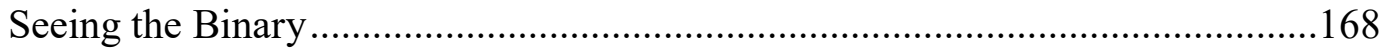

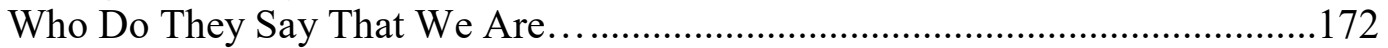

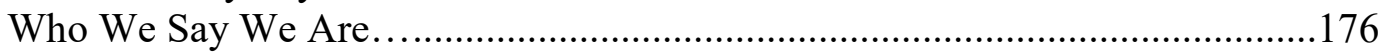

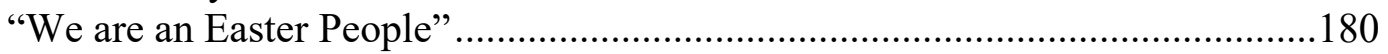

Enforcing Queer: The Logic of Orbit ................................................................184

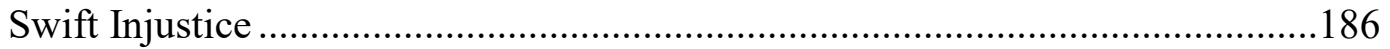

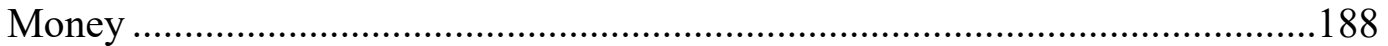

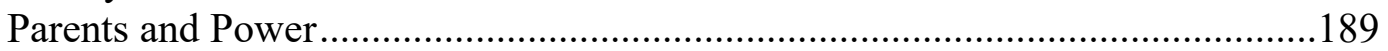

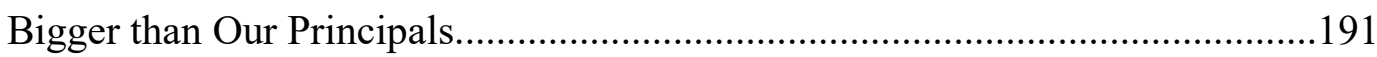

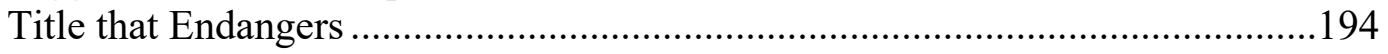

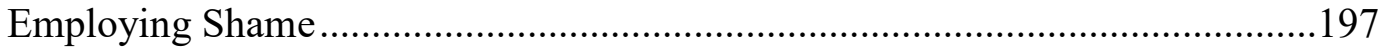

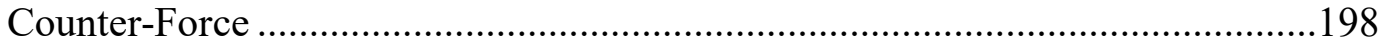

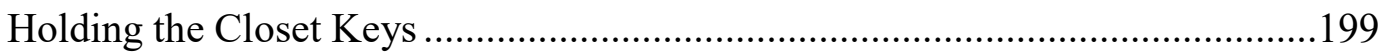

Taking Action and Solidarity ..........................................................................220

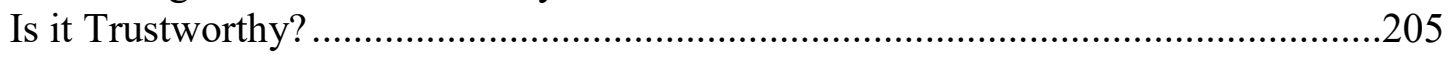

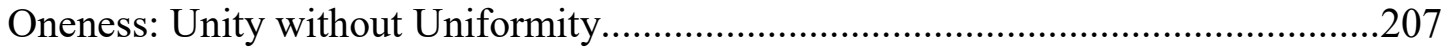

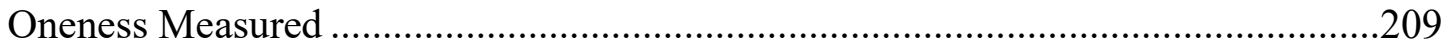

Holiness: Authentic Self-Expression ...................................................................209

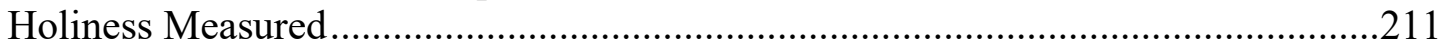

Catholicity: Benefitting All............................................................................212

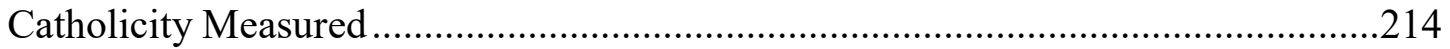

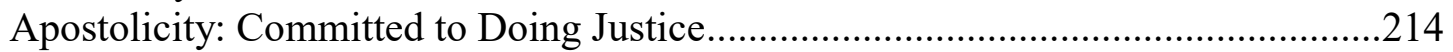

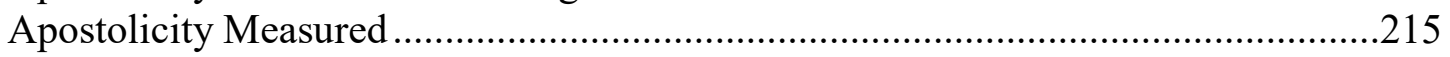

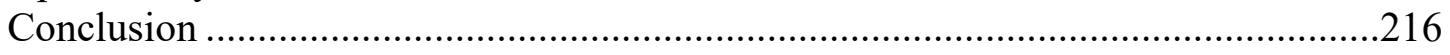

Chapter 6: Moving Beyond the Event Horizon: Emergent Spiritual Discoveries ...........218

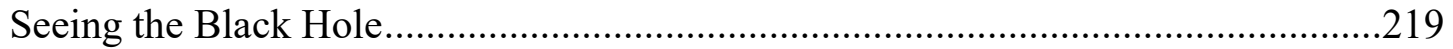

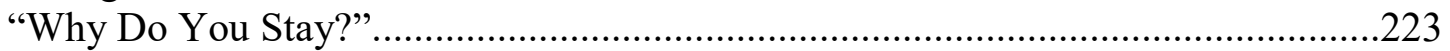

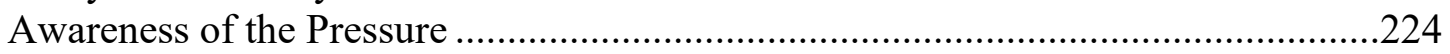

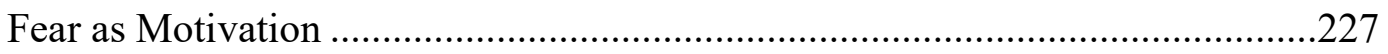

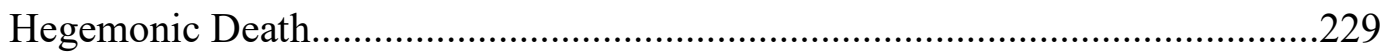

Paschal Victimhood and Easter Transformations ....................................................224

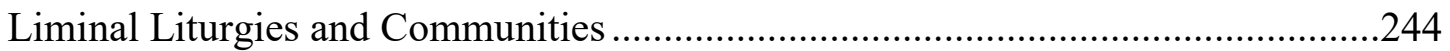

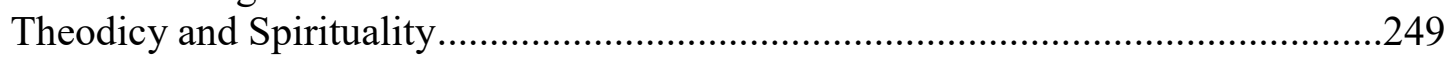

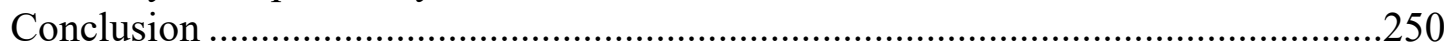

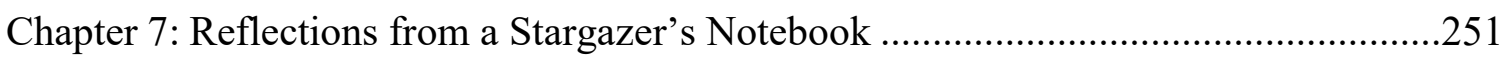

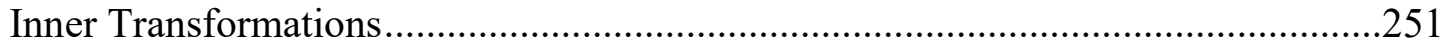

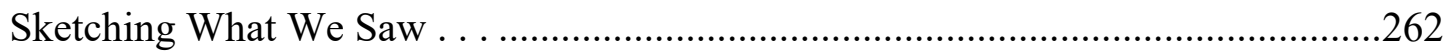

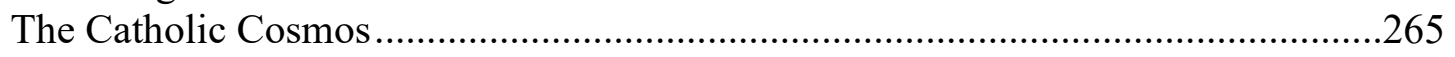

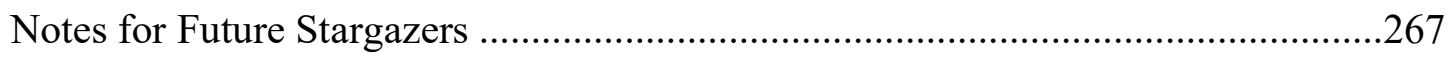

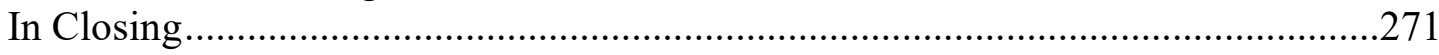




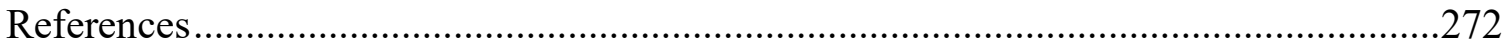

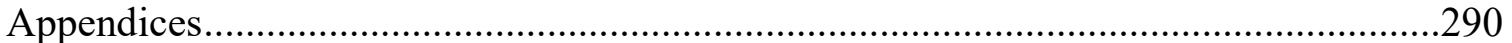




\section{LIST OF TABLES}

Table 4.1: Insider/Outsider Characteristics............................................................. 81

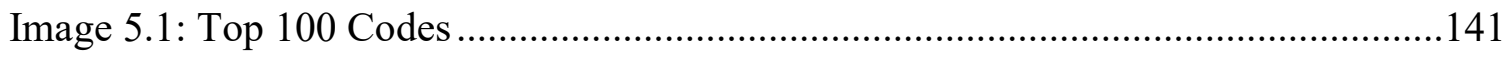

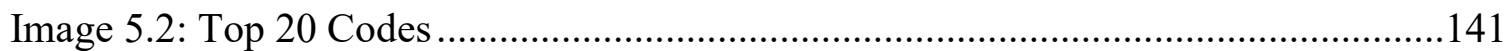




\section{Chapter 1: "Twinkle, Twinkle Little Star. How I wonder What You Are!"}

Looking up into the night sky is something that humans have done for centuries in the pursuit of understanding themselves and the world that they inhabit. Shapes and figures etched into the universe through points of light we now call stars and planets have given meaning to ancient and modern cultures. Four years ago, I found myself on the island of Oahu in the land of Hawai'i as part of a travel course that I was taking with Drs. Suzanne SooHoo and Charlotte Achieng-Evensen which focused on indigenous knowledges and schooling. Late one evening I was exploring a local resort where there was an explanation of the Hawaiian season of Makahiki. It was described as a time of celebration, feasting, and games. It seemed to me that it was truly a season of community. The time of Makahiki was marked by the rising of a group of stars that is called Makali'i (also known as Pleiades). I remember meditating on this celebration and its connection to the stars as I stood in the small museum-like room in the hotel. I could not help myself from thinking how detached I am from the movement of objects in the night sky and the ways that peoples around me and before me have made sense of time and self. Gazing up to the stars, for the Hawaiian people brought them closer to the 'aina (land). Looking up was a way of being rooted in this earth and one another. The stars and heavenly bodies, I had learned, were the guides that led the wakas (boats) of the first Maori people across the Pacific Ocean from a land that is enshrined in their tradition under the name Hawaiki to a home in the Land of the Long White Cloud (Aotearoa). There is wisdom in the stars and planets. Our Earth is one with them all in a beautiful cosmic dance that stretches into eternity. In their whirling, burning, flying, and spectacular patterns, we are given light to see that our own human social existence is a 
cosmos of its own-a communiverse in the universe, if you will. May the mysteries of the night sky serve us in this study as metaphorical guides and bring us to the celebration of new knowledge about what it means to be a queer teacher in a Catholic school.

\section{Led by the Lights above Me}

I know that coming to this study has been more than a simple case of blind interest. My life has led me to this moment. Some might say that it was written in my stars. Only a few years ago I was celebrating Catholic Mass at the altar of one of the largest parishes in the state of Tennessee as a priest. Today, I am sitting at a computer as a lay researcher writing about queerness, spirituality, and educational justice. My story is, by no means, a predictable one. It began in the deep South where I grew up as a white Catholic child steeped in the lessons and stories of the Spirit. Attending Catholic school for the majority of my education, I began to feel "different" in sixth grade when my teacher taught us about the sin of homosexuality. Though I could not have explained what my growing sexual desires were at that age in any coherent way, I knew immediately that the teacher was talking about me. There was a story about people like me in the Church and it wasn't pretty. I spent most of the rest of my middle and high school years praying that my growing same-sex desires would change. I was even more fearful of my sexuality when my favorite English teacher left the school because the administration was uncomfortable with his being gay. My most regular prayer in life until the age of 30 was to be fixed from homosexuality.

Reframing my same-sex desire as an indication of a vocation to priestly ministry, I pursued theological and philosophical studies for the sake of ordination. During the years leading to ordination, I was also a middle school teacher at Catholic school in 
Tennessee. In those years I wrestled with the immutable nature of the sinful inclinations that I bore in my heart (Sacred Congregation for the Doctrine of the Faith, 1994). The Church was clear that such desires were not to be followed, yet I could not help but also assume that this meant that I was less than "truly good" for having them. While I loved the study of theology and the ethos of Catholic education, I was ever aware of the dark, shadowy existence that others like me negotiated to fit in. I have been prayed over for deliverance, encouraged into secrecy, and lectured with doctrine over the topic of samesex desire. Leaving ministry unconvinced that the reason for my entrance was truly a divine invitation, I was led into years of reparative therapy (Nicolosi, 2009) to be psychologically healed of homosexuality. This only led to an ever-growing depression and hopelessness.

Having come out of this darkness, and still deeply tied to the beauty of the spiritual life and Catholic education, I told myself a new story. I began to see my sexuality as good and part of the gift of life. My coming to research was a search for a new kind of understanding and healing. Realizing that it was the story of self that was so fundamental, I wondered what queerness means in Catholic schooling. I thought of the ways that I experienced and witnessed the inner workings of prejudice as a teacher. I wanted to speak with other teachers about these things and explore together in meaningful research. What can we learn from experiences in Catholic schools that will bring light to the way that queer persons are treated, silenced, envisioned, storied, and encountered that leads to the shadowy existence I spoke of above? Convinced that queerness is a social construction benefitting some persons at the expense of others (Foucault, 1978; Jagose, 1996; Sedgwick, 1990) which can best be understood through 
the dialogical exploration of the experiences of the suffering (P. Freire, 2000), this dissertation asks the following questions:

1. How do queer teachers understand their existence as constructed in Catholic schools?

2. What action will queer teachers take in response to the knowledge they gain in answering this question?

\section{Stories of Other Star-lit Journeys}

If mine were the only experience of difficulty in negotiating the world of education as a queer person, then this study would be of little value. The literature, however, shows that I am far from alone. Remarkably, across institutions, the experiences of queer teachers have been tales of heroism. From the history of teacher removals from public schools for believed lesbianism (Graves, 2009) to the current sense of institutional detachment felt by transgender teachers (Harris \& Jones, 2014; McCarthy, 2010), the literature paints a dim picture of the queer educator experience. Teachers in all kinds of schools report that they must carefully concentrate on the negotiation of the public and private sphere of their lives (Gray, 2013; Pinar, 1998a). While heterosexually identified teachers can freely speak of their spouses, partners, and family lives, queer teachers typically cannot speak of such things. These teachers must work daily to maintain a balance between personal integrity of self and social capital in the school by what they reveal, how they act, and to whom they associate with (Taylor, 2011). Ultimately, the queer-teacher experience becomes one of isolation. Feeling removed from their own sense of self, the faculty, and the students, these teachers live a peripheral 
existence in their own institutions (Gray, 2013, 2014; Gust, 2007; Harbeck, 1991a; Woods \& Harbeck, 2012). These findings prove true across all types of schools.

Catholic school teachers have a unique context in which they work. The history of ministry in the Catholic Church with gay and lesbian persons is very recent and is already fraught with contested beliefs and practices. Doctrinal teachings on homosexuality must be upheld in fidelity to the mission of the school (Sacred Congregation for the Doctrine of the Faith, 1994). Catholic dioceses across the country mandate teachers to sign morality clauses which promise that they will not carry on lives which are opposed to ecclesial teachings (Litton, 1999). These contracts are more than a piece of paper, they become reasons for fear and worry in the lives of teachers who identify as queer and engage in queer lives outside of the school. These teachers tell us, in this study, that they are caught up in a life of constant vigilance, fearful that they might be found not in compliance with these contractual statements.

Recently, the news agencies have been reporting a number of teachers who have been fired for being publicly "outed" as gay, lesbian, or bisexual by any number of unintentional means. From having one's recent same-sex legal marriage announced in the paper to the discovery of one's queer relational status when seen at a store, queer teachers can be fired from Catholic schools for the simplest and most begnign realities. Negotiating one's being in Catholic schooling is a matter of employment for queer teachers. We are impelled to ask what queerness means for these schools. Why is it dangerous enough to be a reason for termination but not so terrible as to be a reason against employment? We are also impelled to listen to the stories of the daily lives of teachers who silently live this experience of tension. 
Queer teachers know that this tension exists in the schools where they work. Yet, they choose to remain in these institutions and teach while still holding a queer identity. What we can discover from them will tell us more about the ways that queerness is lived and understood in a social milieu. To limit studies of queerness to public institutions lacks the acknowledgment that religious culture and ideology are part of the social fabric of many American lives. Thus, we turn to the voices of these teachers to understand the ways that religious contexts make sense of queerness. Seeing these lives only from an external perspective leaves us unable to answer the question of why these teachers choose to remain in their schools. Are they engaging in work towards queer liberation? What are the religious narratives of queerness that exist in our diverse society? We will only grasp these answers by asking those who know best. We need an insider perspective. In Catholic schools, whose core missions are often undergirded with a commitment to justice, there is the tension between orthodoxy and the mandate to be places of love. It is the voices of those living that tension most acutely which will reveal new truths about how faith and justice come together. We know that parent and student groups like Concerned Parents and Students: Teach Acceptance in San Francisco are starting to form solidarity movements with queer teachers for the sake of creating institutions which are more humane for these educators. They are responding to hardships experienced by beloved educators in their schools. They are a voice calling out for justice and pointing to the fact that it is a time for Catholic schools to revisit theological and practical realities regarding this topic. The need for a critical examination of queer existence in Catholic schools is pressing, one which can enhance 
our understanding of theology, social being, and institutional practice in the Catholic school.

\section{Shooting Stars Arc Towards Justice}

If the queer teachers are like stars in the midst of the sky, then we must approach them with an authentically stellar plan. In my mind's eye, I imagine that shooting stars arc towards justice and so must all our research. Thus, this study situates itself in a deep ethical commitment for justice, authenticity, and community. Justice does not desire to destroy what is good but to enhance and restore what may be dysfunctional. In this spirit, this study is not framed or intended as an attack upon the richness that is manifest in Catholic education. Rather, it is an exploration of the ways that queer persons are understood and marginalized in this specific context. It is a study of hope for it seeks to reveal what is unjust in order to move beyond the limits of current practices into a more vibrant future.

This research gathered together a community of queer teachers from Catholic high schools into a retreat formation for the sake of understanding what their experiences in these institutions reveal about the discourse of queerness in their educational context. Inspired by the work of James Everitt (2010) and Pat Griffin (1991), this work is situated as an action research study, the community is the locus of investigation with all the members acting as co-researchers in the venture. Through the practice of consciousness raising spoken of by Paulo Freire (2000), and committed to the inspiration of the Spirit which liberates (Holland \& Henriot, 1983), queer teachers revealed what is good and bad and how they are positioned in the schools by Catholic discourse. This study examines the spoken and unspoken stories that are perpetuated by leaders and stakeholders in 
Catholic schools as well as the institutional structures that reinforce the maintenance of these narratives.

While this revelation of the construction of queerness in Catholic schools is valuable in its own right, it is impotent without action. Believing that human persons are created in the image of a Creator God, this study is committed to the employment of human agency in light of the revelation of new knowledge. Recognizing the delicate space that queer teachers inhabit with a constant risk of termination looming over their heads, the community and each individual must ask what response can be securely taken in light of what has been learned together. This counter-narrative begins the progressive march to liberation and hope. Thus, this study becomes a living moment in the progress of freedom and human consciousness.

\section{Walking out Into the Night}

Walking out into the darkness of night time requires us to take a moment to adjust our eyes and get our cosmic bearings. It is the same as I invite you to come with me into this beautiful and complex reality of queer-teacher experience in Catholic schooling. This research is written as one might write a map of the stars for those on earth. It is a systematic, referential, prose-laden explanation to the academy of a world that is far more queer than these structures could allow us to be. This is a description of a retreatresearch process that gathered four teachers into a single space for the sake of many hours of dialogue about their lives and the institutions that they are a part of as educators. We do this kind of linear writing as researchers because we wish to be transparent about our work and its execution. But I hope that there might be enough of a spark of vibrancy in the description that you might know what has taken place is a living reality. In order 
that you might better have your bearings in this living work of queer-teacher reflection and action, I want to share with you that this research reflects primarily on the first moment/retreat in what now has become a movement of queer teachers in Catholic school. As I write this introduction, I have already seen the retreat that I am describing in this dissertation develop into a second retreat led by the participants themselves which tripled the number of queer teachers involved in the process. Additionally, my calendar is marked for a flight where I will meet with a new community of queer, Catholic school teachers that has formed its own self as an action step from the second retreat. I have received interest from groups of other queer teachers in other parts of the United States to do similar work with them. What follows, then, is the systematic description one might wish to have in understanding a catalytic moment for a community seeking justice. From a cosmic perspective, it's the story of the big bang.

We begin our stargazing adventure by choosing the right instrument for our purposes in chapter two, called "Building a Telescope." This telescope is our theory and it is carefully constructed to be able to see multiple realities in the queer-teacher life in Catholic schools. Located in the intersection of queer existence, teacher experience, and Catholic schooling, the experiences that we are seeking to understand must be honored in the approach that we take. Using bricolage, I have woven together three existent theories. Queer theory, Critical Pedagogy, and Liberation Theology will be reviewed and combined into a framework I call queer theo-critical theory. Through combining these three theories we expand the reach of our theoretical frame to authentically embrace the subject matter of the research. 
In chapter three, "Consulting the Star Maps," we will look into history to understand what others have already learned from looking into the night sky before us. Queer-teacher research is not prolific but it is existent and we would be remiss to take off into research without having some idea of what others have already seen. It is this star map that will be added to by any discovery that is made by the research. The second chapter will examine the existent literature on the topic of the queer-teacher experience. Here we discover the common lot of these teachers and discover the lacunae in research. The need for studies which address isolation, institutional context, and personal narrative in Catholic schools are very much in need. I will show that my research is guided by the lessons of the literature, not only in seeking a "missing" element of knowledge, but by means of research construction.

Now it is time for us to begin our star gazing. Chapter Four, "Taking Time to Look Up," will examine the methods employed for the proposed study. Framed in a philosophy of culturally responsive research (Berryman, SooHoo, \& Nevin, 2013), the method of this proposed study is attentive to questions of agency, power, relationship, and research benefits. The strategy of participatory action research is proposed as a mode of study with queer teachers. Action research, most fundamentally engages a community in understanding the nature of a social problem, strategizing actions in response to this understanding, and implementing the action in a cyclic pattern which is continually in the process of action and analysis (Herr \& Anderson, 2005; Park, 1999). Pairing action research methods with traditional spiritual practices, the research seeks to be authentic to its ecclesial context by utilizing a critical Ignatian model. Exploring questions of justice, ethics, care, power, and responsibility, this chapter outlines the way in which this 
research mindfully moves towards justice. It also draws the reader into the living moments of unexpected problems and resolutions which have enriched and informed the outcomes of the study.

One cannot understand the lights in the night sky if you do not focus on particular ones in relationship to others. The Hawaiians know the stars well, but it's an honoring and recognition of the Makali'i constellation that brings about the feasting. Thus, chapter five, "Reflections on a Queer Catholic Cosmology," looks at data and analysis that explains the specific constellation of queer-teacher experience in Catholic schools. The chapter explains a multidimensional process of analysis which honors our theoretical commitment to ethical and authentic knowing. Here we begin to understand that looking at the stars means that they look back at us. Through participatory analysis three themes emerged like planets forming from cosmic particles. Fear, a kind of gravitational force, lies at the center of the star matrix. The first theme is termed "doing queer" and shows the many ways that queer teachers are performatively acting and silencing themselves in relationship to the Catholic school. The second theme is termed "being queer" in which we discover that identity is authored by the teacher as well as imposed from others. The third theme, "enforcing queer," looks at the ways that power is used to maintain the presence of queerness as it is in the Catholic school.

We then turn our telescope away from the bright lights and planets of the cosmos to consider what lies hidden in the darkness, the power of a black hole. Hidden from plain sight, the black hole mysteriously bends the meaning and experience of time, space, and matter. Indeed, the queerest of all things in the cosmos, this object of meditation is a metaphor for an equally mysterious reality in the data, an emergent spirituality. Chapter 
six, "Moving Beyond the Event Horizon," explores the ways that queer teachers have revealed through their words and presence, a new kind of spiritual understanding which reimagines the work for justice. Building of the teachers' own assertions that they are an "Easter People," we come to see how the faith, victimhood, transformation, and hope all come to play dynamic roles in a beautiful meaning making schema particular to queerteacher existence. We are welcomed to understand that by choosing solidarity while also accepting oppression becomes a way of dismantling the power of the Catholic school. The retreat process and the continued action of the teachers beyond the initial study are revealed as moments of spiritual living and social transformation.

Our final chapter, "Reflections from a Stargazer," draws our eyes down from the heavens to reflect on what we have seen. Like any good stargazer, we make notes in our journal. This concluding chapter summarizes the research by exploring the ways that it has transformed the researcher. It asks us to consider what in our star gazing was lacking. Future research and considerations for Catholic schooling is discussed as we acknowledge that this is only one of many viewings of the sky. Looking to queer teachers as they live their unique lives in the sacred halls of these schools, I hope that you can see them shimmer and shine. 


\section{Chapter 2: Building a Telescope:}

\section{A Queer Theo-Critical Theory}

Watching the night skies is nothing new. As humanity has continued to partake in this activity, it has also developed more powerful ways to bring the lights in the sky into the human eye. One way to do this is to take a series of glass lenses and place them in relationship to one another so that things which are at a certain depth of field appear as if they were immediately present to the observer. This art of drawing things closer to us is that of building a telescope. One must choose the cut and shape of the lenses carefully so that they serve the purpose of both the star and the observer. Will the light of the star be able to shine as brilliantly and clearly in the eye of the gazer if the glass stretches our perceptions beyond the plane of the object we seek? No. It will leave the star blurry, unable to shine with all the luster so inherent to it. In our own study, we are looking at three cosmic and intersecting planes of existence. Thus we begin our work by fashioning the telescope (our theory) that will give us best access to these realities.

Theory permeates our vision as human persons encountering the world. It is the mechanism by which we approach reality, drawing together our observations, experiences, thoughts, and feelings into a cohesive whole. Theory is the conceptual structure which informs our espistemological cartography of "the real." Through it, we make cohesive meaning of diverse phenomena encountered both inside and outside ourselves. Theory is informed by the interplay of the interior and exterior world. It is for this reason that bell hooks (1994) observed, "I came to theory desperate, wanting to comprehend-to grasp what was happening around and within me" (p. 59). Theory begins with context. This chapter seeks to explore the beginnings of a theoretical framework for 
an actionable research study with queer teachers in Catholic schools. This theory develops from queerness, Catholicism, and liberatory hope. Drawing from three theoretical families (queer theory, liberation theology, and critical pedagogy), I will show how a dynamic vision of the world of the queer teacher in Catholic schooling lies in the intersection of these lines of thought through the development of a queer theo-critical theory.

\section{Lens One: Queer Theory}

The first theory to explore in this intersectional study is that of queer theory. Beginning our discussion of this theory must be a historical explanation of its development. While queer intellectual theories arose out of authentic temporal contexts, they should not be considered to have done so through a purely linear process (Sedgwick, 1990). Rather, like the ever-changing and dynamic world in which contextualizes this theory, it too is dynamic and multifaceted. In this section we will explore the development of queer theory and the foundational social assumptions which theories of this nature make.

\section{Historical Development}

In our present-day social conception of queerness, there are three major strains of thought which exist simultaneously. Foucault (1978), placed the beginning of the modern construction of homosexuality in the Victorean era. Prior to this time, sexuality was conceived as something fluid and uniquely displayed in each person/society in a myriad of ways. This is why history displays instances of differential gender expression, same-gendered love, and youth sexuality as non-problematized realities (Foucault, 1978; Harbeck, 1991b; Pinar, 1998a; Sears, 1998). Prior to the Victorean age, the Catholic 
church began to increasingly privatize sexuality by drawing it into the sanctum of the Confessional by means of increasing strictures in ecclesial law (Foucault, 1978). In the 19th century, sexuality became a socially taboo topic and was cast into a binary classification (heterosexual/homosexual) which had not existed before that time (Foucault, 1978; Sedgwick, 1990). Homosexuality, in this "first wave" of thought was vilified as deviance (Harbeck, 1991b; Sedgwick, 1990; Tierney \& Dilley, 1998). Evidence of contemporary acceptance of the deviance assumption of queerness can be seen in both psychological and ecclesial writings today (Nicolosi, 2009; John Paul II, 2006; Wojtyla, 1960).

The second and third phases of queer conceptualization came as reactions against this Victorian ideology. The first movement called into question the negative conception of homosexuality and differential gender expression through a push for social acceptance (Harbeck, 1991b; Tierney \& Dilley, 1998). Rioting gay, lesbian, and transgendered persons who opposed police brutality at the Stonewall Inn in 1969 popularly began the movement for equal rights (Harbeck, 1991b). It is important to note that this line of thought assumes that both heterosexuality and homosexuality are normal ways of existing which share essential elements of human experience (Harbeck, 1991b; Pinar, 1998a). Using the terms gay and lesbian in exchange for the pathologized term homosexual, queer persons made "a deliberate effort to challenge stereotypical and oppressive representations of gayness through the promotion of an official ideology of 'we are just like you"' (Carlson, 1998). The binary of heterosexuality/homosexuality is not questioned in this phase. Rather positive meaning is given to each side of this accepted construction (Sedgwick, 1990). The final phase of thought (queer theory) calls into 
question the binary construction itself with its referent of normalcy and the implications of intransient self/social identifications (Carlson, 1998; Foucault, 1978; Pinar, 1998b; Sedgwick, 1990).

\section{Problems with Binaries}

Queer theory must be understood in light of the two previous and co-existent modern sexual conceptualizations. Foucault (1978) and Sedgwick (1990) argued that the placement of sexuality into a stark binary of heterosexual/homosexual is an essential element in the construction of all other ways of social thought along similar dualist frames of reference (good/evil, healthy/ill, sane/insane, etc.). Queer theory does not assume that sexuality has been eliminated from social contexts with the imposition of puritanical mentalities, but that it has become omni-present in its contextualization of all other things. "What is peculiar to modern societies, in fact, is not that they consigned sex to a shadow existence, but that they dedicated themselves to speaking of it ad infinitum, while exploiting it as the secret" (Foucault, 1978, p. 35). The manipulation of one of the most essential elements of human existence is a means by which power is wielded to create the illusion of normalcy and maintain social order (Foucault, 1978). In light of this, queer theory posits that the "problem" with modern sensibilities on sexuality exists not in the positioning of homosexuality as negative but in the fabrication of sexual binaries which give the illusion of a dualist world (Carlson, 1998; Sedgwick, 1990). Thus, the term queer in this theory is not indicative of an opposite identity to straight but as a positioning of the self in a fluid, non-dualist continuum of existence which challenges heterosexed normalcy (Carlson, 1998). This theory seeks to view the normal 
through the lens of queerness to deconstruct social binaries which marginalize and oppress.

Queer theory looks to human history as a matrix of power which works to maintain the status quo by the implementation of laws, cultural norms, resistances, and silences used to reify essential binaries (Foucault, 1978; Graves, 2009). Heterosexuality, positioned as the core of the most basic social unit (the family), informs gender and age roles in the public sphere such that it becomes the context and model of normal existence in social contexts (Foucault, 1978). Gender roles, solidified as they are in relation to heterosexual assumptions of public activity, are set in binary opposition as dialectical elements of sexuality (Sedgwick, 1990). Fluidity of gendered experiences and sexual expressions have no room except in a discourse of deviance (Foucault, 1978; Sears, 1998). The expectations of the purest forms of heterosexual expression are not imposed upon the lower classes but maintained by the dominant class as a sign of superiority. In turn, those less privileged members of society have imposed such normative ways of sexual expression upon themselves with the aim of being normalized in the image of the powerful (Foucault, 1978). The implications of this discourse of sexual goodness can be seen in popular discussion of the general "immorality" or "overly impassioned" lives of non-European peoples and those who are poor. Queer theory begins with the belief that assumed norms in society are the work of a social construction and do not necessarily point to an objective reality (Foucault, 1978; Pinar, 1998b).

\section{Deconstruction}

Queer theory seeks to deconstruct the current social forms of normalcy through the lens of difference. Sedgwick (1990) noted "A deconstructive understanding of these 
binarisms makes it possible to identify them as sites that are particularly densely charged with lasting potentials for powerful manipulation-through precisely the mechanisms of self-contradictory definition or, more succinctly, the double bind" (p. 10). Here the author is pointing to the fact that queer theorist insist that oppressive power does not simply act through a single mechanism in perpetuating itself. Foucault (1978) pointed to the fact that there is, at one and the same time, the imposition of repression upon sexuality while also a sexual resistance to this repression which act together to maintain social binaries. Pinar (1998b) observed that one who actively seeks to resist the ideas of one side of the binary through imposing a new "norm" only replicates the social structure under different terms. Thus, deconstruction in queer theory is sought through the vantage of marginality. For Sedgwick (1990), this marginality is the "closet." When the queer person observes the relation that they have to the closet and the closet's relation to social norms, the marginal experience begins to uncover the workings of social construction (Sedgwick, 1990). All marginal persons are first made to accept an identity of nonnormal as dictated through the dominant (heterosexual, white, male) class' they then are asked to go into hiding ("the closet") with this identity by seeking to normalize themselves to assumed roles in society. This double bind of being forced to identify as the Other while simultaneously urged to act like the norm reifies difference as a location of oppression (Foucault, 1978; Sedgwick, 1990).

Queer theorists employ a new way of envisioning the world. Identity, rather than formulated in firm, finalized communion with one of two possible sides of a social binary, is seen as authentically fluid (Evans, 2002). Transitory self-identification unmasks the silent assumptions of social narratives about gender, sexuality, race, class, 
religion, etc. (Carlson, 1998; Doll, 1998). Tierney and Dilley (1998) put it succinctly "thus, by decentering the norms we move away from a politics of identity that situates analyses within individuals and we struggle to move toward an understanding of institutional and cultural practices that frame sexual orientation in a particular manner" (p. 65). Queer theory does not assume that any one form of power (resistance, repression, silence, etc.) always acts in a specific way to perpetuate social norms, but that oppression can be imposed through certain implementations of these (Foucault, 1978). Thus, Ferfolja (2014) insisted that the silence of queer persons may be an act of power opposing social norms if it is implemented as an act of present resistance. Queer theory unravels a discourse of normativity by pointing to the many ways that queerness fragments the monolithic social narrative (Doll, 1998; Sedgwick, 1990). That which is most "abnormal" therefore serves as the referent for understanding the mechanisms of social control which create norms by exposing manifold differences formally hidden by binary categories. The result of this queer deconstruction is not a space of individuals dislocated by difference from communal identities but one that fosters "technologies of self that will allow them to work together strategically across, as well as within, various identity boundaries to advance common democratic projects" (Carlson, 1998, p. 118). Queer theory sees possibility for difference to be recognized in authentic ways which embrace the intersections of identity as it is manifest in multivarious ways in individuals and societies through questioning of the norm.

\section{Lens Two: Liberation Theology}

When speaking of the intersection of religious and secular worlds, one must consider the impact of theology on the context of one's study. In light of this, I draw 
upon the insights and understanding of liberation theologies in the Christian context. In the Catholic ecclesial tradition, one might state that liberation theology is part of a wider family of theological reflection on social life. Beginning with Leo XIII's (1891) Rerum Novarum and continuing until Pope Francis' Laudato Si' (2015) there is a legacy of ecclesial writing on social topics. Together, all these writings constitute "what would come to be called the Church's 'social doctrine,' 'social teaching,' or even 'social magisterium"” (John Paul II, 1991, para. 2). Not all social doctrine can be termed liberation theology, however. With the writings of the Second Vatican Council (1965a), particularly Guadium et Spes, the Catholic church began to speak of the intersection of secular life and the teachings of the Gospel. Liberation theologies exhibit one mode of critical theological reflection on the lived experience of the oppressed and those in solidarity with them (Gutierrez, 1973; Holland \& Henriot, 1983). Its formal genesis is traced to the reflections of bishops and theologians in a meeting in Medillin, Colombia in 1968 (Gutierrez, 1973). The Vatican, wary of liberation theology and its adoption of Marxist social theories, warned of the dangers of an overly secularized and ideological theology (Ratzinger, 1984). The tension of popular theological reflection and official magisterial teachings remains to the present day. It should be noted that theologies of liberation are also found beyond the Catholic context (Cone, 1975; Tutu, 1994; Yadegari, 1986). Here we will explore the dimensions of liberation theology from a wide Christian perspective.

\section{Faith First}

Unlike queer theory or critical pedagogy, it must be pointed out that liberation theology is, in fact, theology. Thus, the grander perspective of this thought includes not 
only humanity and creation, but the real presence of the Divine. Boyle's (2010) work reminds us that theological reflection and consequent praxis needs to incorporate the knowledge that God is an authentic participant in the actions of the world. As a Christian theology, God is understood according to certain tenants enumerated in the creed of Nicea. God is the eternal author of all creation "that sustains the entire universe, keeps every being in existence, and is always available" (Boff, 2013, p. 10). The central tenant of the faith is the incomprehensible mystery Trinity (Boff, 2013). This means that God is three distinct, consubstantial, and equal Persons in One divine being. The Second Person of the Trinity became human and suffered death as Jesus of Nazareth. The divine economy is the great plan of God to draw all of creation into the divine life of perfect justice called the Kingdom of God (Sacred Congregation for the Doctrine of the Faith, 1994). These eternal realities distinguish theological reflection from traditional social theory and must be held in constant consideration.

Biblical reflection is an important aspect of Christian liberation theology (Cone, 1975; Romero, 2003). Liberation is understood as a present and predominating theme in the Scriptures. God's liberating work in the Old Testament is seen most foundationally in the Exodus when the Hebrew people were led out of slavery in Egypt (Gutierriez, 1973; Sobrino, 1993). The plan of God to free the oppressed is then traced throughout the narratives of the Bible. It is for this reason that Oldenski (1997) stated that liberation theology begins with a primary moment of liberation while stretching towards further and deeper ones. The interpretation of the Scriptures by liberation theologians is not a literalist approach (Cone, 1975). Rather, by seeing liberation as the greater narrative of the Bible, this theology contextualizes the meaning of the Scriptures in a continual 
movement of freedom for the oppressed (Gutierrez, 1973; Romero, 2003). Gutierrez (1973) reflected that "the work of Christ forms a part of this movement and brings it to complete fulfillment" (p. 89). Inspired by the Word of God, liberation theology delves into the continuation of this liberating action of God in the present day (Holland \& Henriot, 1983).

Liberation theology is concerned with more than the intellectual pursuits of conceptualizing an eternal reality (Boff \& Boff, 2012). Scholastic theology, with its minute parsings of theological and moral implications misses the vital reality of human experience. Liberation theology locates its development in the always expanding understandings of faith which revealed in the concrete interplay of society, power, and oppression in the lives of human persons (Gutierrez, 1973). Theologically informed anthropology in the Christian Tradition begins with Creation as it proceeds from the mystery of the Eternal (Boff, 2013). John's gospel eloquently stated: "In the beginning was the Word, and the Word was with God, and the Word was God. He was with God in the beginning. Through him all things were made; without him nothing was made that has been made" (New International Version, John 1:1-3). All creatures are dependent on the Eternal for being. Gutierrez (1973) reminds us of the position that we persons hold in this theological view: "Humankind is the crown and center of the work of creation and is called to continue it through its labor" (p. 90). God's creative power is manifest through the actual work of humanity in re-creating the world. With this comes great responsibility to order things along the way of divine justice (Boff, 2013; Pope Francis, 2015). Humanity is the dynamic epicenter of all that is. 


\section{Consciousness}

Most remarkable in the powers that humanity possesses is that of being conscious of the world (Sacred Congregation for the Doctrine of the Faith, 1994). Speaking of humans, Boff (2013) said "They discover themselves as beings open to wholeness and inhabited by an infinite desire. Mystery becomes more and more sacramental; that is, it is announced more and more perceptibly through human consciousness" (p. 20). It is this consciousness of the world that makes possible the liberation of humanity from the machinations of evil (Oldenski, 1997). Consciousness, intended for the good and peace of all, is not always used to benefit others. Efforts to understand and master the world and others in ways that are against the plan of the Creator mark a tendency in humanity for sin. Cone (1975) reminds us that "we must evaluate a given interpreter of Scripture in the light of the particularity of his or her history" (p. 29). Thus, cautioned against the possibility of oppressive interpretations of Scripture and (consequently) the improper ordering of the world, humanity recognizes that not all forms of consciousness are good. Sin (oppressive consciousness enacted) may be manifest in the direct interchanges between human persons (personal sin) or may become institutionalized in communal technologies of oppression (social sin) (John Paul II, 1984). The entrance of sin, mythically explained in the Genesis narrative, marks humanity's great mission to seek the freedom of God intended in the original creation (Boff, 2013). Without the practice of bringing about justice in the world, the primacy of human consciousness becomes meaningless (Holland \& Henriot, 1983). 


\section{Political Agency}

Tutu (1994) and Romero (2003) both called forth the engagement of the faithful in political and economic realities of their time in recognition of the oppression which lay therein. The theology of social engagement also marked the writings of King (1958, 2010). Vatican II's constitution, Gaudium et Spes (Second Vatican Council, 1965a) insisted that the Christian faith could not be separated from the secular conditions of human life. Liberation theology, born from the experiences of the poor in Latin America, holds to the thesis that the present moment/context is the unique space in which God's presence is found and our vocation made clear (Boff \& Boff, 2012). Jesus' historical position in solidarity with the poor and suffering reveals the authentic location from which human consciousness may critique the power of oppressive sin (Sobrino, 1993). Economic injustice, with its commodification of human life and repression of freedom often is a focus of liberation theologians (Holland \& Henriot, 1983). In solidarity with the poor and suffering, humanity is to move to a more equitable future in which the Kingdom of God is manifest. Through meditating on Jesus' works and Scripture, liberation theologians insist that this Kingdom is made present when we "transform a bad and unjust historical-social reality into a different good and just one" (Sobrino, 1993, p. 71).

In coming to liberating consciousness about the oppressive forces which dominate the poor and suffering in society, practitioners of this paradigm often employ Marxist social critique (Ratzinger, 1984). Discovering the unforeseen justice which comes through the ending of oppression means dismantling the processes by which human persons are made objects of use and abuse (Holland \& Henriot, 1983). God's presence 
with the marginalized re-creates the movement of the Exodus as, through their own efforts, the oppressed seek new horizons of freedom alongside Christ. The promise of the world-to-come is not taken as a balm for the suffering soul meant to placate the desire for a better world (Boff \& Boff, 2012). Rather, the world to come is seen as that Kingdom which humans are called to build in time through efforts towards justice (Romero, 2003). James" words become the creed of the liberation theologian: "as the body without the spirit is dead, so faith without deeds is dead" (James 2:26, NIV). As happened with the Apostles at the Resurrection, Jesus and his Kingdom are revealed through true revolution to all of humanity in the active pursuit of justice.

\section{Lens Three: Critical Pedagogy}

The third theoretical approach which comes to play in the intersectional framing of this study with queer teachers in Catholic education is that of critical pedagogy. The historical development of critical pedagogy was described by Thomas Oldenski (1997) as having four distinguishable stages. He attributed the delineation of these stages to Henry Giroux who spoke of them to his students. The first stage of development came with "the social reconstructionists of the 1930's and 1940's" (p. 81) who began to imagine new ways of understanding schooling. Most notable among these was John Dewey and his work on democratic education and the nature of social progress. The second stage came with the critical theory development of the Frankfurt School and "reproduction theory" (p. 81). Theorists of this school of thought, influenced by Marxist theory, showed that norms are reproduced through social structures (such as schooling). Macey (2000) noted that the goal of the Frankfurt School critique was to show that production of a new social order was possible. The third stage of development came with the "the influence of the 
theories of conflict and resistance" (Oldenski, 1997, p. 82) which insisted that students became agents of change in the process of schooling. From these three important conceptual understandings of learning and society, critical pedagogy emerged as a fourth and final stage. It is the work of the Brazilian educator and theorists, Paulo Freire (2000, 2001) which is foundational to this theory. Here we explore the basic tenets of this theory as it stands today.

\section{Anthropology}

I begin the examination of critical pedagogy with its most central concern: the human person. It is the anthropology of Freire's work that provides a cohesive understanding of the theory which is later developed by him and theorists after him. Situated in history and context, the human person is the agent by which change is manifest (Darder, 2015; Freire, 2000). Straying from a deterministic belief that external scienctific or naturalistic laws act to define the progress of humanity, critical pedagogy sees the fate of socio-global history as squarely in the hands of humanity (Freire, 2001). This is inclusive of both the fate of social realities as well as the perpetuation of nature (Kahn, 2009). Knowing that this human subject is at the center of the theory of critical pedagogy, we must explore further into the nature of humanity.

One of the foundational aspects of critical pedagogy's anthropology is the understanding of the human person as a being-in-process (Freire, 2001). Indeed, Freire speaks of the "unfinishedness" of the human person in his writings (p. 69). The experience of being human is dynamic. By concrete choices and the accumulation of new experiences, humans are changing and developing. There is a fluidity to the human subject who moves through the process of being more or less conscious. Freire (2000) 
notes that human persons have an "ontological and historical vocation of becoming more fully human" (p. 84). For this reason, critical pedagogy speaks not of human being as much as human becoming. This betrays more than a dynamism in the human experience, it also speaks to the existence of an anthropological teleology in critical pedagogy. If one is "becoming," then there must be a terminus or goal. "Humanization" is the authentic process by which persons develop more fully into themselves (Darder, 2015; Freire, 2000). The process of becoming human runs along this continuum of humanization or it is threatened with its opposite: "dehumanization." The writings of critical pedagogues after Freire often reflect on the particular aspects of human existence (race, sex, class, gender) and the current state of humanization connected to these (Darder, 2015; Giroux, 2009b, hooks, 2009; McLaren, 2003, 2009). Their work rests upon this more foundational sense of anthropological becoming and the possibility of progress towards a greater state of human existence.

There is one especially essential virtue in Critical Pedagogy: hope. "Hope is a natural, possible, and necessary impetus in the context of our unfinishedness" (Freire, 2001, p. 69). That is, hope is what keeps humanity moving forward. We are inspired by ethics and aesthetics (goodness and beauty) as we strive to know a better tomorrow. It is the reaching into a brilliant and unknown future of possibility that Nita Freire (2014) called "untested feasibility." Hope is that sense of forward-moving direction in the person that acknowledges incompleteness (Freire, 2001). Hope is humanizing. Hopeless criticism is not authentic to human nature. True hope extends beyond political transformation and touches a consciousness of our entire ecological existence according to Kahn (2009). 


\section{Oppression}

One final aspect of this hopeful, unfinished, and potent anthropology must be examined. Human persons are essentially relational. While critical pedagogues do not deny the presence of the individual, the human person is never seen as separate from a real social context. Critical pedagogy orients itself to a particular dialectic in human relations: the opposition of the oppressor and the oppressed (Freire, 2000; Darder, 2015). This dialectic draws from Marxist social theory (McLaren, 2003). This dialectical relationship is not simply one of ideological opposition but a positioning of power in which a dominant group benefits from the oppression of another group. Power, understood as an ever-present reality, is exerted in such a way that certain groups of persons suffer for the benefit of another group. From a Marxist analysis, in this social relation there is a "unity of opposites" (Allman, 2001) in such a way that each group (oppressor and oppressed) exists only in relation to the existence of the other (McLaren, 2003). McLaren (2009) noted that "the ability of individuals to express their culture is related to the power which certain groups are able to wield in the social order" (p. 65). What is notable is that this oppression may manifest itself along a multitude of differentiating factors. Giroux (2009a) clearly makes this point when he stated that "social relations are structured within class, gender, race, and age formations" (p. 451). hooks' (1994) reflection on critical pedagogy shows that these oppressions may be multiple and complex, placing a person in differing sides of the oppressor/oppressed relational dialectic. No matter the form which the dialectic of oppressor/oppressed is manifest, it is never commensurate with the nature of human existence. Freire (2000) observed that neither the oppressor nor the oppressed are humanized in the dialectic. 
Critical pedagogy, in its examination of human society and potential, dismantles the ways in which oppression takes places. Those most cognizant of the dialectic relation, and perhaps most able to understand the nature of oppression, are the oppressed. It is for this reason that true liberation can only come from those who suffer this profound injustice (Freire, 2000). Yet, even amongst this group, Freire (2000) recognized that there exists those who "having internalized the image of the oppressor and adopted his guidelines, are fearful of freedom" (p. 47). The process of revealing the working of power and the nature of oppression comes through a critical consciousness of one's position in the dialectic and the ways in which the relation is maintained. Paulo Freire's work began with just such work dialogue for the sake of critical understanding of injustice with the poor in Brazil (Darder, 2015). "Almost never do they [the oppressed] realize that they, too, 'know things' they have learned in their relations with the world and with other women and men. Given the circumstances which have produced their duality, it is only natural that they distrust themselves" (Freire, 2000, p. 63). Authentic dialogue validates knowledge and experience. Thus, dialogue continues to be an essential aspect of Critical Pedagogy (Darder, 2015). Through reflection on an experience of oppression, one views the ways in which one is complicit within the process and by what means power is exerted.

The maintenance of the social order is accomplished through hegemony. McLaren (2009) explained that hegemony is "the moral and intellectual leadership of a dominant class over a subordinate class...through the general winning of consent of the subordinate class to the authority of the dominant class" (p. 67). The power of hegemony, though not so powerful as to be immovable, is the construction of a way of 
being and thinking which is validated by both the oppressor and the oppressed. Critical scholars continue to explore ways that the dialectic of power has recreated itself in the classroom. Giroux (2009a) reminded us that the oppressed in the classroom (often students) have the keenest sense of injustice. He reminds us of the critical aspect of the "concept of voice" (p. 454) by which the oppressed make known their experiences in the world. The eliciting of voice is the means by which alternative discourses are constructed which can authentically liberate the world from the oppressive dialectic.

Some forms of knowledge are intended to perpetuate oppressive hegemony. Bartolomé (2009) reminded us that "educational institutions are socializing institutions that mirror the greater society's culture, values, and norms" (p. 341). The teacher, having completed the formal stage of learning, now stands apart from the student as the active and authoritative voice of knowledge. This knowledge, reflecting again upon the words of Bartolomé, are the "culture, values, and norms" (p. 341) of society and are revered as objective truths. In this oppressive form of education, the human mind is shaped by knowledge in a one-sided relationship. Martin and Litton (2004) reminded us that "education is not a neutral act" (p. 15). Teachers and students, according to critical pedagogues, should become co-learners who create new knowledge (Freire, 2000). This dynamic extends beyond the classroom into all forms of domination by which the oppressor and oppressed learn a new way of being.

\section{Conscious for Change}

Critical epistemology is highly contextual and dynamic. As a knower, the human person is ever-creating new knowledge which grows from experiences. Thus, Freire (2001) noted that "teaching that does not emerge from the experience of learning cannot 
be learned by anyone." (p. 31). Knowledge is always being made new, both in the teacher and the student. Giroux (2009a) stated:

In other words, student teachers must develop a critical theory of teaching that includes an analysis of how students produce knowledge rather than just receive

it. This entails an understanding of how students bring their own categories of meaning into play in the exchange between school knowledge and their own subjectivities and histories. (p. 450)

Greene (2009) reminds us that this is the nature of democratic education. It is not imposed uniformity, which we see in hegemony, that produces a genuine free and united public. Rather "a plurality of life-stories must be heeded" (Greene, 2009, p. 95) if we are to produce a genuine democratic society. This is the repercussion of critical epistemology, the possibility of a new future. Freire (2007) insisted that "history is possibility and not determinism" (p. 37).

\section{Our Telescope: A Bricolage Queer Theo-Critical Theory}

As stated in the opening of this chapter, my research question is located in the delicate intersection of teacher identity, Catholic schooling, and queerness. Having looked very briefly at three theories which touch on these areas, I hope to find the intersection of these ways of thinking. Indeed, borrowing from the modes of thought, I tend towards the qualitative tradition of theoretical bricolage which seeks to formulate an approach to research that is richly multi-dimensional and open to the existence of authentic pluralism. Rogers (2012) explained that such approaches "examine phenomena from multiple, and sometimes competing, theoretical and methodological perspectives" (p. 1). Sewing together theories for the purpose of permitting "multilogicality" 
(Berryman et al., 2013, p. 16) to arise organically in a study belies an epistemological assumption already. Here I wish to show how a Queer Theo-Critical theory best embraces an authentic approach to my research.

I have knowingly chosen a bricolage approach to theoretical framing in this research. I am aware the bricolage can fall into the danger of opportunistic theoretical manipulation. What I mean by this is the fact that in hoping to construct a theory that works well in a particular situation, a researcher may be tempted to "pick and choose" elements of theories that serve a particular purpose while ignoring purposefully others. To do this would be tantamount to severing the connective tissue that hold a system of beliefs into a cohesive theoretical body. What comes of it is less of a marrying of theories and more of a recollection of ideas which are acknowledged as having diverse origins, but ultimately detached from the origins themselves. I do not wish this to be the case in my work.

I understand my work of bricolage to be the marrying, as much as possible, of different theories into something broader. Theoretical frames tend to deal with a particular aspect of existence and explain that aspect in a singular meaningful understanding. Thus, we see that critical theory examines the world of education and the ramifications of oppression on the human endeavor of growth. Queer theory looks to the sociological construction of human relations and makes sense of broad concepts of identity and power in light of sexuality. Liberation theology deals with the realm of understanding the divine in light of the experiences of suffering of the marginalized and the process by which oppression is resolved. It is clear that these theories overlap in a number of ways. I also admit that they diverge in others. Liberation theology 
acknowledges the belief in an ultimate truth and final triumph for humanity in the hands of a loving God. Queer theory questions the existence of truth and deals with reality as a site of sociological constructions. The end goal of human society is, for the queer theorist, a matter of human ability to deconstruct and establish alternative ways of relating. This tension between truth and human construction of reality, however, should be honored and not washed away. As is the messy truth with all human existence, opposing forces sometimes seem to exist together. It is the permission for these tensions to coexist in a bricolage theory. Tension itself begets new ways of knowing as unimagined resolution erupts from seeming impasses (Kumashiro, 2002). Thus, I have employed bricolage in a way that values these elements of difference.

Bricolage is particularly powerful for a research study that hopes to address a case of intersectionality, such as the coming together of queerness, teacher identity, and Catholic school culture, when it is employed in a way that enhances the theories involved. I imagine each of the theories as pieces of fabric. They hold a certain coherence in themselves, but as is the case with all things in our finite world, these theories have limits. These limits are the unfinished edges of the theoretical frame. A good work of bricolage draws together theories that cover differing realms of human existence (as was explained above) and then sews together the tattered and unfinished edges of these philosophical musings such that each theory becomes an extension of the others. By marrying queer theory with critical pedagogy, I extend the influence of each of these theories beyond their original limits to influence and be influenced by the other aspects of human meaning. A bricolage theory is not simply a utilitarian and simplistic approach to crafting the way we see our world, but a rich and complex fashioning of 
intellectual lenses for the sake of ensuring that the fullness of the subject matter we hope to investigate is captured.

The crafting of a queer theo-critical theory is, in itself an intricate work. I do not propose to have fleshed out the entirety of the implications for bringing these three theoretical families together. What I do offer to my reader is an examination of three key ideas that emerge from the intersectional crafting of this theory. It will be these three concepts that will be vital for the crafting of the method, choice of modes of analysis, and understanding of the what the research teaches us. These are a theory of justice, a theory of social being, and a theory of knowledge. Drawing on our telescope metaphor, we might understand each of these to represent the cosmic planes of intersection enhanced by our bricolage of lenses. They help us to see each of these realities more clearly.

\section{The Plane of Justice}

The questions of this study concern justice. Liberation theologians understand justice to be the right ordering of a social context such that it redounds to the intention of the Creator (Boff, 2013). At the heart of justice, then, this theory places the pursuit of liberation from oppression as a participation in the work of a Divine being. Liberation is marked by economic, spiritual, and individual freedoms which allow persons to participate fully in the riches of life and culture (Gutierrez, 1973; Holland \& Henriot, 1983; Romero, 2003; Tutu, 1994; Vatican II, 1965). Here we find a keen intersection with Critical Pedagogy on the meaning of justice. Freire (2000) stated that the human vocation "is thwarted by injustice, exploitation, oppression, and the violence of the oppressors; it is affirmed by the yearning of the oppressed for freedom and justice, and by their struggle to recover their lost humanity" (p. 44). Thus, justice, is a dynamic reality 
which seeks the ending of oppression. Nita Freire (2014) reminds us that the goal of justice is a utopian vision whose reality is beyond our imaging. Justice is the freeing of the outcast by the power given them as human persons: "Listen, my dear brothers and sisters: Has not God chosen those who are poor in the eyes of the world to be rich in faith and to inherit the kingdom he promised those who love him?" (James 2:5, NIV). Queering this intersection of critical pedagogy and liberation theology, we attune our understanding of justice to mean the active expression of human authenticity. Queer theory concerns itself with the deconstruction of binary and siloed social classifications from the perspective of those considered abnormal (Carlson, 1998). Thus, justice is found in the authentic expression of sexuality, gender, and multiple other identities. In a Queer Theo-Critical theory, justice is acknowledged as the dynamic process of attainment of human authenticity through the liberation of oppressed members of society. Injustice is the limiting of human diversity and dynamism for the purpose of conformity to an anthropological vision unintended by the Creator.

\section{The Sociological Plane}

Queer theory offers a wonderful starting point for theorizing about the place of lesbian, gay, and transgendered persons in the larger social discourse. A study which focuses specifically on the nature of queerness and its presence in heteronorming institutions such as Catholic schools, is best framed by queer theories of social construction. Foucault (1978) demonstrated the multiple ways that power is enacted to create and maintain social discourses by utilizing sexuality as a site for both normativity and shame. Most importantly, queer theory enables the deconstruction of social binaries which isolate queer teachers from the larger school community (Griffin, 1991). The 
vantage of those who are "other-ed" provides the clearest way of seeing the machinations of the normative discourse. Here critical pedagogy intersects with queer theory in a vital way. Freire (2000) noted:

In order for the oppressed to be able to wage the struggle for their liberation, they must perceive the reality of oppression not as a closed world from which there is no exit, but as a limiting selection which they can transform. (p. 49)

Social binaries (such as oppressor/oppressed), since they are not inherently real, can be changed by the work of human effort. Thus deconstruction is more than an intellectual pursuit but an historical possibility. Liberation theology provides a teleology for human society with a spiritual perspective. Society, riddled with injustice, moves through the actions of human persons towards a final goal of fulfillment of the plan of God (Second Vatican Council, 1965a). An authentic society is that which liberates all persons to fully participate in the benefits of culture. Thus, a queer theo-critical social theory framing a study with queer, Catholic school teachers must be authentic to these intersections. Society would thus be defined as a community of human persons intended by the Divine for the free expression of self which is constructed by human discourses. Present social discourses use binary identifications for the sake of creating a false norm which oppresses certain members of society. Social constructs can be dismantled for the benefit of all when it is critiqued from the vantage of the oppressed.

\section{Epistemological Plane}

Human consciousness is an important aspect of all three theories. Queer theories rely on the assumption that the human person (even in the most oppressed of states) has the ability to consciously conceive of alternative views of normalizing narratives. With a 
reading of history that traces changes in human consciousness regarding sexuality, queer theory informs us that lesbian, gay, and transgendered teachers hold a particularly advantageous perspective for coming to understandings of how normalcy is conceived and perpetuated in Catholic schools. Here, queer theory intersects with the work of critical pedagogues who affirm the primacy of critical consciousness. The epistemological foundations of this queer theo-critical theory are dynamic. That is, knowledge is created from the vantage point of the knower and the context in which they find themselves. Critical knowledge is impacted by intersecting identities the knower inhabits, including gender and sexuality (Fine, 2009). Thus knowledge of any community of persons (queer, Catholic school teachers) brings light to contours of social experience informed by many points of view. Liberation theology relies heavily on a theory of human consciousness as the primary tool for deciphering justice (Gutierrez, 1973; Holland \& Henriot, 1983). Awareness and knowledge of social injustice, these theologians remind us, is done as Christ revealed to us: in solidarity with the poor and oppressed. In this study, liberatory human knowledge, from a queer theo-critical perspective, is that which is developed from a community of the oppressed in solidarity with one another who employ experiences and insight to reveal technologies of oppression and hope in their social context.

\section{Conclusion}

In the intersection of these three theories we find a way of understanding the complex dynamics of the queer Catholic school teacher experience. The theory which develops from this intersection provides a frame for the building of a queer community for the sake of analyzing identity constructions of "otherness." It maintains a spiritual 
lens through which to authenticate faith perspectives in light of the search for justice. It provides an epistemological ground for conceptualizing the power of collective knowledge creation born from experiences of oppression as an essential aspect of the work of justice. Dynamically open to unknown possibilities to develop from this communal consciousness, this theory engages in the power of hope to enliven the agency of queer teachers. Our telescope has been constructed and it will be the instrument of work from here forward. But before we can go about pointing it haphazardly towards the night sky, we need to take time and read the star maps. 


\section{Chapter 3: Consulting the Star Maps:}

\section{A Literature Review}

We are not the first people to gaze upon the wonders of the cosmos, nor will we be the last. Many have spent days, years, and indeed lifetimes looking into the skies and marking on paper the patterns that they discovered. There is value in knowing about the sky that we are preparing to look at. If we turn to star maps we learn what constellations can be seen at what seasons in specific parts of the skies. It is only by coming to know this wisdom that developed before us that we will ever be able to know that we are looking in the right direction. We will also only know if we have found a "new star" if we can make reference to what was recorded before we started our stargazing. This even has religious significance as it was the Magi, the early astronomers from the East, who recognized the rising of an unknown star which marked the birth of a Savior. Their consultation of the star maps of their time led them to be the some of the first to greet the new born Christ. In our study, we must read about the wisdom that has come before us. That is, our maps are made up of the literature that has already been written about queerteacher lives in Catholic schools. Similar to the glittery debris which is left in the sky behind a comet, there is a discernable stream of research in academic literature concerning lesbian, gay, bisexual, and transgender (LGBT) teachers in schools. Examining the research in the field, I come to know that my work can be informed, challenged, and refined by critical reflection on the literature.

\section{A Brief History}

To understand the body of knowledge which is being examined, we must place it in its historical context. Tracing humanity's earliest musings on sexual difference and its 
place in education would be a difficult task. Indeed, both Sedgwick (1990) and Pinar (1998a) reminded us that the intersection of queerness and teaching reach into Greek and Roman times. Yet, the body of research and theoretical literature on queerness primarily does not seek to situate itself in a trans-historical understanding of the queer teacher, but in one which is highly informed by the contemporary social mileux (Evans, 2002). Queer theory has been born from a combination of both political activism and philosophical development (Pinar, 1998a; Tierney \& Dilley, 1998). The birth of the gay rights movement is considered to have taken place at the historic raid of the Stonewall Inn in 1969 (Sedgwick, 1990; Tierney \& Dilley, 1998). Developing from this event was an historical movement that involved both civil rights activism and intellectual developments on the question of sexuality. Foucault (1978) in his work on power and sexuality ushered in a new wave of thought on the historical development of homosexuality as a minoritizing category. Moving homosexuality from a clinical diagnosis to a constructed form of oppression gave fuel for a growing gay and lesbian rights movement and eventually the development of queer theory (Tierney \& Dilley, 1998). The research that is examined herein comes from a post-diagnostic mentality, meaning that researchers do not understand queer sexual orientations to be pathological maladies (Harbeck, 1991a). The goal of the present research on queer teachers is social and political. Much of the knowledge is intended to serve efforts towards social justice development (Evans, 2002; Graves, 2009; Griffin, 1991; McCarthy, 2010; Rudoe, 2014).

\section{Lessons in the Literature}

Contextualized by this history, this chapter proposes to examine research present in the field as it informs future studies with queer teachers in Catholic schools. This 
dissertation will examine four major themes found in the present body of research: (1) the negotiation of the public/private binary, (2) isolation and alienation, (3) the effects of context on queerness, and (4) the primacy of narrative. I wish to note that these themes cannot be disconnected from one another. Rather, they inform each other in a fuller understanding of queer-teacher identity and experience. After exploring these themes, I will question what, if anything, still remains to be pursued in this field of research. Finally, I will explore the possibility of actionable research with this population and its potential benefit for the queer-teacher community.

\section{Negotiation of Public/Private Realities}

When examining the existent literature about queer educators and their experiences and practices in schooling, one finds a predominating theme of teachers negotiating the private/public world. This conception of the private/public binary comes from Sedgwick's (1990) groundbreaking work Epistemology of the Closet. The dual world-view may be described in the literature in a number of ways. The public sphere might be described as the professional and socially visible sector of life. What remains hidden and personal is considered one's private life (Rudoe, 2010; Sedgwick,1990; Woods \& Harbeck, 2012). For the queer teacher, who works in a public world of heteronormed schooling, there is a need to strategically negotiate between these two worlds (Gray, 2013; Pinar, 1998a). In one world (private), they are free to be queer, in the other (public) queerness is often unacceptable (Griffin, 1991). Woods and Harbeck (1991) spoke of the participants in their study saying 
They accepted living in these two worlds as a necessary way of life for a lesbian physical education teacher, yet their stories reveal a high cost in emotional energy and self-esteem as a consequence of this bifurcated existence. (p. 160)

We see already, that there is a disjunction between the public and private spheres for the queer teacher. Indeed, some researchers have claimed that queer teachers are always in a process of relationally constructing, dismantling, questioning, and refining their selfhood according to the context in which they are placed (Evans, 2002). This aspect of the literature explains the techniques that teachers have used to negotiate these worlds, the ways that teachers conceptualize power in these spaces, the discourses which teachers note about queerness in schools, and the effectiveness of bringing the private self into the public sphere.

Unanimously, the literature testifies that being queer in schools as a teacher is not an easy reality. The work of negotiating the world of school as a queer teacher requires a conscious balancing of risk and precaution. Griffin (1991) reminded us that, in looking at research about queer teachers: The consistency of responses in these studies is striking: "Gay and lesbian educators believe that a strict separation between their personal and professional lives is required and that to be publically 'out' at school would cost them their jobs" (Griffin, 1991, p. 168). Thus, it is discovered that teachers employ a number of strategies to maneuver through the hetero-normative school system (Rudoe, 2010; Woods \& Harbeck, 2012). The most notable research on the management techniques of queer teachers is that of Pat Griffin (1991), although these themes are found in other research as well (Cummings, 2009; Evans, 2002; Ferfolja, 2014; Gray 2013; J. M. 
Jackson, 2007; Rudoe, 2010; Woods \& Harbeck, 2012). Griffin (1991) outlined these techniques under two major categories "safety-making or risk-taking" (p. 175).

"Safety-making. "Saftey-making" techniques discovered in the research

literature are various and are used with the intent to protect teachers from the adverse effects of bringing their private queer identity into the public world of teaching (Gust, 2007; Griffin 1991; Woods \& Harbeck, 2012). One technique that is employed is becoming very aware of portraying a hetero-normative appearance in behavior and dress (Gray, 2014; Griffin, 1991; McCarthy, 2010; Woods \& Harbeck, 2012). Another is to employ silence on issues of concerning homosexuality in school, including bullying, curricular issues, or student questions (Gray, 2013; Ferfolja, 2014; Woods \& Harbeck, 2012). It should be noted that silence can be seen as both an imposed reality for queer teachers as well as a tool of power in negotiating the public world (Ferfolja, 2014). One particular aspect which queer teachers remain silent about is discussions of sexuality, though some academics argue for a more open curricular discussion (Rasmussen, 2004). The most notable method of safety-making is to become an exemplary teacher, thereby supplanting any negative feeling others may have about the educator's perceived queerness (Endo, Reece--Miller, \& Santavicca, 2010; Griffin, 1991; Taylor, 2011). Rudoe (2014) noted that there is a "heightened importance of being a good teacher in this context (teaching), which is necessary as a defense against the threat in school of a homophobic response to lesbian sexuality" (p. 30). These primary strategies are ways in which the queer teacher maintains protection from the possibility of negative consequences which come from a hetero-normative institution. 
Risk taking. While safety-making is an essential component in the negotiation of the professional self, researchers have also discovered that there are ways in which the teachers also take risks. In the work of negotiating the public and private self, there is a desire that is manifested for authenticity and integrity (Evans, 2002; Griffin, 1991). In order to find this integrity, teachers take risks in bringing their private self in touch with their professional lives. This can be done in any number of degrees, from explicit proclamation of queerness to more indirect actions which may insinuate identity (Woods \& Harbeck, 2012). Herein we deal with the question of "coming out" in school. Along the lines of gender queerness this becomes more explicit, particularly for those who are transitioning while they are a teacher (Harris \& Jones, 2014; McCarthy, 2010). Coming out as queer, for many cisgendered teachers takes on a number of methods and intentions. For some, risks can be taken by choosing to make a statement about one's political and philosophical alliance with the cause of LGBT rights (Cummings, 2009; Evans, 2002; Griffin, 1991; Macgillivray, 2008). For others, it may take the riskier step of confiding in a colleague, parent, or administrator (Griffin, 1991). Gray (2013) noted the risk in this practice saying, "the LGB teacher, once out, occupies a particular and marked presence within the staffroom" (p. 709). Many studies examined the practice of coming out to students with the clear intention of making the classroom safer for LGBT learners (Evans, 2002; Gust, 2007; MacGillivray, 2008; Rofes, 2000; Rudoe, 2010). Some teachers use silence and permissive inference to give students the freedom to read sexuality and self-understanding through the pedagogical practice and presence of the queer educator (Ferfolja, 2014; Khayatt, 1999). All of these actions are risks for queer teachers in a heteronormative institution. 


\section{Queerness and Isolation/Alienation}

With heteronormativity holding sway over our society, there is the insistence that all persons should comply with hegemonic standards of sexual performativity. Endo, et al. (2010) insisted: "Where schools are concerned, this is more than an assumption: it is an expectation. This expectation has made the classroom environment hostile for queer individuals, students and teachers alike" (p. 1023). Queer teachers may feel pushed by civil rights discourses to "come out" while simultaneously urged by the heteronormative discourse of the school to remain hidden (Ferfolja, 2014; Gray, 2014; Sedgwick, 1990). In negotiating this difficult space, there is a necessary consequence for queer teachers. This consequence is isolation and alienation (Gray, 2013, 2014; Gust, 2007; Harbeck 1991b; Woods \& Harbeck, 2012). In Griffin's (1991) groundbreaking study, the extent of this experience is made clear: "All participants were aware of maintaining a strict separation between their personal (gay/lesbian) identity and their professional (educator) identity" (p. 174). In this section, I wish to explore what is to be found in the literature about alienation and isolation in the queer-teacher experience. We will explore isolation under the three following categories: isolation from the faculty, student alienation, and isolation from the self.

Isolation from the faculty. One of the most notable experiences of LGBT teachers is the sense of isolation that they express in reference to their colleagues. A majority of studies made reference to the ways that this is made manifest in the lives of teachers. What is interesting is that this isolation comes about in a myriad of ways. With queer sexuality constructed as deviance, this pattern of isolation and silencing is 
testimony to the sexuality/power theories of Foucault (1978). This sense of isolation may take on one of two distinctive forms: externally imposed and internally imposed isolation.

Externally imposed isolation comes from institutional practices and informal actions of the faculty which serve to distance or isolate queer persons from the community. The most notable is the fact that, in some institutions, queerness may play a contributing factor in decisions to hire teachers (Endo et al., 2010). While overt discrimination may be outlawed, some queer teachers sense that administrators purposefully disregard queer-teacher applications. Graves (2009) reminded us that there is a history of removal of queer teachers from schools in parts of the United States as a purging of deviance in public faculties. While some teachers may be able to successfully hide their queerness by passing or covering, others are more conspicuously identifiable (Griffin, 1991). This is particularly the case with transgendered and gender queer teachers whose physical morphology, personal dress, or mannerism transgress the cisgendered norms of society. Such teachers often experience distancing of faculty accompanied by a sense of fear on the part of colleagues (Harris \& Jones, 2014; McCarthy, 2010). For queer teachers who choose to come out, there can be the experience of ostracization. Studies show that queer-expressive teachers find that their opinions, insights, and contributions are ignored after coming out (Ferfolja, 2014; Gray, 2013). Gray (2014) noted: "Schools actively close down the possibilities for speech on LGB issues and deliberately perpetuate the demarcation between LGB teachers' private and personal worlds" (p. 711). Indeed, teachers who had previously sensed a connection to their colleagues express the sense of being invisible (Gray, 2013, 2014). Even in higher education, one research noted that even academic alignment queerness and 
relating theories may have delitertious effects on a career. Such researchers are considered to be in the "lower echelons of acadamia" (J. M. Jackson, 2007, p. 2). In education, external reactions to queerness often have the effect of distancing queer teachers from their peers.

While external pressures may be a large contributing factor to queer-teacher isolation, the research also points to the fact that self-distancing may by an internally imposed drive that has the same effect (Griffin, 1991). In seeking to fit into the heteronormative school environment, teachers take on a number of isolating strategies to maintain safety. Queer teachers have demonstrated trepidation toward relating with people of the same-sex for fear that suspicions of inappropriate intentions or behavior may arise in the faculty (Litton, 1999). Indeed, fear of queerness in a school may limit all teachers from making same-sex friends. More broadly than distancing from certain genders, queer teachers express a fear of socializing with their peers outside of school so as to maintain secrecy about their private life (Taylor, 2011). Continual management of the self due to a fear of negative consequences from being "outed" leads queer teachers to isolate from general faculty interaction in school as well (J. M. Jackson, 2007; Rudoe, 2010). Perhaps the most insidious kind of isolation comes from the intentional avoidance of queer teachers in interacting with each other (Taylor, 2011). Association with another teacher who may be known as or suspected to be queer may result in further isolation from the faculty and thus is avoided. While Griffin (1991) stated that many queer teachers desire to be able to express themselves fully in school, many do not want to take the great risk. Indeed, most queer teachers feel more free to counter homophobia through more covert ways than by coming out (Gray, 2013). 
Alienation of parents and students. Because heteronormativity is prevalent throughout our modern society, it should be of no surprise that queerness can affect a teacher's ability to connect with students and parents. In Giffin's (1991) action research study, she noted that the public displays of political alignment with LBGTQ rights or identity could threaten positive connections with parents. Studies with teachers who came out to their students show that this could result in a kind of alienation. Students who were queer or who experienced bullying for perceived gender/sexual non-conformity often distanced themselves from queer teachers after they had come out (Gust, 2007). As transgender teacher identity also led questioning students to purposefully seek to disassociate with the educator in question (McCarthy, 2010). Although some researchers and theorists conclude that a teacher coming out is a positive experience for classroom environment, the research itself seems to say that coming out may cause an undue burden on students of negotiating identity (Macgillivray, 2008; Rofes, 2000). When queerness remains hidden, there is also a disconnect in the classroom. Closeted queer teachers noted that there is a sense of inauthenticity in their classroom because they are trying to be another (heterosexual) person (Nixon \& Givens, 2004). Researchers like Khayatt (1999) noted that explicit declaration of sexualities as well as intentional hiding of queerteacher identity may have negative effects in the classroom and that a more nuanced approached of indirect queer-expression may be needed to negotiate this space well.

Isolation from the self. The third form of isolation to make note of in the queerteacher experience is isolation from the self. Griffin (1991) noted that queer teachers consistently express a desire for integrity inside and outside the classroom. By this is meant that queer teachers wanted to be fully expressive of themselves in school without 
having to fabricate hetero-compliant identities. Nonetheless, Woods and Harbeck (2012) reported that "Because of engaging in self-distancing behavior. Many of the participants felt misunderstood, isolated, and dishonest”' (p. 152). Rudoes' (2010) work demonstrates that silence around one's sexual identity leads to a separation of self-identity as a queer teacher. Many queer teachers feel like they lose integrity with every effort made to hide their sexuality (Taylor, 2011). Some choose to hide and isolate due to fears of school actions, yet others do so out of an internalized homophobia which causes a rift between the queer self and the teacher identity (Endo et al., 2010). In fact, Griffin (1991) and DeJean (2010) discovered that some participants had never considered the merging of the self as queer and teacher before taking part in the research. Gender-queer teachers find themselves bracketing certain forms of self expression in order to present a teacherpersona which is normative to cisgendered, heteronormative society (Litton, 1999). Even those who have positive regard for their sexuality did not express a diminishment in the feeling that a teacher could not be fully present as queer in the classroom (Woods \& Harbeck, 2012). After enduring isolation from peers and alienation from parents and students, queer teachers must also endure the crucible of internal isolation from the queer self while at school.

\section{Context Makes a Difference}

In her work on the development of queer-teacher identity, Evans (2002) noted that selfhood is a fluid and mutable reality which is highly dependent on the context in which one finds oneself. Unambiguously she writes, "I am positing that identities are not static but are an effect of interacting with others and with larger concepts that are conveyed through the circulating discourses" (p. 4). This theory on identity and experience as fluid 
concepts is validated through the multi-various ways the literature describes the experience of being a queer teacher. The context in which the identity of queer teacher is negotiated brings about its own individual experience. A prevailing heteronormative social discourse assures that no queer-teacher experience is simple, but the particularities of their environment may mitigate or increase the already difficult process (Endo et al, 2010; Pinar, 1998b). Being queer and a teacher means balancing and negotiating the two identities through the multiple layers of expectations around professional identity and personal integrity (Endo et al., 2010). Rudoe (2014) wrote, "Lesbian and gay teachers will use a variety of strategies to negotiate the continued marginalization of queer sexuality in schools, and depending on the local context, will have differing experiences" (p. 67). The context for negotiating queerness might change suddenly in a school by the nature of a single interaction. Thus, in a singular school environment, there are manifold arenas and contexts in which a queer teacher must negotiate their selfhood and identity (Ferfolja, 2014). In essence, the literature informs us that there is no monolithic queerteacher experience which can be identified since each person is situated in a unique context.

Factors that influence context. While identity may be individual, the extant body of research does point to certain patterns in context which may affect queer-teacher experience in common ways. It is found that schools serving lower socio-economic populations or a large number of religious students prove to be more difficult for queer teachers to feel free to be out (Rudoe, 2010). Along similar lines, rural schools prove to be more difficult places for teachers to incorporate queer sexual identity into their professional work than urban schools (Juul, 1995). Gender queer and transgender 
teachers find the negotiation of a school system more difficult or isolating than queer teachers who are cisgendered (Harris \& Jones, 2014). The enforcement of policies and laws have significant effects on the queer-teacher experience. Rudoe (2014) and Gray (2014) showed that curricular policy can help to change school context according to the way it deals with queerness. The interpretation and deployment of an inclusive curriculum often has its own discourse which supports or refutes heteronormativity. Neary (2014) showed that changes in the law which privilege equal freedoms for LGBT citizens can make a teacher's negotiation of queerness and educator identity simpler. Opposingly, laws and community fears of queerness can lead to a hostile context for these teachers to be present (Graves, 2009).

Catholic schools. Of particular interest in my examination of the literature is the impact of the Catholic school context on queer teachers. It must be noted that there have not been many studies done which look exclusively at the subject of queer teachers and Catholic schools (Everitt, 2010; Ferfolja, 2005; Getz \& Kirkley, 2006; Litton, 1999; Maher, 2007). What is discovered does not diverge widely from the information found in the literature as a whole. Nonetheless, Litton (1999) reminded us that "Catholic teachers do not have the same kind of protection that their public school counterparts receive under state laws" (p. 4). Catholic school teachers often sign contracts with morality clauses which state that they may be terminated for living/teaching in a manner contrary to the Catholic faith (Endo et al., 2010). Maher (2007) made an honest assessment in noting that, "Catholic schools are not only difficult places for gay and lesbian students, but also for gay and lesbian teachers" (p. 455). The same heteronormative discourses which exist in other schools can be found in these institutions as well. 
Discourses of heteronormativity are amplified or questioned by an interpretation of faith unique to different contexts (Endo et al., 2010). Gray (2013) said that certain religious traditions can lead to affiliated schools to enact exclusionary practices towards LGBT persons. Within the context of the larger global Catholic context, Maher (2007) believed that Catholic schools in the United States fall under the leadership of a community of "bishops [who] tend to place greater emphasis on the pastoral care of gay and lesbian people" than the legalistic emphasis on immorality (p. 449). While I believe this to have been true at the time of his writing, there has been a renewed emphasis by the members of the American episcopacy on the moral implications of homosexuality. It would be plausible that this shift informs the context of Catholic schools in this country. Local leadership and discourses can also affect the experience of being queer in Catholic education. Some queer teachers in Catholic schools expressed an acceptance and honoring of gay identity by administration (Endo et al., 2010). This context facilitates self-negotiation by queer teachers. Others noted that Catholic schools are institutions where fear of coming out is intensified because they can be places "where the existence of homosexuality is denied" (Endo et al., 2010, p. 1028). Knowing the difficulty, queer teachers still choose to be in these institutions for various reasons. They must endure the tension of being authentic to self and the teachings of the Church (Litton, 1999). It is in this difficult place of tension between transcendent beliefs and immanent personal experiences that the queer Catholic teacher negotiates identity.

\section{Importance of Narrative}

One of the distinctive features of research about queer teachers is the fact that it is overwhelmingly narrative in nature. As one delves into the literature, it is discovered that 
"story" and "storytelling" plays a strong role in bringing light to the life and experiences of this population (Dejean, 2010; Endo et al., 2010). Researchers, presumably influenced by the work of Foucault (1978) and Sedgwick (1990), enact a deconstructive process of revealing social discourses which influence school contexts through the use of alternative queer narratives (Nixon \& Givens, 2004). There is no singular method of engaging and employing narrative to be found in the literature. Each work is individual and contextually informed. Nonetheless, we can gather important knowledge by examining the general methods used to employ narrative and its meaning in the existent research.

Social discourses. The first kind of narrative of note is the social discourse discovered through research with queer teachers. While exploring the queer-teacher experience, existent research makes note of some predominating social discourses about queerness and teacher performance. Sedgwick's (1990) work in Epistemology of the Closet posits that the queer subject is a constructed reality. The queer subject is part of a system of social binaries which bifurcate all of reality into dialectical opposites which are outlined in a societal narrative (in/out, good/evil, etc.) (Foucault, 1978). Thus, it should be of no surprise that those who mine the private/public binary in reference to queerness should also discover hidden narratives which perpetuate its existence. A few of these discourses have been exposed in the current literature. One particularly powerful narrative is the idea of the queer teacher as a sexual deviant, often connected to pedophilia (Evans 2002; Graves, 2009; Griffin, 1991; Nixon \& Givens, 2004; Rudoe, 2010; Sears, 1998; Taylor, 2011). Another discourse paints queer teachers as recruiting students to become gay or lesbian (Rudoe, 2014). Internal to the queer rights movement, there is a discourse that coming out in the classroom is an ethical mandate (Cummings, 
2009; Ferfolja, 2014; Gray, 2013). Research about the effectiveness of coming out to students and its positive transformative is mixed and inconclusive (Gust, 2007; Macgillivray, 2008; Rofes, 2000). These discourses affect the choices teachers make in how they actively negotiate the public/private sphere in both safety and risk (Evans, 2002; Griffin, 1991).

Telling stories. Not surprisingly, global (social) discourses which weigh heavy upon queer teachers from the outside are not the only ones found in the literature. Stories of/about/from queer teachers become essential data for the analysis of the experience of negotiating self and identity. Dejean (2010) posited that queer stories act as a counternarrative to oppressive discourses. Some research have taken the approach of offering an historical narrative of the development of queer presence, theories, and struggles in society (Getz \& Kirkley, 2006; Graves, 2009; Harbeck, 1991b; Sears, 1998). These genres of literature tell history in a way that questions the dominant discourse of modern society and exposes the interplay of marginality and normativity. Other researchers employed narrative through an auto-ethnographic lens (Cummings, 2009; Gust, 2007; J. M. Jackson, 2007; MacGillivray, 2008; McCarthy, 2010). Nixon and Givens (2004) noted that marginalized stories reveal the oppressive exertions of power found in society. Having authority and power over their own experience, these researchers emphasized the contextual nature of the queer-teacher experience. This literature exposes greater social narratives through the particular lens of a single personal experience. The largest portion of the literature employs the stories of queer-teacher participants as its data (DeJean, 2010; Endo et al., 2010; Evans, 2002; Ferfolja, 2005; Gray, 2013, 2014; Griffin, 1991; Harris \& Jones, 2014; Litton, 1999; Neary, 2014; Nixon \& Givens, 2004; Rudoe, 2010; 
Taylor, 2011; Woods \& Harbeck, 2012). This subset within the literature houses a number of differing strategies for gathering and analyzing these stories, though the number of participants are consistenly small. Use of multiple stories reveals the multiple kinds of experiences that queer teachers have. The telling of queer stories invites others to share their experiences and counter the historical silencing of queer voices (Nixon \& Givens, 2004; Sedgwick, 1990 ).

\section{The Lacunae: Blank Spots on the Map}

The above thematic analysis of research about queer teachers is not exhaustive. Rather, what has been said is a gleaning of collective knowledge from many individual pieces of literature on the topic, each of which has its own merit and nuance, in order to offer a broader landscape of the field. Using these four themes, I will examine where the field of queer-teacher research can continue to expand. While growing, the amount of published literature on the experience and history of queer teachers is relatively sparse. With many queer-teacher researchers citing foundational figures as their intellectual guides (e.g. Michel Foucault, Eve Sedgwick, Pat Griffin, Didi Khyatt, Karen Harbeck, Tania Ferfolja, \& Eric Rofes), there can be no mistake that this corpus constitutes as a cohesive family of literature. Perhaps the first place of growth, very generally, would simply be a proliferation of research on the topic. As studies continue to be undertaken, they will contribute to a fuller vision of the experiences of queer teachers.

The first major theme that was explored was the negotiation of the public/private binary. This theme is seen in all queer-teacher research as it delves into the question of being in/out. Most of the queer-teacher research mines the experience of being "out" as LGBT in school. Griffin's (1991) foundational observations on the methods teachers use 
to negotiate queerness in school have led to numerous studies on the topic. Yet, if we ask what it means to be a queer teacher in schools, then we should likewise ask what it may be like to be a queer teacher outside of schools. Sedgwick (1990) observed that "the space for simply existing as a gay person who is a teacher is in fact bayonetted through and through, from both sides" (p.70). How does an LGBT person bring their heteronormed identity as teacher into the queer world? What are the challenges, possibilities, and dangers in doing this? As researchers discovered, some participants had never thought of their queer and teacher identities simultaneously existing when they thought of their identity. What would doing so in the "private" world reveal?

Isolation/alienation was the second theme that was explored in the literature. Researchers and participants explained that this theme could be found along three relational planes: the queer teacher and (1) other faculty, (2) students, and (3) their interior self. It is of note that this theme was not discovered as an effect of direct researcher intent to explore these experiences, but as a consequential revelation developing from questions of identity negotiation. Some researchers have begun to question whether the silence of isolation can be reconceptualized as an act of exercising the power of the queer teacher against oppressive discourses demanding conformity and self-identification (Ferfolja, 2014). This research opens new and important lines of further inquiry. How do teachers experience and employ isolation/alienation for successful negotiation of the public/private worlds? In what ways are isolation/alienation experienced by queer teachers outside the classroom? Griffin's (1991) research is noteworthy as it sought to counteract isolation through the employment of a communitybased and self-reflective action-oriented methodology. More studies of this sort would 
be invaluable. Thus, the literature points to the need for more research which positions itself in opposition to isolation while reframing questions about what this experience means in a queer teacher's life.

The third theme found in the literature is that of the effects of context on the queer-teacher experience. Every study of queer teachers adds in some way to this inquiry about contextual import if it can be situated in its historical, social, geographic, and physical context (Endo et al., 2010). As research continues to make efforts at understanding the way that hegemonic discourses are perpetuated on the national scale in education, it is important to note that the local context of a school can be equally as important in shaping queer-teacher experiences. We must ask what contexts have yet to be explored in the research? What contributing factors make one context more difficult to navigate for a queer teacher than others? How do queer teachers understand the interplay of multiple contexts in their lives? Who has the power to shift these contexts and how? Further research on particular contexts would provide an insight on how queer identity is negotiated across a variety of locations. Additionally, such studies can question how social contexts are affected when a queer teacher is present within them.

The final theme found in the literature is that of narrative. Existent research explores both the unspoken discourses of heteronormative expectation (i.e. the dominant social narrative) and the individually articulated stories of the marginalized queer-teacher experience. Gray and Harris (2014) explained that narrative research sheds new light on how discourses construct queer sexual identity. This important assertion leads us into further inquiry. How (by what process) can queer stories prove to change discourse? Does the effect of sharing marginalized narratives prove to assist with queer liberation 
over a long period of time? How does the context in which the story is told affect its formation and power to counteract hegemony? Having looked specifically at the work on queer teachers in the context of Catholic schools, we ought to note that the literature is regrettably sparse and seldom employs narrative. Further research inclusive of narrative should be done in Catholic schools. Generally, further explorations into queer narrative and its interplay with context, community/isolation, and negotiation of the private/public social binary should be undertaken.

\section{Contribution to the Maps}

How does this study with queer Catholic teachers be contextualized in this sea of literature? I begin by noting the complexity of what has been discovered in the delineated themes. These themes do not signify utterly distinct aspects of the queerteacher experience. Rather, like a corkscrew, the ideas explored in the literature spiral down along new planes of comprehension while traveling along the same circular path. First, the discussion of the tension of queer life while negotiating the public/private binary becomes our starting point. On this plane, we come to know that queerness (private) and teacher (public) identity do not belong on the same side of the binary. Negotiation of this dual world is both internal and external struggle. Secondly, we delve deeper by exploring the primary effect of isolation on queer teachers in the struggle to navigate the hetero-constructed binary. The intent of the public/private construction is evidenced by its effect of marginalizing isolation imposed on the queer teacher. Third, we reach a new plane of understanding in considering the reality of multiple, unique educational contexts. The monolithic discourse of normativity starts to fragment. There are revealed a multitude of iterations of the "normed" school experience in reference to 
queerness. Finally, the primacy of voicing narrative reveals the power of the oppressed to counter hegemonic discourses (Freire, 2000; Giroux, 2009b). Queer existence does not seek to become normed (for to do so would negate their queerness) but it is able to inform the dominant discourse with divergent narratives, opening new political and cultural possibilities. This study contributes to the field must acknowledge all of these layers of the queer experience.

\section{Actionable and Beneficial}

A participatory action study with queer, Catholic school teachers is most appropriate for meeting the demands of the present literature while simultaneously pushing into new realms of research. Through the lens of each theme, one might imagine the significance of such a study. Not only is such a study beneficial to the participants and the expansion of the field, but we also discover that the research, as proposed, performs as a deconstruction of discourse which lends itself to the authentic possibility of actionable participant responses.

The four themes will outline the contributions of this future research. By conducting research in community with queer teachers, the research situates itself in the nexus of the public/private binary. This research asks that the queer community question a public reality (schooling) which is situated within the private sector (Catholic Church). Thus we discover how the doubly "privatized" queer Catholic teacher experience reveals the echoes of public hegemonic discourses in a private institution. The aspect of teacher isolation is a key theme that must be addressed in any research. The intentional establishment of a community of queer teachers who acknowledge all aspects of their public/private self is a mode of counteracting isolation. Thus, the very act of 
deconstructing institutional discourses about queerness in a community is an act of redefining ways of being a queer teacher without silencing or isolation. In reference to the import of context, this study adds to a very small body of literature on Catholic schooling and queer teachers. The study finds itself in the intersection of several contexts: the universal Catholic Church, the American culture, and the particular context of the schools served by the participants. Finally, this study will continue the tradition of narrative primacy. The story which is constructed will be the collective voice of a community, rather than a conglomerate of solitary voices gleaned from interviews. The additional narrative of spirituality will become an essential part of this study as these teachers find themselves in Catholic education. Having told stories in a way that challenges isolation and questions context, there is the possibility for the development of a collective action constructed by the community which could serve a more just future. Gathering at the margins in authenticity, this study could enable both personal/communal identity development for the participants and a reframing of possibilities for queer presence in Catholic schooling.

Of particular concern, knowing that a study of this kind may be action-based, is the question of who benefits from the work (Berryman et al., 2013)? The literature shows that the mere engagement in queer voices first is healing to the oppressed by restoration of lost agency (Griffin, 1991). Likewise, the fact that all of the authors I have found doing such research are queer points to the fact that engaging this work contributes to the betterment of the queer community. There is benefit, at least psychologically speaking, for those in the community to draw together to voice shared stories. The community built by this work creates a novel space accessible by queer teachers for 
seeking solace and connection. Social change may be slow, but this study can

authentically begin with the assurance that it stands to benefit the isolated and hurting by the work of their own hands.

\section{Conclusion}

Having looked at the literature, like one might consult various star maps, we have come to understand the common plight of the queer teacher and the dynamics of working in schools for these people. The maps have pointed out to us both a direction in which the study ought to go if it is to contribute to the field. They also give us clear markers that we might use to make sense of the discoveries that are made in the research. Now that we know about what has been written into the annuls of astronomers before us concerned with queer-teacher existence, it is time for us to begin star gazing. 


\section{Chapter 4: Taking Time to Look Up:}

\section{A Critical Ignatian Retreat}

There are maybe as many ways to look at the skies as there are people who do it. Stargazing is an art, as is the work of research. One must come to clearly understand what they wish to do as they take up their activity. This chapter seeks to explore the ways that a study with queer teachers in Catholic schools which is framed by a Queer Theo-Critical theory demands a culturally responsive methodology. This brief examination of the most salient aspects of such research will also show why Participatory Action Research is the most natural strategy for answering the questions of inquiry in a just way. The method used in the study developed organically, and perhaps queerly, as dictated by the situations that presented themselves to the researcher. Since the mutation and development of the study is part of its essence, I choose to be as transparent as possible with the reader about the development of a study that embraced a traditional ritual in the Catholic Church, the retreat.

\section{Theoretical Framework}

I begin my exploration of method by acknowledging that I do not come to this study as a tabla rasa, but as one who embraces a certain way of seeing the world (Berryman et al., 2013). I employ the art of bricolage to construct a queer theo-critical theory which is dynamically open to the multiple ways of being and experiencing the intersection of queerness, teacher roles, and spirituality (Berryman et al, 2013; Rogers, 2012). Drawing together theoretical families provides a space for multiple authenticities to be manifest in human experience. Here I provide a brief re-statement of some of the most cogent aspects of a queer theo-critical theory. 
In the intersection of critical pedagogy, liberation theology, and queer theory, I have found a location in which to situate my study (Queer Theo-Critical Theory). Here we discover that our anthropology/ontology is a dynamic one. Informed by Freirean hope, the human subject is an ever evolving and developing being who expresses themselves through active involvement in the world (Freire, 2000, 2001). The human person is a being made in the Image of the Creator with the power to affect the world around them through a definitive vocation given by the Divine (Boff, 2013). Our anthropology also tells us that human persons, understood in the context of a social fabric, impose and adopt normative ideologies of categorization. They wield power and, as such, are in an historical process of social and self-construction along and beyond binaries (Foucault, 1978). Thus, I must adopt a method which is designed to provide the widest possible breadth for human subjects to express this dynamism. It must embrace the social nature of authentic human hope which can only be found when the human horizon is left undetermined (Nita Freire, 2014).

Queer theo-critical theory sees knowledge as something equally as dynamic as the human persons who create it. Liberation theologians, drawing upon the Christian tradition that reason and faith mutually inform each other, designate pride of place to human consciousness in the socio-spiritual life (John Paul II, 1998; Holland \& Henriot, 1983). Human consciousness arises from the lived experiences of the world, molded by sociological narratives, and produces a perspective for human life in history (Freire, 2000; Gutierrez, 1973; McLaren, 2003). Critical pedagogues remind us that, in the context of time and space, knowledge is ever growing and being developed. Queer theorists emphasize the fact that modern thought is predominantly fixed into binary 
opposites or strictly intransient categories which hinder authentic human knowledge of plural experiences (Carlson, 1998; Foucault, 1978). Authentic human consciousness and knowledge are able to deconstruct the imposed strictures which can stymie social development (Foucault, 1978). The engagement of human knowledge in conjunction with the active power of persons as historical agents must be echoed in our methodology (Freire, 2001).

Finally, this theoretical frame has an ethical stance in terms of justice. Human agents are not neutral beings in the world, living outside of a moral imperative. For liberation theologians, this imperative is not solely expressed through a demand for orthodoxy (right belief), but more importantly as a call to orthopraxis (right action) in the world (Gutierrez, 1973). Theologically, the touchstone of orthopraxis is liberation as best exemplified in the work of Jesus in solidarity with the poor (Boff \& Boff, 2012). Critical pedagogues call this moral progress of the person and society: "humanization" (Freire, 2000). It connotes development of am ever-more full expression of freedom. Queer theorists, in questioning the binaries and normative discourses of modern society, also move towards a moral imperative to reconstruct a community in which difference and connection are authenticated, beginning with sexuality (Sedgwick, 1990; Foucault, 1978). The ethic of this hybrid theory concerns justice. A concordant methodology must be oriented to a similar understanding of social justice as outlined by this theoretical frame. It must be active engagement in justice or it will fall short of the vocation and potential of human existence. 


\section{What is Justice?}

If I am to embrace a methodology and research strategy which enacts the imperative ethic of justice, then I must be clear about what justice entails. Justice must be queer, theological, and critical if it authentically finds a home in our theoretical frame. Vatican II (1965) outlined a definition of justice:

everything should be rendered to a person which is required to lead a truly human life, such as food, clothing, shelter, the rights to free choice of one's state of life ... to the protection of one's private life and to a just freedom, including religious freedom. (para. 26)

In this expansive definition of justice, one ought to note that there is no delineated political or sociological structure. It is the attainment of peacefulness that authenticates the presence of justice. Gutierrez (1973) stated, "The connection of peace with justice is an important theme in the Bible. Peace is promised along with the gift of the kingdom, and it requires the establishment of just social relationships" (p. 159). As Paul VI reminded the Church: "If you want Peace, work for Justice" (Paul VI, 1972, para. 16).

The ecclesial definition of justice seeks to be ahistorical such that it might be applied generally to all places and locations. What I gain from critical pedagogy and queer theories is a more contextualized look at justice. Borrowing from the work of decolonizing theories of indigenous persons, one must recognize that injustice is found in large part to the limitations of freedom due to an historical and perpetuated form of forcible normalization/colonization. I propose that "indigeneity" can be read as a form of social queerness and "colonization" as a means of imposed norming. Smith (1999) said of indigenous persons: "Our orientation to the world was already being redefined as we 
were being excluded systematically from the writing of the history of our own lands" (p. 33). Justice in such a world means a de/reconstruction of forms of injustice in order to permit all to be authentically themselves (Foucault, 1978). Thus justice is a process of reimagining social life beyond the binaries which brings permits authentic expression of difference and community. Freire (2000) reminded us that this does not mean a role reversal of oppressor and the oppressed through some trade of positions of power. Here I call to mind Freire's concept that liberation and justice means the freeing of all persons: oppressors and oppressed. Justice requires equity. In being just, this research must participate in this queer theo-critical process of liberation for the sake of a growing freedom for all.

\section{Philosophy of Method: Culturally Responsive Methodologies}

The most natural conceptual frame for this research is that of Culturally Responsive Methodologies (CRM). CRM have their roots in the interplay of critical pedagogy and kaupapa Māori theory (Berryman et al., 2013). These theoretical approaches originate from very different communities. One theory was born from experiences of oppression in Brazil while the other is born from the indigenous livedexperience in the modern world. From one source we see the importance of critical assessment of the world and power that is championed by the oppressed (Freire, 2000, 2001). From the other, we find the importance of representation and relationship that is informed by the Māori (Berryman et al., 2013). While the two may have deep similarities in their approach to power and empowerment, it is important that they are not coterminous (Siope, 2013). Rather, by the interplay of ideas between the two, there has arisen a conceptual framework which positions culture and relationship as the most 
central considerations in the work of scholarship. It places those who are being researched as having full agency in the work of scholarship meaning "researchers must frame their research with a more respectful, less powerful, and more deferential stance" (Berryman et al., 2013, p. 14).

Drawing from the work of critical pedagogy, this approach to inquiry "reframes the researcher's stance as expert to one of learner" (Berryman et al., 2013, p. 5). CRM do not seek to replicate the kind of tyranny of academic dominance that has objectivized the researched (Nevin, 2013). Rather, built on a philosophy that the knowledge possessed by a community belongs to them, culturally responsive researchers come with humility to learning (SooHoo, 2013). Being informed by kaupapa Māori, the resistance to colonizing approaches is coupled with a belief that the researcher should be invited to share in research with a community (Macfarlane, 2013). Thus, the entire approach of methods in this framework begins with the honoring of the community with which one wishes to work.

CRM see relational being as a key part of ethical research. Macfarlane (2013) explained the depth of the Māori understanding of relationships which is primary for CRM: "Whanaungatanga, as a core Māori construct, can be seen as the process of engagement in which relationships, connections, obligations, and responsibilities between persons are strengthened" (p. 143). Authentic relationships are those realities in which knowledge is co-constructed between the researcher and participants. This cannot be done in the solitary isolation of a research desk. Rather "reciprocity, dialogue, and relationship building are the core of co-creation" (Berryman et al., 2013, p. 7). Because this interaction of human persons cannot be replicated outside of the specific context of 
the study, the knowledge created therein is unique to that social interplay. Thus, coconstruction does not mean the achievement of some eternal truth but a discovery of one of many possible truths. Thus, this conceptual framework rests on the belief that multiple truths exist (Berryman et al., 2013).

CRM hold that the only authentic and worthy study is that which serves the needs of "the social good as determined by the community" (Berryman et al., 2013, p. 17). It is based on an ethic of human dignity and cultural sovereignty. Thus, such research honors both the individual and the community as having agency in making meaning of the world. It is methodology that sees clear spaces where the researcher may not enter without invitation and humility (Macfarlane, 2013; SooHoo, 2013). Of greatest import is the dialogical space that such a methodology prizes (Siope, 2013). In the listening and sharing between participants and researcher, new meanings are made and transformation takes place. What comes of the research will be authentic to the community as well as impactful upon all involved as determined by the community.

\section{CRM and Justice}

There could be no other conceptual framework upon which I could effectively hang my research for justice than CRM. It has been shown to be important for queer research through the work of Anna Wilson (2013). As I seek to engage a community in the adventure of consciousness raising, meaning making, dialogue, critical analysis, selfreflection, and action, from what better vantage point could I approach my work? Seeing its specific connection to justice is essential. It is not for me to impose myself upon this community. Let us call to mind Smith's (1999) famous statement, "The word itself, 'research,' is probably one of the dirtiest words in the indigenous world's vocabulary" 
(p. 1). It is dirty because research has for generations been a tool of colonizers ("normalizers"). In broader, critical terms, one might say that it has been an instrument of the oppressor. In research we have traditionally found a positivism which objectifies subjects of study (Nevin, 2013). The history of oppressed persons shows the whitewashing of culture, the measuring queer realities by laws of normativity, and the erecting of unjust structures through the misuse of research (Milne, 2013). We must remember that research is never politically neutral. Amoral and altruistic research does not exist; there is always more than meets the eye:

Many researchers, academics and project workers may see the benefits of their particular research projects as serving a greater good 'for mankind', or serving a specific emancipatory goal for an oppressed community. But belief in the ideal that benefiting mankind is indeed a primary outcome of scientific research is as much a reflection of ideology as it is of academic training. It becomes so taken for granted that many researchers simply assume that they as individuals embody this ideal and are natural representatives of it when they work with other communities. (Smith, 1999, p. 2)

Justice in research means, for the researchers, examining ourselves, our goals, our projected outcomes. It means working in such a way that is equitable and ethical. It means employing the "us" of research alongside the "I." One must remember that equity is not the same as equality.

In my own research, I sought to engage with a silenced community who is part of a sub-culture (McLaren, 2003). The literature showed that queer teachers in Catholic schools find themselves unable to express their experiences of love, gender identity, and 
sexuality openly in ways that heterosexual teachers can (DeJean, 2010; Harris \& Jones, 2014; McCarthy, 2010; Rassmusen, 2004). Concerns with institutional morality and the pressures of ecclesial administrators have contributed to a heteronormative culture (Litton, 1999; Maher, 2007). The question of justice comes into play here. Is this a place where selfhood and agency are honored? What does justice look like in schools balancing competing moral beliefs of freedom and constricted morality? Who has the right to say what is just? Justice and liberation come primarily from the oppressed, according to Freire (2000). Only from the margins or "closets" does one have the best view of the systematic structures of injustice and feel the resultant push of limiting powers (Sedgwick, 1990). If educational research is not apolitical, then it must make a clear stand (Martin \& Litton, 2004). Research, that means, should be a means of working for justice. So, I seek to give pride of place to those voices that have been unheard (Moss, 2004). Research which is done in this way, giving primary import to the marginalized perspective, seeks to make a new vision of the future.

CRM help us move beyond simply identifying the ills of a social situation by insisting on the active engagement of those who are participating in research. Smith (1999) reminds us that "taking apart the story, revealing underlying texts, and giving voice to things that are often known intuitively does not help people to improve their current conditions" (p. 3). That is, research which exists "from the outside" replicates the hegemony that has often silenced the very communities of interest in my study (Pinar, 1998b). Rather, liberatory justice begins first with the action and choice of the marginalized. This is the message and promise of the beatitudes (Matthew 5:3-12, NIV). Freire's (2000) words are poignant here: "It is only the oppressed who, by freeing 
themselves, can free their oppressors" (p. 38). I must turn from traditional methods of representation on behalf of others to a new orientation which explores the world with others (Siope, 2013). Wilson (2013) expressed that "I need to consistently remind myself that I must be cognizant of the many implications of doing research with a marginalized group of power differentials, of various expectations of various peoples, of respecting peoples' boundaries" (p. 257). This respect of boundaries means that I must be welcomed into the process of liberation by the community of interest (SooHoo, 2013). In fact, privileging the marginalized in research is a nod towards justice but it cannot be just until that privileging means letting the community take lead. Thus, just research begins, proceeds, and ends with the community itself (Berryman et al., 2013; Freire, 2000; Holland \& Henriot, 1983).

If this is to be more than a self-serving venture to get published or a vitriolic gesture to advance gay-rights, then this research must be organic to the community of queer teachers. Ferguson's (2013) exploration of queer methodology, a philosophy which seeks meaning in the divergent, reminds me that justice means acting in a way that is authentic to multiple perspectives. Thus CRM, with their primacy in relational constructions of knowledge, best meet my vision of justice in research.

\section{Research Questions}

The questions that I am exploring in this study concern justice as explained above. My research hopes to be a moment in the process of humanization through the utilization of the tools of experience, community, and knowledge creation. Specifically, I approach my study with two questions. First, How is the construction of queerness by Catholic schools revealed/understood by a community of queer teachers in these institutions? 
Through a queer theo-critical lens I am truly concerned with how queerness is named, empowered, reified, differentiated, and expressed through the multiple levels of social discourse. This deconstruction of sexual normalization can best be discovered by those who witness and participate in rituals of Catholic school life as teachers (McLaren, 1999). My second question follows the first by consequence: How does such a community respond to the knowledge that develops among its members in this process? Rooted in a praxis oriented theory, my study must ask what the engagement of human dynamism for the advancement of justice will be in light of critical consciousness. The analysis of both thought and action provides possibility for new horizons of justice in Catholic schooling.

\section{Community of Interest}

At the outset of this research, I gathered a community of non-heterosexually identified teachers from Catholic schools in a particular region of the United States. All participants were currently employed by a school at the time of the study. The teachers could teach any subject in the K-12 range at an ecclesial institution. The title "Catholic" must be assigned to the school by the Church, acknowledging it as an authentically representing the ecclesial body in question. Participants need not identify as Catholic themselves but must identify, if only personally, as part of the LGBTQ community. No further restrictions are placed upon the participants and no compensation was made for participation.

I did not have a ready-group of LGBTQ teachers to join in the work of research. Thus, I hoped to contact these participants by means of snowball sampling, by making contact via shared acquaintances. I focused my efforts by speaking to teachers whom I 
know in Catholic schools, university professors, and queer advocacy communities about the intention of my study, inviting them to direct possible participants to me. Knowing that this population suffers threats of termination for public display of sexuality outside heteronormative expectations, I expected that this participant group would be relatively small.

It should be noted that the participants teach in institutions which formally acknowledge communion with the Catholic Church, its teachings, and its hierarchy. As queer persons, they inhabit a special place in this global body of belief. In order to understand the community which will be assembling in this study, one ought to understand the religious teachings and ministries which pertain to homosexual persons (this is the ecclesial terminology). While aa historical overview of the relationship of homosexual persons and the Church is far beyond the purview of this study, I would be remiss not to acknowledge some of the most salient aspects of this question.

Looking at the teachings of the Church in relation to the homosexuality, one must recognize that there are two ways of "listening" to the voice of the Faith. First, there are the universal proclamations which come from the Roman Pontiff, Vatican Offices, and Meetings of Bishops from around the world (called synods). This first group of teachings are meant to be universal, touching on the common humanity of all and pertaining to moral teachings. Traditionally, these are unapologetically clear stances on the truth and falsehood of certain beliefs and the objective morality of certain acts. The second level of Church teaching is that which comes from local church communities such as dioceses, archdioceses, and geographically regional conferences of bishops. Declarations which proceed from such positions in the Church are typically more pastoral in nature. While 
they do not deny the absolute nature of universal dogma, there is a contextualization of the living of these teachings in accord with local circumstance. Below we will look at both the universal and local teachings as they pertain to homosexuality in the Church, including its presence in schools.

\section{Homosexual Persons and the Universal Church}

When we look at LGBTQ issues in the universal Church teachings, we find ourselves dealing primarily with the question of religious sexuality. We know, through stories of recent teacher firings, that some teachers in Catholic institutions are civilly married or in same-sex unions. For the Church, marriage is clearly defined as the union of a man and a woman for the purpose of procreation in the documents (Pope Benedict XVI, 2009; Pope John Paul II, 1981). Thus, divergent expressions of sexuality are considered "objectively disordered" (Sacred Congregation for the Doctrine of the Faith, 1994, para. 2357). Moral judgment lies solely on the active sexual union which takes place outside of its intended heterosexual purposes. For such circumstances, the Church has developed a morality which seeks to condemn sin without condemning the sinner. Vatican II says "a distinction has to be made between error, which should always be rejected, and the person in error, who retains the dignity of a person even when contaminated by false or inaccurate religious ideas" (Second Vatican Council, 1965a, para. 28).

Ecclesial involvement in queer politics has urged that the state should ensure that proper laws are in place to ensure that do "not permit the body to serve the evil inclinations of the heart" (Second Vatican Council, 1965a, para. 14). This is a question of human and social dignity. Social forces should actually uplift all proper forms of 
married union because "those acts which are proper to married life and directed in accordance with true human dignity are to be treated with great respect" (Second Vatican Council, 1965a, para. 51). So great is the union of marriage that the Church can say "the sexual nature of man and woman and the human faculty of reproduction are wonderfully superior to what is possessed in the lower stages of life" (Second Vatican Council, 1965a, para. 51). Clear insistence on the single moral norm of heterosexual married activity is privileged in the Church, leaving queer persons asking where they can situate themselves in the community of believers.

The pastoral teachings on queer unions, or other alternative forms of marriage, pointedly make clear the disapproval of the Catholic Church. It is Benedict XVI (2005) who said that only the heterosexual marriage offers humans an "irresistible promise of happiness" (para. 2). Because homosexual couples do not share the complementarity of sexes and the possibility of procreation, "the Church teaches that homogenital behavior is objectively immoral" (National Conference of Catholic Bishops, 1997, para. 83). While writings on homosexuality have increased since the 1980 's, there is a desire to show that the Church is not changing any teaching on marriage. Thus we read "the Church has consistently taught that homosexual acts can never be approved" (Canadian Conference of Catholic Bishops, 2011, para. 5). The awkward struggle of these documents is an insistence on the immorality of certain acts while also embracing and accepting those who are acting in this way. After speaking against gay and lesbian unions, the Church says "it is crucially important to understand that saying a person has a particular inclination that is disordered is not to say that the person as a whole is disordered" (United States Conference of Catholic Bishops, 2006, p. 6). The differentiation made by 
the Church in condemning activity is difficult for many queer Catholics to personally grasp. Often condemnation of the expression of love can feel like a condemnation of the queer person who enacts it (Cheng, 2012).

\section{Homosexuality and the North American Church}

Teachings from local bishops and conferences of bishops tend to reiterate universal teaching while calling forth a more pastoral approach to dealing with homosexual persons. The American bishops wanted to differentiate between same-sex desire and the sin of homosexual sexual activity by stating that: "By itself, therefore, a homosexual orientation cannot be considered sinful, for morality presumes the freedom to choose" (National Conference of Catholic Bishops, 1997, para. 81). Yet, in our modern political reality in which our schools exist, there is a demand for greater freedom to choose a life which is not in concert with current Church teaching. Teachers, living lives freely expressing their queerness in their private lives, hope to be able to live just as authentically in the public space of their schools. We will hear more about this in the words of the study participants in the next chapter. This is seen by the Church as permissiveness which ignores eternal truth. The Bishops of Canada recognized how "the moral and spiritual relativism of our society can make the Church's teaching on sexuality in general and homosexuality in particular appear bizarre, out of touch, and even intolerant" (Canadian Conference of Catholic Bishops, 2011, para. 10). Sexual relations between persons of the same sex is against natural law (Sacred Congregation for the Doctrine of the Faith, 1994 para. 2357). Social movements to allow acceptance of these immoral acts "do not admit an objective basis for moral judgments" (United States Conference of Catholic Bishops, 2006, p. 14). Rather, laws help to safeguard from 
immorality and direct human freedom to its ultimate end. "The progressive maturing of a person's freedom is a long-term process that can be encumbered by numerous obstacles," (Canadian Conference of Catholic Bishops, 2011, para. 8) such as the relativism of our culture. The Church does seek to love homosexual persons "for truth and love are not opposed" (National Conference of Catholic Bishops, 1997, para. 78). Thus we see that queer teachers find themselves in the midst of a discourse of love in the Catholic milieu which simultaneous excludes same-sex union. Ministries which have been officially approved by the Church are those which reach out to empower homosexual persons to live celibate lives. The question of transgenderism in the Church has yet to be taken up in a robust theological manner.

\section{Researcher Positionality}

In using CRM to guide my work, I must begin my work with an authentic selfinterrogation (Glynn, 2013). Who am I? Why have I come to this study? Where do I find myself in the community and how do I find that I am outside of it? Nevin's (2013) words about this work of clarifying one's positionality resound as a warning in my mind: "Through this journey of self-interrogation, I gained an understanding of how my own culture and identity influenced the way I undertake research with any community” (p. 123). I do not come to research unbiased. I must trouble myself before we can trouble the problems of the world.

I should begin with my history. I am White, Catholic, queer, cisgender man born in the southern United States in an "upwardly mobile" middle class family. I identify as more politically and religiously progressive than much of my family. Until my postgraduate work, I had primarily attended Catholic educational institutions. As a White 
man, I had fallen victim to the belief that I have no real culture to speak of, as if the White man is somehow devoid of bias or his own ways of being (Nevin, 2013; Smith, 1999). Exploring beyond this space of social privilege, I discovered layers of culture which intersect in my being. To begin, mine is a southern culture, one of stories and unspoken intentions. I also come from a highly spiritual culture that understands all things as existing in relation to both materiality as well as immateriality. Likewise, mine is a culture of privilege that is not used to asking itself questions about justice for others. My southern culture prizes feeling and story over logic and quantification. I am part of a queer culture that leans to the avant-garde and transgressive. It is also a culture of activism and protest. I am part of an academic culture that envisions the world through lenses of both precision and nuance. I am part of a southern Californian culture which is marked by the importance of appearance, excellence, and conformity. These cultures inform the way that I live in this world. I tweak them in my lived experience as well as bow to their assumptions in my replication of their values. These cultures, along with others, come together to form who I am and why I am interested in the questions of this study.

My personal history gives rise to my questions as well as to my approach to inquiry. I grew up as a queer young man in Catholic education. As early as sixth grade, I realized that I was different from other kids in my school. I struggled with attraction to other boys while also learning that homosexuality was considered a sin. Entering high school, I found that my greatest struggles centered on the constant battle to hide my same-sex attractions from others while striving desperately to be normal. Outside of confessing my attractions as sin in the confines of the Sacrament of Penance, I spoke only 
once of my queerness to a trusted friend (Foucault, 1978). I did not bridge the divide in myself between acceptable and unacceptable social identities, but sought to condemn my orientation as worthy of being silenced. I was different and I never had a chance to share that difference with others.

Only a few years ago, with my exodus from the ministerial priesthood, did my story begin to take a new turn. I came to embrace my queerness as something good, not only for me but also for humanity as a whole (Cheng, 2013; Yoshino, 2006). I taught at a Catholic high school fully accepting my queer identity while negotiating appropriate "outness." My questions seek to understand how the queer self is understood/constructed in a religious setting. I am also intrigued at the ways that religious bodies embrace, silence, or reject queer persons. The most creative of spaces for justice and possibility are in these very spots of tension. Like Asher (2002), I take time to prepare myself to be in these places of possibility:

I believe that, in order to make such a difference, I need to engage in my own self-reflexive spirituality work. Indeed, I have encountered my own pain, anger, denial, guilt, and conflict, and my need to heal from the same. (p. 246).

I come to this study knowing that I seek healing with the other participants.

How easy it would be for me to assume that my story and experience of Catholic high school as a queer teacher was prototype experience of all other non-heterosexual teachers. The simplicity of such a belief can be alluring and allows for the elimination of complicating nuances. Morris (2013), when speaking of her work with Native persons, reminded us that: "Periodically, we make the mistake of placing our needs on those of the tribal community" (p. 67). Cautioned by this, I must realize that as much of an insider as 
I might feel, the purpose of my work is not to meet MY needs through the participants I work with. I cannot usurp the voice of the oppressed to liberate a repressed rejection that I feel from the Church. I cannot color the study with the myth of sameness between all persons involved, thus denying the beautiful richness of diversity and potential places of emerging justice (Glynn, 2013).

After high school, I moved into post-secondary education at a Catholic University. I became entrenched in the belief that being queer was a spiritual and psychological malady (Harbeck, 1991a). My studies plunged me deep into theological and philosophical inquiry. I was seeking answers to this great divide and ways of fixing this feeling of being "on the outside" from the normal human experience (Foucault, 1978; Freire, 2000; Sedgwick, 1990). After receiving my degree, I taught middle school religion in a Catholic school for a short while before entering seminary. I entered the priesthood while seeing myself as deeply broken and intrinsically disordered (Sacred Congregation for the Doctrine of the Faith, 1994). For this reason, I sought psychological help to change my orientation. After a year, I left ministry believing that it was not my true calling.

I know that I play both the insider and outsider roles with many different parts of the community at the same time. Figure 4.1 is a chart I constructed to explain how I see my insider and outsider status existing in terms of the research. 
Insider Characteristics

- I have been a teacher in Catholic schools, including a Catholic high school in this region like my participants.

- I am acquainted with Catholic rituals and terminology like many of the teachers.

- I am Catholic who attended parochial schooling as I grew up, as are a majority of those who teach in the Catholic schools.

- I am identified as non-heterosexual as are the teachers in the study.

- I am knowledgeable of several cultures in the queer community, especially in the studied area.

- I believe education to be an ennobling and essential act in society as do the majority of teachers.

- I am a cisgender male, like my participants.
Outsider Characteristics

- I come to the study as a researcher currently unemployed by a Catholic high school while the other participants are current teachers.

- I am a doctoral student engaged in theoretical study while the participants are engaged in enacting education in practice.

- I am a recent transplant to California while most of my participants were locals.

- I am a former priest and part of the Catholic hierarchical structure while few teachers hold that same identity.

- I am relatively recently "out" while some teachers have embraced an LGBTQ identity much longer ago.

- I am a white man, while this identity was not shared by all participants.

Figure 4.1. Insider/Outsider Characteristics

This is but a cursory look at the ways in which I am both insider and outsider to the participants in my study. I came into the study aware of these and expecting that relationships would be built along the lines of these roles. At times, I found myself swinging along a pendulum of insider-outsider status (Jankie, 2011). I sought to keep first an inner acknowledgment that that it is a community belonging to the participants and that I am coming to it to do no harm. Adler (2004) remarked, "I may use my insider knowledge and behavior patterns to build rapport, but I must be careful to honor their 
words" (p.113). At times this set me too distant from the group, who ultimately sought to welcome me to conceive of myself as a genuine part of the community.

\section{Choosing A Research Strategy}

Before I outline the research strategy which might best enact research for the sake of justice in the community, I wish to outline the most important aspects of research as they pertain to two dimensions of the population with whom I worked and gained a sense of research methods currently used in the field. First, I explored the nature of queer research knowledge. Second, I explored the nature of spiritual knowing in research. Finally, we looked at the family of research that exists in order to find a strategy that is welcoming to these forms of knowledge while maintaining the praxis-ethic of the study.

\section{Queer Research Background}

I am not the first to work with queer participants in research. Rather, the queer community has been researched and hypothesized upon in many different fields of study. The negative light in which this community has been painted led its members to engage in self-research which redefined ways of enacting the production of knowledge. First among the principles that queer scholars have identified is a fluidity of truth. Ferguson (2013) said, "epistemologies are instable and hardly universal-they are always unique to the specific framework of each study" (p. 4). There may be many truths and ways of knowing within any single community or person. Because queer study exists in this ambiguity of truth, it struggles to prove its own rigor in the academy using its own authentic measures (Corber, 1998).

Queerness transgresses the boundaries of a normalized society. It calls into question the assumed binaries of human social experience and elicits the revelation of 
plural ways of inhabiting this lived reality (Foucault, 1978). As Yoshino (2006) discovered, the revelation of queerness often helps the dominant culture to question their own normality. As such, queer methods seek to highlight those most divergent of realities which have been historically ostracized (Carlson, 1998). Ferguson (2013) "propose[s] a queer theoretical (feminist) implosion of the scientific foundation of qualitative methodologies to deconstruct and reconstruct an area of inquiry that is foregrounded in an appreciation of diversity vis-à-vis a rejection of codes, categories and thematic preoccupations" (p. 2). That is, queer research no longer limits study to preset categories but honors that plural and contradictory as unique and valuable.

\section{Spiritual Research Background}

Spiritual considerations in research are present in the academy, though they may not be copious. In looking at a few of these, I am informed by the ways that I may foster a method which is truly spiritual. I long to have a method which stands with a spiritual openness. One that does not impose itself but receives and shares. For this, I must first acknowledge the power of humility. SooHoo (2013) wrote, "Humility means the blurring of Self so that the Other may be more visible" (p. 209). This is a spiritual practice, though it need not be rooted in spirituality. Metanoia, that powerful conversion which is present in many spiritual traditions, is grounded in humility which "means a willingness to be transformed" (p. 208) by others in our relational research.

I would like to reflect on two important aspects of cultural knowing that inform spiritual research: (1) it is communal and (2) it is narrative. The first aspect of research can be found in Meyer's (2001) reflection on spiritual knowledge in her Hawaiian culture. She insists that all knowing exists within "a well-defined framework of 
community and family dependence" (p. 135). Knowledge is shared with the community, understood in relation to the other while felt deeply within the self. The second aspect of spiritual knowledge is that it is often storied. Story, as told in the great religious books and the sacred tales of peoples across the world, is a mystical location by which we access the richness of spiritual knowing. In his writings about Islamic epistemology, for example, Stonebanks (2008) reflected that due to the positivistic (non-narrative) approaches to spiritual knowledge "we are mired in perspectives that portray Islam in singular ways and singular approaches" (p.134). Thus, any research that is dedicated to the spiritual stories of knowing must be a research also embracing of plurality, contradiction, and ambiguity.

\section{Existent Research with Queer Teachers}

In working with queer teachers in Catholic education within a theoretical framework devoted to praxis and justice, I employed a strategy which can meet with with these values. Previous research with queer teachers has taken a number of forms. Outside of semi-positivistic national surveys of queer students that only tangentially touch the question of queer teachers, most research has been qualitative in nature (Kosciw, Greytak, Palmer, \& Boesen, 2014). Research focused mainly on the question of teacher identity and negotiation of the professional world. Pride of place in current research goes to formal interviews (DeJean, 2010; Gray, 2013, 2014; Endo et al., 2010; Evans, 2002; Harris \& Jones, 2014; Ferfolja, 2005; Litton, 1999; Neary, 2014; Nixon \& Givens, 2004; Rudoe, 2010; Taylor, 2011; Woods \& Harbeck, 2012). Some queer researchers have examined their own teaching experience and produced knowledge through auto-ethnographic means (Cummings, 2009; Gust, 2007; J. M. Jackson, 2007; 
MacGillivray, 2008; McCarthy, 2010; Rofes, 2000). Other researchers have participated in historical research to demonstrate the development of the current climate facing queer teachers (Getz \& Kirkley, 2006; Graves, 2009; Harbeck, 1991b; Sears, 1998). Finally, some scholars have developed theoretical reflections on queerness as it is described in other literature (Ferfolja, 2014; Maher, 2007; Rasmussen, 2004; Rudoe, 2014; Tierney \& Dilley, 1998). This literature continues to grow as more researchers explore LGBTQ issues in education (Wimberly, 2015). Two particularly notable studies by Everitt (2010) and Griffin (1991) approach the question of queer-teacher experience in school from a collaborative and action-oriented approach. It is in these studies we see that communal knowledge of queer oppression is geered toward action for social change. It is just such an approach which best meets with the ethical underpinnings of my study.

\section{Participatory Action Research}

Being culturally responsive in Catholic schooling means maintaining a commitment to justice. Likewise, our theoretical framework impels the study towards enactment of agency. Thus, I have chosen to engage in research through the employment of Participatory Action Research (PAR). Park (2001) defined this mode of research in this way: "Participatory research is action-oriented research activity in which ordinary people address common needs arising in their daily lives and, in the process, generate knowledge" (p. 81). I will briefly demonstrate how this strategy best coincides with the aims of the study. PAR is a method of research that is popularly believed to have started with the work of Kurt Lewin and William Foote Whyte in the 1940s and 50s for the purposes of organizational development and the end of discrimination (Fine, Torre et al., 2003a; Glassman \& Erdem, 2014). In the 1970s, PAR began to take on a more 
revolutionary form through the work of Orlando Fals-Borda and Paulo Freire who employed it as a means of engaging with the marginalized in seeking the end of oppression (Fals-Borda, 2001; Glassman \& Erdem, 2014). PAR takes a number of forms today in fields throughout the humanities including psychology (Fine, Torre et al., 2003a; Fine, Weis, Western, \& Wong, 2003b), theater (Campbell \& Farrier, 2015), sociology (Cahill, 2007), education (Davies, 2015; Nygreen, 2010) and others. The goal of this research offers to create social change for the betterment of some oppressed or marginalized, oppressed, or suffering group or institution. PAR's broadest strategic effort is to "challenge the artificial borders separating theory, research, and action" (Fine, Torre et al., 2003a, p. 96) through the unity of all three.

Though participatory research may take any number of forms in the field, it can be classified as having a basic structure (Park, 1999). Here, I borrow from the work of Peter Park (1999), Kathryn Herr and Gary Anderson (2005) to give light to their most basic elements. PAR begins with the identification of a problem that is impacting a social community or organization (Park, 1999; Herr \& Anderson, 2005). The problem is identified as existing in "a society characterized by conflicting values and an unequal distribution of resources and power" (Herr \& Anderson, 2005, p. 4). The locus of inquiry derives not from the researcher but from the community at large. Thus, the community experiencing the problem begins by seeking to understand the nature of the problem itself through critical consciousness (Freire, 2000). This deep understanding of the contributing factor and consequences of the problem must then move towards some action seeking improvement of the present situation (Park, 1999). The action itself is part of a greater cycle of understanding in which the community is led to deeper 
understanding in response to what has transpired. Thus action and understanding are in mutually constitutive relationship which is the essence of action research (Herr \& Anderson, 2005). Below we will examine essential aspects of PAR and its fit to the study at hand.

\section{Relationship and Justice}

PAR closely ties relationality to the work of justice. In this research there is a “commitment to working with communities" (Cahill, 2007, p. 362) as opposed to imposing our expert knowledge upon their experiences. In PAR, the development of insight comes from the experience of being in relationship with a community of knowers. This "shared process of discovery" (Glassman \& Erdem, 2014, p. 207) means that PAR as a method implies a reciprocity. Breaking with traditional ways of delineating study roles, PAR "blur(s) what might be a clear delineation between research and researcher" (Campbell \& Farrier, 2015, p. 85). Thus PAR is a means of living out the reciprocity which is so key to a culturally responsive research method (Berryman et al., 2013). PAR fits well as a method because it prizes the relationship and deconstruction of traditional power roles in research in a way that can be truly culturally responsive to queer teachers. When dealing with a community that senses isolation, relationships are an important part of liberating research.

In my study, I sought to do justice alongside others, thus my very methods must be a living form of justice. So, responsive to the community that I am seeking to research with, I must "develop relationships by first listening respectfully and being responsive to those with whom one seeks to engage" (Berryman et al., 2013, p. 21). PAR first chooses to do justice, as defined by the community itself, above all other commitments. As my 
definition of culturally responsive justice urges, we must be open to a plurality of ways of envisioning progress. Consensus on ideas and meanings need not exist in this method because it is open to multiple voices (Fine, Torre et al., 2003a). By authenticating differing ways of being and experiencing queerness in schools, this research acts justly towards queer teachers. Here PAR answers these demands.

\section{Silence and Dialogue}

Working with a minoritized population, it is important that I find a method which allows participants to be authentic. In schools, queer teachers find themselves isolated and silenced (Ferfolja, 2014; Gray, 2013; Woods \& Harbeck, 2012). PAR studies make "a commitment to centering marginalized voices" (Cahill, 2007, p. 363). Speaking of PAR, Fine, Torre et al. (2003a) noted that "the silenced are not just incidental to the curiosity of the researcher but are the masters of the inquiry" (p. 175). Thus, the investigation of social issues (such as the treatment of queer teachers) is led by the experiential knowledge of the afflicted community. We see this in a number of studies working with populations that are hidden or unreachable (Fine, Torre, 2003a; Cahill, 2007; Campbell \& Carrier, 2015). PAR utilizes dialogue among community members as the means by which consciousness is raised about particular issues (Fine, Torre et al., 2003a; Freire, 2000). "Dialogue occupies a central position as inquiry" (Park, 2001, p. 81) because its reciprocal nature allows for the ever deepening creation of knowledge. Thus, in research with queer teachers, PAR offers the dialogic space needed to honor queer voices. 


\section{Authorship and Action}

PAR is particularly oriented to actionable results which flow from knowledge creation. This action, however, must be authored by the community in question, rather than imposed (Fine, Torre, 2003a). Cahill (2007) noted that the term PAR may be used for research which may not be very inclusive at all. By employing PAR in a culturally responsive way, we know that benefitting communities means not encroaching on their freedom to act. Fals-Borda (2001) wrote, "we needed to decolonize ourselves, that is, to discover the reactionary traits and ideas implanted in our minds and behaviours mostly by the learning process" (p. 29). Culturally responsive PAR calls into question the ways that we live out dominant discourses as researchers and demands a more equitable approach. Thus we seek "representational, relational, and reflective knowledge" (Park, 2001, p. 83) which comes about from a community experiencing oppression in order for them to reconstruct social patterns of their own. This best fits the ethical demand for justice set out for this study.

When producing the results of PAR work (which is often narrative), "careful consideration of the consequences of telling particular stories and how they can be used or potentially misinterpreted" (Cahill, 2007, p. 367). Fine, Weis et al. (2003b) insisted that the space we create for community knowledge to be developed must be safe. This allows for the authentic expression of human agency for justice. Action that arises from knowledge needs to come from the lived experience of those who are oppressed. This is called vivencia and it goes beyond dissociated forms of activism (Glassman \& Erdem, 2014; Fals-Borda, 2001). PAR works from the belief that "human activity shapes history, produces an understanding of the world and thereby contributes to people's actualization 
as free social beings" (Park, 2001, p. 87). Thus, when working with queer teachers in Catholic schools, I chose a methodological strategy which allowed the participants and myself to define that action which best expresses the knowledge attained through our work together.

\section{Plurality and Messiness}

PAR allows for numerous meanings and ways of knowing to take shape in the self-same study (Davies, 2015). Unlike other forms of research, there can be messiness in the multiplicity of outcomes that develop in a community-led project. The process often involves negotiation of new issues previously unforeseen (Davies, 2015; Fine, Weis et al. 2003b). Since relationality is important in culturally responsive PAR, some messiness comes from "engaging the emotions provoked by our research" (Cahill, 2007, p. 367). These contribute to our knowledge and reveal new aspects of the experience of community. Researchers may find that the results they hoped for are not what comes from the projects. Smooth transitions into liberating action are seldom seen. "Change processes engender inevitable tensions between resistance to changes based on internalized strategies for survival and a developing desire for greater control over one's own life trajectory" (Glassman \& Erdem, 2014, p. 213). PAR opens wide the door to plurality which also means that it is seldom tidy.

Queer teachers negotiate the spaces of normativity and self-identity in ways that are unique and highly contextualized. A study which seeks to be authentic to the unrepeatable nature of queer existence in Catholic schooling must be open to the messiness of working with human persons. Regarding PAR in queer research, Campbell \& Farrier (2015) noted: 
Queer PaR is thus attracted to messiness as a methodology, where messiness is imbricated with queerness and where cleanliness in knowledge production is associated with knowledge forms that have routinely occluded the queer and the non-normative in an effort to tidy up the hypotheses and conform to hegemonic forms of 'rigour.' (p. 84)

Thus, PAR affords a method for queer teachers to enact knowing in a way that is non-normative. Leaving spaces for potential creation of new possibilities which derive from the experiences of the community, PAR's flexibility becomes a perfect match for this study. It recognizes that, because such research is the product of ever-growing relationships and human agency, this research has no specific end point (Glassman \& Erdem, 2014). This is a messy place to work, but "messiness here does not equate with methodlessness" (Campbell \& Farrier, 2015, p. 86). Rather, PAR is a messy, queer method for exploring oppression and enacting change.

\section{A Critical Ignatian Method}

As can be seen above, participatory action research is a strategy for drawing together certain aspects of knowledge, power, and practice into a cohesive project. Action research is not a prescribed mode of work but is incarnate in the specific contexts of the community in which it is taking place. The following is the proposed action research method for a community of queer, Catholic school teachers exploring questions of social construction. I believed that it should be centered on dialogue and reflection (Freire, 2000). It must acknowledge the values and dignity of all. It should be rooted in a spirituality authentic to the community itself (Meyer, 2001). I needed to be open to 
multiple epistemologies (Beryman et al., 2013). The method needed to be malleable but not completely amorphous. Thus, I used a Critical Ignatian Method of research.

St. Ignatius of Loyola, founder of the Catholic religious priestly community named the Jesuits, is considered a master of the spiritual life. Drawing from this rich history, I propose a method built from a popular spiritual practice of Ignatius called the Examen. This quotidian prayer is a reflection on the events of the previous day for the sake of committing oneself to positive action in the world. The process has several steps: (1) Invite the Divine to be present with the pray-er for insight, (2) Review in detail the events of the past day without judgement, (3) Identify the ways that the pray-er brought goodness into the world through their actions in thankfulness, (4) Identify the ways that the pray-er's actions led them or others away from goodness, (5) Commit to one action that can attempt to change what evil may have been encountered in the past day. This simple prayer assumes that knowledge is spiritual, actively engaging, and transformational.

This Critical Ignatian Method is always open to alteration and adaptation according to the desire of the community. One of the most difficult things about being critical in a Catholic school is that it may call into question teachings of the institutional Church (Dallavis, 2011). The Critical Ignatian research would transform the original questions of the Examen and focus them on the task at hand. Together, a group of queer, Catholic school teachers used the art of reflective mediation to uncover truths about queer existence. This meditation and dialogue in community is, itself an active work. I point to the work of Griffith (1991) and Everitt (2010) which are defined as action research studies as I assert that dialogue is itself a rich form of action, especially when it means 
taking a risk of outing oneself to others. The Examen questions take on the following form in this research model: (1) Call to mind the presence of the spirit (as defined by each participant) as an active aspect of research, (2) Recount one salient event (in detail) which speaks to the experience of being a queer teacher in Catholic schools, (3) Acknowledge, as a community, goodness in the stories while identifying what makes these positive aspects possible (institutionally, religiously, socially, personally, etc.), (4) Discover, as a community, how injustice is found in these stories and what structures lie behind these injustices (institutionally, religiously, socially, personally, etc.), and (5) What action does this group wish to take, if any, in response to the knowledge gained from this reflection? What is gained from this is the answer to this research question: What action will queer teachers take in response to the knowledge they gain?

\section{Is it Queer?}

While the approach of the method (modeled after the Ignatian mode of daily reflection and placed in the context of Freirean-style consciousness circles) might be easily identified as both theologically and critically informed. We might ask about how this method is simultaneously queer. In the first sense, the research is taking place amongst a group of queer identified persons, making it queer in the embodied sense.

Queer theories and theologies often are most notable for the fact that they are authored by queer persons (Cheng, 2012, 2013; Foucault, 1978; Jagose, 1996; Kelly, 2007; Kumashiro, 2002; Pinar, 1998b; Sedgwick, 1990; Sullivan, 2003). Yet, we must acknowledge that queer persons are able to act in normative ways, replicating hegemonic discourses of sexuality, gender, race, class, and any other number of differences (Barnard, 2004; Carlson, 1998; Sullivan, 2003). Thus, queer methods must be more than 
those engaging queer persons, they must perform queerness (Butler, 1990). I propose that this method ventures to be queer.

Kumashiro (2002) wrote about the interplay of queer theories in pedagogy for the sake of creating anti-oppressive spaces in schools. He has explored the power queer positions in listening to stories of others in a way that demands that we open up new possibilities for meaning through self-interrogation. Queer theories deconstruct binary oppositions in data by coming at the information from queer spaces. The framework of our method derives from a practice of the ecclesial hierarchy (which condemns homosexuality) to be used as an individual examination of the events in encountering the secular world. This research queers this in several ways. The method is no longer used as an individual meditation, but as communal consciousness raising. Its aim does not seek to understand a religious being in a secular world but, rather, examines the encounter with a religious institution. From a particularly queer lens, we discover that the community does not ask solely what meaning they can give to the stories that arise, but what meaning the stories make about them as queer teachers. It draws a community into the fertile space of uneasy self and institutional examination "to put uncertainties and crisis at the center of the learning process" (Kumashiro, 2002, pp. 7-8). Knowledge and ignorance, understanding and confusion are allowed to exist in the process not as opposites but as meaningful wholes, a queer approach (Luhmann, 1998).

\section{Developing a Research Retreat}

This section of the chapter will briefly examine the pre-investigatory work that was done in preparation for the study itself. I reviewed my original plans and musings on the idea of working with queer, Catholic school teachers. I also noted my earliest 
considerations on the concept of power in the midst of conducting a research study of this kind.

\section{Leading Up to the Study}

To understand what developed in the method of this study, and consequently what is discovered in the final results of the study, we need to trace the lines of methodological development. Some two years previous to the formal beginning of this project, I started to work through a way to engage the intersection of queerness and Catholic schooling. There were several possible ways to take on such a study. Only a few of the approaches I considered are noted here. First, I could look at my own experiences in teaching in many capacities in Catholic schools as a queer person. Second, I could explore historical literature hidden in archives across the nation about queers in the Catholic church and argue that these same experiences are present in the Catholic context of schooling as well. Third, I could interview queers who had past experience in Catholic schools (alumni, past teachers, former administrators, etc.). Fourth, I could seek to speak with queer teachers currently engaged in Catholic schooling. I chose this last option because it drew me as close as possible to the actual contemporary moment in Catholic education and queer identity. The next question was: With whom shall I work in this research?

Taking my cue from critical pedagogy and liberation theology, I was drawn to seek the voices of those who were least powerful. The solution seemed obvious: Look to the students! Thus my research began a specific interest in the experience of LGBTQ youth in these schools. As a queer teacher in Catholic school, I found myself becoming mentor to students who were negotiating the world of sexuality, gender, and nonnormative self-expression. I learned from our queer alumni the social patterns in the 
school that acted as both safety nets and danger zones for these students. I watched the organic development of informal groups of queer students at lunches and breaks. By the end of the year, I saw the flowering of an official school club designed to provide a time and place for the youth to discuss and organize around issues of personal experience of being queer. Non-exclusive, the organization was a welcoming space for queer students and allies. However, within the next academic year, the club became the target of much anger on the part of parents who feared that its presence indicated the school's approval of immorality. Students experienced pressure from peers to dissociate from the group. Seeing the turmoil that even establishing a club could cause, I wondered whether conducting the study might also become a new font of undue pressure on students and administration alike. I had also learned from other researchers who had attempted similar studies in my region that access to the population was routinely denied by the leaders of the Catholic school systems. All this served to point me in a new direction.

If I was unable to look at the experience of queer students, then I ought to consider the experience of queer teachers. Teachers are entrenched in an educational system and could offer insights from experience that might even be more refined and insightful than what students could share. Indeed, if others had similar experiences to me, then they also had knowledge of student experience through informal mentorships and classroom observations. Likewise, teachers are often more aware of institutional structures and policies that effect learners and teachers alike. The more I thought about it, I realized that queer teachers faced a form of silencing that even students did not encounter in reference to these institutions. Although a very difficult decision, students are free to identify as LGBTQ without fear of being removed from the school for such 
information. However, teachers who are queer are far less free to discuss sexual orientation, and practically forbidden to speak of queer relationships due to the binding power of morality clauses found in their contracts. In fact, it would seem, in reference to sexuality, queer teachers were much less empowered than their pupils. I knew that I needed to explore this intersection of queer teachers and Catholic schooling. It was in this most oppressive and silenced place that I could discover the ways that queerness encounters Catholic norms in a space of coexistence (whether functional or dysfunctional).

In the start of my inquiry, I reached out to one of my former teachers from high school. Midway through one of the academic years, this teacher announced that he was leaving the school. The students were devastated. He is an outstanding instructor, dynamic in his pedagogical approach, and inspiring in his authenticity. His departure was sudden and rumors soon circulated that he was asked to leave because of his sexual orientation. Though he never "came out" to us, we all knew that our teacher was gay and that might have been part of why we loved him so much. I undertook a two-week investigation to find the whereabouts of this teacher because I wanted to know the truth and to understand his experiences. No former teachers had his current email or contact information. So, I scanned the internet for teachers with his name throughout the country and sent out a few emails to see if any of these people might be him. A couple weeks later I had a reply from him, surprised that I had reached out. I asked him about his experiences and his departure from the school. He stated that he left of his own choice due to the conflict in personal beliefs with administration regarding sexual orientation. He stated that he would be open to being part of a study, though he was uneasy about 
rehashing the pain of the past. After this initial contact, despite several attempts to reconnect, communication fell silent. This was an important aspect of this process of this study. These moments of fits-and-starts in conversation with queer teachers became a normative experience. There was something, perhaps, too difficult to be shared even with a queer researcher and former Catholic school teacher.

From this disappointing encounter, I began to dive deeper into the literature written about queer teachers in schooling. My findings already have been discussed in Chapter Three. This reading started to refine my desired approach for this study. Most striking in the readings was the sense of isolation that queer teachers felt. I did not want to do an isolating study based on individual interviews. Rather, I needed to make sure that this study offered a space for a new knowledge to be born, one that was open to community and connection.

\section{Original Research Plan}

I imagined a study that drew queer, Catholic school teachers together into groups to answer the question at hand: How do Catholic schools understand queerness? In my grand imagination, I would establish meetings over the course of several months in which a group of teachers would meet in a secure location for regular conversations about this topic. In between the sessions, teachers would have a month to consider what had been discussed in the previous meeting and record their musings. This thought process would provide more stories for the group to consider for the next Critical Ignatian Meeting. During the final encounter, we considered an actionable step that would come from all that we had discussed in the previous meetings. 
Data from this project would be collected in a number of ways. First, as researcher, I would maintain a research journal. While this allowed me to develop my own theoretical understanding of the progress of the group discussions, it was more important as a way of self-examination on my research engagement. It also allowed me to record the happenings of the meetings. All participants would be encouraged to collect data on their personal reflections on queer-teacher experiences in a journal, but these artifacts would be solely the possession of the participants unless they choose to reveal them to the group. The recorded reflections of the group Critical Ignatian meetings would be collectively worded by the group and written on large sheets of paper in front of the group. These statements would be the main forms of data for analysis.

\section{Power Considerations}

I knew that there were some ethical considerations of power that I needed to take into consideration as I constructed my research. We would be fooling ourselves to believe that discord and injustice does not exist in the queer community. Identity is fluid, as well as complex (Butler, 1990; Sullivan, 2003). While popular stories of LGBT culture is painted in highly monochromatic tones, universalizing the experience of a very diverse group of individuals, the truth is that many of the modes of oppression found in heterosexual communities play themselves out in the queer community. Unequal power according to gender still exists. Between cisgendered gay men and lesbian identified women, there has been a history of tension due to a lack of dedication of gay men to lesbian liberation (Jagose, 1996; Sullivan, 2003). Women still find themselves victim to masculo-dominance in the queer community, while transgender persons are further marginalized. Despite the fact that transgender persons of color were some of the first 
people to riot against police violence at Stonewall, their presence is hardly noted (Jagose, 1996). There has long been tension between the lesbian and gay identified persons and the bisexual community, perhaps because these persons inhabit desires which transgress gendered-binaries. Due to the power of identity politics and media representation within the community, bisexual persons have been made to feel invisible or ridiculed (Cheng, 2013; Kumashiro, 2002). Additionally, there is inequity based on race. White male queers remain the "gold standard" in the community, relegating queer persons of color to fetishized locations in the community (Cheng, 2012, 2013; Kumashiro, 2002). Knowing that this existed, I regret that there was not a more gender-representational group that came forward to the retreat.

I entered the research aware of the historical dynamics and the ways that power is leveraged amongst certain identifying groups. My plan allowrf each person a chance to lead a group by sharing their story and facilitating the group discussion that came from it. All was set up, I would lead several months of research that was based on a simple set of questions. It seemed simple and perfect. Yet, research rarely unfolds in simple and perfect ways. This study definitely did not.

\section{Gathering Participants: A Harrowing Endeavor}

Once I had established the method, I sought IRB approval and received it from my Institution. With this in hand, I needed to find participants. Knowing that queer teachers have recently been fired in Catholic schools after being outed as being in relationships, I knew that I needed to take the greatest of caution in my search for participants. I wanted to find a way to allow participants to initiate connection with me due to the nature of the research. Agreeing to participate was tantamount to coming out 
to me as all participants needed to be queer and should remain squarely the prerogative of teachers in this situation. There was no local gathering place for queer, Catholic school teachers nor a local network which I could tap into for sharing news of the work. The idea of advertising in schools themselves seemed either unlikely or inappropriate as principals could become aware of my connection with participants while also being aware of my form of research. In lieu of all this, I put out a call for participants through highly trusted colleagues in the academy and in Catholic schools. By snowball sampling in this way, relationships were honored. My friends contacted queer friends of theirs in local schools but did not share identifying information to me about these people. My contact was passed on and those who were interested were free to make contact with me. To my knowledge, a large number of people were contacted, though only one returned with a statement of interest. His name was Jae (pseudonym used).

Connecting with my first possible participant, Jae, I shared my vision of the research study and answered his questions. Rather than being close to my local area, the man was several hours away. I was not dissuaded by the distance, however. This teacher stated that he would be happy to share more information with other queer teachers that he knew in Catholic schools. I sent him an email that I hoped would accomplish a few very important tasks. It needed to introduce myself and my research. It needed to express my clear understanding of queer-teacher reality in Catholic schooling in light of recent firings. It needed to show that I was willing to be both transparent about my intentions and confidential about their information. Finally, it needed to introduce what it was that they were volunteering to take part in. My email to this participant which he forwarded to his queer acquaintances follows. 
Hello:

I wanted to share with you the way I hope that the research would go for the study I wrote to you about with queer identified teachers in Catholic schools. Let me begin by stating that it is of the utmost importance for myself and for my faculty committee for this dissertation that the primary benefit of this study should focus on the members of the study itself. This means that the protection of participants and confidentiality of the proceedings of the study have been very carefully thought through. As a queer man, former priest (in good standing with the Church), long time student of and teacher in Catholic elementary and high schools, I am very aware of the climate of our present situation. I know that queer teachers have been dismissed for stated "breeches of morality clauses." I know that teachers and parents in Northern California are bringing added light to the issue in efforts to support LGBTQ educators in their Catholic institutions while others are doing quite the opposite. I love my time in Catholic education and am devoting myself to it all the more in my doctoral studies. So, I come to this study imagining that each teacher who is queer and chooses to teach in Catholic schools does so for a good and important reason. Thus, I would never want to make participation in this study an occasion of employment jeopardy. I also know that, as a community of diverse queer teachers, there is something positive to be shared with one another in conversation. This study is the active gathering of Catholic school teachers in a safe place to have discussions about what queerness means in their lived experience of school-life. I hope to explain how this study not only seeks to protect the participants but also give the teachers shared ownership in the very direction the study takes.

I would like to find a group of 3-5 teachers in a single geographic region to come together as a group. I hope to find a physical place, removed from any school campus but mutually agreed upon by the group, where we can come together to have several discussions (4 or 5) about our experiences as Catholic school teachers. Normally, researchers audio or video record such meetings, taking notes for their later analysis. However, I feel that, due to the climate of the current state of affairs, it would not be ethical to do this. There will be zero audio or video recording of any meeting that we have as a group. In fact, I will not be taking away notes about stories that are shared or discussions that are had without the express permission of the entire group. During the conversation, THE GROUP will decide what information they feel can be used as data so that they feel secure that nothing identifying puts anyone in jeopardy. If someone has a story about teaching in Catholic schools that they wish to share as data, they alone can choose to give permission for its use. If the group were to choose to submit a "montage of stories" that speaks to the essence of the collective experience, that too is permissible. I will not use nor remove any data in the writing of the dissertation without the permission of each group member.

The idea is that I am not studying queer teachers but that I want to join together queer teachers so that WE, as a group, can explore the meaning of queerness in a Catholic school. I am not seeking to go against Catholic schooling, nor do I have an agenda against the Church that I wish to prove through this study. I believe that there is a kind of knowledge when only a group of learners can come to together, and this is what I am looking to do with each of you. WE (as a group) are the 
researchers, and we all become the authors of the findings. Thus, I hope to ensure that there is equitable sense of power and responsibility across the group and an assurance that the study is mindful of the lived situation that teachers have.

Meeting in a physical place is important, however, it does not mean that there is a trail of information. The discussions are formatted after the Jesuit Examen and I can explain more about how they are structured with anyone who is interested. I am more than happy to speak to any possible participant in person about concerns or interest. Distance is not a factor; the only factor is making it possible for queer teachers to have a voice about the stories and knowledge they already possess about Catholic schooling. Withdrawal from the study can be done at any time without impunity if a participant should ever wish to do so.

If anyone would like to meet in person, speak on the phone, catch coffee, talk, etc. ... please feel free to give them my contact information. I respect the courage it takes to even think about participation and wish to assure you that confidentiality will be honored from first contact. (As a former priest, I am well versed in the importance of confidentiality.)

Many Thanks, Kevin

Jae quickly shared this information with queer-teacher contacts that he had in his local area. After months of waiting and trying to gather participants, I suddenly had seven teachers stating interest by means of contact with a single interested party. I noted in my head that relationship was crucial for any work of this kind (Berryman et al., 2013). Nine days after sending out the email by way of this teacher, I received a list of seven emails of interested persons from him. I came to learn that the sharing of the email was accompanied by personal conversations encouraging the others to take part in this research which this gateway participant found so important.

Upon receiving the names and emails of this group, I wrote again to each individual to explain my research. I wanted to begin to build the kind of relationship that would build a sense of security for those taking part in the study. I offered to meet with each person, knowing that face-to-face contact would have a greater impact and allow more frank conversations about the research. My introductory email that each participant received was: 
Hello (Name),

My name is Kevin Stockbridge and I am a colleague of "Jae." I received word from him that you expressed interest in being part of the research that I am doing for my dissertation at Chapman University in Orange, CA. I believe that he forwarded an email that I sent to him about the nature of the research, but I wanted to summarize it here very briefly.

The main question of the research is "How is queerness constructed in Catholic Schools?" As a former Catholic middle and high school teacher, and someone who is a product of Catholic schools, I know that this question is best answered by those living the reality itself. For that reason, I want to draw together a community of LGBTQ identified Catholic school teachers to talk about our experiences in Catholic schools. Rather than making myself an investigator who interviews his subjects, I wanted to make a more just and open space where we can all be co-constructors of knowledge and co-researchers through our stories. Together we discover the good, the bad, and surprising realities that only conversations like this can bring to light.

Of greatest import to me is your personal confidentiality. Thus, I want you to know the following:

- No audio or video recording will take place during the study

- No names or identifying information will be used

- Data collected in a session must be approved by all members before it can be used in the dissertation to ensure all feel confident in the information that is shared

- Stories from individuals may be submitted to the data only with express permission

- I will share my final findings with the entire group after the study is complete for the approval of all before it ever is submitted as a dissertation.

I know that these few pieces of information may leave a number of questions. I would like to have the opportunity to meet you in person as an individual and speak before we gather as a community. I feel in this way, you can come to know me and ask any questions that you have. I am going to be in (your area) from February 5th until the evening of the 7th. I would love to have a chance to catch some time to talk if you are free. If this does not work, we can find another way to speak.

Thank you very much for your interest in the project! It is an honor and joy for me to make contact with you.

Many Thanks,

Kevin

After sending this email I became very excited about the possibility of beginning

the research work. These first steps of establishing relationship were most important,

however. In my readings, I found that two other action researchers, (Everitt, 2010;

Griffith, 1991), who had worked with queer teachers had intentionally structured

relationship-building into their study. For Griffith (1991), relationship-building took on 
three stages: relationship with self, relationship with the researcher, and relationship with the queer-teacher community. In Everitt's (2010) work, the process of research intentionally was set in individual interviews allowing the researcher/participant relationship to be developed first before a voluntary group session took place. Relationship and trust needed to become the firm ground upon which I would build an open and honest study.

While theoretically, I knew this to be fundamental, I may not have been fully ready to realize how difficult the process would become. After sending out the personal emails to teachers, there was a period of silence. I wondered what the appropriate line was between being humble/patient and being too pushy could be. Should I send another email or should I wait in the discomfort of silence believing that the teachers were in the process of deciding on whether they would attend the study. I chose to wait until the last week before my trip to visit the group before I wrote the group again. I had not received any confirmations that I would have attendants to this first meeting. One teacher, however, did let me know that he believed it would be easier if I had a single meeting that could answer all questions together. While I knew this was convenient, I was unsure if all the teachers were ready to "out" themselves to other teachers for the sake of only an informational session. Taking all this into consideration, I wrote a second email stating: $\mathrm{Hi}$,

As I look at my plan to go up to (your area) for the weekend to meet with participants, I have heard from some that it might be good to set a time for everyone to meet together for a short introduction that I can present to the group and take any questions that people have. I do not have any fully confirmed meetings with anyone set at this time and so I am writing to each of you to see:

1. If you would be comfortable meeting with the other possible participants for $a Q$ and $A$ about the project? 
2. If there is a desire to make such a meeting take place this weekend? (If so, when?) Or if you would like to meet individually first in person? (When?)

3. If this weekend is not conducive, I am able to change my travel plans. Which date would be best?

Just checking in!

Happy Thursday!

Kevin

After writing this email I began to get responses from the teachers. One teacher sent a note to ask if it was permissible to attend the retreat even if he was not Catholic. I assured him that the only requirement was to be employed and teaching at a Catholic school, religious affiliation was of no consequence. Any queer experience was valid in this study which intersected with Catholic schooling. He seemed excited though he was unable to meet on the dates that I had suggested. I then heard from a second teacher who wished to talk by phone as he also was unable to attend the meeting date. This conversation was enlightening to me as it helped me to understand some of the delicacies of managing participation in a study where people shared honest stories about queerness in Catholic schools. I will discuss this further in Lessons Learned about Queer-Teacher Rality. A third teacher, my only interested female identified participant sadly notified me that she wished to be a part of a study like this which she found to be important, but family issues limited her ability to commit to this work. Up to the final date of the planned trip, I had no confirmed meetings. Thus, I chose to cancel this meeting time.

\section{Lesson Learned about Queer-teacher Reality}

While the meeting did not take shape, I did learn a great deal by way of the few communications that came my way from those who contacted me. First, I realized that beginning this study would mean doing more work divesting people of the standard idea of research in order for them to be open to what I hoped that we could do. More than 
once in the emails that I received I was asked about the "interview process." Research seemed to mean one-on-one interviews for these teachers. It was something that could be done by phone or in person. I needed to explain that I wanted us to come together physically as a group to discuss questions of queerness. This level of knowing was more complex because it meant that they would be asked to share their own stories with others who were not professional researchers and they would be asked to participate in analyzing what these stories meant. I had a sense that this was difficult for people to envision even as I tried to explain it. I learned that teachers assumed that as one researching Catholic schooling, I was interested in the stories of Catholics. The idea that I was open to those who did not feel like the "typical" Catholic school teacher (despite the queer feature) seemed surprising. I was explaining away the idea that I was looking for the queer Catholics as if they were an in-crowd who best understood the workings of Catholic schooling. Assumptions did not only exist in the minds of these interested teachers, I had some as well.

One participant revealed a new complication in my plan. Since none of the emails given to me were school-related emails, I was unaware of the places where each of these possible participants were employed. They had requested to use private emails because they did not want discussion of sexual orientation to be on school servers. My assumption was that I was speaking to a diverse group of teachers from across a group of schools. He explained that all the teachers were from a single school. He quickly grasped the nature of the study and spoke to me about his trepidation in participating. With a quick email to Jae, it was confirmed that, though the teachers were not aware of who had agreed to the study (since I kept all emails blind copied), they did all teach at a 
single school site. While I made the initial assumption that this would alleviate the long process of relationship building among the teachers because of their acquaintances with each other, a more realistic difficulty was explained to me. I was asking this group of teachers to come together and share stories about teaching at an institution that they all knew. It was explained that stories could be less freely shared because they may include the presence of other teachers in the room. One would have to be careful about which stories one told because queer teachers had allegiances with others in the school and may be offended by negative (though true) tales involving their friends. This could strain the connection among participants with whom they worked on a daily basis. On this ground, an interested party withdrew from the study. It became important to make sure I addressed this issue forthrightly in my first meeting with the teachers.

\section{Just Keep Trying}

After my first meeting failed to become a reality, I contacted Jae for his insights.

I knew that I needed the cultural knowledge of a teacher at this school from one who was willing to be honest with me about my approach. Jae suggested that my first attempt asked too many questions. I needed to be more firm with my established dates and times and place less responsibility on the side of the teachers who were already overwhelmed. He explained that teachers were very busy, especially on the weekends. Jae asked that I come to see the teachers on a weekday directly after school when they would all be present. Though it made timing complex with my own teaching schedule at the University, I agreed that this might be the best approach. I went to the school website and found the annual calendar and identified the best possible days for a meeting with the 
teachers. I chose a few possibilities and sent out this third email to those who had not formally withdrawn their interest.

Hi all,

I know that planning for an initial meeting this last weekend did not pan out for a number of reasons. "Jae" did help me to realize that setting a concrete time and date might make getting together much more tenable. Also, it might be more helpful if I am able to come up on a weekday and meet with you after school in a location accessible to all. I would like a short 30 min. meeting to just begin to meet everyone and introduce myself. Also, it will allow us to set at least the next few meeting dates. In light of this, I want to offer two possible dates for meeting:

Wednesday-Feb.24@3or 3:30pm

Friday-Feb.26@3 or 3:30pm

I teach at Chapman on Tuesdays and Thursdays, which limits my ability to be in (your area) on other days of the week. If there is a better day/time, please let me know. If there is an optimal place in the area, I can try to make it a reality.

Thank you all for your understanding as I am pulling this together. Please know that I want to respect your work and honor who each of you are in every way possible.

Many Thanks,

Kevin

I was very excited for the possibility of meeting with the teachers after sending

this. I was sure that there was no more teacher-friendly way to have meetings than for me to come to their city by their institution to meet with them for one hour once or twice a month to have a study. I altered the schedule of my course to prepare myself for this first meeting. Yet, very quickly I learned that this group would not take place because teachers had responsibilities that extended to after-school. Some stated that they would not be available for months. I began to wonder how I would make this study happen. I considered the option of interviews but was again convicted by my conscience that this work needed to be done in a communal social atmosphere. I needed to open the space for a kind of knowing that could not exist in institutions where isolation and silence was the norm for queer persons. All the literature pointed that schools were just such places. 
Thus, I knew I needed to look in new places for participants and reconsider my approach. My only committed interest was Jae, with whom I stayed in regular contact.

\section{When One Door Closes...}

Around the time of my realization that this group would not work out, I attended a religious education conference in my area. During the evenings after the conference meetings, there were social gatherings for LGBTQ Catholics. While attending these social hours, I spread the word of my research hoping that I might find new leads. At the end of the three-day conference, I had 11 people state that they were interested from places across the United States and Canada. Some were current teachers, some were administrators, and others were former teachers. For the first time, I recognized that there was more than simple interest in the topic, there was a thirst for the kind of community that a study like this could bring. Repeatedly I heard versions of the following sentiment: "It is time for us to talk about the experiences that we face in schools and to let others see our struggle." It was during this same conference that I began to re-imagine the shape of the study. I did not want to face the same complication of scheduling that became the demise of my first attempt. Rather, I wanted to make something feasible for teachers and required only a single commitment of time. I also needed to find a way to open my study to teachers from across the country (since people were interested from places outside of California).

\section{Participants}

The participants who took part in the research were four in number. With ever fluctuating numbers of possible participants, I was unsure of the final count until a few weeks before the research took place. I want to take a few moments to describe the 
participants who took part in the research, and with whom I have come to establish a wonderful friendship which extends beyond the academic work we undertook together.

The group was made up of four cisgender men who each identified as gay or queer. We were aware that this does not comprise a representational group touching all possible demographics of the queer community teaching in Catholic schools. Below is a brief description of each of the participants using pseudonyms that they chose for themselves. They are all high school teachers in California Catholic schools. These descriptions are brief as I believe that the recounting of their stories will provide insights into what is left unsaid about them.

Jae

The youngest member of the participant group (in his 20s), Jae brought a bright and energetic spirit to the process. I consider Jae to be a key part of how this research progressed. Like myself, Jae is in a doctoral program and saw this involvement in the research as mirroring what he would like to do in his own work. Upon hearing about the study and my own aims, this man seemed to be set on fire about the work before us. He is bold and vibrant. He charges forward with passion in every aspect of his life. As a teacher of theology, it is clear that Jae is closely tied to the Church. Being Catholic is an important part of his identity. He is also a Latin man who thrives on connecting to his community. In fact, community is something that enlivens everything that Jae does. It was for this reason that he almost immediately found seven interested teachers in his own school to be a part of the work. And even though this did not pan out as the final group, Jae reached back into his queer-teacher connections to gather together a community of action which has developed from the study you are now reading. 


\section{Mateo}

Perhaps the most consummate of all story-tellers in our group, I would describe Mateo as the beating heart of the work. Having been a former religious, Mateo's life is deeply connected to the Catholic Church. He is a Portuguese man with a wonderful sense of humor who was also the eldest in the group. Mateo's life has included seeing and being involved in some of the most important efforts at queer activism in the Catholic church. For all of us in the group, the experiences of this man and those of his generation were the paving stones for all the good that existed for queers in the Catholic church. Mateo lost his life-long partner, Michael (pseudonym used), relatively recently and has made his own pain transform into blessings by being with others who feel the same. It was Mateo who extended an invitation for me to share my own life more fully with the group. That is the kind of man he is, thinking of others always. He said that I was the second researcher to interview him about his teaching in Catholic schools, though I do not have the name of the first.

\section{Gary}

The quieter and deeply pensive member of our group, Gary has a special gift for piercing through a concept or a story to reveal the deepest aspect of its meaning. A true wisdom figure, Gary was also the only non-Catholic in our group. He grew up as an Asian American young man in California and he attended public schools throughout his education. I think that all in the retreat would agree that Gary is both calm and very purposeful in his way of being in the world. Yet, he was far from aloof. Gary's humor and joy always added richness to the group's time together. His desire for justice seems to come from his inner core. He brought the only science teacher presence to the table. 
Because of this Gary was able to nuance the ways that teachers made sense of the stories.

He is joyfully partnered with a man who is also in education and with whom he shares his passions. A few years older than myself, Gary was able to masterfully draw the retreatants into a consideration of their own goodness, whether he was aware of this or not. Happening upon Catholic school teaching after years educating in the public system, Gary was offered better pay and resources by his institution. His voice, well measured and intentional, enhanced the study immeasurably.

Pablo

When an artist enters a room, the lighting just becomes more brilliant and nothing can be seen the same way. That is how it was when Pablo was part of a conversation. I met Pablo years before I started into this work when I attended a Catholic educator's conference. Like myself, Pablo had a history that included being part of the ex-gay Christian world. Moving away from the unfulfilling illusions that reparative therapies offered, Pablo has become a man on fire for justice. His eye for inequality is keen and he is willing to speak out against it. He lives his life authentically as a proud Latin man in his 50s from California. A few years ago, Pablo met his husband, Anton (pseudonym used), and married him, which has brought him endless joy. He is a dedicated theology teacher who has educated young people in a couple of different high school institutions in his area. More than any other teacher, Pablo seems to have had the kind of effect on students that leads to a lifetime mentorship that extends long into their adult years. In addition to teaching, Pablo loves music, writes scripts, and reimagines the world constantly. He brought a passion into the research that sustained the group through long 
hours of discussion. A man with a mission, there is no doubt that Pablo will always be an activist for queer justice in the Catholic world.

\section{Lessons Informing the Method}

My original vision of a once-a-month series of single-hour meetings shifted and I developed the idea of a queer-teacher retreat. I consolidated the meeting times into many hours of research work during a structured weekend. I made an effort to include socialization, meditation, sharing, and analysis organically into the master plan. This three-day endeavor could accomplish the work of the study while taking its cue from what was learned in the participant gathering process. Each of the lessons that I apprehended and the ways that I hoped that creating a retreat would address them are explained here.

First, I learned from the first group of seven possible participants that teacher lives were busy. I imagined that while it might be feasible to have a single meeting, having multiple meetings was highly unlikely. A retreat condensed the time of commitment to a single weekend on a calendar, meeting the needs of the participants. The literature notes that LGBTQ teachers in any kind of school report feeling like they need to work harder to prove themselves or to ensure that their seen as equally valuable teachers to their straight counterparts (Endo et al., 2010; Griffin, 1991; Taylor, 2011).

Secondly, after hearing the desire for such a group encounter expressed by teachers at the religious education conference, I realized that a very important part of the research was its ability to establish community among the participants. The conference social hours were places of life and joy for queer persons in this Catholic conference. I wanted to capture that in my study as well. A series of short meetings over the course of 
several months could do this, but it would take a significant amount of time for relationships to form due to the space of time between meetings. A retreat, on the other hand, provided a space of intensive interaction. Participants could come to know each other and develop trust due to the shared time together. Attendees would share meals, be housed in a central location, and participate with each other both in and out of formal meetings. This communal experience lends itself to the communal knowledge sought in this research. This allowed for participants to continue conversation developed in our formal meetings in informal settings.

Thirdly, I learned that getting teachers to share openly and honestly required the delicate balance of trust, community, and anonymity. I came to see that there could not be the intimacy of a shared teaching institution as open expression of feelings could introduce unintended conflict among queer co-workers. Additionally, stories from a single institution would lack the larger scope of understanding Catholic schooling in several contexts. The retreat allowed people to come together from various institutions while also providing important space and time for developing the kind of connection needed to make honesty possible. In other words, it could be a space of research and community building for teachers from very different locations. This made the work richer in its scope and more secure for the participants.

Fourthly, I knew that my approach was foreign to so many, as was evidenced by the questions I fielded about my method and the expectation of interviews. Research had a very clear meaning and it was not necessarily connected to the idea of "Catholic" being. My group meetings were already modeled after the Jesuit Examen, a spiritual model that sought to be culturally responsive to those who worked in Catholic schools. Yet, the 
Examen was being forced into research meetings that were not part of the Catholic schooling practice. Teachers do not do research meetings. "No one speaks interview" (S. SooHoo, personal communication, March 2, 2015). Schools rarely practice interviews for acquiring research knowledge. I needed the work to take a more culturally responsive shape while maintaining the critical Jesuit method. Retreats have long been a part of Catholic schooling. They are occasions of relaxation, spirituality, learning, and growth. By making a retreat that performed as participatory action research, I was able to marry the Catholic milieu with the academic work of the project.

Finally, when thinking of a retreat, I realized that this format could profit me as a researcher as well because it afforded much more time with participants than my first plan had. Six single meetings spread over the course of months could only give me data of 6 to 8 hours of discussion. I had planned to offer participants journals to write down their thoughts in between these meeting, but ultimately "group knowledge" could only take shape when the group was convened. In a retreat, however, you could benefit from discussions that were both formal and informal. Over the course of three days, the participants could be free to take up discussions of the topic at hand during meals, on their free time, or during unscheduled hours. While it seems like a single weekend retreat reduces the scope of the research on the calendar, it actually proved to widen its possibilities.

\section{Retreat Outline}

Knowing that what was afforded me in this new retreat format would be a very concentrated and singular opportunity to achieve a number of goals, I was very intentional in the arrangement of the schedule. I hope to explain the way that I imagined 
that structure could serve mission in the establishing of a retreat schedule. I should make note here that retreat development and facilitation is not something new to me. Though I never expected the ministerial skills that I developed over my career as a religion teacher, youth minister, priest, and social justice program coordinator to come into play with my research, it seems that the two worlds were meant to overlap. So, in creating a weekend that could serve the purpose of building community and establishing new knowledge, I found myself easily imagining and grafting a weekend encounter. I hope to explain here how each part of the retreat served intentional purposes. I will simply break down the retreat into its constituent days.

\section{Friday}

The beginning of a retreat is, perhaps, the most important part of the entire process. The ways that a retreat begins often sets the mood and expectations for what will follow. To begin a retreat in a way that is overly structured and heavy in content is a common mistake. While this establishes a sense of "urgency" and "gravity," it also ignores the fact that the human process of knowing includes establishing relationships. To put participants too quickly into a consideration of content also allows participants to escape the more difficult process of self-revelation and other-discovery. On the other hand, there is also the danger of starting off a retreat without any concrete structure at all. In an artificial reality, like that of a retreat, one ought not imagine that community will spontaneously take place. Rather, community must be facilitated through careful encounters. They should be open enough to allow for people to authentically present themselves to a group while also structured enough to eliminate some social stress from the participants. As simple as it may seem, the choice of constructing Friday the way that 
I did sought to establish the intent of the retreat/research while also enabling powerful community creation.

I designed a retreat that I hoped would accomplish all of these goals explained in the previous section. An outline of the retreat is shown in Appendix B. It began with a night of socialization. I knew that, if teachers were coming from several locations to share in this work, we needed to establish a common ground. Friday night included a shared meal in which I was able to answer questions which still remained about the procedure of the retreat and give time for short introductions. Then, we moved to one of the local "gayborhoods" for optional drinks and discussion at a bar. By doing this, an engagement of the very intersection of queer and teacher was built. By bringing the retreat into the bar, in some ways, the double bind of silence around the lives of queer teachers was unbound. Private and public identities were now free to be authenticated in a single space. This reversal of daily life provided the kind of queer space (perhaps one of discomfort?) which gave birth to new ways of knowing. This social space, gave rise to a fruitful day of discussion.

In designing the opening of the retreat, I was drawing from personal and culturally informed knowledge that bars and clubs have been safe havens for queers in this country. There is an historical connection between queer identity and the space of the bar. The Stonewall riots, which have been popularly designated as the beginning of the "gay rights movement," has a bar in Greenwich Village, New York named after them (Harbeck, 1991b). It was in this space that queers fought back against the oppression of their society. It is often the bar in which LGBTQ persons first experience the sense of "belonging." Bars and clubs are sites of joy, safety, and connection for many. This does 
not mean that all queer persons attend the social spaces, but that these locations have become icons of community and queer identity. For this reason, the bar seemed especially appropriate to start out our journey of research. A few months after the retreat took place, on June 12, 2016, a gay nightclub in Orlando named Pulse was entered by a shooter who took the lives of 49 people present that night. Once again, the importance of the gay bar as a location of both joy and struggle between queers and other parts of our society was brought to the fore. I hope that some of the lessons that we began to learn as a small community of co-researchers which started at a gay bar in southern California will do justice to the many voices that were silenced forever in Orlando.

\section{Saturday}

After retiring to a common house after Friday night's discussion, the retreat continued the next day. On Saturday the group did the majority of its work in investigating their stories. Each participant was given two notebooks. One was for reflections which they wished to keep private and take with them after the retreat. This was important because I wanted there to be primary benefit to the participants in this work and they should have a space for personal reflection. The participants would also be given a second notebook in which they could make notes they felt were applicable to the research or information that they personally wanted to submit to the data. Since this research was not audio recorder or videotaped, the information came in the form of handwritten notes and reflections of the researcher. By placing notebooks in the hands of the participants, I was able to multiply the chances that important information would be recorded and authenticated the role of the participants as co-investigators in the study. Additionally, I knew that our time was limited in discussion when compared to the years 
of experiences each person brought. Thus, these notebooks would allow a place of expression for ideas, questions, and insights that individuals had in the retreat which time might not have allowed. Finally, knowing that stories are sensitive pieces of information which can be misinterpreted, poorly remembered by hearers, and possibly personally identifying, I needed a space in which participants could submit written versions of their own stories. My research purposefully focused on the meaning of the stories over the stories themselves; however, I knew that many had already expressed a hope that their experiences could be brought to light. These two notebooks took the work of reflecting, remembering, and analyzing and addressrf it at the individual level. They honored the sacredness of human knowing. A private notebook (which we cannot know the contents of in this dissertation) speaks to the truth that some knowing must ethically remain in the hands of the knower(s). The shared notebook honors the fact that knowledge belongs to the one who has come to know and may be shared only by an authentic choice of the knower.

Holding all meals in common, giving space and time for conversation, and community to grow was important. Free time was designated in the schedule to allow for participants to rest between reflective sessions and provided the researcher time to take notes on each process. The remainder of the day was taken up by the exercise of the Examen. In essence, each session enacted the process of my initial research design. Rather than having these sessions once a month over the course of a longer time, they would take place during a single day. Each participant was given a sheet explaining the questions that would be asked during the reflective process. Before we began the first session, there was time for questions to be asked and suggestions made for amending the 
process. At all times, the participants were free to structure sessions in ways that best enabled them to examine their own stories of queerness and Catholic schooling. Prior to beginning first session, each participant was asked to take time to consider what stories they felt they wished to share. Each labeled his shared notebook with a pseudonym which would serve as his identifier for the study. All took that time and chose to make notes about their stories in their shared notebooks.

During these times each participant took the role of leader, shared their stories, and the group collectively examined the questions about the "good" and the "bad" they felt was reflected in the narrative. Participants were encouraged to strengthen their analysis by sharing stories from their own life which resonated with the lesson they felt was drawn from the primary story of that session. The day ended with a late dinner and much conversation about all that had been discussed during the day.

\section{Sunday}

Knowing that Sunday would only afford us enough time to meet once, the participants took time in preparation for the morning breakfast meeting to write down what they wished they could do after all that we had talked about. Sunday morning's session was like the ones on Saturday, extended and full of good conversations. We established a list of ideas, hopes, and actions that the four participants brought to the table in response to the question: "Where do we go from here?" Closing out the retreat, the participants were asked to submit their notebooks to the researcher and all would go their separate way, hopefully having established a group action and a healthy community. At a later opportunity, the researcher contacted the participants with his findings to have them check the validity of what he had found. 


\section{Is this Research?}

. One might ask the question at this point: Is this a Catholic Teacher Retreat or is it Culturally Responsive Critically Queer Participatory Action Research? It is both. The ability of the research method, as a retreat, to be enacted almost seamlessly within the cultural boundaries of the Catholic school teachers' lives reiterates its intent and mission in being truly culturally responsive. Highly relational and open to unforeseen results, the retreat-as-research held to the tenants of CRM (Berryman et al., 2013). The ambiguity of the method also brought light to its innate queerness (Campbell \& Farrier, 2015). It situated itself in ways that question the traditional and hierarchically-oriented power assumptions found in many retreats (often led by clergy or religious professionals). It acted as retreat but did so queerly, placing the leadership of the process fully in the hands of the participants, calling forth disruptive narratives of identity and experiences in a heteronormative schooling system. It simultaneously acted queerly in terms of its role as research. Tending towards the spiritual and relational dimensions of human becoming, the research-as-retreat questions were the authoritative methods of an Academy too at ease with the separation of spirit and data. The retreat was critical in using the institution's own tool (here, the Ignatian Examen), originally intended to critique the lives of individuals for the sake of fuller moral compliance, to question power structures within the Church itself. This turning of power queer the method itself, even though it may be borrowed from a traditional setting. Finally, it is participatory action research-as-retreat modeled directly from two studies performed previous to this one (Everitt, 2010; Griffin, 1991). In both, the processes of the work included critical discussion as a community which had the intention to moving towards actionable results. This tradition was 
perpetuated in this study in which retreat-as-research becomes a source of transformative knowledge.

\section{Conclusion}

This chapter has given us a bit of time to consider the art of examination. There are beautiful things to consider in both the stars and the ways that we look at the stars. When stargazing, one's approach to the skies is dictated by the mission you have.

Looking at a meteor shower as its peppers the blackness of night with shooting streaks of light, one might choose a fine glass of wine, a blanket, and a soft patch of grass for the viewing. For organizations like NASA, whose missions include seeing galaxies beyond our own, stargazing may include a high-powered telescope, a rocket, and hours of observation through a live video feed. Method makes a difference; it tells us how we are going to do something. It considers the implications of certain ways of engaging in research and their impact on the outcomes. It sets the standards of ethics and the mode of pursuing knowledge that most authentically answers the question.

As we have seen, the construction of this research has been a process of learning and evaluation. Adopting CRM as a research framework, we acknowledged that our method must be structured in a way that considers the importance of humility, relationship, and community benefit. Inspired by the participatory action research work of Everitt (2010) and Griffin (1991), this research acknowledged that engaging with an isolated community requires an action step, one which draws people out of isolation and into community for the sake of continuing into new modes of action. The creation of a research retreat came about organically, by paying attention to the needs of the participant community as well as the goals of an action research project. Intentionally 
creating a space in which the lessons of the research literature about storytelling, isolation, school context, and social binaries could combine into a new and fruitful contribution to the field, the method hoped to set up the right conditions for gaining new knowledge. What happens after the set-up of a participatory study is not fully in the control of the researcher. It is like a stargazer who has read the maps, brought a telescope, and pointed it knowingly into the sky with the hope that they will find something new. Sometimes that will pan out, and at other times there may be nothing to be found. In this case, I was fortunate to see many interesting things as I turned my research telescope towards the queer-teacher constellation of the Catholic school galaxy. 


\section{Chapter 5: Reflections on a Queer Catholic Cosmology Data and Analysis}

My twin niece and nephew are two years old and bring me such a sense of joy and wonder. When I get a chance to visit them, we spend a lot of our time discovering new things in the world. It's marvelous to see how their eyes light up when they see something they knew or recognize something they love. One such thing is the moon. When the moon rises in the sky, you can't keep their fingers from pointing to it constantly. "Hi, Moon!" "Look, the Moon!" "Night night, Moon!” From their tender perspective, the moon is a friend who lives in the sky surrounded by a blanket of a million little stars. That is what their perspective affords them to understand. But if I were to take them with me on a trip into space far enough, they would see something quite different. There is a pattern to the universe. The moon circles our Earth. Planets circle our sun. Solar systems hang together as galaxies. When we go into the cosmos we see it much differently than we did from our first earthly perspective.

In this chapter, I would like to bring the reader to see the Catholic school cosmos from a very different perspective than is traditionally afforded. The analysis process described here launches us into the midst of the living internal experience of queer teachers. We discover in their voices, evidence that there is a pattern to the way that queer teachers experience power, identity, and the mandate to comply. With this we discover the ways that queerness maintains its orbit in the Catholic school, close enough to benefit the system but far enough to keep from troubling the norm. It was in the process of analysis and thematic discovery that our cosmic metaphor was both, arising 
from the process naturally and surprisingly. This is a whirlwind tour of the queer-teacher experience in Catholic schools.

\section{The Problem of Traditional Analysis}

Analysis of data in a traditional research study is typically the work of the academic investigator. From this perspective, the researcher is the expert who alone has the power to pierce the information that is collected with a true explanation of all that has been revealed. In qualitative research, with its roots in sociological inquiry, there is a tradition influenced by colonizing approaches to academic work (Achieng-Evesen, 2016; Smith, 1999). Here we find a history replete with the practice of academics entering the field of research for a time, gathering information, and then retreating to give authentic interpretation to these data. These researchers may have engaged in the field with moreor-less cultural sensitivity, but the process of analysis is ultimately the exclusive right of the academic. Analysis is the post-work of the method of collection, or at least it is done once one has removed from the field sufficient enough data to gather an "objective" view. But the very problem with this is that it makes the human subjects which have been observed into objects themselves. As kind and genuine as the researcher may be in interacting with a cultural field, the process of analysis can betray an insidious assumption of expertise (Smith,1999). It replicates and enacts the colonial process of othering the "queer" (read here as strange and curious) subject accompanied by an unequal distribution of power.

Privileged in the traditional process of analysis are the viewpoints of the researcher. The claim of academic objectivity is an effort to neutralize the impact of bias on the part of research investigation. Yet, this claim seems implausible, and, according to 
my theoretical frame, impossible. The interpretations of the academic are filtered through the specific logic adopted by the analyst. This logic may be adopted by the researcher from his/her/their studies in literature of their particular field, developed uniquely through a careful crafting of personal philosophies, or adapted from what has been learned from the epistemology of the culture in question. No matter the source of the logic, it is singular because it comes from an individual point of view and, therefore, necessarily negates all other logics. This is exactly the process of establishing a "common sense" as described by Kumashiro (2009). And as such, the process of analysis is not unbiased and never can be. Simultaneously, traditional analysis places power to exercise that common sense over the data solely in the hands of the researcher. This places the interpretation and meaning of the knowledge of a culture at the mercy of an outsider. By this process the academy repeatedly colonizes locations through placing authority in the hands of its representatives to make decisions on the meaning of information garnered as an outsider about a social reality.

Indeed, I do not propose here that there might be a perfect form of research analysis in which bias has been eliminated and all logics of understanding have been duly honored. In the finitude of research and the complexity of qualitative inquiry into the messiness of human existence, do not permit us to come to an exhaustive explanation of what is before us. Not only must we do away with the perception of objectivity, which is so easily problematized through the discussion of bias, but we must likewise remove the sense of comprehensiveness in academic research. To investigate is to look at a problem from one, or even many, standpoints, but it cannot be said that one has seen this reality in its fullness from all perspectives. Speaking along the axis of time, in the present moment 
of our research, the perspective of the future is not attainable and must remain hidden from us. Thus we must assert that analysis is a biased exercise. It is most authentic when it is acknowledged as such and makes an effort to honor multiple perspectives. This does not mean that analysis should not be rigorous, only that it will forever be imperfect.

What is presented in this chapter is the result of a duo-logical pattern of data analysis. Drawing together two modes of knowing, I hope to reach towards a fuller understanding of the question at hand. As explained in the previous chapter, a group of queer teachers gathered in retreat to explore the two questions: (1) What is the Meaning of Queerness in a Catholic School? (2) What do Queer, Catholic school teachers wish to do in Light of this Meaning? The primary data in question in this study are the stories, conversations, hopes, and experiences shared by queer teachers in the retreat. The first mode of analysis was that of communal reflection. Here meanings were drawn from individual stories by all those working in concert towards a greater comprehension of the reality at hand. This will be further explained below as the participatory analysis process. The second level of coding was performed by myself in which I gathered recollected stories, lists of group-developed codes, records of actionable outcomes, and shared retreat journals. A queer thematic analysis of the participatory analysis process outcomes was performed to produce a majority of the content found below. Drawing together the multiple voices, approaches, and understandings of the group along with my own comprehension of what was revealed, I recognize that I, as the one who is engaging in the secondary level of analysis, have the power to influence the pattern that emerges and tread in the dangerous zone of colonizing queer-teacher reality with my own meaning. I have employed a member-check process to ensure that this is the case. 


\section{The Participatory Analysis Process}

As I stated before, traditional modes of research put the work of analysis squarely in the hands of the researcher. While data collection is the "find" part of the work, the retreat from the field marks the "making sense" analysis. Yet, this leaves all sense making to the academic, negating the possibility that populations often make sense of their own worlds in vibrant and complex ways. In my research, I was aware that my queer theo-critical theoretical framework would not permit a traditional practice. I needed to engage the participants and myself actively in the work of analysis together. Standing on a theory which defines and demands justice as an essential dynamic of authentic research, I needed to ask how I might step away from the epistemological danger that is inherent in the practice of traditional analysis. Rather than opting for a linear approach to my work (collect, analyze, report), I embraced a more complex matrix. The research itself was to become queer, and perhaps messy. There were to be layers of analysis, the first of which was participatory in nature.

The participatory analysis design of these retreats meant that the collection of raw data (the narratives of the queer teachers) was interwoven with the intentional practice of analysis on the part of the participants. With a group of teachers around a table, we used the Critical Ignatian Method to draw out our narratives and expose them for the purpose of understanding what these narratives meant. With each teacher who led the process, there was a new set of stories (raw data) which was presented. And after these were shared, there was discussion amongst the group about how they analyze these data according to a simple set of questions prescribed by the method itself. Leaving the questions broad allowed for multiple interpretations on the direction of the ways that the 
group made sense of the stories. Making this process even more complex was the fact that teachers were encouraged to "story match" with each other in the group as they underwent their analysis. If a part of a story resonated with another teacher's experience then they were asked to share that as they were making sense of the narrative at hand. This means that analysis was producing even more raw data. Sometimes these new data confirmed the group's primary analysis of the narrative, and at other times, they gave greater nuance to ways that the story should be interpreted. The work of making sense of these dissonant and consonant stories in their lives was the group itself. The work of the researcher was to be in the conversation while also recording the developing knowledge of the group.

The questions, as I mentioned above, for the first analysis process were broad and simple. The group, having listened to one teacher share a narrative, were asked: "What good is revealed in this story and what makes this good possible?" and "What bad is revealed in the story and what brings this bad about?" In fact, the room was set up with two large white sheets of paper hung on the wall with the words "Good" and "Bad" so that the analysis could be recorded in the sight of all. Analysis took the form of conversations. The teachers would select one or two salient aspects of the stories that resonated with them and began to discuss what they thought they meant for queer teachers in Catholic schools. As they discussed, they were deciding, collectively, what large and small meanings derived from the narratives. Once the group came up with a meaning, they asked for it to be written down on the sheets. During this deliberation process, teachers might give examples from their own lives which helped to make sense 
of the first narrative. At times this group would decide that seemingly opposed meanings both applied to narrative and thus both were recorded.

This primary analysis stage insured that the foundational understandings of the narratives which would guide the rest of the dissertation process, were authored by the participants. What should also be noted is that this analysis does not replicate the old mode of traditional research by simply switching roles between researcher and participant. If I had asked each participant to individually analyze the stories, there would be the danger of simply placing each single teacher in the role of the "objective observer" who then escapes from the field and make meaning based on their own authority. No such thing was done here. The analysis was communal. This means that the first layer of analysis/understanding derived from collective knowing. More than the fact that it is a group who is developing the knowledge/analysis, is the reality that the members of the group are also the sources of the data which is being analyzed. This dynamic interplay of individuality (brought to play in the stories) and collectivity (in the process of creating meaning) makes this participatory analysis process an action of authentic community. The analysis embraces the ethic of authenticity for each teacher while also actively working against the power of isolation which most queer teachers seem to face (Gray, 2013, 2014; Gust, 2007; Harbeck 1991b; Woods \& Harbeck, 2012). By doing this, the group produced 206 individual statements of meaning that were derived from the stories that they shared in four meetings which totaled a bit more than eight hours. These statements were all written onto the sheets in the retreat room. Eighty-nine of these statements were listed under the title "Good," meaning that the group found positive meaning in the narrative. One hundred seventeen statements were 
listed as "Bad," in which the group discovered negative meanings deriving from the narratives. This was not the end of the participatory analysis, however.

Once the group came up with these statements as a group, they were asked two further questions: one was meant for individual reflection and the second was given for the group. The first question was "What are your hopes and dreams for Catholic schooling?" The participants were asked to take time alone to answer these questions between when they went to bed between the second and third day of the retreat. They brought these answers and shared them with the group and the dreams and hopes were discussed. A list of these were recorded in front of the group during a breakfast meeting. Fifteen individual hopes were shared. But in the midst of this discussion a further 30 collective dreams and hopes were produced making the final list totaling 45 statements in all. The sharing of these hopes included the revelation of new stories (raw data points) which served to help make sense of why these dreams were so important. This queer dance between the traditionally sequential processes of data collection and analysis is part of the messiness of a research project which sought to embrace the fullness of human knowing in a rigorous way (Campbell \& Farrier, 2015).

The group was then asked a final question, just as much a part of the analysis process as the previous three. The question was "What do we want to do now after all that we have learned together?" This question was perhaps the most difficult to answer for the group. The conversation was intense, looking at all that was learned during the retreat and weighing which realities needed to be acted upon most. Thus from all the hopes and dreams, while introducing some of the political limitations of teacher agency in Catholic schools today, the group sought to find what ways they wished to move ahead 
that honored the meanings which they had deduced as a group. Once the final decision was made, it was ratified by the group and became a single answer. The participants decision was to request that I should take the information from the retreat and analyze it to see what might develop. All of my findings were to be shared with the group members by email. I was given a month to perform preliminary analysis before the group was to reconvene via Skype to discuss the findings. The participants wished to delay the decision of which action they would take until they had seen the analysis, ratified or changed the researcher contributions, and felt secure in the steps that they would take. Rather than traditional method of analysis, which is undertaken at the will of the researcher, I had a commission at the behest of the community to perform a analytic duty as an extension of the social body for the purposes of their benefit.

As explained above, this participatory analysis process was able to take a rigorous look at the questions of the research project while avoiding the domination of the researcher over the data. In fact, it allowed for new data to always emerge along the lines of the analysis process. These data complexified the issues at hand by introducing new contexts and experiences. The arrangement of the questions also allowed the retreat to produce a richness to the analysis process which may not, at first, be obvious. The questions about the good and bad of our stories provided an analysis by the group about the present state of queer teachers in Catholic schooling. The questions about hopes and the decision to make a certain action in light of this understanding provided an analysis of the possibilities for the future of queer teachers which was based on the evidence of the present state. Participants brought individual voice to the table and these voices came together in conversation to produce communal knowledge. This means that the analysis 
process included its own means of validation by asking all teachers to find alignment and understanding in light of the multiplicity of queer experiences in the Catholic school context. Action becomes a new layer of analysis as the teachers commit to embody their understandings of the meanings of queerness in Catholic schools and the potential for change that they perceive from the analysis process. From this first layer of analysis, the researcher moved into a new process which developed from the first.

\section{Post-Retreat Analysis Process}

The post-retreat analysis process ought not be understood as the work of an independent researcher, disconnected from the participatory aims of the action research. In CRM, approaches to academic work, informed as they are by highly relational senses of ontology emerging from Maori philosophies, introduce a new dynamic into research that traditional research does not possess (Berryman et al., 2013). Previous to the retreat beginning, I stood as an outsider from the community who possessed similar experiences, but not kinship. During the retreat, by means of a formal invitation by the participants for me to share in the story-telling and analysis of my life, I was welcomed into the "us" of the research. This created an ontological change in terms of researcher-participant positionality as defined by the community itself. Thus, when I was welcomed to perform analysis on the data by the rest of the participants, I was given a role to perform as the designated extension of community. I could not have designated myself but, since I was requested by those in my new community to perform analysis as I saw fit, the work done alone becomes equally as participatory as it was before. The community defined participation, designated roles for the research development, and created a method for 
ensuring that results did not stray from the intent of all participants by having member checks with the group inserted in the process.

\section{Remembered and Emotional Analysis}

Immediately upon dropping the last participant off at the airport, I went on my own retreat to record my own memories of what had transpired during the retreat. This was done at the suggestion of Suzanne SooHoo, my chair, who encouraged taking time to make notes about the events of the study since I was not video or voice recording it. While the participatory analysis process may have had formal times and places for its occurrence, it was an organic reality which could not be limited to any one finite time. The sharing of stories among the participants happened all hours of the retreat. Likewise, these teachers were making meaning of these stories in their conversations. Often they asked that these be recorded by bringing them up during the formal reflection process. Yet, I knew that it was important to record those times and happenings which occurred outside of the designated meeting times in my own notes. All of these influenced and were developments of the entirety of the research retreat processes.

During this time for my own reflection, I acknowledged emergent themes which seemed apparent to me immediately following the retreat. I wanted to examine the retreat from my perspective as a participant and sense what I thought were the most natural themes that I could see across all that I recollected about the retreat. I took time to record as many stories as I could remember, interactions, participant ideas, comments made, etc. I did this without looking at the written list of meanings that the participants and I had constructed as "good" and "bad" lessons found in our stories. This was a time to examine the ethos of the retreat...where was there energy invested by the participants? 
What stories and themes seemed to be significant to me as the researcher? Why? What kinds of stories were repeated throughout the retreat? What were the queerest parts of the retreat and what did they reveal about the cohesion of the analyses we had made?

Why is memory valid in analysis? It must be noted that there is a connection between memory and knowing. Memory, from a queer theo-critical frame, is essential for the process of humanization and epistemological authenticity by means of consciousness. Memory, along with the power of imagination, are queer tools at the disposal of the human person. In a world marked by the repetitive and unstoppable progress of time and space, all moments are by nature of their relation to all other things, finite realities. Unrepeatable, no present moment of knowledge can be replicated or exists in relationship to the people, place, and time of its inception. We are caught forever in the now which is passing. Relational knowing is essential for a study of this kind, situated as it is in an ethic of respect and justice. Yet the concept of relationality must be extended beyond the simple definition of human connection into the very structure of ideas. Knowledge is a construction of context in which present, future, and past stand in relationship to each other.

What is so queer about memory and imagination is that they are the two powers by which humanity is able to escape the confines of the present moment and extend knowing into a continuous act. This is an amazing power. By our imaginations we project the possible set of relations of an as-yet unknown future. This allows us to extend our knowing before us as a guide to the possible. By means of our memory, we examine knowledge and experience from the vantage point of the past. As was stated above, the only vantage point which we, as human beings, have absolutely no access to the future is 
that of the past. Yet, once we have reached the future moment, the power of memory gives us the ability to understand things as once apprehended. Indeed, much of our knowledge is validated because of our ability to establish a continuity between the past and our "now." Thus, to remember is to know twice, it is to know again from the present while also knowing from the future. My analysis borrows from this power, along with the power of human imagination, to explore revelations made possible from this study from its present, past, and possible future readings.

\section{Practice of Stage Two Analysis}

In order to engage the power of knowing through the lens of memory, I took specific steps. I read through each of the notebooks that were given me. I made my own researcher journal categorizing the stories according to which of the retreatants had shred them during the retreat. I first did this by recalling the retreat chronologically and letting my memory trip over the conversations that were had with me, with the group, or in my presence. I wrote down as much of the story as I was able to recollect in a section of the notebook designated with the narrator's name. After this, I began to let my mind look at all that was remembered through non-temporal relationality. What I mean is that I followed lines of free thought in my notebook that allowed me to draw together disparate elements of narrative and group analysis. I put these organic groupings into families of thought which made sense to me and stored them in another notebook. This grouping of stories often reminded me of narratives that I had forgotten during my chronological examination and I took time to record these stories under the names of their storytellers. In this way I was mirroring the practice of my participants, allowing remembered data to cajole forgotten narratives to the surface of my recollection. Often this was done by 
means of emotional resonance. For example, a collection of humorous stories that I was listing under a relational theme might remind me of another story which made me laugh, lifting it into my consciousness. Recording these items according to speaker and preliminary categories took a week of concerted and solitary writing time.

As stated above, the direct proximity of this time to the actual retreat allowed me to be connected to emotion. Certain stories drew me to tears because of the suffering of the teacher in question. Others incited rage at injustice. Repeatedly I found myself feeling hopeful when I reflected on the positive nature of the discussions and the resolutions for action that were proposed by the attendees. Parsing through feelings implicit in the stories and analyses of the study draws upon some of the queerest forms of knowing, those which are felt. This form of knowing, honored in Hawaiian epistemology, may be one of the few ways that we can uncover hidden structures of oppression (Meyer, 2001). It is in the body, feeling joy, pain, anxiety, sorrow, and all other sorts of emotions that we discover what we know. This remembered and felt analysis produced a collection of themes and categories which were able to make sense of a collection of past moments into a kind of relationship that could serve to give light to the future; imaginative and remembered analysis at work.

\section{Systematic Coding}

After taking time to call to memory the events of the retreat, permitting the logic of time to give way to a new logic of thematic relation, I put aside the notebooks that I had created in the secondary layer of analysis and revisited the sheets of statements created by the participants during the retreat. Over the course of a week I transcribed the statements into an Excel spreadsheet. I coded the results of the participatory analysis 
process. As I typed out each statement, I tried to note if I could remember a specific person in the group being the originator of the idea. Often I was not able to pinpoint a single person to a statement. As I wrote each statement, I also followed it with a series of codes that developed from the statement itself. These codes derived from the general intention of the statement, the most important word/s, the assumption underlying the statement, a feeling, or a concept described by the statement. I did not limit the number of codes that any one statement should be assigned but took time to fully explore what was being revealed and shared by this piece of participatory analysis data.

Here, I would like to expand on the way that data and analysis begins to become interwoven in this multidimensional process. As I coded the statements that developed from the participants during the retreat, I began to treat the primary analysis process as its own layer of data. Stories and accounts of the retreat, the original data, were gathered and thematically collected in the second stage of analysis. I propose that even the narratives shared at the retreat are themselves forms of social analysis as they are told from the specific interpretive perspective of the queer teacher. Nonetheless, we take these stories to be forms of valid primary data. Thus, it should not be out of the question that the participatory statements of analysis should themselves be treated as data in the process of analysis. The queer interplay of primary and secondary provides an authenticating richness to the study that acknowledges the many layers of knowing always at work in the act of coming to consciousness (Freire, 2000).

This process of analysis took me through several examinations of the statements and the codes that applied to them. My first pass through the statements produced a large group of rough codes. I then reviewed the statements again and amended codes that I 
used which may have been synonymous. I either did this by choosing a single code that best fit or by making a complex code through combining words. Thus I decided that "change agent" and "activist" were best described under the title of "activist." I also decided that "threat" and "danger" were terms that were touching on the same issue, though I felt it best to use the code "threat/danger." In this case, I determined that there was a nuanced difference between the statements being coded but not enough to merit a full differentiation of groupings. A copy of the coded statements can be found in Appendix C.

Because of the large number of codes, I knew that I would need to find the most prominent groupings of statements if I were to start to make sense of what was emerging from what was before me. I undertook a two-step process to do this. The first part of this process was an effort to find the numerically most common codes from the Excel sheet. I did this by copying all the codes and placing them in an online word-clouding site named worditout.com. By doing so I was able to visually grasp the most common codes that had been produced. After gaining an image in which the size of words were scaled from largest to smallest according to the frequency of their occurrence of the top 100 codes (see Figure 5.1), I limited the cloud to only the top 20 codes (see Figure 5.2). This helped me to makes sense of those with the greatest frequency. Below is a copy of the word clouds that were produced by the site. 


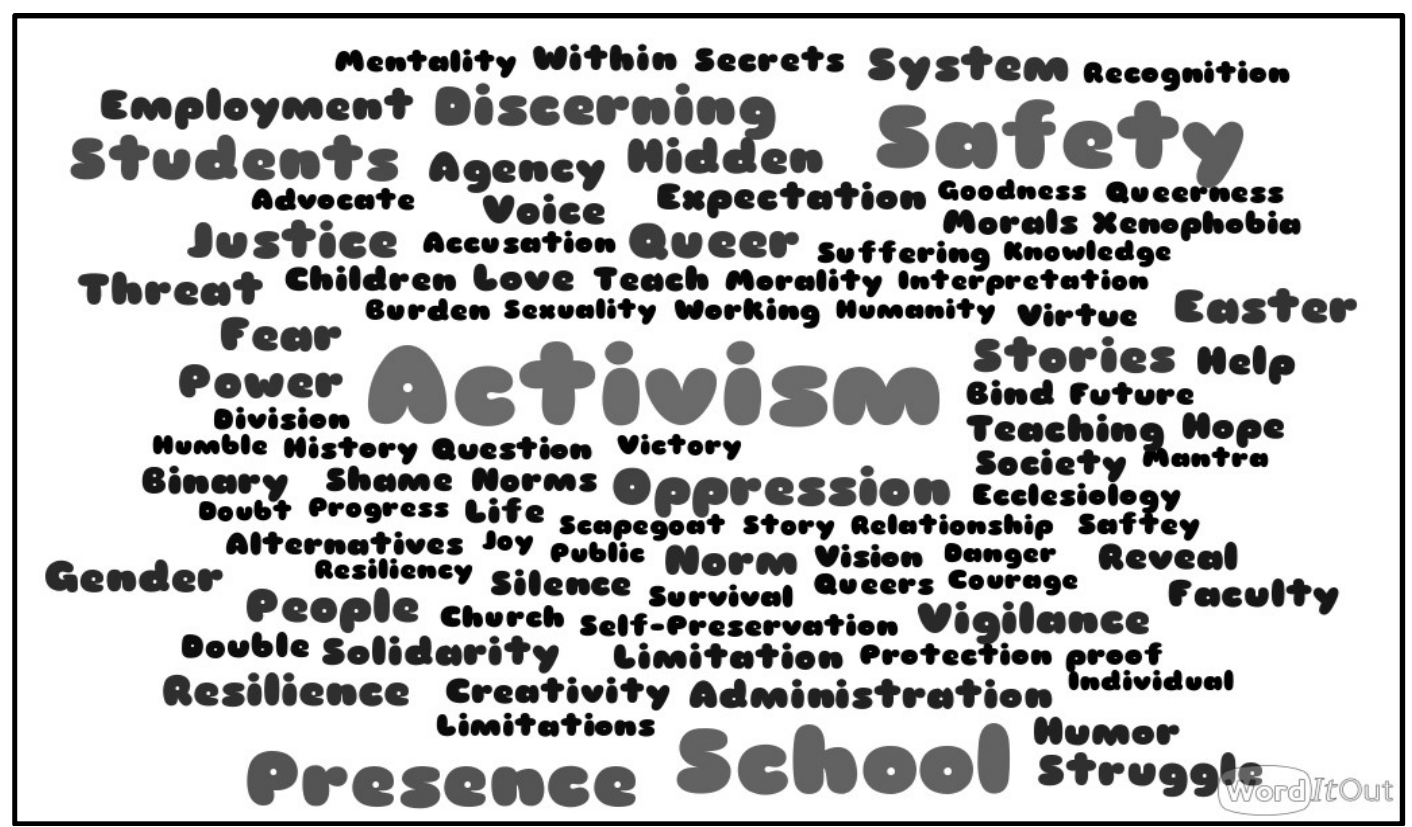

Figure 5.1: Top 100 Codes

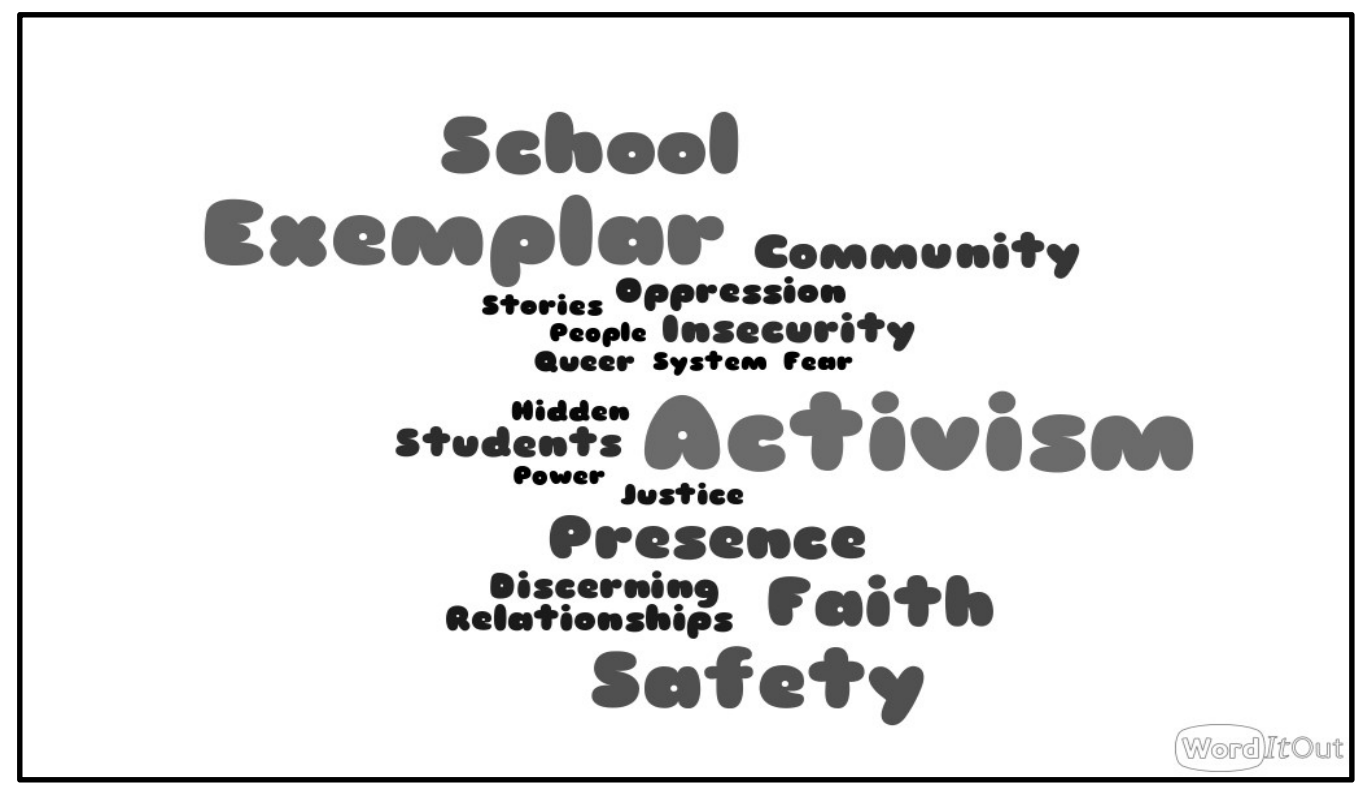

Figure 5.2: Top 20 Codes

This collecting of codes according to frequency was followed by a rereading of all codes a third time with the intention of seeing how all other codes and statements fell in relationship to the most common codes. I asked the following questions in this analysis. 
Is there a code or codes which, while they may not appear with greatest frequency, are connected to the emotional importance for the participant group? This is something which a word cloud cannot grasp. What are the ways that these codes gravitate towards each other into families? Are there groupings of codes which act like satellites around a common concept? Asking this, I found that the codes began to arrange themselves more or less naturally into rough conceptual families. I identified 17 conceptual families. These concept families were titled the following: Unique Role, Community, Easter People/ Resilience, Threat/Danger Vigilance, Power, Oppression, School/Faculty Students, Relationships/ Children, Activism, Voice/Silence, Agency, Safety/Insecurity Security, Faith, Fear, Solidarity, Discerning Presence, and Presence. Using an Excel sheet I made columns for each of these conceptual families and listed as many statements that applied to that concept according to the codes that had been given them. This meant that statements often appeared in more than one column. I included an 18th column entitled "Other" in which I listed those statements which never occurred in any of the concept-family lists. Knowing that these were the most queer/divergent statements, I wanted to preserve them in order to allow them to trouble my arrangement of the participatory analysis statements into such groupings. This information can be found in Appendix D.

\section{Member Checks}

One month after the retreat, the participants of the research retreat received a copy of all the analysis work that I had to that point. This included a listing of the remembered-felt themes which I called to mind directly after the retreat, the excel sheets containing the transcribed statements and the codes that I had assigned them, and the 
final Excel compilation of the concept families that derived from examination of the codes. Each participant had a week to look at this information and consider whether the process of analysis was going along lines that were authentic to the group itself. The participants decided on a date to meet vis Skype to discuss the information they had received and to come to a final decision about the action that the group wished to take in light of all that had been learned in the retreat.

A few hours prior to the meeting, Pablo, one of the participants, notified the group that he would not be able to join for the meeting. Due to a bullying event perpetrated by a student at his school involving queer students and teachers, a mandatory meeting was called by his administration in order to discuss how the institution would respond. Pablo was himself a victim of the bullying and the excitement of gathering again with this small group of queer, Catholic school teachers was overshadowed by sadness of reality in these places of learning. When the group convened, the immediate response of the group was sorrow and aggravation that one of us had to, again, be involved in questions of queerness at school which drew them away from community. This specific context framed the opening of the conversation for the meeting. During this time. the group acknowledged the good that they experienced from the retreat. I took notes on what had been shared. The conversation returned to the wish that Pablo, and all of the teachers who have had such experiences, did not have to be alone in a meeting but rather surrounded by community.

The remainder of the meeting was used to look at and address the analysis that had been done while coming to a final decision about an action. When asked about the analysis and any additions or amendments that the participants felt should be made, the 
group stated that they were in agreement with the direction of the work and had nothing to add at that time. I spoke to the group about my own reflection about what I felt was being learned. I had started to have a sense that one of the concepts played a more significant role than the others, even though it was one of the smaller families of statements. This was the concept of fear. I told the group that I felt like all the other concepts somehow touched on fear in some way and wondered if that made any sense to them. Immediately a conversation sparked among the group. Each of the men affirmed the sense in which fear was at play in the experiences they recounted. Most significantly, the group stated that one of the greatest impacts from attending the retreat was a sense of a reduction of fear. They discussed how they believed this had happened by means of the retreat and encouraged me to continue along this line of inquiry. In fact, this conversation easily moved them to decide on an action. The group decided to have a second retreat in another part of California. They believed that they might be able to gather a larger number of participants through the relationships they had and they wanted to extend the benefit they experienced to others. With all this information recorded, the meeting ended. Work on the future retreat was to take place as I simultaneously deepened my analysis of the research.

\section{Forming Planets}

With the group's discussion and agreement on the direction of analysis, I began to let myself contemplate "What about fear?" was coming out in the research, especially if it was not at first coded as the primary and largest concept for the retreat. I let myself ruminate on the topic. I found myself reading three significant texts during this time. The first was spiritual text by theologian Paul Tillich (2014) called The Courage to Be. 
The second one was a text by Michele Foucault (1977) entitled Discipline and Punish. And the third was a work by Gregory Baum (1975) called Religion and Alienation. I note these readings in order that I might be transparent about the process I used to jostle the concept of fear out of the data and codes that were before me. I read these bookd round-robin style, each day taking up a different text. I took time to also read nothing other than the materials that were before me from the retreat. This process was intentional. I did not want to read any one theorist into the data such that I was not letting the unique reality come to the fore. Rather, by reading very different ideas about society, fear, and spirituality, I was mentally priming myself to encounter fear. And by meditation upon the conceptual families, the center of my focus was the retreat itself.

Aware that I might be giving too much primacy to fear, I put consideration of the topic aside for a week. I wanted to ensure that I was not overlaying the work with some kind of personal expectation, even if the group itself seemed to sense the accuracy of the insight. I sought for a time to construct a clear understanding of the concepts that had emerged in the final stage of analysis by reading through all the statements that fell under each topic. I wanted to gain a better sense of what was being described in each set of statements. Moving through this process, I began to realize that certain concepts made better sense when they were collapsed together. As if there were some kind of epistemic gravitational force drawing these conceptual bodies into more complete collections of thought, I found my 17 concepts becoming 7. These were:

1. Queer Presence

2. Power and Money

3. Working with non-queers 
4. Students and Parents

5. Doing Good

6. Faith

7. Community and Solidarity

I took all the statements once more, printing them individually on pieces of paper and physically arranged them under these new, more robust conceptual families to see if there was a true distribution of data points within these themes. I was surprised to find that the information fell quite naturally into these themes. I believed that I had come to my conclusion.

Yet, as I was sorting, and consequently, intentionally reading through all the data a fourth time, I was again drawn to the sense that there was something about the centrality of fear that was acting like a subtext to my discovery. I realized that I could not understand fear and what was being revealed about it until I was able to accurately sense the relationships that each theme had to the idea of fear. It was clear, that as much as I had wished to be done with the analysis process, I had not exhausted the inquiry process. Only by examining fear could I make sense of the resulting experiences of the retreat for those who had participated. I felt its centrality. I remembered its presence in the stories. And, through rigorous and intentional multi-layer qualitative analysis processes, I uncovered its omnipresent reference in the research materials. What still remained was to understand the matrix of connection between fear and the groupings I had before me.

Employing the metaphor of gravitational force which I had sensed in the natural collapsing of my original conceptual families into more robust thematic collections of 
data, I imagined fear as a kind of force which dictated the relationship of each of these themes to one another. Perhaps another instance of queering the analysis, I began to create a piece of art with the information that I had on hand. Playing on this metaphorical hunch, I tried to demonstrate the relationship of the thematic collections of statements to this subtext of fear. I wrote the word FEAR on a piece of paper and placed it in the center of my desk. I then arranged each of the thematic bodies around FEAR as if they were satellite bodies orbiting about it. I took time to ask myself how central fear was to the understanding of what was being revealed in each grouping of statements and I arranged the themes closer or farther from the word FEAR according to my answer. I then asked myself how these themes related to one another in light of this relationship that they had to fear. I moved themes which seemed to relate in similar ways to FEAR closer to each other by placing them above, below, left, and right of the center. I walked away from this collection several times and came back to it over the course of two weeks. In the end, I found that the themes began to collide and I was left with three major themes which were both authentically representational of the data and truly robust. It was through understanding these themes that a grounded and contextual theory of fear developed. Below I explain the three themes which finally developed from the research. I entitled them: Doing Queer, Being Queer, and Enforcing Queer.

\section{Results from the Analysis}

What follows below is the result of the rich, participatory, and multilayered analysis explained above. While there may be any number of discoveries made from the examination of the data, one especially strong realization loomed above/underneath/ within/and in contradiction to the data before me. It was something acknowledged a few 
times by the participants in their analysis. It was an undertone in the stories that were shared. It was evidenced in emails, patterns of behavior, and even in the expression of hopes. Looking at all the stories, research memos, and coded themes, it became evident that all these pieces of information were like satellites whose patterns betrayed a central gravitational force. This force was fear.

\section{Fear}

In the midst of the retreat, a particularly salient statement was made in analysis of the stories that were being shared. It was plain and simple, "Queer teachers live in fear." There was not a single contestation to this simple fact when it was written on the notebook pages during one of our Examen sessions. What has been discovered in the midst of this work is that fear is hardly as simple as we might first believe. Its authorship is not always easily discovered, though its presence has definite effects. What fear means, how it is felt, where it comes from, how it is used, who its intended audience is, and how it functions in the lives of queer, Catholic school teachers was what we were discovering the more that we opened our experiences to one another. Fear was the challenge, weight, and constant norm of queer-teacher life. It is a reality that is so focused on queer persons in these schools that it can have residual effects on others who would associate with them. Fear was the complex but common thread holding together the research.

What is being unearthed, by looking at Catholic schooling from the vantage of the queer teacher, is a "mechanism of fear" by which the cultural and sexual norms of Catholic schooling are maintained and privileged. This term was coined by Jae who, during our collective Skype meeting to review initial analysis of the data, noted that he 
felt how a "mechanism of fear" was at work in his life. Gary seconded this sense when he noted, that after the retreat, he was aware that there was a weight of fear that was alleviated which he had not been previously aware of in himself. An exploration of why this action research project has been so successful in the personal and collective lives of the participants and the researcher will be presented a little later. At this time, it is sufficient to see that at the research had served to reveal a hidden part of daily life by means of evidence in personal stories. A reality that could be traced across various narratives and contexts. It was part of the living system of this schooling culture.

Fear is a mechanism because it serves particular purposes and could be traced to a source. For example, it may be the fear of parent pressure, administrative authority, monetary implications, student privilege, or hierarchical power. I wish to invite the reader to withhold moral assumptions about the exercise of fear. I do not mean to state that fear is used with malicious intent in Catholic school systems. From a queer perspective, we need to see fear as a mode of relationality that is one of many operational ways of social being. It is a mechanism of the binary, delineating the presence of opposites and maintaining their presence. From a critical perspective, we realize that this fear is best understood in the light of consciousness experienced by those who bear its weight. Here the fears of queers are the revelation of patterns of social existence. We come to the light of these mechanistic patterns by means of deep reflections of collative experiences. Finally, from a liberationist perspective, fear is a mechanism of limitation. It is something, as we shall see, that withholds the full and authentic expression of human personhood. Thus fear becomes an invitation for freeing action and an ever-new understanding of the Spirit working in our midst. 
As we move into greater specifics from the data, I wish to make an analogy. Like planets circling in steady reference to one another in maintained elliptical patterns around an unexplainable central body, the patterns of the data come together to present a first look at the nature of the forces which make them possible. Just as the pattern of the planets gives us very little insight into the gaseous nature of the sun, so too we must acknowledge that this research does not lend itself to full comprehension of the nature of the "center" of this social schooling system. As the orbits of planets reveal the forces of gravity, so too does this data set provide a glimpse into the mechanics of a force which, at one and the same time, draws queerness towards itself (normalizing) while maintaining it in the most peripheral existence possible. Here I have termed that force fear. Below are the major themes developed when we took into account the common thread of fear.

The danger of research and analysis in the final stage of description is that it can become dislocated from the lived reality of participant lives. Dragging practical realities too far into the ether of theoretical explanation can hinder our ability to put our knowledge into play. Thus, I will introduce the reader to the themes at hand in the very ways that I was introduced into them, through the powerful and poignant narratives of the participants. To maintain the confidentiality of these teachers, these stories can best be described as fictive retellings of true accounts. The changing of names and certain identifying details, however, does not fundamentally change the event being shared. Jumping off from the story, we will explore one of the themes at hand in its fullness.

\section{Doing Queer: Patterns of Rotation}

Pablo has been a dedicated teacher in his Catholic school for a number of years. He has also been an important part of the queer community as an awarded artist. The two worlds have never been brought together and his achievements have never been noted in the school. In both realms of his life, he has developed strong 
bonds with others. From the volunteer work he has done in the queer community to the lessons he teaches in his classroom, his work is that of being a voice of justice in the world. His passion has been to make those who are invisible visible and appreciated. His mission is to love.

As a single man, Pablo wondered if he might find love in his own world. He had just started to settle into the idea that a long-term relationship might not be his lot when he met Anton (pseudonym used). Quickly his world changed, he found someone else who shared his passion and brightened his days. Pablo found a joy that he had not known, one that brought him to life. When the two decided to get married, everything in Pablo wanted to shout it from the rooftops! He wanted to bring together all the parts of his life for a huge celebration, friends from school and the queer community. But he knew that he could not do that if he wished to keep his job. At best, he could tell fellow teachers and students that "something exciting" was happening to him.

Taking a sick day to make it possible, Pablo married Anton in a small ceremony lacking most of his closest friends from school. He says he was filled with joy to promise a life of love to this man. Yet, a few days later, when he returned to school, Pablo was relegated to silence. No one congratulated him. No announcement was made over the intercom as was typical with other newly married teachers. Life just went on as if nothing happened. His love wasn't something to be played out in the school. Rather, he was ever more certain that his role and expectations in the Catholic school were specific and bifurcated from "private" joys. He flattened his affect, walked into the classroom, and taught as was expected, saying nothing of the marriage or his beloved Anton.

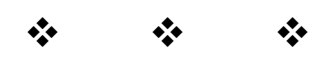

In the social order of things, we know that we all have certain roles to play. This is true in large social matrices, like nations, as well as smaller social units, like families. These roles may or may not be natural to us. One such role is that of gender. Butler (1990) explained that gender is delineated by a collection of behaviors and relationships with others that follow socially established norms. Gender is performed and perpetuates the expectations of a social norm. The assertion of a belief in the performative nature of gender requires us to imagine that social roles, gender included, are not innate and internally constructed. That is, it is not only nature which dictates how a person will behave in the world. Rather, as social beings, we take on and enact performances which have first been determined and demanded by outside forces. In examining the data, it 
became clear that there were certain roles that queer teachers found themselves playing and witnessed in others. In what follows, I will flesh out some of the ways that queeridentified teachers in Catholic schools enact their roles in these institutions.

\section{Silence}

At the opening of the research retreat, you would think that the participants were long lost friends who had a lifetime to catch up on with each other. What I mean is that, from the first moment when Mateo and Pablo drove up to the location for the retreat until the moment when everyone departed, I don't think there were very many moments of silence. The entirety of the retreat depended on open and honest communication and I found that the participants were willing and able to make that happen. Humor and telling stories, self-revelations and sharing sorrows; these were the ways that we as a community came to knowledge. In light of this, it might be surprising that one of themes of our conversations was silence. Or, given the literature that was reviewed in an earlier chapter, perhaps this isn't so surprising. As the participants so clearly stated in their group analyses: "We are always cheating our authentic selves by hiding." Silence is truly a choice and action on the part of a queer, Catholic school teacher, and my participants couldn't make enough noise about it in our meetings.

In our opening narrative, we learn of the heart breaking experience of Pablo whose marriage to a man was overshadowed in some ways by a veil of silence which lay over his queer personal life in the school. After hearing this story, the teachers agreed: "We are not able to bring stories of love for fear of the consequences." It seems that one of the most significant ways that silence comes into play in the lives of queer, Catholic school teachers involves relationality, particularly romantic and familial relationships. 
"Relationships between persons of the same sex are limited in their expression," they explained. Friendship might be acceptable among two men or two women, but anything beyond this must not come to light. All the teachers were aware that queer romance and love are not welcomed in the public life of the queer teacher in Catholic schools. "There is a sexuality double standard. While heterosexual teachers and staff can talk about their wives and children, we cannot mention partnerships.” As Pablo pointed out, his heterosexual colleagues could publicize their love with a single picture of their family on their desk. The teachers spoke of administrators who informed them that sexuality is not something that any teacher brings into the classroom, but they are quick to point out simply saying the words "my husband" or "my wife" introduces sexuality to a conversation. The difference for queer teachers is that they must not speak of such things at all. Gary explained this well in the analysis process and it was recorded by the group. He showed us what acting out silence around one's sexuality looks like: "There must be care taken when considering what is brought into public conversation and what remains private. We learn to speak in coded public conversations, talking about our 'roommate and dog' rather than 'partner and child.'”

Pablo was not the only person in the group to talk about his relationship and the way that this important aspect of life must be carefully hidden. Of the four teacher participants, two were in long-term partnerships and one had lost his life-long partner to death. These teachers emphasized the fact that: "If we marry, it must be in secret so that we can remain working.” They explained that secret/confidential marriages were a possibility in California. The pain of a life in hiding became all the more real hearing Mateo speak about the loss of his partner. Having spent many years together as a couple, 
sharing a life and a home, his relationship became a central part of his life. This life did come to play in his life at school, though its limitations in expression were marked by silence. Mateo explained that the presence of his partner at school events would not necessarily be an issue as long as no recognition of the romantic relationship was brought forward. Thus, his partnership was known, though seldom recognized by others. With the passing of his love, Mateo requested that there be nothing particularly formal on the part of the faculty to recognize this event. This was his choice in mourning and in maintaining the way things were in the school. Silence was a part of being in relationship, and silence became part of the process of loss. Simply put, the teachers realized that queer teachers "have to condition ourselves so that we don't want public recognition for events in our lives because of the constraints we live under.” We will look at those constraints in another section.

When it comes to sexuality, family, and gender, the participants explained that all silences are not the same. Participants acknowledged that: "Queer men are measured by gendered norms. We recognize this in the language employed by our schools in phrases like, 'You talk like girls' which carry shameful connotations." While there was diversity with respect to age, locations of work, and race in our retreat group, it was quickly noted by all that there was not gendered diversity. This is not due to a lack of interest. One lesbian-identified teacher was very excited to participate in the retreat but was unable to due to some family demands. This research lacks a lesbian perspective, and the male participants wanted to make sure that was noted. On the analysis sheets, we wrote: "Even as gay men, we can recognize the power and privilege we possess which our lesbian counterparts simply do not have because of gender." They explained how queer 
cisgender male privilege can be exercised in ways cisgender female queer teachers experience danger or oppression. "When a gay man has a child, no one questions how the child came to be because he can hide behind the heteronormative assumption. A lesbian who did not carry her child biologically cannot do such a thing" (Retreatants). The expectation that pregnancy and motherhood are mutually inclusive experiences means that lesbian mothers who are not pregnant before the birth of their child are resigned to hide the child's existence. But even pregnancy isn't a magic solution to the issue. "Pregnancy and lesbian identity is especially difficult because if a lesbian woman wants to be pregnant she must 'disappear' because of the multitude of questions that a pregnancy brings" (Retreatants). Questions of partnership, fatherhood, and the morality of right conception force a lesbian teacher into the kind of silence that is often masked by untruths. "Queer people must often pretend that they do not have children at all" (Retreatants).

Of the four who attended the retreat, three of the teachers taught theology in their secondary institutions. Though I had not purposefully targeted religious education teachers, I feel like there was a specific richness that their conversation brought to the questions at hand. One of the fundamental aspects of all these teachers' classroom experience was the teaching of the concept of justice. In fact, each of them identified ways in which justice became a central concern in their work. Pablo, in particular, worked to incorporate the primacy of justice in the issues that he teaches. He told the group that he often draws from the movements for justice that have been important in our national and global history in the liberation of peoples. Yet, the justice issue closest to his heart and all the hearts of those at the retreat was the freedom for queer students and 
teachers to be themselves. Jae noted that: "Queer teachers are often the recipients of the very injustices in Catholic schools that they teach are wrong according to the Church's teaching." Yet, there is a silence that must be kept around this topic for the queer teacher because championing this cause can draw too much attention to them and risk their jobs. The teachers were clear: "If we do certain things or speak on issues that connect to queerness, it becomes a threat to us." The religion classrooms in which justice is discussed are constricted spaces in which only certain teachings can take place. "There is an insistence that we remain silent about the issue of queer justice which means that we are unable to re-story and transform theologies through our lived experiences. Orthodoxy is the norm" (Retreatants). What is particularly interesting in this last statement is the fact that, while engaging in the silence, these queer teachers longed to offer new understandings of the teachings which they passed on in their practice. Silence is not accepted as right but is seen as a necessity.

The stories shared among the teachers revealed that non-queer teachers, however, do have the freedom to speak out in safety. The key for the justice-minded teacher is finding them. "The burden is on us to convince others that this issue is something that they must fight for" (Retreatants). This sense of justice that is called to action, when it is met with the demands negotiating of silence in a Catholic school, develops what the retreatants called vigilance. Allies exist in schools while there are also those who would be antithetical to the pursuit of queer justice. "The life of the school never gives us a chance to be on break from the vigilance" (Retreatants). Aware of the dangers of outing themselves while also desirous of a better situation in Catholic schooling, these teachers walk a line of ever present, and exhausting, awareness. "We are always watching the 
world around us and silencing parts of ourselves" (Retreatants). When the group spoke of vigilance, it was referenced in absolute terms: "constantly," "always," "never." Vigilance is watching out for danger while also seeking safety. The participants described this by saying, "We live in limbo." We will see this playing out in our other themes as well. In this case, vigilance is a tactic for discerning allies from foes.

Mateo shared a particularly powerful story with the group that highlighted this idea of vigilance in a powerfully humorous way. He brought the group back in time to one of his earliest teaching positions at a new school. He was excited to be working at the institution, but he was also very conscious that he wanted to make a good impression on the rest of the faculty. He was committed to be himself, but not in a way that would draw any attention to himself. In some sense, we was making sure to play down the queer so that he could connect with everyone else. He says that things were going well with his project when he went out for a social event with a group of male teachers at the school. As they sat at the table, everyone ordered a drink and they began to talk and laugh. Things were going great, Mateo said, until I looked down at the table and my heart stopped. He said all of a sudden a sense of dread overcame him and his breathing became tense at what was before his eyes. We were in suspense as he told the narrative. Mateo recalled looking at the drinks around the table and in his head taking note: “Corona, Corona, Corona, Strawberry Margarita!" He had let his guard down and his non-masculine drink was threatening to break his cover. Everyone shook their heads as they laughged because we have all sensed that dread and recognized the humor at the same time. The group quickly analyzed the story saying: "We live in paranoia." Though Mateo was never approached about the drink choice, the reality of the power of silence 
was ever-present. Could there be safe spaces in these schools where the oppression of silence was less taxing on the queer teacher?

The key to answering this question is the finding of those who teach who would not pose a threat. Returning to the story of the death of Mateo's partner, we discover how allies emerge in a sea of silence. Mateo related to the group, that there was a teacher in his school who was particularly conservative and not inclined to express or adopt views of acceptance for queer partnerships. The relationship between Mateo and this teacher was professional but not personally enriching. He could not share with her about his relationship. As the group noted, "We are always assessing our audience before we act or speak." Silence is an active project. Some months after Mateo lost his partner, the teacher came into his classroom during an off period. She started by saying that she had heard that he had lost his partner. Mateo felt the dread that was expressed in his story above. What was her intention in saying that? Then she continued by saying how difficult it must be for him to lose someone he loves so much. She asked if he wanted to talk about it. Over the next few weeks Mateo shared with her about his love and the sense of loss that he had. Because she could identify with that sense of love that she had for her husband, she became an ally. She needed to be the one to break the veil of silence, but once she did, there became a safe relationship for Mateo to freely be himself. Silence is the rule for queer teachers, but it is a rule that, under the right circumstances, can be broken.

\section{Being Put to Good Use}

Being silent is one of the most fundamental ways that queer teachers enact their presence in schools. It is the heart of what it means to "do queerness" in the constraints 
of the Catholic school. Yet, silence is not the only way that queerness is lived out in the schools. Queer teachers bring certain abilities and gifts into their schools that are leveraged by the institutions for its growth. I describe the forms of action that queer teachers take in the school setting which they sense are particularly meant for them as "being put to good use." Here I wish to show both the queer elements that the teachers sense that they bring into schools as well as describe the modes by which those gifts are put into action in ways sanctioned by the school (both by direct request or tacit permission). I make no claim that the institutions or their administrators consciously manipulate queer teachers for a certain purpose by describing my findings. I also do not rule out a subconscious bias at work in the employment of queerness for the sake of the mission of the school.

In our discussion of the "good" and "bad" that was revealed in the stories that were shared over the course of the weekend, all of the teachers agreed that queerness brings with it its own gifts and talents. Some of these have been gained because we have learned to negotiate a world in which we are not fully welcome. Others are part of our very spirit as queer beings. Universally it was agreed that: "We rarely get acknowledged for the gifts that our queerness brings." Each of the teachers told stories in which they sensed that their simple presence in the school as a lesson about diversity. "We are able to reveal the reality of difference." In some ways, this truth of difference is sought by those who hire these teachers. Jae recalled being very nervous when he applied for a job at a school while acknowledging his gayness. The principal was unconcerned with his queerness and knowingly hired him, tacitly welcoming his difference into the school. Catholic schools live under the teaching that the Church is universal, reaching across 
cultures, races, ideologies, and classes. It is important that this be reflected in the school body itself. Welcoming the queer teacher can be a way of seeking to live the mission of the school. Pablo and Mateo agreed that: "We come with unique gifts and school diversity can shine through us." Thus, doing queerness means being that light of diversity in the institution itself.

Because the queer experience questions, the boundaries of cisgendered and heteronormative assumptions of human ontology, queer teachers enter the Catholic classroom with very particular vantage points. Gary brought this to greatest light for the group when he described his decision to teach at a Catholic institution. His background differed from the rest of the group in the fact that Gary was not raised Catholic, never attended Catholic schools growing up, and had no particular intention of finding himself engaged in the work of private education. Having taught in public schools previous to his hiring at his current placement, Gary did not know quite what to expect coming into his new position. He accepted the job because the resources and infrastructure of the school promised to facilitate his work in teaching while the salary was also very competitive. Yet, upon entering the school, he was welcomed into a culture he had never known. He became more acutely aware of his queerness in this space because of the sense of silence that ran rampant. In his queerness, he realized that: "We see more than black and white." We can conceive a world outside of male and female. This special queer sight of his was welcomed into the school because it brought a new depth to the school culture. This queer vision "bring[s] creativity to our schools." Doing queer for Gary, and all the other teachers meant seeing things outside of the box. "We are able to see things in new ways and can produce new curricula" (Retreatants). Gary does this in his science classroom, 
but it can only be done within certain limits. He learned that being in his school meant accepting the mandate to do queer but don't do it too much.

One of the foundational moral imperatives that marked the missions of the Catholic schools represented by the teachers at the retreat was that of enacting justice. This derives from the teachings of the Catholic church in which justice is held as one of the Cardinal virtues. In the midst of the current climate facing queer teachers, there is an internal awareness of the need for justice in these teachers' lives. Jae described working at a school when he learned that a local teacher at another Catholic institution had been fired because of being outed as queer and in a romantic relationship. He recalled the terror that came over him at hearing the news. He told us that there was a sense of dread that seemed to be palpable when he saw other teachers he knew were also queer. The Church that had hired this teacher into a school, most likely aware of their queerness, had then asked them to leave. It was done in the name of justice, the very virtue that pushes many administrators to hire diverse teachers. As the group reflected, "We call people to stand for justice" by being the oppressed in their midst. Yet, for this teacher, it was now seen as unjust to expose students to immoral queer lifestyles. All the participants shook their heads: "We are made to live with hypocrisy on the issues that threaten our lives the most." Queerness has this dual role of promise and threat in the school.

The theology teachers reflected on their practice as those who hand on the faith, saying: "Our religious teachings are the underpinnings of our social character [as a school] and it is also the facet which leads to homophobia. Yet, we become the teachers of this through our presence in the schools." In some ways queer teachers feel that, by their choice to teach in these institutions while adopting the patterns of silence imposed 
upon them, they bolster the negative aspects of Catholic teachings. The hiring of queer teachers and their placement in the classroom is a conscious choice of the administrators in these institutions. We cannot say what their ultimate intention is by doing this as that is beyond the scope of this research. But we can acknowledge what sense teachers make of their presence in these places of learning. Somehow, they feel that their queerness can be utilized to advocate the very practices they wish they could act against. It is a lamentable reality for queer teachers: "When we work within the [Catholic school] system, there is the danger that we might be seen as advocating the very oppressive system we are caught in.” Sometimes doing queer might mean silently and unintentionally lending support to anti-queer beliefs.

Mateo, a consummate story-teller, shared a memory with us about a bus trip he took with a queer friend. It served as an analogy for us to understand what queer teachers bring to the Catholic school. He recounted getting on the bus and immediately going to take a seat at the back with his friend. The rest of the people were gathered towards the front. During the trip, he and his friend were telling jokes to each other, laughing, and becoming highly engaged with all the interesting things they were seeing. Far from being reserved travelers, the men were boisterous and highly emotive. He said that a funny thing happened as the trip continued, rather than people being annoyed, they began to move further away from their seats at the front of the bus in order to engage with Mateo and his friend in the back. The joy was contagious and gave a rather boring tour the kind of spice it needed for it to become memorable. In many ways, queer teachers find themselves in the "back of the bus" of the school, he said. We are separated from the rest of the faculty by silence and we know where our proper place is in the grand scheme of 
things. Our marginal place in the school is part of our oppression. But the thing that queers have been best at for so long has been the ability to face this hardship and meet it with resilience and humor.

Life is tough and school is tough! Schools need places of light in the midst of all the difficulties of this world. "We are able to find meaning and joy in light of all the bad in life," said the participants, because we have been doing that all our queer lives as marginalized persons. It's true that when a school employs a queer teacher, they are welcoming a person who can "offer hope to those who suffer (teachers and students alike) by sharing in struggle" of their lives. In thinking about the kind of hope that queer teachers bring to a school, the participants reflected on the needs of students especially. Knowing that our schools include LGBTQ identified learners who are struggling with their identity, teachers recognize that they are able to be safe spaces and sound voices of hope. It isn't easy to be queer in a Catholic school, having to question what lessons about the immorality of homosexual activity might mean about you as a queer young person in the eyes of God and the world. Only a queer teacher is able to answer these questions and give solace to a hurting non-heteronormative, non-gender conforming and/or questioning heart. By choosing to be a part of the faculty:

We [implicitly] teach that all are made in the image and likeness of God and, so, wish to show our students that we are all good. Yet, the shame placed upon us and lived out in our hiding speaks against this and hinders the students from believing this truth. (Retreatants)

There is no doubt that the presence of these teachers advances the mission of a school seeking to love, honor, and develop all students authentically. Doing queer in a Catholic 
school means being a light of hope. But, that light can only shine so bright. Pablo and Jae noted that: "We find ourselves assisting the queer questioning, and struggling students while we must remain silent ourselves." Queerness can be employed, in the right measure, for the good of the school. Too much queerness, though becomes dangerous.

\section{Acting Against}

We have looked at several ways in which queerness is negotiated in the school in ways that maintain the status quo. But this idea of queer action exposes another, more hopeful, element as we see the ways that queer teachers push boundaries and seek justice. I have called this "acting against." I do not mean that queer teachers see themselves as acting against some essential part of Catholic schooling in some revolutionary move to destroy the very institutions in which they choose to work. No! It is quite the opposite. In many ways, these queer teachers see themselves as acting in concert with the deepest heart of the Catholic mission by pushing against oppressive forces. They do this in ways that masterfully negotiate the world they inhabit.

In reference to silence, these queer teachers noted that one need not shout in order to be heard. There is power to presence-a way of being an advocate and activist which requires no words. "Our actions speak louder than our words can." A teacher like Pablo, who takes time after school to speak to a student about his questions concerning a new boyfriend or attends an athletic event to provide a sense of solidarity, is speaking to the goodness of being queer in a way that is much more powerful than mere words. Teachers like Gary, who include lessons about the same-sex pairings and alternative forms of sexual bonding that we see present in the animal kingdom, maneuver the curriculum to 
honor difference despite the normative culture of the school. "We offer our students alternative ways of seeing the world," the teachers asserted. If being silent is a mode by which queer teachers "do queerness" in Catholic schools, they are quick to show me that they are able to make that silence their own.

The fear of becoming an unintentional advocate of anti-queer ideologies by choosing to remain teachers in schools that are the sites of oppression was very real for those present at the retreat. But, they acknowledged that if all queer teachers were to leave the Catholic school system, there would be no one to fight from within. As much as these teachers wished that they could have honest discussions about their struggles in schools and the parts of their lives that they currently keep hidden, they were all keenly aware that doing so would likely cost them their jobs. Gary made a wonderful observation, one which became a mantra for much of the retreat: "We cannot all be Harvey Milk, sometimes we need to be Harriet Tubman, working from within." Queer teachers acknowledged that they were actively working towards improving their schools but they were doing this quietly. When they are their authentic selves in the classroom, especially if they are not trying to hide non-gender conforming interests or ways of behaving, the teachers say that they "show that there are different paths for moving through life." Mateo says that when he honors or recognizes the attributes of male queer students as good, he is dismantling cultural expectations. He says: "We work against the 'macho watcho' vibe that can permeate a school community." By being in the school, these teachers are making it queer.

"Because we aren't the norm, we are able to trouble and disrupt the norm" (Retreatants). This might be one of the best ways to describe what it means to do queer 
in Catholic schools in ways that seek to deconstruct oppression. Mateo told a story about being asked to use his artistic talents to prepare for events and liturgies at his school. When the principal gives thanks to him for his service, he says that he makes sure to accept the recognition. In some way, because that talent is so connected to his queerness, the principal's gratitude for the art is simultaneously a word of appreciation for being a gay man. All in the group agreed with that. They said of themselves: "We are able to take individual recognition and make it a space for community among the queer individuals in the school." All four of the teachers could state that they were actively involved in the life of the school, bringing their talents to the service of the community. When Pablo brings in his love of music into the classroom (especially the music of queer artists which has been a source of healing in his life) he is showing the students the ways that he lives fully in the world as his authentic self. Jae said of this, "We live the truth of the Catholic Social Teaching that it is more than just surviving in the midst of oppression, it is about learning to thrive." Doing queer is a form of liberation in Catholic schools when it seeks to open new pathways in the face of oppression.

\section{Doing Queer Conclusions}

In this theme, we have meditated on the ways that queerness is enacted, employed, and leveraged in the Catholic school. Silence is a way that queer teachers live out their identity in the Catholic school. The silence can be oppressive and destructive. We see teachers who feel the need to hide their relationships, families, and concepts of justice. Silence puts these teachers on "high alert," forcing them into a constant state of vigilance. Yet, we have also seen that these pedagogues have found ways to transform that same silence into something powerful and revolutionary. Queer teachers find 
themselves at the service of their schools, bringing with them the gifts and talents natural to their being for the purpose of advancing the mission of the institution. Compassion, artistry, creativity, and hope are brought into the school with the queer teacher and helps the school to flourish. These same gifts are limited in their expression, however. Being too queer can be a danger. Asked to be the educational representatives to a theology that does not honor the value of their love, these teachers are troubled by the way their presence is employed in furthering certain ideologies. In light of this, these teachers have taken risks to be present in their authenticity, to trouble the cultural assumptions of their institutions, and become mentors for the queer students in their care. Doing queer in a Catholic school is a complex matrix of performative engagement in which power and resistance make up the daily existence of these teachers.

\section{Being Queer: Naming the Celestial Bodies}

It's the beginning of the second day of the research retreat. Participants and researcher alike are negotiating that awkward discomfort of preparing to share deep personal realities with people they had not previously known. There is a bit of familiarity amongst us all from an evening of socialization at the bar the previous day. That had been a great time to talk about trivial and entertaining subjects. We had shared a few stories about our schools and pasts but nothing that wasn't completely safe to speak of with strangers. Now we are sitting in a circle and writing in our notebooks the most personal stories we had about our queer identities and being part of Catholic schooling. Everyone is quiet. There is a different tone.

As time for personal reflection ends, I raise my head and ask which of the teachers in the room wants to be the first to share their stories with the rest of us. They knew that we were not just sharing stories, but that what was being told would then become the heart of our collective reflection for the next hour. The room fell into a deep silence as we waited for the first volunteer. Suddenly, Mateo raising his hand in a very confident voice said "I will go first. But I have a lot to share, if that's okay?" We all said he was more than welcome to share as much as he wished. And with that, Mateo opens his notebook and began to share story after story.

Towards the end of his narrating, he tells us about moments when he was part of early gay activism in the American Catholic Church. He had been present at meetings, Masses, and rallies. He talks about creating bonds and becoming part of queer organizations. Then he recounts a time when one of the activist events was being televised. He stood proudly in the crowd, but when the television camera 
swung in his direction, he quickly raised the pamphlet in his hand to cover his face. He could not risk his job.

At once, Mateo stops talking and begins to cry. He stated, "I wish I were

more brave." The room falls into silence again. The stories have filled our eyes with tears. From across the circle Gary raises a tender voice to say, "It's odd that you think that you are not brave. Mateo, when I hear you share your stories, all I can hear is the story of a hero. You are very brave. It's the system that makes us feel we aren't brave when we are trying to protect ourselves. You are brave to me!."

In our constellation of themes, the second is that of ontology. I call this theme, "being queer" because it involves the identification of a class of people and their relation to their social setting. Gathering together all that had been written, reflected on, and discussed in our time together as a community, there emerged several ways of describing what it means to be queer as Catholic school teachers. These identities are the most basic descriptive artifacts opening our understanding of "what queer means" in a Catholic school. The social constructivist perspective afforded us through the use of queer theory, allows us to see identities as fluid and manufactured. What follows is a description of what has been discovered together about who queer teacher are and who they are perceived to be. We will look at this theme through several categories. First, we will examine the basis of differentiation in the Catholic school, established social binaries. We will then look at the identities that others place on queer teachers. This will be followed by an examination of the ways that the queer teachers in this study chose to identify themselves in their work in schools. Finally, we will look at the rich ways that teachers identify themselves spiritually in reference to their work in Catholic schools.

\section{Seeing the Binary}

As I listened to Mateo tell the story above and watched as he began to cry while asserting that he was not brave, I wondered who had told him such a thing. Where does 
that voice come from that tells us anything about ourselves? I recognized that, as I discuss the theme of identity, this question demands an answer. Identity is a complex and rich reality. As was discovered in the retreat, our answers to this question form a kind of ontological dialectic. The give-and-take of sources of identification also produced multiple layers of identity itself. How does one hold conflicting identities and what sense can be made of such existence? Before any of this can be uncovered, I want to demonstrate the ways that these teachers made sense of the world and its dualist structuring. The term "binary" was first used by Gary and Jae to describe a number of realities that affect queer teachers being seen as the other. Describing their work places, the participants said "Our institutions are very binary, teaching an 'us and them' mentality." The world is full of "two option" circumstances which these retreatants had to learn to negotiate. This is the basis upon which the group seemed to make sense of their identities as queer teachers.

The great measure of one's identity in a Catholic school, according to our conversations, can be described in relation to the idea of normality. Either a person is in the norm or they are out of it. These are the two options the teachers sensed in the Catholic school. It was revealed very clearly by Mateo's earlier story in which he realized that he was the only man in a group of other male teachers who was not enjoying a beer, but was drinking something typically considered feminine. The teachers agreed that "heterosexual lives are the strict norm" for those working in a Catholic school. As Pablo observed, it is unquestioned for straight teachers to have pictures of their families and partners displayed. Such things are normal and indicate, perhaps unintentionally, belonging to this standard group of humanity. Such is not the case for queer teachers: 
"Queer love is limited. I cannot bring all my love to the school" (Pablo, 2016).

Queerness is abnormal, and indeed, less than acceptable, in the school. This privileging of straightness and its clear differentiation from queerness is the basic binary upon which queer identity begins to take shape.

One of the consequences of privileging a standard of human existence as the norm against all others, is that it plays itself out along a new binary: private versus public. It's not surprising that these teachers discussed this reality in the retreat since we have seen how deeply this theme is played out in almost all of the literature about queer-teacher experience that was examined for this study. Describing their lives in relation to these two worlds of public and private life, the teachers said: "We must dance between how public and private we need to be in our lives and schools." Pablo spoke to the group about how he negotiates his life on social media. Knowing that students, parents, and faculty are able to see his postings, Pablo says that he is constantly monitoring what he says. He crafts this art well, posting statements supporting justice issues that are of importance to the queer community while never specifically outing himself. He talks about music and films which come from queer artists and which address queer themes on social media, but does not let this one topic predominate. The participants were quick to say that: "Queer teachers use an unhealthy skill of constant self-monitoring that keeps us safe from being fired." That is why Pablo is of the limitations of open queerness in the Catholic public sphere and maintains a safe but purposeful position on social media. As much as he wants to share his relational life like his straight counterparts do so freely, he knows that, for a Catholic school, "In dealing with queerness, there is no gray area or dialogue." To go too far in being public is to find oneself without a job. 
Being outside of the norm means more than just being private, it also comes with its own demands. The binary of queer/straight or public/private are not equally weighted experiences. Gary made note of this when he said: "Queer teachers have to work harder just to prove that they are as good as any other worker." We saw this in the review of the literature as well. To be queer doesn't just mean to be abnormal, but it means working harder. I could not help but reflect on the difficulty that I had in trying to gather participants. The loss of many teachers as possible participants due to their busy schedules made me start to wonder. Was this the way every teacher experienced their lives in Catholic schools or were the queer teachers just much more likely to be involved in more work. Jae acknowledged that the teachers who were my first possible participants were all very involved in extracurricular projects. Each of the participants who did attend the retreat were involved in multiple aspects of school life, knowing that the binary mentality created a deficit that they needed to overcome. Queer teachers are trying to overcome it all the time: "Ours is a resiliency that is learned from bearing above and beyond the normal load of pressure dealt with by those who are considered the norm" (Retreatants). It was this resiliency and tenacity that brought this retreat together as these busy educators carved time to come together in this space.

What is particularly interesting in this sense of the binary construction of the Catholic school social order, there is a particularly theological undertone. When the teachers talked about the dualist reality that they worked in, they often did so in reference to the teachings of the Catholic church. The Catechism of the Catholic Church, a collection of the beliefs of the ecclesial body, states that homosexual activity is "objectively disordered" (Sacred Congregation for the Doctrine of the Faith, 1994, 
para. 2357). The moral teachings of the Church delineate the boundaries of the binary by overlaying another layer of dualist thinking. Queer teachers said: “All issues [of sexuality and gender] are painted in a stark 'good and bad' narrative." Normal is good, queer is bad. Remaining faithful to the teaching is paramount in the Catholic school as it means maintaining the teachings of what is good. In fact, it was discussed in the group that some dioceses have formed oversight groups which seek to ensure that theological teachings are adhered to in schools. These groups seem to be highly concerned with teachings of sexuality. Either one is right or wrong in their teachings, little gray area is afforded. Jae said that even parents come to argue against more pastoral approaches to religious education which place primacy care for the individual over rote learning of specific beliefs. There is a sense that 'bad' teachings about sexuality are actively being sought to be silenced. He said: "Orthodoxy is the norm. All things are framed as 'faithful' or 'unfaithful.' It becomes a kind of neo-Inquisition which is happening in the church today." This is the kind of binary theology that sets the foundation for the identities that queer teachers perceive are placed upon them by others in their institutions.

\section{Who Do They Say That We Are...}

The theological underpinning of the social structures of the Catholic school do more than establish an extrinsic binary. There are personal implications to encountering the teachings of the Catholic church in a school of this nature. While the church condemns sexual activity between same sex persons, it simultaneously calls for compassion upon the ones who are inclined to such genital expressions of affection. The teachers said that they "feel the internal divide in a theology of 'love the sinner but hate the sin." For those like Pablo and Gary, it would seem that they must accept that they 
are lovable while their expressions of committed love are detestable. "Queer teachers are stuck in the cycling thought of 'How can this [part of myself] be wrong or seen as evil?'” (Retreatants). The discourse is clear, however. My own educational history in Catholic schooling included plenty of cases in which queerness was clearly unacceptable in the eyes of the Church. As I wrote in an earlier chapter, my favorite senior year teacher in high school was asked to leave his position mid-year due to the fact that he was gay. Could there be a clearer image of the unacceptability of queerness in Catholic school teachers? Queer teachers wear a label, always suspected of engaging in sinful behavior. Most profoundly, they expressed this with a truly lamentable reality: "I must be reminded that I am 'intrinsically disordered."' This is who they have become by means of a theology that dictates their identity. "Queer teachers must wrestle with the question 'Am I good?"' (Retreatants).

Along with a religious message that tells these teachers that they (or at least their actions born of love) are disordered, there is a more haunting message about who they are. Pablo shared a story we could all identify with that revealed the identity we bear. According to this devoted educator, he is perhaps the most "out" teacher in his school. He has shared his sexual orientation with administration and suspects that most teachers and students also have deduced that he is gay. Pablo was an advocate with some queer students in his school who wanted to form a club that could be a safe space to discuss questions of sexuality and faith. He did a lot of work speaking with administration and constructing the club in support of the students' desires. When the club finally took off, Pablo was excited to see it take shape and facilitated the conversations of the club. This was the expectation of the student founders as well. Directly after the institution of the 
group, Pablo was notified by the administration that he would not be the moderator. That position had been given to two heterosexual ally mothers who were asked to oversee the all-male identified queer student group. Even when he was welcomed to be part of the club picture by students as an important mentor, he was asked to remove himself. His queerness was not welcome. Even more, the message was that queer teachers are dangerous. Wearing his identity, another teacher confessed: "I internalize myself as dangerous and so I keep safe by not seeking promotion, working harder than others, and holding off on having children" (Retreatants).

Queer teachers feel like they are kept at a safe distance from the rest of the school community because of the danger associated with them. "Queer existence is always seen as a problem. Administration always sees us from a problematic viewpoint and speaks of queerness in that way." It was problematic that a queer teacher should want to moderate a queer club. When everyone of the teachers in my study told their administrators that they were queer, there was acceptance. But the acceptance was couched in a dialogue of how the school would negotiate the issue of queerness that the teacher was bringing into the school. There is a dual role that the teachers play from the point of being hired. They said, "queers are both an object of interest while also being the locus of conflict in schools." Especially following the priest abuse scandal in the Church, with the popular association made between homosexuality and pedophilia, queer teachers realize that there is an unspoken label they wear in some people's minds. People have bought into "a story that we are child molesters that is stirred up in conversations about the sex scandal which blames sex abuse on gay identity" (Retreatants). This dangerous identity is not easy to divest oneself of, even if it is not based in empirical fact. 
Theology and administration are not the only sources of imposed identity for the queer teacher. Especially when we talk about the label of being dangerous, there are other parties at play in the construction of queer-teacher identity. Jae noted that it was not unusual to encounter parents who question the "fidelity" of his curriculum to the standards of orthodoxy found in conservative Catholic circles. Parents have a great deal of leverage in the decisions of a Catholic school and its larger culture. Jae and the other teachers noted that "There is a sense that parents think that we are going to indoctrinate children. As if they are saying 'I don't want them to turn my kid gay." Labeled by some parents as the teachers of a perverse doctrine, endangering their children by threatening to make them queer, the teachers sense that they are always being watched. "We have a target on us," they said. It feels as if they are always being examined and measured more critically than others. And what is the result of being labeled as dangerous beings? "We are detached from a sense of security since we are never fully safe" (Jae). Since students cannot be seen as fully safe in their care, then these teachers cannot be fully secure in their job.

Jae continued to explain the stress that was felt being a queer teacher in a Catholic school in our current national ecclesial environment. As a personal reflection, I noted that as national laws have changed and secular mentalities are shifting towards greater acceptance, it seems that queerness has become a larger focus of Catholic school concern. The group mentioned that "We are scapegoats for other issues (divorce, poor pedagogy, religious difference, etc.) in the school and thus feel more pressure to comply [with normative demands]." What they meant was that while there are a myriad of issues, both theological and educationally, that are happening in their schools, the only focus seems to 
be on them. Divorce and conjugally consummated remarriage without an ecclesial annulment is a sinful act. A teacher who engages in this is just as guilty of breaching the morality clause (to be discussed later) of the Catholic teacher contract as a queer teacher in a sexually intimate partnership with a person of the same sex. Yet, none of the teachers were able to cite a case in which a divorced teacher was fired. They could, however, list names of terminated queer teachers. By focusing on the elimination of queer sinfulness as the benchmark of institutional orthodoxy, the school is able to turn a blind eye to other problems. What is the identity they bare? "There is a sense that I am less human because I am not the norm" (Retreatants). Untrustworthy, expendable, and problematic, the queer Catholic school teacher isn't told that they are equal players in the mission of the school... at least not according to their own experience.

\section{Who We Say We Are...}

Identity is more complex than just what we have been told that we are. If what was said above was the only option for understanding the identity of a queer teacher in a Catholic school, then I can't imagine any of the participants remaining in their institutions. What they helped me to see, at the same time that they acknowledged the negative images placed on them, is that there are ways that queer teachers understand themselves which are life-giving. These teachers spoke for and about themselves with a kind of passion that indicates both the authenticity of humble self-assessment and the boldness of proclamation, a counter-discourse. I hope that this section will do justice to their self-identifying statements. These are, for the most part, a collection of simple and short sentences which were asserted in reaction to negative ideologies that were discovered in the analysis of the narratives shared at the retreat. I have gathered them 
here and assert that they are just as genuine a reflection of who a queer teacher is in a Catholic school as are all the identities described above.

One statement is so poignant and fully directed to you, the reader of this dissertation, that it deserves to be stated from the beginning. As I was driving Gary to the airport to fly home at the end of the retreat, we were making casual conversation. As I pulled into the traffic lane to exit the freeway for the airport, Gary said that there was one thing that he really hoped that people would understand about queer teachers. He said his hope was that I could explain this in my work. He said, "I wish that people could see that we are more than our sexuality, we are a culture!" I hope to share some of the ways that those who are part of this culture see themselves.

I return us to a consideration of the story that opened this section on queer being. Mateo recounted his choice to conceal his face when the television cameras turned in his direction. His immediate reaction was a sense of shame. There have been so many queer freedom workers in the LGBTQ community's history, there is a general sense that it is mandated that one be bold in their queerness. So, as these teachers negotiate their identities in subtler and somewhat hidden ways, they sense that they are seen in a negative light by other LGBTQ people who might be looking on. Gary was the first to put forward this statement: "We constantly find ourselves questioning our bravery." And yet, the group also acknowledged at the same time, the teachers countered this presumption of others by saying: "Ours is a hero's story of bravery." The retreatants had innumerable stories to share about ways that they encountered negativity and oppressive mentalities in their schools. We looked at much of that in the previous discussion. And in light of the collection of stories, the teachers reaffirmed their bravery in working in the 
midst of this climate. They stated, don't be mistaken, "We are brave for even being in a Catholic school." There can be no doubt, in the face of institutional oppression "we are survivors!”

It is more than being a brave survivor that they see in themselves. Jae recounted a time when he was faced with a true dilemma. He described teaching at a place in which the student climate was not as well imbued with the virtue of respect as one might hope. He encountered a lot of difficulty with the students showing him respect and received very little support from administration. One day he was notified by the principal that there was a rumor that some students had seen Jae coming out of a known gay club. There was photographic evidence, according to the school leader. His job was on the line in that moment. Jae knew that he was at that club on the day in question. He also knew that the entrance/exit to the club was a shared door that led to a coffee shop and a store in addition to the club. He was also aware that any picture of him would include his two female friends who accompanied him to the club. Quickly he surmised that there could not be enough evidence in the picture to identify him as gay or as necessarily being in the club. But, before he started into that explanation, Jae asked to see the picture. The administrator stated that he had not actually seen nor received a copy of the picture. He had called him in on hearsay. Jae pointed that out and the whole conversation came to a close. He was more than brave, Jae had shown that he knew how to work the system for his benefit.

Jae was not the only teacher to tell a story about thinking on the spot about ways to keep themselves secure from being fired. Being queer means that "we learn to negotiate the system as masters of the process." These teachers have become so 
knowledgeable of the contractual and ecclesial system that they can maneuver themselves around possible employment danger with greater ease than the administrators they work for. They realize that as those who suffer under the weight of insecurity, they have become champions and true masters in the art of maintaining their presence in these schools.

In the classroom, these teachers take on any number of roles and identities. The classroom does seem to be a safer space than any other in the Catholic school, particularly when there is mutual respect between students and the queer instructor. Pablo, who teaches lessons which include the history of LGBTQ non-violent tactics to demonstrate ways to enact justice, says that, as representatives of the oppressed in the classroom, "We are the voices of justice." In fact, when he or other queer teachers introduce such lessons into the classroom, they are revolutionizing the curriculum. Jae draws on dialogue to bring queerness into the curricular conversation. By doing this, they artfully turn theological conversations to include communities not typically considered. These teachers "know how to see things from many angles, to re-vision things, and to queer them." It was in seeing this, and all the multiple ways that each queer teacher was making headway in their school towards greater acceptance through the curriculum or personal relationships that the group agreed that "We are activists!"

One of the most surprising revelations to me as a former Catholic school teacher came when the teachers shared stories of the ways that queerness was demonstrated in the student body. Every one of the teachers had a story of a student same-sex couple that attended a dance in a Catholic institution. There seemed to be little problem with this expression of queerness. Mateo said that a student that he mentored was surprised when, 
in asking the administration if bringing a same-sex date would be problematic, was told that it would cause no issue. Regarding students, queer teachers realized that, in the school, they were mentors and role models. By being their queer selves that said that they "show that there is no one way to be a man or woman." Thus, Mateo, in using his artistic talents helps his students to question what it means to be a man. Their lesbian counterparts in schools also question what it means to be a woman. When talking to students and honoring all the ways that these kids express gender and relationship, the teachers say that they "can open up a language of fluidity in a binary world." They see their personal presence in the school as part of the curriculum of the school. Even without overt proclamation of their queerness, they said they presumed that students knew about their difference and were watching them for lessons about life. They found this most important for the queer students who so often lack role models to offer hope in the midst of struggle. In the most positive way possible, the teachers said, "We represent an alternate lifestyle." They are lights of hope and they can see that light shining in the lives of these young students who are taking bold steps to question the gender binary.

\section{"We are an Easter People"}

Theological expressions of right and wrong played a significant role in the negative identities that queer teachers felt were imposed upon them. There are numerous ways that queer teachers in Catholic schools may respond to such negativity. One of those is to reject the theological tradition that has born this fruit of oppression. Yet, rejection is not what the community expressed in the queer teacher retreat. What developed in the conversations was a very strong sense of spiritual identity among these queer teachers. This was especially true for Pablo, Jae, and Mateo as members of the 
Catholic church. Yet, Gary also found a personal space in these identities as a nonChristian that he could share with the others at the retreat. I believe that the reader will discover that, much like the musings of liberation theologians, the insights of these teachers in their spiritual identity is based first in their common experience. From meditation upon their own lives, they began to see faith, religion, and themselves in a new light.

Three of the participants in the study had dedicated their professional careers to being stewards of the discipline of theology. As teachers of religious doctrines and morals, these teachers sensed themselves as being in the heart of the Church. Despite the sense of isolation that permeated their daily existence in the Catholic school, they knew that they had a particularly important role as members of the Body of Christ. They did not stand on the margins of the Church as outcasts, they explained. Rather, "we can see the Church in ourselves." In their teaching, they are the voice of the Church to their students. Also, by their lives dedicated to justice and goodness for all people (but especially the queer community) in the name of love, they knew that they were the hands of the Church. They said: "The work of the Church is our own work. We are the Church." In the face of being pushed away, these teachers found in themselves a new and surprising identity.

Of all the statements that had been made during the entire retreat, the one that was brought up with regularity by all the participants throughout all the sessions and after the end of the retreat was: "We are an Easter People." While seemingly simple in its construction, the statement has a very deep and purposeful meaning. It was shared in the group by Mateo. He explained what he meant by this in greater detail. First, one must 
understand that Easter is the most important holiday of the Church's liturgical life. During this season, the Church recalls the triumphant resurrection of Jesus Christ. Easter is the promise that death does not have the final say in our world and that God has overcome the power of evil in our world. It is the revelation of Jesus as truly God. All else in the Church flows from this moment of grace when Christ rose from the dead and filled the world with a new grace. Because of this, the Church believes that all of humanity will rise from the grave in the coming of a new and perfect world in the fullness of time. Every Sunday, the day when the Resurrection took place, Catholics attend Mass to commemorate this day. Liturgically, Easter Sunday Mass is the most important liturgy of the entire year. It is the only time when new adult members are brought into the Church. It is celebrated with more Scriptural readings, greater pomp, and additional solemnity. All other Masses are considered smaller reflections of Easter Mass. Thus, to call yourself an Easter people has a lot of significance.

Mateo explained that they are not just a Resurrection people. To be identified only with the newness of life that comes in the resurrection is to miss the journey of the queer teacher in schools. Jesus' story did not begin with rising from the dead, he first had to suffer and die on the cross. Easter embraces the mystery of death and rising. The teachers all had stories in which they felt the pain of being seen as "less than human" but pushed beyond this to thrive in their teaching. Some, like Pablo, whose dreams of mentoring queer students in the club that he helped to found, were put to death by administration. Yet, he found ways to contribute to these students' lives by addressing topics in his curriculum and personal conversations. They said that they know that the small disappointments (deaths) of their lives are not the end, "There is hope." 
The teachers have been "building resiliency [that] comes through learning how to deal with the obstacles in our life in schools." This is in the community's DNA and their long tradition as an oppressed people. They said they are a people that don't give up. The teachers said that when there is the temptation to leave and wash their hands of working within a Catholic system, they think back to when times were worse. There was a time in the history of the Christian world that we were killed for simply existing. Now we are so much closer to a life of justice. "We value the long battle," they explained. As teachers working in schools which don't honor them, they learn powerful ways to endure and become better. Jae put it plainly: "We grow in the virtues." The queer virtue par excellence is something they called "stick-to-it-tiveness." Easter people are those ready for the entirety of the death and resurrection process. They see the value of endurance because they know that lasting through the turmoil of the present will produce fruit in the end. Mateo, the teacher who had been in Catholic schools the longest, stood as a light of hope for the group (without his intending to) because he had entered teaching when oppression was greater. He became part of the earliest LGBT justice movements in the Church and had seen these groups squashed by the Church. And because of all that his generation had endured, teachers like Jae were able to enter schools that were less oppressive. "Look how much fear has been diminished for queer teachers already" (Retreatants). They all acknowledged that this spirit of triumph endured in them as an Easter people.

Easter isn't just a heady theological concept like the Resurrection is, I recall Pablo saying. Easter is a holiday, it is a celebration. Queerness, the teachers' reflected over the course of the retreat, isn't just an idea. In fact, as Gary was so desirous to remind the 
reader, "we are a culture." As such, being an Easter people is something living and dynamic. It is about bringing joy into somber lives. The teachers, for example, noted that an activity that would have made the retreat even more wonderful would have been incorporating a drag competition in which each participant was given time to shop in the local flea market for supplies and create a character. This insertion of joy and humor into the retreat was what the teachers said they did all the time in faculty meetings, school events, and personal gatherings. They said that queer teachers are the people that others come to for comfort. Pablo said that he had mentored a student for years and later came to find out that she chose him because she could see he had the gifts to help her through depression. "We are able to move from pain and suffering in this world into happiness."

Mateo noted that it was queer teachers like himself who contributed artistic talents to decorating for Masses and school retreats. If all the world celebrates Easter, then we are like the ones who bring the most beautiful Easter bonnets and baskets! They are a people of hope and life! They are an Easter people.

\section{Enforcing Queer: The Logic of Orbit}

It's a typical Thursday for Jae as a teacher. There have been hours filled with the challenges of explaining new concepts and moments of laughter with students in the classroom. There have been planning periods, where he has been grading the work before him and thinking about what he is going to do when the final bell rings. Nothing out of the ordinary. That is until he gets a note from the office asking him to come to speak with the principal. Though unusual, there is nothing alarming about the request.

Walking into the principal's office, Jae sees that there are two others already inside sitting in chairs and looking at him. Although he does not know what the meeting is about, he feels immediately uneasy as everyone turns to look at him. Quickly he runs through his mind and wonders if there is something that he might have done. And he asks himself if he recognizes either of the men in the room with him. Nothing is registering. At that moment, the principal introduces the two men and says that they are part of a volunteer corps of Catholic parents who are working with the diocesan Office of Education to oversee the spiritual health of schools. Jae leans over and shakes their hands with a smile. 
The principal continues and says she called Jae into the office at the request of these men because they believe that he might not be promoting Catholic teachings in his personal life. One of the men says that he looked into Jae's Twitter account and saw postings promoting the "homosexual agenda." The principal stated that administrative action might need to be taken at the request of the diocese but that she felt it unfair not to ask him to explain himself. Immediately, Jae requested evidence of any tweets of this nature. He knew that he had never written anything like this. The men fumbled with their computers and phones. Neither one was able to find such a post. Upon this revelation, the principal apologized to Jae for disrupting his day and sent him back to teach.

As we walks back to class, Jae cannot stop the questions running through his head. Why did they choose to look into his Twitter account? How could they request his firing without actual substantial evidence that he had broken some contractual rule? Why was supporting an oppressed community a violation? Heaviest on his mind was the fact that in the file cabinet behind the principal sat his contract which held on it the promise that he would be employed for this school year. With one simple allegation of promoting the "homosexual agenda" that contract could be revoked and he would find himself without a job. This wasn't his first occasion to think such a thing. Perhaps this WAS just another typical day with typical feelings for a queer Catholic school teacher...

As we have seen in the previous two themes, queerness performs itself in Catholic schools in particular ways through teachers and it also holds particular identities and labels. These realities of who the queer teacher is and how she/ze/he acts come into clearer light when we ask the question: "How do these things come to be?" The original question of the research study asked "How is queerness constructed in the Catholic school?" That is, we were hoping to uncover in the conversations we shared together about our lives teaching in Catholic schools, the ways that power is at play in making queerness what it is in this setting. What was revealed was an interesting collection of reflections that pointed to the ways that Catholic schools "enforce" the maintaining of queerness in the ways that we have described. In some ways, the use of power by the school ensures that queerness remains marginal, contained, and "normed." I cannot state that such regulation of queer teachers is a consciously intentional schema of identity and 
performance enforcement. What this theme provides us is a sense of the felt ways that these teachers feel both the force of external power upon them as well as their ability to exert resistance. We see both of these aspects in Jae's story above.

\section{Swift Injustice}

In this chapter we have looked at two stories of Jae's in which he felt the impending possibility of the termination of his teaching contract. One is the story which opens the chapter. The second is time in which a student reportedly took a picture of him coming out of a gay club and the administration, upon having been told this, called Jae to his office. In both occasions, it was very clear to Jae the termination was the assumed position of the school with each report that was made about his queer lifestyle. Queer teachers asked that I explain in the research that: "The choice to fire us has been made based on accusations before we get a chance to talk." In both cases, Jae knew that it was his responsibility to turn the tide of the conversation to show his innocence if he was to escape the loss of gainful employment. In neither case, was there substantiated evidence for the reports made against Jae. Word of mouth alone was sufficient to start the "neoinquisition" as he termed it. The teachers told me: "We are not able to trust others to look out for our best interest." When it comes to preservation of jobs, the queer teacher must be at the ready as their own lawyer. Every teacher explained that in such situations, "The burden of proof that we are not in the wrong always falls to us in matters of sexuality."

There was a fair amount of time spent during the retreat sessions in which the teachers called to mind the stories of colleagues at other schools who had lost their jobs. In the news, there are stories of teachers who have been notified that they are fired 
because some aspect of their lives as queer persons was made public by media. This is never a malicious action on the part of newspapers or television stations which carry information about recent weddings or capture the image of two women holding hands. Rather, once the information enters the realm of the Catholic school it becomes a dangerous tool by which queer teachers find themselves removed from their positions in the classroom. Following the news of such firings, the teachers are well-aware that "When we are fired, it comes swiftly and silences our rebuttal so as to protect the administration from being called into question for our presence." The moral standing of the school must be upheld above and beyond all else. Teachers are in institutions which can seem callous in their rapid removal of queer teachers. "The decisions about our lives are made beyond us and often without full consultation" (Retreatants). The exercise of power is fully in the hands of the institution, leaving queer teachers ever aware that they must be and act in accord with the dictated norms of the school.

So what is it that enables Catholic schools to terminate queer teachers so rapidly? It is an element of the contractual agreement made between the educator and the institution itself called the morality clause. These clauses, often worded carefully by the legal affairs departments of a diocese, state that teachers are at-will employees of the school and may be terminated for any reason, particularly if the life and teachings of the educator fail to be in accord with the moral teachings of the Catholic church. Often times, as has been the case with my own employment in Catholic schools, a promise is specifically made by the teacher in the contractual paper to uphold the teachings of the faith in their public and personal life. Catholic schools are free to reference this section of the contract upon their firing of a teacher if they are able to demonstrate that the life of 
the teacher does not align with the Church's moral teaching. This is especially the case with practiced or espoused homosexual identity. This clause ensures that institutions remain safe from being sued by terminated teachers as it has been repeatedly found sound cause for termination by courts. Teachers at the retreat were unable to name a single instance in which a colleague that had been fired successfully contested the school's decision in a court of law.

\section{Money}

One of the strongest ways that the power of institutions is felt by the queer teachers as a force that dictates their existence in the institutions is the possibility of the loss of a steady income. The teachers voiced this by saying: "There is a real economic need that I am dealing with. The power to have an income is squarely in the hands of the school. So, I can only work from within to a certain extent." Pablo recalled for the group a time in which he was to leave an institution at which he worked. He said that, despite the cryptic reasons he was given, he sensed that his queerness was at the core. Having faced this reality of losing a job and realizing that it was a constant possibility for him in any Catholic school he might worked at, he spent several years away from the classroom pursuing the arts. While monetary stability in this new field was far from assured, he had the calming sense that his gainful employment was not based upon the whim of a Church that seemed to disdain his queerness. Pablo, as I have said before, has a true heart for justice and his curriculum reflected that. Yet, queer teachers reminded each other that "there are real stakes at play that limit our struggle for justice. Those include our job, family, promotion, student benefit, student response, and others." If you want to be successful enough to keep a job, you have to play the game. Playing that game means 
accepting one pretty hard truth described by the reflective statements of the retreat participants: You will have "no sense of security" because "queer teachers are unprotected" in the Catholic school.

\section{Parents and Power}

Unlike a public school, which is financed through the allocation of governmental resources deriving from an entire local populace, the Catholic school depends on the constant income of tuition dollars paid by the parents of those who attend the institution. Some schools, such as Cristo Rey schools (pseudonym used), whose student populations come from poor and struggling households have found other means of supporting their institution but tuition almost always remains a vital aspect of the financial viability of Catholic schools. Parents, who make these payments to the schools, are clearly the primary stakeholders in the institution itself. This places a great deal of power in the hands of the parents. In the most dire of circumstances, the teachers explained that "Parents are given total power (as stakeholders) to call us out on our queerness to the highest powers and to threaten our jobs."

Understanding the way that queerness comes to be understood, leveraged, and constructed in a school, one asks about the influence that parents have with regard to the treatment of queerness in the school itself. The answer to this question is highly contextual. Teachers hailing from schools in Northern California noted that they experienced parents typically as advocates. In at least one case, a group of parents and students formed an activist organization denouncing the termination of queer teachers from Catholic schools. Yet, the experience of teachers in Southern California, was that parents could be far more adverse to having known queer teachers present in the schools. 
In neither case, were all parents "on the same page" but the generalizations helped to show that power can be exercised differently in various contexts.

Jae shared with the group that he finds himself wary of the ways that he speaks about queerness in his theology curriculum. While he is personally certain that he is always teaching religious truths that are in line with the heart of the Gospel message, and thus, truest to the Catholic spirit, he has encountered parents who have complained to him and his principal about discussions he has held in his classroom. While he tends to draw his students to consider the pastoral ramifications of Christian teachings in light of the theological traditions of the church, "uber conservative parents hold to moral orthodoxy and are adept at dismantling progressive theology by putting it into a framed of 'faithful' verses 'unfaithful."' (Jae). A community of parents who insist on conservative iterations and expressions of theological teachings can make it difficult for queer teachers to even bring up discussions of queerness in the classroom.

Parents hold certain expectations about the content and context of their children's education in a Catholic school. The participants knew that, often, part of the cause for queer-teacher removal is due to parental intervention. It is parents who typically see media coverage of a queer partnership and then report it to the ecclesial or institutional leaders. "Queer teachers rarely have the chance to defend themselves once a stakeholder has pushed for our dismissal" (Retreatants). It is clearly not in the interest of the school to cause strife with its primary or sole source of financial resourcing. Though the teachers said that they wished they could feel assured that the school would provide them with security, they said that in reality: "We must live with power being manipulated in ways that always protect the school and the Church.” The morality clause can then act as 
a tool that can be actualized by the institution to remove the cause of discord from the school (i.e. the queer teacher) for the appeasement of its stakeholders.

Overall, the teachers were less concerned when parents complained about the content of classroom than they were about parental allegations of teacher immorality. And since immorality can be substantiated by little more than being seen embracing one's queer identity or being outed through no personal choice of ones own, queerteacher lives inside and outside of the Catholic school are marked by an intense vigilance. Mateo was a part of a gay men's choral group for a long time during his career as a teacher. It was a source of community for him. One day a student came to his desk bearing a piece of newspaper saying that they had seen Mateo's picture singing in this chorus. Doubtless this had also been seen by any number of parents as well. He dreaded what may come of it. "We find ourselves afraid of possible parental attacks against us for moral reasons" (Retreatants). This uneasiness was held in him for a while until he felt certain that no negative repercussion would come of it. In this case, Mateo saw the other side of power as he eventually was given encouragement from others for his use of God's gift of song.

\section{Bigger than Our Principals}

Each of the teachers present at the retreat were out in some way to the administrators at their school. None of the teachers tried to hide their sexual orientation purposefully at the time of their hiring. In fact, each of the teachers seemed to have a reasonable and accepting relationship with their administration. This is particularly true with the principals and presidents of the schools at which they are teaching. These queer educators understand the role of the leadership in the school to include offering 
protection and support to teachers who find themselves in conflict with those outside of the institution. Yet, sadly, this does not seem to be a realistic expectation for queer teachers. As the participants explained, "Administrators cannot offer us security in our jobs." The reality is that the effects of queerness and the power that is exerted on the queer teacher is larger than the particular administrator themselves. There is a matrix of expectations and power that assures that principals are in the service of two especially significant groups: the institutional Church and parents. If there is an action that is performed, then it must be done with the blessing of these two groups and mirror their moral compass. Teachers explained that, "Our principals are disempowered, even if they support us." Even the most socially justice minded and progressive leader is unable to leverage enough authority to make queer teachers feel secure. The plight of the principal is just as dire as that of the queer teacher for "administrators find their jobs on the line [even] in places in which unions may protect teacher but [the administrators] fall directly underneath the oversight of the hierarchy." Gary explained by saying that principals who refuse to execute a termination of a contract are, themselves, likely to be terminated for not taking a proper moral stand on the issue for queerness

Jae told the group a story about being hired at his first Catholic school. As he sat with the principal and was offered the position to teach, Jae was given only a single piece of advice. His future principal was admittedly very accepting of his new teacher and his presumed sexual orientation. Yet, Jae was told that it would be best if he avoided spending too much time with another faculty member who was quite flamboyant. This teacher's queerness might cause complications for Jae if he were to become too connected with him in the minds of the parents or students. Queerness has effects that 
can go beyond LGBTQ teacher lives. Teachers said that "Our own community of friends is threatened by their association with us." This was the warning that the principal was offering to Jae, to beware that he was not negatively affected by the queerness of this other man. In that same school, Jae encountered a great deal of bullying from students. Statements made these students and rumors perpetuated by them were not taken up as a cause for punishment by the administration. Pablo himself missed the final Skype meeting of our research due to online bullying pointed at him and others in the school. The teachers said: "We experience bullying from our students and they get no repercussions sometimes." None of the teachers believed that the bullying was condoned by the principals in leadership, but that there was a larger reason that they did not take greater action.

Queer teachers are well aware that, though the principal is the person in leadership to whom they have regular access, this is not ultimately the source of danger or security for them. As extensions of the mission of the Catholic church, schools fall under the oversight of the religious leaders and bureaucracy. As at-will employees of the school, these teachers (both Catholic and non-Catholic) are essentially performing their jobs in the service of the local Ordinary (a term of art used to denote someone who hold the authority of Bishop). Thus, being fired as a queer teacher is very often an act that starts with a demand of the leadership of the local Church. All the teachers noted: "In our dioceses we see that in the hierarchy there are those who are threats to us because of their positions to oversee (anti-queer) morality in schools." This is a person with whom the teacher may have no relationship at all. The role of the Bishop is to be care takers of the members of the Church, it is for this reason that they are referred to as Shepherds. As 
one who protects the laity from the evils of the world, Catholics turn to the Bishop for leadership and care. Yet, since the Bishop is often the one handing down the sentence of termination for teachers. Jae observed that: "Our shepherds become our enemies."

\section{Title that Endangers}

In 1990, Pope John Paul II wrote an apostolic constitution to the Universal Church entitled Ex Corde Ecclesiae (From the Heart of the Church) that would change the nature of Catholic school governance in a way that greatly affected universities. Universities in the Church were rarely run directly by dioceses but were outreaches of religious communities such as the Jesuits, Religious of the Sacred Heart, Christian Brothers, Marianists, and many others. As the Catholic church and diocesan leaders were tending to emphasize stricter sense of orthodoxy in the years after the Second Vatican Council, Universities were places of creative interpretations of the theology and safe places for dissenting voices. Such spaces were protected and supported by religious communities who honored the academic freedom of a university. Being concerned with the discordant teachings present in some schools of higher learning, John Paul II changed the governance of these universities by this letter. Herein, he stated that since a Bishop is charged with care of the souls of all who live in his geographic region, then he is given authority to oversee and approve any theologically or ministerial work that the school does. By handing over this oversight to the more conservative Bishops, the Pope was seeking to move the Church away from spaces that harbor heresy. All theology teachers in Universities must state that they will not teach heresy in their classrooms to maintain or gain employment. Yet, many read this in even broader terms, stating that all work in a university is ministerial and thus came under the authority of the Bishop. 
The participants of my study were not University professors, but this letter does have an impact on how they negotiate the workplace. Bishops have, for the most part, always had oversight of the teaching that happened in Catholic schools. Part of this is because many Catholic schools are diocesan and directly report to the office of the Bishop. Those religiously-run high schools often found themselves mirroring the practice of Universities, and were overseen by the religious communities that owned them. Now religious-run schools found themselves under greater scrutiny as well. The theological question of who is a minister was the key. Originally this term of (canon) law was reserved to deacons, priests, and religious. Yet, it became increasingly common for the members of the Church to understand that ministry in the Church could be done by the laity. Now it became the call of the Bishop to ensure that any ministry being done in the name of the Church was of sound nature. In many dioceses, there was increased discussion on the "Catholic identity" of schools and ways to measure and ensure that these institutions were acting 'from the heart of the Church' (ex corde ecclesiae). Queer teachers realized that there was something much more dangerous at hand. They said: "The concept of Catholic identity has been employed as a catch phrase and movement that puts queer teachers in schools at risk." Being a truly Catholic school meant not tolerating outed queerness.

Pablo spoke from his heart to the group as he lamented the changes that had come to the Church with regards to the oversight of Bishops. He explained that what he does in his school is more than teach minds, he cares for the souls of the students in his classroom. For a long time, he longed for the recognition that what he did as a religion teacher was more than imparting facts. Thus, when the leaders of schools and priests 
started to dicuss the work of teachers as a ministry he said he was overjoyed. They all longed for their work to be seen as a ministry. Now, that honor has suddenly become a risk. His words were: "To be seen as a minister in the work of education was once positive but now becomes a threat to queer teachers" because it puts us under the power of the hierarchy. Now there was genuine canonical reason for Bishops to state that they had direct oversight in regards to the work happening in these classrooms. They also had right to make demands on the lives of the ministers themselves as the Bishop's authority directly relates to the regulation of ministers. This becomes combined with public legal sanctions which protect ecclesial bodies in their decisions with regards to ministerial governance. Jae reminded the group that "Ministerial exemption to legal protections for teachers has been extended to all teachers in Catholic schools or is being tried [to be extended] in order to make firing easier." That is, if the Church can convince the state that all teachers are ministers, then the state would relinquish its insistence on the protection of employment as this no longer comes under their purview.

This exercise of power and the orientation of the school and teachers in relation to the hierarchy has dictated much about the internal and external identities of queer teachers. First, there is an internal desire to be recognized as ministers because, in essence, it is how many of the queer teachers in the retreat saw themselves. Yet, at the same time, they were all the more forced into silence and hiding once that recognition had been given them. While they saw themselves as an expression of the Church itself, they recognized that being seen as a minister of the Church removed them quickly from any legal protections that the secular world could offer. In other words, to be seen as 
they were while expressing themselves authentically in public was a danger too risky to take. Negotiation was called for as self-protection.

\section{Employing Shame}

This idea of being a "bad minister" opens up for us another conversation about the ways that power is employed in the Catholic school in regard to queerness. On a psychospiritual level, the teachers brought up the employment of shame in the school setting. They said: "Shame is empowered by the silencing and hiding of queer lives." Gary, coming into Catholic schooling from outside the system, said that this idea of shame was not something that he had dealt with in his own education. He said that what he saw in this was a "xenophobia" that was rampant in the school. And this xenophobia expressed itself in shaming. "Catholic schools can be highly competitive locations in which there is already the kind of need to feel better [about oneself] through shaming others. This can be especially dangerous to queers" (Retreatants). Shame is an isolating tool. It can happen quite passively, as when the school touts a specific expression of masculinity or femininity as the standard of the school's expectations. These are shared in catch phrases used in a school, the expectations rolled out in faculty meetings, or simply in the casual conversations with others.

Mateo agreed with this assessment. He drew from his theological understanding to explain why each of the teachers felt this weight of shame while none of them were able to point to a singular defining moment when shame was blatantly imposed. "Homosexuality is a focal point for the internalized shame in our theology," Mateo said. In our current day and age, the concerns of those preaching from the pulpit usually center around a few key issues. Homosexuality is one of those. With the insistence on the 
sacredness of heterosexual religious marriage, gay lives are constantly painted as sinful and shameful. These messages act as the backdrop for what one thinks about when talking about being "Catholic." Shame of the queer is an expectation (for both the straight and queer person alike) and thus is felt as part of the school's ethos. Mateo was very honest in saying that "the issues and psychoses of the writers of theology (Augustine, Aquinas, Luther, Puritans, etc.) gets passed along in the teachings themselves as a general milieu of sexuality." Much of our theology derives from men who had negative relationships with their own sexuality and bodies. Catholic schools are the inheritors of this mentality, bringing shame upon the queer teacher for any semblance of honoring their queer self.

\section{Counter-Force}

According to Foucault (1978), power and resistance exist simultaneously. This is true for the Catholic school. Queer teachers spoke of ways that they are able to counteract the weight of school pressures. I would ask that the reader to see with the eyes of the queer teachers in their understanding of how they resist power. They remind us that "small victories are typical for us rather than large wins in our efforts." It would be wonderful to say that teachers stood up, came out, were heard, and all issues were resolved. That has not been the case. But there have been times when good things have happened. For example, schools like the ones served by these teachers, have relatively recently opened up clubs that honor student voice and experience around queerness in non-judgmental ways. When people look at what resistance means for the queer teacher, the participants say that they fail to honor the kind of persevering work that is being done. "Others do not understand that the struggle is often a forward-and-back kind of 
process. We take two steps forward but then take a few steps back." But in the end, the teachers say, their resistance has moved the balance of power forward to reflect something more positive.

\section{Holding the Closet Keys}

You sometimes find the power to resist in the least likely places, such as your local gay bar. Pablo and Mateo shared experiences about this from their lives. Pablo recalled a time when he was at a club and he saw a male religious from his school at the other side of the bar. He felt a sense of fear at first that he might be caught before he realized that they both were in this queer space. He did not interact with the guy at that time. Yet, on another night, he found himself in line at the bar with the same religious priest behind him and he engaged Pablo in a conversation. Yet, at school, there was no acknowledgment that they had seen each other. This man was part of the administration. Mateo too had come to know of the queer life of an administrator by means of his own past as a religious brother in the same community. Both Pablo and Mateo knew that they held a powerful secret that they could leverage when seeking to protect themselves from being fired. They said: "We know what is really going on because we have seen the hidden lives of others (especially clergy)." And in both of these cases the clergy held administrative power, thus the power to fire them.

Mateo spoke of the ways that this can be used in resistance. He was called to an administrator's office for allegations of living a queer life outside of school. He was informed that he would be terminated for this and that the administrator felt sad that this was the case. He said he wished that he could do more, but that he was sure that Mateo understood his situation. Immediately, Mateo said that he did not understand and 
reminded him that he was fully aware of his own "double-life" which included queerness. He knew that he was threatening the administrator with absolute truth to ensure the protection of his job. "We hold power when we know the secret queer lives of others." Mateo was not terminated and, remarkably the issue was resolved. When others, particularly those in the clergy, are in the closet and hold administrative power, queer teachers can hold the key to opening the closet up. They all agreed that this is a power they despise holding. It means leveraging fear back on their own community, yet it is a safeguard. Queer religious are often more protected and further separated from the queer laity than any other group. They become the enforcers of the power that affects the community. But queer teachers are acting back.

\section{Taking Action and Solidarity}

Why do these teachers stay in these schools if it seems like the odds are stacked against them? I asked the group to come up with a single story in which the schools they were in honored or benefited their lives without looking for some benefit from them in return. There was none that they could express. Yet, they said that this was an erroneous way of looking at the relationship they had with their work. They said that they stay in Catholic schools because they see it as a calling. They could choose new career paths but they know that being present in a school is part of their work. They are making a safer and better place for students and faculty by remaining. "Our very presence in schools in the midst of the oppression is a light of hope and a work of activism." Teaching in Catholic schools is a way of changing it from the inside. Some have done this by coming out to select colleagues and students and sharing their own journies. They remind us that: "We give a face to injustice the more we are 'out' or honest about the oppression that is 
happening in schools." In these sacred Catholic school halls, they are disrupting the discourse of normativity by being who they are. When a queer teacher makes themselves visible in a school presentation about "how to be a good man," for example, they are immediately a challenge to the narrative of normativity in the eyes of the student. They know that. It is as if the teachers are saying: You can have this conversation about sexuality and gender if you want, but you will have to do it in my queer presence as your colleague and friend. It is a powerful act of resistance. Here's how the teachers explained it: "We make an issue of queer justice by existing in these spaces even if we are not referencing them directly."

The most significant ways that queer teachers act against oppressive power are through efforts at solidarity. Gary said that when there was a firing of a teacher in his area, the reality of the precarious nature of queer teachers in schooling was felt throughout his school. Almost immediately, the teachers who had suspected each other of being queer, found each other. There was a sense of companionship that emerged as they spoke to one another about the case and the ways that it impacted them. There was a sense of "us" in the school that never existed before for queer teachers. It lacked deep substance, Gary explained, because they did not facilitate deeper conversations about their private lives, but in coming to know each other, they countered the isolation of being in the matrix of the Catholic school. In some sense, they were acknowledging that it was okay to be themselves. "We can help others who are caught in binary tension to live in the grey of this world" (Retreatants).

Jae became a part of a local parent-led movement in his area that sought to support queer teachers specifically in the wake of a teacher firing. He expressed the fact 
that the greatest power he had ever experienced in countering anti-queer power came when the heterosexual parent community stood in solidarity with queer teachers to speak back to the hierarchy in disapproval of queer-teacher termination. He said, "Our effect on improving our lives in schools is indirect because we need allies to speak on our behalf." But what was particularly powerful was the fact that this group included and listened to the voices of queer teachers. These teachers' identities are protected, but their needs are fully honored. Thus, through this mouthpiece of solidarity, they speak back. "We show that the locus of solidarity is in the work of justice in our current cry for right treatment" (Retreatants). Thus, if we want to be truly one, then we must honor each others' needs. Solidarity and justice are closely united.

After the retreat was completed and the group came together for the Skype meeting, the very first thing that was said by all the members was how much they missed talking to each other. There was a community that was made in the retreat, a three day event in which strangers came to become friends. I would like to say that that moment of solidarity happened when Gary looked at Mateo and told him that he truly was brave. At that moment, Gary and all of the other participants looked at each other with a new light because they saw the best in each other. They saw themselves in each other and the rest of the retreat was about understanding who they were together. The Skype reunion was beautiful to behold. The teachers said that when they went back to their schools they felt "lighter" and "more confident." As Gary explained, he had a new sense that he wasn't alone (even if the teachers were in other schools). This had changed the kind of power that the school held over them without even getting the administration involved. Jae said that there was a sense that fear was diminished because of the power of sharing stories 
with the others. Solidarity in this retreat was an act of resistance that the teacher acknowledged was real.

As a group, the teachers decided to take a next step and continue to take action towards a better life for queer teachers like themselves. As they talked about the final question ("What do we do now?"), they unanimously decided to put on another retreat and invite a larger number of teachers using their own relational influence to gather participants. Solidarity in story and shared presence, they decided was the most authentic and powerful way they could act against the negativity they experienced in schools. In the following months, the teachers planned the retreat and took leadership in inviting new participants. Jae himself asked if he might take lead in facilitating the retreat that "this is my community." I was happy to see the research flower into an authentic action of the participants. The teachers and I planned logistics and found funding for the retreat so that no cost would be accrued by those who wished to join us.

In September, a second retreat was held with 11 teacher participants from California and beyond. It was a powerful experience. The format was changed to make the entire retreat flow as if it were a single Critical Ignatian Examen. Hours were spent on each section.
A. Where is God acknowledged?
B. What stories do you have from being queer in Catholic schools?
C. What are the Blessings you see?
D. What are the challenges?
E. Where do you want to go from here? 
The retreat itself was hosted by a Catholic University who generously provided resources of space and support. It was financed largely by a solidarity movement of parents which work to protect queer teachers from wrongful termination by challenging ecclesial approaches to queerness. The retreatants were honored by a formal dinner at a Catholic parish, a visible statement of solidarity between some clergy members and queer teachers. The time included laughter, tears, crying, dancing, singing, and even attending a few queer bars. All who attended stated that it was a powerful experience of community that refreshed them. It was an enactment of this power of solidarity as a queer act of resistance.

As if the completion of the retreat were not enough, more has developed from this study which is applicable to this topic. The group at the second retreat decided that they wished to expand on the sense of community and solidarity to reach to other teachers in the particular region where the retreat was held. Thus a decision was made to establish a queer-teacher group that would meet formally every other month. Planning meetings for the first group have already taken place and have been led fully by the retreatants themselves with myself as a welcomed guest and equal member. The meetings will focus on two main goals: sharing stories so that we can come to know each other and the establishment of true hospitality for the queer teachers. It is the expectation of the group that through this they hope to discover issues that they can address more formally in their Catholic schools with direct action. Until that time, they believe that the most powerful work they can be a part of is building community away from the pressures of an isolating school-power matrix. In addition to this, some of the participants from the second retreat have requested assistance to hold a similar retreat in their local region in the Pacific 
Northwest. Queer teachers are taking true actions in light of all that has been learned and these are part of the small victories that they spoke of so readily in their conversations with one another.

\section{Is it Trustworthy?}

Drawing this chapter to a close, I want to ask if this work has maintained the elements of trustworthiness that assure its authenticity. Qualitative research, with its relatively recent birth, has struggled with delineating parameters of validity within a research paradigm which is not positivist (Anderson \& Herr, 1999). Just as qualitative research denies the possibility of purely objective researcher positionality, so too must it be wary of objective markers of quality. The hegemony of scientific modes of measure which are inauthentic to the internal continuity of a study cannot be accepted. Rather, the multiplicity of knowledges, contexts, and methods which make up the family of qualitative research must be met with a multiplicity of measures by which these works can be measured. We must note the words of Ferguson and Ferguson (2000) who remind us that: "Just because there is no single standard does not mean that there are no standards at all" (p. 180). Rather, rigorous work should be marked by well-thought and explained internal markers which authenticate its construction, procedures, and resulting knowledge. I propose to offer here four marks of quality (oneness, holiness, catholicity, and apostolicity), drawn from the rich tradition of the Catholic church and explained through the lens of a queer theo-critical understanding, by which this work might be guided and internally assessed as trustworthy. 
For a Catholic, the marks of the Church are like four foundational characteristics of the scope of the Church's being and action in the world. The Catechism of the Catholic Church (Sacred Congregation for the Doctrine of the Faith, 1994) stated these indicate essential features of the Church and her mission. The Church does not possess them of herself; it is Christ who, through the Holy Spirit, makes his Church one, holy, catholic, and apostolic, and it is he who calls her to realize each of these qualities. (para. 811)

Note that they do not denote aspects of completion but paths of progress along which the authentic work of God will always be situated. In the recitation of the Nicene creed, the faithful state that they believe in "One, Holy Catholic, and Apostolic Church." These markers were the ancient church leaders' ways of differentiating authentic teachings and rituals from those of other heretical bands. This formulaic statement has been reflected upon throughout the many centuries of the church's existence and a deeper understanding of what is meant by each of these marks has been revealed through the diverse voices of theological inquiry. Here, as we venture to explore the nature of the construction of queerness in a Catholic milieu, without simultaneously standing in dialogical opposition to the ecclesial body itself, it is appropriate to use these marks as clarion points of research "validity." Indeed the hierarchy of the Church sees the presence of these marks as "great and perpetual motive of credibility," (Sacred Congregation for the Doctrine of the Faith, 1994, para. 812) and thus indicators of trustworthiness. As we will see below, the use of these terms is not additive to a queer theo-critical participatory action research in Catholic schools. Rather, these are authentic points of reference for the flourishing of knowledge creation in this study. Additionally, they provide a dialogic validity with the 
Catholic church itself whose very theology becomes the refining and queer guiding light towards new possibilities (Anderson \& Herr, 1999). As is the case with many queer realities, these marks do not stand independent of each other, but overlap in rich ways, nestling the study in layers of qualitative rigor. Below is an explanation of each of these marks and the ways in which the study has maintained trustworthiness.

\section{Oneness: Unity without Uniformity}

Perhaps it may seem odd to say that a study influenced by queer theories would look to oneness as its guide. Yet, I propose that normativity, too often assumed as synonymous with social oneness, is not the same thing as unity. In the theological discussions of the church it is clear that:

From the beginning, this one Church has been marked by a great diversity which comes from both the variety of God's gifts and the diversity of those who receive them. Within the unity of the People of God, a multiplicity of peoples and cultures is gathered together. Among the Church's members, there are different gifts, offices, conditions, and ways of life. (Sacred Congregation for the Doctrine of the Faith, 1994, para. 814)

Thus, we see that plurality and unity are not only possible companions, but desirable ones. Drawing from this rich ecclesial reflection, we begin to see how multiple voices in a single study enact oneness in an authentically just way. A queer theo-critical study like the one proposed here should seek to hold in communion and tension diverse ideas, ways of being, and expressions in such a way as to produce fruitful knowledge which goes beyond the expected and common-sensical and into realms of new revelations for justice (Ferguson \& Ferguson, 2000; Kumashiro, 2002, 2009). 
Anderson and Herr (1999), in elaborating on the multidimensional ways that qualitative studies might express validity, point to the need for us to question what might become a danger against a high quality execution of a research project. In this case, we would say that oneness is threatened by uniformity and normalizing discrimination. Even at the Second Vatican Council (1965b) it was observed that: "The church therefore condemns as foreign to the mind of Christ any kind of discrimination whatsoever between people, or harassment of them, done by reason of race or colour, class or religion" (para. 5). The research is threatened by means of any form of continued marginalization within the community of researcher-participants which demands a singular identity, narrative, or truth. The study is one in its difference, united in its divergence from norms. A queer community, according to Sullivan (2003), is not an impossibility but an expression of the collected singular presence of diverse voices which fruitfully opens paths of new knowledge of self, other, and the world.

Thus, this study must be measured by queer unity beyond uniformity as a means of validity. Anderson and Herr's (1999) "democratic validity" and "process validity" might find a home under this mark. By stepping beyond uniformity both in the process of shared voices and data analysis, all those involved might participate fully in expressing a cohesive truth incorporating difference. It is for this reason that, upon the completion of the study, the participants should together acknowledge and approve the written results of the dissertation, giving resonance to a united approval echoed in differing voices. Member checking "makes sure I captured the essence of what they said but also to inspire further reflection by participants" (J. Jackson, 2010, p. 41). And I must ask myself the following questions in light of this mark: In what ways is the process proceeding that 
hinders diversity being expressed? What does the unity/disunity of the group reveal about the validity of the study itself? Is there unity made between the seeming opposing views (i.e., the church teaching and queer lives)? This mark of unity, which stands as a clear response to queer-teacher isolation and binary divisions of public/private queer lives validates the knowledge of this study as liberatory and authentic.

\section{Oneness Measured}

I believe that it holds to the test of Oneness. As stated, this does not mean that there is a uniformity among participants or even among the patterns of analysis, rather oneness means that there is a unity to the project. Starting from the investigation of literature about queer teachers in schools with its revelation of experienced injustice and struggle, the study proceeded through the construction of a method which sought to directly address the forced navigation of public and private life, sentiments of isolation, uniqueness of social context (here Catholic schooling), and the importance of narrative

meaning. This analysis process remains dedicated to the same theoretical frame and pulls forward the lessons of research, retreat, and understanding in a movement of continuity, oneness.

\section{Holiness: Authentic Self-Expression}

With the church teachings about homosexuality which position same-sex genital expressions of love as unholy, one might question why holiness would become a mark of a queer study of Catholic schools. Indeed, with the passing of laws enabling same-sex couples to civilly marry, some have stated that queer unions are a challenge to the sanctity of marriage. Indeed, I think that such persons are right! Queer expressions of monogamous love, as they are validated by civil authorities do not question the reality of 
marriage (though queer theorists and theologians are breaking new ground with this), but demand that the nature of marriage's sanctity be questioned. If marriage is not holy due to procreative possibilities, of what does holiness consist? Perhaps the words of

St. Ireneaus might inspire us to an answer: "The glory of God is the human person fully alive." Here we see that holiness cannot be measured by a normalizing pattern but is manifest in a myriad of ways according to the context and reality of persons across the globe. If this be true in the community of marriage, it should also be true in the research community. Is the work holy? That is, does it provide for the authentic self-expression of all involved?

Pope Francis (2013a) noted that: "Sanctity does not consist especially in doing extraordinary things, but in allowing God to act. It is the meeting of our weakness with the strength of his grace" (para. 3). To see how this statement is applicable to the validity of a queer theo-critical study, we must borrow from the insightful work of Patrick Cheng (2012). He explained that a queer understanding of grace is one that reads this reality as maturity. That is, holiness, or the grace-filled reality, is that which acknowledges the full presence of individual and collective realities brought to full fruition. Attuned to love, which seeks what is best for all (1 Corinthians 13), maturity of grace in a queer research community shows itself in deeply genuine relationships.

Ford (2013) reminded us "that culturally responsive research acknowledges and works within the cultural discourses of the participants so that their knowledge and ways of being have authenticity and legitimacy" (p. 103). Authenticity is the measure of welldone qualitative and culturally responsive research. Moss (2004) pointed to those "acts of integrity that researchers take to ensure they seek truth by contextualizing their studies 
and disclosing all relevant procedures used in the study" (p. 371) which are the measure of a good research project. Harrison, MacGibbon, and Morton (2001) acknowledged that researching well in the academy is difficult by saying

we strive to avoid Othering yet are compelled by the nature of our work, the constraints of the institutions we inhabit, and the requirements of academic publishing to construct research projects in certain ways and produce certain types of texts as we talk among ourselves about other people's lives. (p. 341) The only sure way that we can counteract this process is through authentic and meaningful relationships with our participants (Ferguson \& Ferguson, 2000).

Relationships, according to Peter Park (1999), are forms of knowing that are specific to participatory research. Holiness is that mark which demands that these relationships be fostered in the fullest and most authentic ways possible. Discord (not necessarily disagreement) becomes a danger to holiness for it limits genuine relationality. Normative assumptions should be challenged in the writing of the dissertation as well as in the process itself as a measure of holiness. Since the relationality of the study between formally isolated queer teachers is the driving force of a new knowledge, we might liken holiness to the measure of Anderson and Herr's (1999) "catalytic validity" (p. 16) by which it is maintained that all in the research are moved to deeper knowledge and commitment to action. It is the relational, mature holiness of a study which makes it a space of fecund potentiality for understanding and collective action.

\section{Holiness Measured}

The second mark of a rigorous and exemplary study of this nature is termed Holiness. Holiness, defined in a study with queer identified Catholic school teachers, 
refers to its dedication to authenticity. Developing from a method which sought to honor the truth of participant memory and experiences, the work of authenticity can only truly flower if the unique character of the process is carried through from the moment of study into the delivery of the written dissertation you hold in your hands. In order to do this, the duo-logical process of analysis was essential. In the participatory analysis process we recorded, as a group, the written words which best encapsulated our understandings of the meanings locked in our own stories and those of others. What I provide in the secondary analysis is a map of the constellations constructed in this retreat. The terms of analysis belong to the group and I hope to provide in my writing a means of finding kinship among the thoughts by anchoring them, for the reader, back to the many narratives and actions recalled during the study. By doing this, I hope to maintain an authentic representation of the realities at hand. I have utilized a member-check process to ensure that my co-researcher participants agree.

\section{Catholicity: Benefitting All}

The third mark of the research is that of catholicity. Here, I do not mean that the study is tied essentially to the teachings of the Church known as "Catholic" but something more expansive than this. The Church explains it to us in this way: "The word 'catholic' means 'universal,' in the sense of 'according to the totality' or 'in keeping with the whole"" (Sacred Congregation for the Doctrine of the Faith, 1994, para. 830). From an ecclesial understanding, Pope Francis (2013b) tells us that "the Church is catholic, because she is the 'home of harmony' where unity and diversity know how to merge in order to become a great source of wealth" (para. 3). It is this same sense of catholicity to which the study can be held as a standard of quality in a queer theo-critical sense. 
Catholicity is the assurance that the kind of particular interests that lead to domination and oppression of one group over another do not creep into our readings of personal narrative. This work must seek justice for all.

In the work of Paulo Freire (2000), we discover the critical insistence that oppression cannot be advantageous for anyone. Indeed, the oppressor is in need of liberation from the dehumanizing acts that are committed, just as are those who suffer under the pressure of the injustice. A truly catholic venture in action research, therefore, seeks to benefit all of the greater society through the liberation of the marginalized and suffering. It can seem like a daunting task to ask a study to impact social fabric in a totalizing way, unless one can make a connection between particularity and universality. Theologically, there is an insistence that in each small community there exists the entirety of the larger whole of which they are a part (Pope Francis, 2013b; Sacred Congregation for the Doctrine of the Faith, 1994, para. 831). This is the case because each particular relationship re-echoes (in miniature) the bonds of community and justice which exist in the world at large. To seek transformation in the particular context of the Catholic school, can have broader effects as relationships and processes are redefined for the sake of justice.

One might ask what the threats to catholicity might be in such a study. The primary threat comes from the dominance of a singular narrative or discourse. Queer theories which insist that multiple ways of knowing and experiencing reality are always co-existing and providing paths for the new unknown (Kumashiro, 2002) caution us from a universality which is tainted with the stain of normativity. Rather, catholicity only advances as multiple knowledges combine and challenge us to understand things anew. 
The more that we draw together divergent voices and experiences, even through mediation on the teachings of the universal church as a community of queer teachers, we enact Anderson and Herr's (1999) “dialogic validity" (p. 16) through a peer refinement which strives towards a more universal devotion to the manifold truths of particularity as well as the ethics which inform this.

\section{Catholicity Measured}

If the question of Catholicity asks that the work is of benefit for all involved, my duo-logical approach to data and analysis has ensured that the benefit of understanding the meaning of queer experiences belongs to those who share them, affording them primacy in dictating how their lives are understood. My own analysis sought to gather together these meanings in a way that honors a full representation of all that has been revealed. The subsequent actionable outcomes of the study becomes the means by which teachers have taken what is learned and brought it to benefit others.

\section{Apostolicity: Committed to Doing Justice}

Our final mark is apostolicity. The characteristic of apostolicity in the Catholic ecclesial community is that mark by which the leaders of the Church derive their authority directly from the first 12 Apostles who followed Christ (Sacred Congregation for the Doctrine of the Faith, 1997). Apostolicity, however, can have another meaning outside of the sense of authoritative continuity. The word "apostle" derives from the Greek language and means "one who is sent." The Apostles were those who followed Jesus of Nazareth and were also sent by him into the world to continue his divine work in the world. In just such a way, our study can be measured by its ability to "send out" participants to enact justice in their world. If this action research study does not produce 
at least the intention to rectify injustice, then it cannot be said to have been successful to its own commitment.

Apostolicity ought not be understood in the sense of proclamation of an orthodox set of teachings about queerness and Catholic education. Rather, borrowing from liberation theology, the emphasis is laid upon the importance of orthopraxis (Gutierrez, 1973). Does the study do justice in a queer and authentic way? The very gathering of a queer community of Catholic school teachers is itself an act of orthopraxis from which the research finds its impetus and source of knowing. While we might not be able to predict what will come from the work in terms of action, we can measure the "outcome validity" of our work by its apostolicity (Anderson \& Herr, 1999, p. 16).

\section{Apostolicity Measured}

This brings us to the final measure of the study, its ability to move from theory to action. This is the apostolicity of the work. Perhaps this might be likened to the idea of "catalytic validity" of qualitative research in which one seeks proof that the action research has itself affected some change or active engagement in the world (Anderson \& Herr, 1999, p. 16). The analysis of the work is itself an embodied work of knowledge in action. The analysis of the stories shared in the participatory process took place in this first cycle of action. Teachers, having experienced isolation, came together to put community into action. While doing this, they deconstructed the meaning of the isolating experiences which they actively counter-acted by means of participation in the study. What comes of this is, in turn, the invitation to take action in light of what was learned in this new space of community. The mode of analysis in this study does not merely open itself to the possibility of action but requires it to be authentic. Thus, as we see the choice 
of participants to create a second retreat and a local queer-teacher group, we are assured that the work is truly apostolic.

\section{Conclusion}

Living together as a rich human community, individuals and groups in dynamic relationship to one another, we form our own kinds of constellations on the surface of the earth. As with looking at the stars, we will never be able to fully comprehend or exhaust the fullness of reality of any one particular cluster. In this chapter, we have looked at one particular constellation of human existance by asking about the forces that bind the existence of queerness, teacher identity, and Catholic schooling into a single, lived experience. The researchers were the memers of the queer-teacher community itself. Here they showed their lights brilliantly through the sharing of their stories. Then, they engaged with the process of analysis, uncovering the meanings of the stories themselves. The very stars of the constellation came to know what held them in their places. Our analysis sought to embrace multiple perspectives and ideas. By coming together in the act of raising personal consciousness, the analysis of the rsearch became a queer work of deconstruction of social meaning while also a theologically liberatory work of uncovering the hidden modes of oppression in religiously led institutions.

Queer reality in Catholic schooling, we discovered, is held in place by means of a mechanism of fear. It is not simply a sense of the abjectness of the queer, as one might suspect with homophobia, but a complex system of silences, power, and permissions that resonate as fear in the individual. We found that queer perceptions of school and personal life can be drawn into three categories, which I likened unto planets orbiting fear. First was that of "doing queer..." These teachers often perform their queerness in 
chosen silence while sharing their desired gifts with the institution. Yet, queerness also means acting in ways that are sometimes transgressive. The second theme was that of "being queer.." Here the teachers uncovered the double edged sword of identity. One side is the negative voice of many in Catholic schools. Yet, despite this imposed identity, queer teachers have come to see themselves in positive ways, incorpating faith and hope. Finally, we see that queer lives in these schools always are in reference to power. In "enforcing queer" we see that there are structures that apply specific pressures to ensure that teachers live their queerness within specifc limits. We also discover that through insight and solidarity there is a counter force of queerness which seeks to find greater justice. Measuring our discovery and work against the marks of the Catholic Church, we have closed our gazing. Now we turn our eyes to something hidden in the grand narrative of the data and analysis, a mysterious presence lying unseen in the darkness of this constellation, which we will see is a powerful queer-teacher spirituality. 


\section{Chapter 6: Moving Beyond the Event Horizon: \\ Emergent Spiritual Discoveries}

I met my best friend, Preston Lopez, while attending college at a Catholic institution and he taught me a great deal about seeing life from new perspectives. One of his favorite activities was to climb to the highest point of our hilltop university where the athletic fields were found and lay down on the grass silently watching the stars. I remember going up to those fields with him and others to star gaze and talk about the sense of our smallness before a vast Universe. It is the bright and twinkling stars that first caught my imagination. The different ways that planets and stars presented themselves fascinated me. But I have found that there is also something very fascinating in looking at the blackness of the night sky as well. In those lightless areas of our universe there exists one the most intriguing phenomena of all: black holes. These points of singularity in which time, space, and matter is crushed into a volumeless collection of infinite mass are vastly unlike our own realms of space.

Black holes were, for a great deal of my life, one of the key reasons why I never felt inclined to become an astronaut. Who would want to unknowingly fall into something that would crush you? I'd rather stay far away while completely intrigued by the power of these space monsters! Black holes are surrounded by an outer ring that is called an event horizon. Essentially this is a boundary line. All matter which finds itself within the event horizon moves unidirectionally towards the center of the black hole, which is the singularity I spoke of above. Nothing is able to resist this movement. For a long time, it was believed that black holes were realities that had no temporal terminus, they last forever. But Steven Hawking (1975), applying the laws of thermodynamics to 
black holes, showed that a very miniscule number of particles actually radiate out of a black hole and beyond the event horizon. This is called Hawking Radiation. This continual process of infinitesimal escape of particles actually results in the eventual dissipation of a black hole and its crushing pull on matter into a singularity. This revelation powerfully reconfigured the concept of black holes and their existence in the universe. My understanding of these realities are pretty rudimentary. Yet, I think that the concepts of Hawking Radiation and black holes offer us a nuanced cosmic metaphor for this chapter. Here I hope to share how the spirituality of these queer, Catholic school teachers is like the escape of particles from a black hole; infinitesimal, constant, and powerful enough to dissipate the crushing pull of hegemonic fear.

\section{Seeing the Black Hole}

Through the last chapter, we explored the vast and complex answers that arose from the research in response to the inquiry of the study. That is, we revealed the ways that queerness finds and is given meaning in the Catholic school context. We also discovered how queer teachers reacted to the knowledge they gained by means of shared discussion on the topic. Through an intricate process of data production and multilayered analysis we saw the emergence of three aspects of queer life and Catholic school structures as they apply to teachers in these institutions. First, queerness is employed in certain ways, held under the demands of silence, to serve the purpose of the schools. This is the Catholic school's way of "doing queer" which is impressed upon the nonheteronormative teacher. Yet, "doing queer" also means purposefully acting in ways that subvert negative readings of queerness in sometimes veiled ways. Secondly, we discovered that the ontology of queerness is dictated by the ethos of a theologically 
driven institution in ways that paint the queer teachers as "less than" and "dangerous." Alternatively, queer teachers have adopted personal meanings of "being queer" which area hopeful and revolutionary. Thirdly, we explored the mechanics of the Catholic school that maintain these demands on teachers to act in certain ways while bearing specific identities. The positioning of power in the hands of ecclesial leaders and parents results in queer teachers feeling like they "have no security." The schools' ways of "enforcing queerness" assure that such human existence profits the institution maximally while protecting it from unwanted repercussions from anti-queer power holders. Queer teachers, however, are always finding even small ways to establish a new sense of security that dismantles a totally externally centered locus of power and repositions themselves as authors of their being. Specifically, the choice of the group to establish a second retreat and, eventually a queer-teacher organization, is both the answer to the second inquiry question as well as evidence that Catholic school efforts to enforce the boundaries of queerness can be dismantled. Emerging from a study which asked the teachers to take a first action step of gathering into a community acknowledging oneself as queer in the face of others, the participants moved from "isolation" to a sense of community. Likewise, they find liberation from the sense of fear, which has proven to be the psychological indicator of oppressive power dynamics in threatening queer-teacher thriving.

In this chapter, I wish for the reader to take a brief step back with me from the particulars of the social construction of queerness in Catholic schooling, to consider the emergence of a grounded spirituality firmly rooted in the sociological realities of queer teachers immersed in Catholic schools in California. As I began this research from a 
queer theo-critical standpoint, I welcomed the multiple dimensions of knowing that might be present in the intersectional space of queerness, teaching, and Catholic schooling. This bricolage approach positions the study to consider issues of justice and power from a liberatory and humanizing standpoint. This fecund space of the intellectual consideration, which has welcomed multiplicity and contradiction as authentic ways of existing and knowing, also becomes the vehicle of understanding of a queer justice oriented spirituality. I hope to draw together an insight into this beautiful reality and show its presence in the data that we have just discussed.

I wish to first begin by attempting a definition of spirituality as I use it in this context. It has become increasingly more popular in the last several decades for people to describe themselves as spiritual but not religious. What is meant here is that to be religious is to identify some part of your faith and/or personal existence with an ecclesial institution or formally enumerated set of beliefs shared among a formalized community of believers. Religion is a formalized set of beliefs and practices that establish a social group and set boundaries of human existence. Doctrine and dogma belong to the realm of religion. Yet, religion is stagnant if it is not animated by some other core reality. This separate animating reality is spirituality. As Lepherd (2015) pointed out:

There seem to be almost as many definitions of spirituality as there are writers on the subject, with authors referring to the diversity of understanding the concept in such terms as 'puzzle,' 'nebulous,' and 'fuzzy.' The absence of a theoretical base for spirituality might be the difficulty associated with its concept. (p. 567) Lepherd pointed out that spirituality means being connected to the innermost life-giving part of a person and the meanings they make in the world. We could expand this to mean 
that spirituality is the core lived-experience of religious communities, although one need not find home in a particular religion to connect to their inner-most sense of self and the world. In this instance, I intend spirituality to mean a mode of acting and communing in the world which makes meaning of one's particular identity in light of a larger and more transcendent reality. This definition opens itself to a broad interpretation which may or may not be inclusive of religious affiliation, faith in a personal diety/dieties, consultation of a sacred text, or multiple adherents.

Of the many vibrant spiritualities in the world, one might ask if there is any common denominator that unites them all. First might simply be that they are realities connected to human existence and interaction with other persons and the physical universe. Thus, humanity itself is a common factor (Lepherd, 2015). One professor of Spirituality conjectures that, in his work and research, a common thread in many spiritual practices and expressions is the concept of humility (Feldmeier, 2016). Freire (2001) tells us that humility means "being open to the word of the other, to the gesture of the other, to the differences of the other" (p. 107). SooHoo (2013) reminded us that humility is an elusive way of being upon which we may not personally claim lest it should disappear from our possession. The multiple interpretations of humility which are manifest in various spiritualities, demonstrates that it is a virtue that is rich in meaning and practice (Lepherd, 2015). Unearthing a spirituality among the queer teachers in this research was not an intentional effort. Rather, I believe that using a methodological approach which sought to honor humility, such as is the case with Culturally Responsive Methodologies, there was created a space for a spirituality to manifest itself. Without expectation, I began to see what I share here in this chapter. It is a spirituality that 
develops from the experience of daily life for these Catholic queer-school teachers. It was described in their own words and found resonance with them all, not because they have spoken about this spirituality but because it echoes true in each individual life. What became possible in this study, was the drawing together of spiritual adherents to establish a level of community centered on this deeply meaningful way of existing in the Catholic school system.

\section{“Why Do You Stay?"}

During the research, as stories of life in Catholic schools were shared, I found myself touched deeply by the narratives of pain and fear that seemed to flow so freely from the teachers. I knew that I, myself, had stories of pain from Catholic schooling and my affiliation with the Church, but I wondered how these teachers endured through the daily existence they were describing. I had to ask the critical question that I felt begged to be answered. If life is this painful at times in the Catholic school, "Why do you stay?" I expected the answer for many of the participants to be because they were theology teachers and thus had no other choice outside of Catholic schooling to teach their discipline. This would have seemed like a reasonable answer. But that was not what was shared with me. Rather, I was told that they remained in Catholic schooling because it was a "calling." This was a very intriguing answer. This gave new meaning to the answers that they had provided because the work in the school had a mission.

The idea of having a "calling" to do work specifically in Catholic schools was echoed again in the second retreat that the participants helped to organize and facilitate. This theme was shared by all. And for those who were Catholic, it seemed that the calling was directly related to their relationship with God and the Church. However, 
even non-Catholics expressed this sense of calling. When a Jewish teacher at the second retreat expressed his own feelings of pain, the Catholic members of the retreat asked him why he would stay in the school. He again said that it was a calling. Gary, too, expressed this sentiment in words that spoke of a mission to a work greater than himself. This is the first aspect which opened my eyes to the presence of a spiritual way of existing for queer teachers in Catholic schools. Being present in the schools itself had meaning because it was tied to a transcendent reality. Transcendence, however, need not be understood as a personal god or Church but could take the form of a disembodied mission.

Perhaps this similarly shared mission is what made the process of consensus in the group analysis of the narratives so easy. It was surely the reason that the sharing of narratives became a unifying process, because time and again the teachers discovered that their individual experiences in Catholic schools and their choice to remain in these institutions were grounded in a common way of making meaning of the world. This is a common spirituality that has developed in each of the individual lives of the teachers but had greater resonance when expressed as a community. I believe that this discovery of commonality, that was expressed by Gary (the only non-Catholic in the first retreat), in the most unitive assessment of queer persons made in the entire retreat: "We are a culture." I hope to express one aspect of this culture as I came to see it in my research.

\section{Awareness of the Pressure}

While the previous chapter delineated the multiple ways that power, fear, and resistance interact and define queer-teacher existence, here I wish to draw all of these together to understand that these numerous realities force aspects of a single pattern of 
their life experience. Fear of the threat of power being exerted upon the queer teacher has taught them that they can never let their guards down. "We are constantly on vigilance," they said. With a single forgetful moment, a teacher could miss an unforeseen threat from others or their own self. This is what Mateo feared would be the case when the other male teachers at the table with him recognized that he was sipping on the only strawberry margarita. Yikes! As one might imagine, this constant vigilance requires that the queer teacher place extra energy into a psychological process that others do not experience. Jae was insistent that this finding alone was enough to substantiate the worth of the research project. The retreatants insisted that, "Queer teachers use an unhealthy skill of self-monitoring that keeps us safe from being fired.” By learning that others were always on the watch for possible threats, Jae wondered if non-queer colleagues had any idea of the weight that this places on educators like himself. As the group said: "There is no security" for teachers like them.

I cannot emphasize to a strong enough extent the pressure that is applied to the queer teacher as a result of the situation they find themselves in as faculty in Catholic institutions. I think their words are enlightening: "The life of the school never gives us a chance to break from the vigilance." It is the very "life of the school" that they are citing. This means that the pressure comes from all parts of their teacher lives. Because of the pressure exerted from the hierarchy, teachers feel like they have no safe place to turn in which they are no longer called into question or let down their guard. Recall that they acknowledged that: "Our shepherds have become our enemies." This ecclesial oversight and mentality exerts pressures upon the administration as well. Thus, teachers say, "administration cannot offer us security in our jobs." If this were not sufficient enough 
pressure, teachers are aware that "Parents are given total power (as stakeholders) to call us out on our queerness to the highest powers and threaten our jobs." This suspicion and mistrust of parents was described as a "neo-inquisition" in their analysis. Finally, there is a kind of pressure that comes from the students as well. "We experience bullying from our students and they get no repercussions sometimes," they lamented. From all sides and from the school culture, the teachers are aware of the heteronormative culture that demands their insecure stance in the school. This is what Mateo called the "macho watcho."

In addition to being an oppressive weight, vigilance also becomes an opportunity for queer teachers to develop consciousness about the patterns of power in their schools and dioceses. It is this awareness of the ways that their jobs are threatened, teachers learn to understand systemic realities more acutely than those in administrative positions. When Jae was presented with the threat of losing his job due to the insistence of a parental group that his social media promoted non-Catholic values, it was his keen awareness that led to the demand for evidence even before the principal intervened. They exposed themselves as highly aware of systemic power by saying, "We learn to negotiate the system as masters of the process." The vigilant perception of the queer teacher opens their eyes to understand the reason for the insecurity that they sense. For the participants, it resulted in conscientization of the social realities of the Catholic school (Freie, 2000). This is particularly true as it refers to their own sense of queerness, seeing that "Heterosexual lives are the strict norm." To deviate from this norm has financial implications on the life of the school as it fails to benefit parents and hierarchical leaders in ways that they demand, causing stakeholders to retreat from investment in the 
institution. They understand that Catholic schools are meant to produce a certain kind of student and that they are employed to ensure that this mission is accomplished.

In order for us to understand this queer-teacher spirituality, we must understand that it rises out of a highly conscious and aware ontological presence within a specific system, the Catholic school. If teachers were not aware of the realities in school, then what follows in describing the spirituality of the queer Catholic school teacher cannot be counted as authentically espoused. Rather, just as liberation theology and the spiritual practices of its adherents in Central and South America grew out of a specific reflection on the social conditions of the poor, so, too, does this spirituality derive from a true awareness by the teacher of their own social condition. It is rooted in the context of the Catholic-school condition but tied simultaneously to a transcendent reality which serves to call the teacher.

\section{Fear as Motivation}

The vigilant teacher sees the pressures of conformity pressing in on all sides. Here we might allude to the idea of the pan-optics of power described by Foucault (1977). This is the idea that the ever-present "eye" of the normative and acceptable society rests its gaze upon us to ensure that we are always in line with expectations. At any time the eyes of the normative power of society may be upon us, though we will not always be fully aware of when. This is how society ensures discipline in its midst. Teachers, in this case, are ever aware of the possible threat that comes in being seen acting in queer ways that challenge the norm. The teachers explained this when they said, "Queer teachers find ways of hetero-ing ourselves." This means that queer teachers act and speak in ways that will not draw undue attention of the eyes of power which 
threaten their jobs. This awareness of the possible monitoring of their lives brings with it the sense of fear that we discussed in the previous chapter.

Surprisingly, fear in Catholic schools, as uncovered by the research, is not a simple unidirectional homophobic expression of dread sensed by the teachers from nonqueers. Additionally, as I was corrected in my own conjecture by the retreatants, there is no sense that fear is purely self-manufactured in response to a misreading of heterosexual pity. Fear of queer sexuality and gender may be at play in some of the decisions made by those in power to maintain a heteronormative schooling system. But, as we discovered in the previous chapter, fear is something more complex than a single sourced reality. It is something which, in this case, is found to surround the queer person like a force-field. It exerts a kind of pressure exerted upon the queer teacher through elicitation of a mandatory emotional response which halts natural responses to particular contexts in order to maintain normative expectations of Catholic teacher ontology. Thus, they told me, "We live in paranoia." And because this fear surrounds the queer teacher, it has a similar effect on those who share a close relational proximity. This fear, therefore, is something perceptible by non-queer persons who seek to find unity with these teachers. "Our own community of friends is threatened by their association with us," they lamented. Its effect is to incite such companions to insist upon queer-teacher compliance and/or to remove themselves from a close relational stance with the teacher. Indeed, the purpose of the fear is dual: to isolate and to assure compliance. This is why Jae was warned by a principal upon being hired to avoid close contact with a more flamboyant teacher in the school. This is the matrix of the school life of the teacher, one which is awash with what Jae helped to term as a "mechanism of fear." 


\section{Hegemonic Death}

From a social constructionist lens, which I carried into our study through the inclusion of queer theory in the bricolage approach, we might say that queerness in Catholic school teachers is the product of the institutional pressures. In other words, it is delineated by the set boundaries established for normal and acceptable teacher existence. Queers are the social group which are identified as existing outside of these boundaries. This may be internally or externally manifested, but it is always existent in relationship to them. That is why the teachers say that: "Queer men are measured against gendered norms. We see this in the kinds of language that is used to shame or negate a person [such as] 'You talk like girls."' It is the interaction with these boundaries and the possible repercussion of their transgression that elicits the fear spoken of above. This is the inward draw of the "school life" mandates that queer teachers live in a way that is not always authentic to them. This is the power of hegemony, here maintained through institutional and theological norms.

We have seen, however, that teacher queerness is not completely banished from the school hallways. It is true that every one of the teachers in the retreat were out to members of their administration currently or at the time of their hiring and have not been removed from their institutions. Queerness finds some permissible space within the school itself. We saw that queer gifts and perspectives are utilized by the institution to advance its mission. It is the compassion, artistry, creativity, and other talents that are brought into the school by queer teachers which serve to enhance the school's efforts to educate well. Thus, aspects of queerness, are welcomed while others are refuted. "Safe" ways of being queer do not incite the same level of fear in the queer teacher. Teachers 
negotiate their lives by sensing the pull of fear away from more transgressive and challenging presentations of queer ontology.

Yet, queer teachers, even when they seek to safely walk the line of acceptability, remain precariously in a danger zone as it is impossible to shore up the boundaries of safety when you have already been deemed abnormal. The participants explained a few non-transgressive ways that they could act which become threatening to their jobs if interpreted in the wrong light: "Queer teachers are able to be outed in the most subtle ways: where we go to church, what our weekend plans are, who we talk to, the issues we advocate for, the students who seek our mentorship." It is a tight-rope of enacting one's gifts and muting other parts of your existence. Pablo noted that straight teachers publicly out themselves with every family picture or statement about their husband or wife. He reminded us that they do this public display of sexuality while simultaneously asking us not to bring our sexuality in the classroom as it would be inappropriate. The double standard, indeed the "double-bind," placed upon queers is just as present in the Catholic institution as it is in the rest of heteronormative society (Sedgwick, 1990). I wish to remind the reader of the statement of the retreatants about the way this double standard affects their lives: "I internalize myself as dangerous and so I keep safe by: not seeking promotion, working harder than others, and hold off on having children." In so many ways, queer teachers find themselves hemmed in and over-exerted.

Equity is never afforded the queer teacher, even when they are to comply with the pressures of hegemonic power: "There is a sense that I am less human because I am not the norm." What happens is something likened unto a class system in the Catholic school which might be enlightened to a greater degree through Marxist analysis (Allman, 2001). 
Perhaps queerness is embraced as a necessary dialectical opposite to straightness because it serves, in an economy of identity and morality (upon which is situated a wealtheconomy through the appeasement of hierarchical and parental stakeholders), to productively benefit straightness while simultaneously bearing an undue burden. The evidence of the real worth of queer teachers is evidenced in the decision making that goes into terminating these educators.

Firings remind us that the Church is looking at two real issues in their decisions: one is the question of poverty as when a teacher loses their position and struggles to be employed, the other is the question of moral acceptability as in the case of queer lives going against teaching of the Faith. In the end, it is the morality issue that wins out, it is ultimately about the teachings and not the person. (Jae) The measure of moral differentiation, I purpose, rests on an economy built on the concept of grace. Thus, fear is exerted by the threat of being graceless, that is, shameful. Retreatants surmised that:

Shame is redoubled by means of the negative light put on queer teachers in: contracts, consequences, rumor mills in schools which often seek to point out immorality, and the deferred shame that others don't want to feel and, therefore, can be placed on us as scapegoats.

Thus, what grace (in identity and morality) may be lacking in the straight community may be taken from the queer community through an unfair trade called scapegoating. Thus, even the failings of those who are not queer become threats to queer-teacher thriving because they are ever in the service of producing what is lacking in the other if even by means of blame. 
Taking a look at what is happening in this hegemonic dualist and oppressive structuring of some institutions from a more theological lens, I believe there are dire implications of the present state of queer teachers in Catholic schooling. First, we must acknowledge that there is heritage at play when we talk about any facet of Catholic culture. Heritage, according to Gregory Ashworth (2011), is not the same thing as tradition in the sociological sense. In this case, tradition means a set of beliefs and ways of acting that have been passed down from a previous time and overlaid on the present moment in absolute continuity. Heritage is, however, "a product of the present that draws upon an assumed imaginary past, and justifies itself by reference to an equally imaginary future" (Ashworth, 2011, p. 21). Catholic school heritage is specific to its moment in political history and social environment in which the institution is situated for it is through these lenses that the past is interpreted and the future is perceived. Thus, even when we speak of a theological heritage, we are playing with a selective process of contextual interpretation. Speaking of this heritage, the retreatants agreed that: "The issues and psychoses of the writers of theology (Augustine, Aquinas, Luther, Puritans) gets passed along with the teachings themselves as the general milieu of sexuality." In other words, queer teachers find themselves in a situation in which the selected past of a heterosexually pure theology makes meaning of their own existence and bodily presence in the school while (by definition of heritage given us from Ashworth, 2011) it projects and directs the work of the school into an imagined future of pure heteronormative existence. The very sense of fear, according to Tillich (2014), is the human response to the knowledge of the very possibility of death or non-being. In this case, it is the internal awareness that the pressures of the school threaten to push queerness into non-existence. 
This is a heritage that mandates that "Queer teachers must wrestle with the question 'Am I good?" Thus, such teachers, particularly those who are members of religion faculties are aware that this particular trend of heritage is tantamount to the intentional and theological erasure of queerness in religious and sociological future imaginaries. This is the depth of feeling that was present when the teachers expressed the following statement: "When we work within the system, there is a danger that we might be seen as advocating the very oppressive system we are a part of" (Retreatants). Shall they be a part of a system that seems to be directed to their own elimination?

St. Irenaeus famously stated that "the glory of God is the human person fully alive." The flourishing of human existence is evidence of a life lived in the Spirit of God. We see this sentiment in the Gospel of John when Jesus speaks to his followers using a parable about being the Good Shepherd. He differentiates his leadership of people from that of religious leaders, whom he likens unto thieves, that took advantage of the faithful. He said: "The thief comes only to steal and kill and destroy; I have come that they may have life, and have it to the full" (John 10:10, NIV). This Scriptural verse finds resonance with the statement that teachers made in the retreat: "Our shepherds become our enemies." Drawing parallels between these two quotes, acknowledging that these teachers are well versed in theology and were referencing the image of the Good Shepherd in the Gospels, I wish to point out the three-fold anti-vivifying works that they are identifying in their school and Church leadership: stealing, killing, and destroying. This is metaphorically enacted in the Catholic school for the queer teacher. They remind us how much this is evidenced in the termination process: "We have no say in the final analysis. The decisions about our lives are made beyond us and often without full 
consultation. The choice to fire us has been made based on accusations before we get a chance to talk." There is robbery of agency and human authenticity. Being a queer teacher from this perspective is to be the victim of a system of death, and little hope is afforded when this is the only vision. It is for this reason that I continued to expect to hear about ways that teachers were escaping the system, pushing it, and dis-identifying with its negative existence. Yet, I found quite the opposite!

\section{Paschal Victimhood and Easter Transformations}

Some four months after the first retreat, as I was involved in the analysis process and understanding the major themes that came out of the multiple layers of data, I received an email from a couple of teachers in the Pacific Northwest. They said they had heard from Pablo about the "Easter People" retreat and wanted to be a part of the second one that was being put together by the participants. This simple sentence in this email confirmed for me the foundational importance of the one sentence that was repeated in every single critical Ignatian session that took place during the retreat: "We are an Easter People." I must admit that while it sounded nice, I was not convinced as I was recording the sentence that it had the depth of significance that I have come to understand and discover through working with these teachers in relationship and by meditating on their words in our retreat. Honestly, as the sentiment was repeated so regularly, I was hesitant to write it again and again on the large sheets of paper where the analyses were recorded for each session. I figured that I need not repeat myself if the information was already on another sheet. But the retreatants encouraged me to write it down anew each time. There was something essential to the statement that they could identify with, though its importance was something that I missed. 
As was discussed before, the celebration of the holiday of Easter is the epicenter of the Church year. Easter itself centers on the theological mystery of the Resurrection, when Jesus Christ revealed himself unquestionably as the Son of God and the Savior of Humanity by rising, body and soul, from the dead. But the retreatants noted that they were more than people of the resurrection, they were an Easter People. One way of describing this meaning that they had for themselves was that, while a resurrection is a physio-spiritual event in time, Easter is an ethos which is imbued with the extra element of celebration. As Mateo reflected in our meeting, there would be little festivity in Easter if there were no beautifully decorated baskets and bonnets. And who are the people that make those beautiful things the best? He insisted that it was queers! (I believe that since the participants were all queer men this statement skewed towards that form of queerness, though the retreatants often reflected on the fact that there are many gifts that queer people bring outside of artistic ability.) Easter was a celebration and queer teachers were celebrators. The retreat itself had plenty of jubilant moments in which a story would lead the entire room to bust out in hearty laughter. They spoke about the power of queer humor a number of times. "Our humor allows people to feel more relaxed, especially when it is self referential or about the world.” They are an Easter People because they can celebrate the good things in life and help others celebrate as well. They were able to celebrate life even when life got tough: "Our humor is an Easter element. Queer humor is the kind of humor that says "Fuck Fear" and laughs in the face of oppression." And this statement brings us into a more nuanced sense of what it means to be a People of Easter because it means that one must face oppression, and even death. 
I knew that there was something else being revealed in the Easter People statement. In fact, they noted in the analysis, "Easter is about hope, more than the fact that we make nice Easter bonnets and eggs." The mystery of Easter must be seen in its fullest sense, inclusive of the suffering and killing of Jesus of Nazareth from which he would later rise. When the teachers said that they were an Easter People, it was clear that they were talking about the fact that they are undergoing a kind of death in the institutions where they work. We briefly examined on the ways that this death is manifest in the daily silencing and perpetual sense of insecurity experienced by these educators. But that death has not been able to hold them totally down from what they do. They made statements such as the following: "We have come so far in school and society" when they were explaining that oppression has not been able to completely silence queer existence. They had a spirituality of resilience, in which their suffering made them stronger. Once again, humor becomes a tool of this virtue: "Our humor in the world becomes a lesson about how to be resilient or buoyant." But these queer teachers were honest in assessing that their situation was not the same as others in their school or the world. In many ways, the oppression of the school pressed into their very core. Transparently they admitted: "Ours is a resiliency above and beyond the normal load of pressure dealt with by the norm." Just as Easter is the greatest of all celebrations and events in the Church calendar, so, too, was their resilience the pinnacle of social rising from death. This was a particular queer meaning to Easter and begins to draw us towards the emergent spirituality revealed in this research.

None of the things discussed above were greatly surprising to me. I wrote them off as the standard Christian interpretation that might be adopted by any oppressed or 
marginalized group. The fight for existence in our world, especially for those whose ontology does not coincide with the vision of a hegemonic heritage of normality. Perhaps this is why I was not interested in repeatedly writing the statement. It was this idea of having to go through a continual process of metaphorical and internal dying and rising in one's location of work that urged me to ask the question I noted in the beginning of this chapter: "Why do you stay?" If the Gospels tell us that God's intent is to give us life, then it seems counter-productive to stay in a place that was filled with death. And even though Jae and the other teachers insisted that they benefitted from the oppression in the schools saying: "We grow in the virtues," I wondered if this were the optimal way to grow in these characteristics. All that I could surmise was that this identity of being an "Easter People" was so foundational that it was somehow discovered in every single story told by the teachers themselves. It wasn't until I stepped a bit further back from the data before I realized that there was something much more radical happening in the spirituality of this group. A kind of world-shifting way of acting and making meaning which allowed them to revolutionize their institutions under the same pattern offered by the Christ himself.

In the above scenarios, I have offered an understanding of queer, Catholic school teachers as victims of an oppressive system. Traditionally victimhood is a state-of-being demarcated by the impression of some oppressive power upon a party despite their resistance or ignorance of the oppression. There can be no doubt that these teachers are victims. Not a single one of them desired the negative realities that they faced. The teachers also expressed that they felt called to this work in Catholic education. Thus, in some way, they had a calling to be victims in the process. There was a mission and 
meaning to their being part of an oppressive system, even as they admitted that they were afraid that their presence in the school could be interpreted as advocating the oppression. They reminded me that: "We are able to find meaning and joy in light of all the bad." They were victims, but they were joyful victims. Yet, all this continued to see, masochistic to me, even as one who had been in Catholic schooling. What I was still missing was the revolutionary turn that victimhood could have when it was understood from an Easter frame of reference. Jesus was not, simply a victim of the system, he was paschal victim, an atoning victim, a scapegoat of the highest order. Paschal victimhood transgresses an individualistic interpretation of suffering and gives an entirely new and transformative import to the process of resurrection. These teachers were espousing such a paschal approach to a spirituality that was focused on transforming life in their schools.

To term something paschal is to place it in reference to the Exodus story of the Israelites as they prepared to leave Egypt (Driscoll, 1910). The paschal lamb was the sacrificial meal which the Israelites consumed by the mandate of God on the night before the Exodus. The blood of the lamb was painted on the thresholds of their doors protecting the people from the Angel of Death which took the first born of those who were their oppressors. It was the blood of the lamb which protected and set free the people from death as they passed out of slavery and into an unknown future. Jesus' death on the Cross is said to have been prefigured by the Exodus event for he has become the new Lamb of God who is sacrificed on behalf of all humanity for the forgiveness of their sins, drawing all into the life of grace. He is a paschal victim, but he gives new and profoundly revolutionary meaning to the idea of a liberating sacrifice by means of his volition in the process. The Letter to the Philippians talks about the willing acceptance of 
the Son of God (Jesus) to undergo the suffering and death of his victimhood in its exhortation to the faithful:

Have this mind among yourselves, which is yours in Christ Jesus, who, though he was in the form of God, did not count equality with God a thing to be grasped, but emptied himself, by taking the form of a servant, being born in the likeness of men. And being found in human form, he humbled himself by becoming obedient to the point of death, even death on a cross. (Phillipians 2:5-8, English Standard Version, ESV)

Jesus did this, according to Christian theologies, not for his own sake but for the forgiveness of the world which was plagued by sin. I will not get into the finer details of this process, but I do want to note that a paschal victimhood, in this sense, is a victimhood of atonement on behalf of others. That is, Jesus Christ (Son of God), placed himself into human hands as victim in our name, suffered a death exacted by human effort on our behalf, and conquered the power of death and sin so that we were made free from the very sins which led us to put him to death. Paschal victimhood means embracing the oppressor and undergoing suffering on their behalf.

Coming into the research, I understood activism to be pushing against, speaking against, acting against, and living against the injustices which have been cast upon us and others. I expected to find activism as part of queer-teacher lives in Catholic schools because it seemed like the only possible way for them to survive in institutions that were connected to a Church which sees queer love as "objectively disordered" (Sacred Congregation for the Doctrine of the Faith, 1994, para. 2357). This is the interpretation that I read clearly and easily into the activist statement: "We cannot all be Harvey Milk, 
sometimes you have to be Harriett Tubman, working from within.” I acknowledged that activism had to be quiet and subtle. They were under great pressure and, as much as they wanted to do huge things, the teachers acknowledged that it was small acts that were more common: "Small victories are typical for us rather than large wins in our efforts." And the work of these teachers was something that I expected, honestly, to be under appreciated by queer persons engaged in activism and the schools themselves as I had conversations with people in both of these groups wondering why they remained or lacked the fortitude to speak up more boldly. The queer teachers validated this assumption for me when I heard them say: "We constantly find ourselves questioning our bravery." But I, like so many others, was missing the revolutionary act of their justice work until I meditated upon two of the queerest statements one might ever hear from a group that identifies itself as oppressed. First, they said "The work of the Church is our own work; we are the Church." And later they reflected that: "We exist in school and, in some sense, we are the school life in a microcosm." It is this deep identification and solidarity with the Church and Catholic school which gave new meaning to the victimhood, indeed they were undertaking a process of paschal atonement in their acceptance of the oppression in their lives.

I ask the reader to consider some of the implications of a spirituality that makes meaning of one's presence in oppression as a calling to draw the oppressor into their own oppression for the sake of atonement. Does not Paulo Freire (2000) remind us that oppression is as much an offense to the humanization of the oppressor as it is to the oppressed? In this heinous cycle, both must be freed. Yet, it is the oppressed who most readily understand and are conscious of the oppression. In queer-teacher terminology, we 
would say that "vigilance" has made them "masters of the system" and thus, they have learned to dismantle it in ways that honors the goodness in them and in others. What if activism for justice did not always have to be performing against? What if work for social justice was wrapped in spiritual meanings of hope and could be about pushing into, speaking into, acting into, and living into the process of hegemony so as to dismantle it through an Easter process of resurrection and personal thriving? This group of teachers was demonstrating in their stories and analyses, that such could be the case. They had adopted a spirituality that could acknowledge that they were connected to a more transcendent reality that "called" them to make a new meaning of their own suffering, a meaning that benefitted more than their own virtuous development but included the transformation of the school itself. I believe that such an approach takes tremendous bravery and faith for it is hidden and uncertain.

"We are an Easter People," makes sense when you acknowledge that the crucifixion of Christ made sense only when he rose from the dead. These teachers had plenty of stories of dying. But one might miss the ways that they talk about their resurrection if you do not know that the stories of life that pertain to others in the school (students, parents, administrators, and fellow queers) are simultaneously stories of their OWN rising, for they have bound their identities to include all. "We are the Church." "We are the school in microcosm." The theological musings of the Letter to the Romans might put into perspective the spiritual insight of the paschal victimhood and Easter moments that are daily taking place in Catholic schools. What Christ has done for humanity, they are doing for these Catholic institutions: 
Since we have been united with [Christ Jesus] in his death, we will also be raised to life as he was. We know that our old sinful selves were crucified with Christ so that sin might lose its power in our lives. We are no longer slaves to sin. For when we died with Christ we were set free from the power of sin. And since we died with Christ, we know we will also live with him. We are sure of this because Christ was raised from the dead, and he will never die again. Death no longer has any power over him. When he died, he died once to break the power of sin. But now that he lives, he lives for the glory of God. So you also should consider yourselves to be dead to the power of sin and alive to God through Christ Jesus" (Romans 6:5-11, New Living Translation, NLT).

The power that they are overcoming is the power of the hegemonic pull to a dualist class system based on false notions of grace which places the queer in an inescapable position of suffering and inauthenticity while making the enforcers of this power structure inhumane. A concrete example of the natural way that these teachers bring their oppressors into their suffering for the sake of bringing about justice can be found in the fact that one of the teachers in this study chose a pseudonym that was the name of the most homophobic administrator in his school. As he said: I will make him gay for everyone who reads this dissertation and my suffering will be his. This administrator is now a part of any good that comes from this writing because he was brought into the process by a queer teacher who is convinced that this is a true act of social justice.

I share here a few statements of resurrection, in which they have brought about a new reality in their schools. These give us, as scholars dedicated to social justice, reason 
to step back and wonder at the power of a spirituality which empowers suffering to bring about change. When this group of teachers says "We are survivors," they have opened that up to include all of the school and the Church. This is some of the good that they see in their institutions because they have chosen to be authentic parts of the schools:

- "We are a safe space for those who don't fit into the norm because of the pressures of school, expected life timelines, due to sexual phobias, or any number of non-normative experiences." (Retreatants)

- "By being in personal relationships with others in our schools, we transform the sense of justice and solidarity in our community.” (Retreatants)

- "We can align ourselves with faculty members who are homophobic or have negative attitudes and change them by our friendship.” (Retreatants)

- "Since we have lived in such deep fear, we are able to come alongside others in fear as well." (Retreatants)

- "We show that there are different paths for moving through life." (Retreatants)

- "We can help others who are caught in a binary tension to live in the grey of this world." (Retreatants)

- "When we move beyond fear (or tell the story of our lives moving into selfpower[ment] when coming out to ourselves) we then give the gift of truth [and] power to our students." (Retreatants)

This spiritual call to immerse themselves into the oppressive structure of the Catholic school while holding tightly to a solidarity which identifies them as the school itself, makes the queer teacher the living example and promise of what can be when injustice is conquered. That is why they said: "We show that the locus of solidarity is in 
the work of justice." Only in the pursuit of justice could solidarity make any sense, particularly the Easter solidarity of the queer, Catholic school teachers.

\section{Liminal Liturgies and Communities}

I did not expect for this research to reveal a specific queer-teacher spirituality. Nonetheless, I consider spirituality to be an essential element needed for surviving the difficulties of this world. Lepherd (2015) insisted that it is a basic part of being human. Yet, I could not have imagined that such a spirituality would be so rich and revolutionary as has been shared by these Easter People. What I have now come to realize, in light of this, is that the queer-teacher retreat was not an aberration in the way that queer teachers enacted justice. Rather it fell directly within the boundaries of their spirituality, although the context was unusual, taking place outside of the school itself. What I wish to propose is that this research methodology is tantamount to a liturgical celebration of the Easter realities of queer teachers in Catholic schools. They are the celebrants of this ritual liturgy, taking up the potency of memory within the context of a transhistorcial moment, and thus imparting upon the school and themselves a new kind of grace, one which moves from fear into freedom (Brueggeman, 2015; McLaren, 1988; Rohr, 2002). Let me explain what I mean below.

First, I am proposing that the queer-teacher spirituality discovery dialectically casts light back towards the practice of research to reveal it as something deeper than expected. It would seem that this dialectical relationship has revealed itself time and again in the process of this work. Data leading to analysis leading to data such that both require each other to be present in order to exist. In the thematic families, we find dialectic relationships: silence that requires utterance, personal identities in relationship 
with institutional ones, resistances that appear because of power. Here I find that the discovery of the nature of this spirituality needed the engagement in this kind of research, and in turn, the discovery of the nature of the research requires the existence of the spirituality. I claim this action-research project engaged in a specific kind of action, not only one patterned after the action research projects of Griffin (1991) and Everitt (2010), but one that is informed (and thus culturally responsive) by the vantage point of the queer teachers. I claim this research is liturgy. New Advent (Liturgy, 2012) gives the following etymological definition of the word liturgy:

Liturgy (leitourgia) is a Greek composite word meaning originally a public duty, a service to the state undertaken by a citizen. Its elements are leitos (from leos $=$ laos, people) meaning public, and ergo (obsolete in the present stem, used in future erxo, etc.), to do.

Often in Catholic catechetical classes, liturgy is described as a "work of the people." I would like to call our attention to certain important elements of the meaning of this word. First, it is an action, even according to the Catechism's definition (Sacred Congregation for the Doctrine of the Faith, 1994, para. 1136). The gathering of a community to share stories about their oppression, hopes, joys, fears, and future plans is an active engagement. Secondly, liturgy is done by a member of a group (citizen) for the good of the larger social structure (state). To see this retreat as liturgy is to insist that it was done, not only to benefit the queer teachers but all the members of their schools and communities. This is an extension of the daily work of paschal victimhood into a space of critical reflection. Along with the teachers they brought with them the members of their communities, the power structures that cling to them in the emotional form of fear, 
and the visions of a future yet to come. But we can only come to understand how this happened if we understand a few more nuanced theological realities.

In the finite progression of chronological time, each present moment is unique. The knowledge that derives from that moment involves the contextualization of the present in connection to the past. Thus, we know that memory is at play in our daily life knowing it enables us to establish epistemological continuity from one moment to the next. Imagination, as I said in an earlier chapter, also comes into play with chronological existence, as it projects the possibility of continuity into the future of the present patterns. Memory and imagination do not, in fact, make present the future or past in this finite pattern of time for those realities are beyond our reach. This time is designated by the Greek term "chronos." Yet, there is another kind of time, the one which holds eternal beings, such as God. This divine time has been term "kairos." If God is eternal, kairos must be eternal; thus all moments are present simultaneously and in an infinite amount of relations to one another. Once one has entered into kairos, the function of memory is no longer the same. To remember something when in divine time is to actually make the essence of that very moment (which we would call "past" in chronos) to become present with all its realities simultaneously with the essence of the now. This highly technical explanation of time is important to understand how the retreat acts to bring transformative grace to persons and institutions not physically present in the chronological now of the research processes. Liturgy always takes place in kairos.

In the Eucharistic liturgy of the Catholic church, memory takes on the very role that I described above in the moment of kairos. Theologically speaking, the liturgy which is celebrated by the Church, remembers the events of Easter mysteries, inclusive of 
the suffering, death and Resurrection of the Lord. Because this memory takes place in an eternal time, all who celebrate this recollection are simultaneously untied to all those moments and we are brought into the eternal present with the dying and rising Christ who imparts his life of grace upon us. A pressing question may be: How do we know that we have been assumed into divine time? First, I must state that the evidence for this lies behind the veil of faith and proof of the ethereal and transcendant will never suffice the scientific mind. Having acknowledged that, we can point to a ritual performance which marks the departure of chronos for the entrance into kairos. This is called an epiclesis. Liturgically, an epiclesis is an intentional prayer of submission and welcome to the Spirit of God to draw us into that eternal presence of the life of the Trinity. In our own Critical Ignatian Method, we began every moment with a prayer of petition to the Spirit. This epiclesis sanctified the process itself, drawing it out of purely chronological time into a more ethereal and eternal kairos. This liturgy was led, not by an ordained priest, but by each of the participants, making them the celebrants of the work.

To engage in storytelling in a moment of kairos with a community of others is to enact the same kind of remembering that happens in the ecclesial celebration of the Mass. When a queer teacher, after the epiclesis, uses their memory in reference to persons, institutions, pains, joys, and organizations, they are bringing those very things INTO the research in a very real way. As the community begins to deconstruct these stories, they engage in a spiritual moment of dismantling the oppressive powers of isolation and hegemony while also strengthening the grace of community. In other words, they are no longer alone in the terror of an encounter with a principal, but are accompanied by others. The grace of authenticity, which they begin to build within themselves, is not separable 
from the institutions they call forth in memory. They are not in chronological time, but they are engaging in a middle time, a liminal time, which is neither here nor there (LeMaster, 2011; McLaren, 1988; Skjolder-Nielson \& Edelman, 2014). It is a movement from the structure of daily life into an "anti-structure" which allows them to relate and re-member the constituent parts of queerness, Catholic culture, and teaching in innovative ways that move them towards freedom. Liminal spaces are temporary, as is liturgy, and thus they are geared toward the re-integration of these teachers back into the daily structure of the school (Trebilcock, 2016). If the liturgy, as a work of engaging in the transformation of the Catholic school, has been valid, then the return to daily life should be evidenced by a change.

After the retreat (or perhaps we should say queer liturgy), the teachers did return to their schools and reengaged in their daily work under the established structures. A month later the teachers congregated for a meeting over skype and the reunion was joyous. The question was asked by me: "How have you been since the retreat?" The response that I received was that the teachers felt like something had changed in their schools. One said that he felt "lighter" as if the weight of something had been lifted. Others said that they felt like there was less isolation in their experiences because of the community they now had in other schools. The consensus was that there was a reduction of "fear" in their schools and its pull upon their lives. School had changed for the queer teacher by means of this liturgical practice they had undertaken. It had effected a new present moment, so powerfully different that they decided to engage in the work again by facilitating another retreat. This too had positive effects in the lives of queer teachers and the fear they felt in school. Thus, this liturgical practice has been ritualized among a new 
organization of queer Catholic school educators every other month in which story and memory is employed in a divine moment of prayer and reflection for the purpose of transformation. Thus, this queer-teacher spirituality, one which moves into the heart of the school through identification with the school and solidarity with their oppressors, takes on a new powerful moment as they remain in solidarity while seeking selftransformation and understanding for the sake of a more just future.

\section{Theodicy and Spirituality}

"O felix cupla!" These are the opening words of the Catholic Church's Easter liturgy. The opening lines in English are: “Oh, happy fault! Oh, necessary sin of Adam! That won for us a Savior." The Church, in remembering the joy of the Resurrection of the Christ, is drawn to contemplate the ways in which evil was at play in his death. If sin had never entered the world, if humanity were perfectly loving, then there would have been no need for God to become human. Additionally, if our hearts were not turned from good by a sense of hatred, then we would not have been the authors of the death of the Innocent One on the Cross. Yet, it is the birth, death, and rising of Jesus of Nazareth that is the core of our ecclesial lives. This gives rise to theological musings of a very queer sort. Here theologians begin to speak of theodicy, the mystery of evil. I would be remiss if I did not note that, even though the oppressive forces of the Catholic school might be seen as evil, they are also necessary in the making of a new spirituality. It is the happy fault of the overly-normative school that it becomes the seedbed of the queerest of all spiritual existences. Life is never as simple as black and white, the teachers remark, it is often filled with a great deal of mysterious and unexplainable grey. 


\section{Conclusion}

In concluding this chapter, I return us to the image of the black hole. The power of this celestial reality is world crushing, literally. Yet, it can be dissipated by the practically imperceptible progress of Hawking Radiation. What we have discovered in this research is a beautiful spiritual pattern of social transformation rooted in solidarity, humility, and constancy. Our simple retreat has become a potent source of school transformation because it has been inserted with a spiritual truth. Drawing us truly beyond the outer limits of chronological time, queer teachers in Catholic schools embrace their mission to re-form Catholic schooling by means of an inward focused paschal victimhood. Sometimes we discover that what lies in the darkness has much to teach us. Refreshed in hope by this spiritual reality, we come to the close of this dissertation. 


\section{Chapter 7: Reflections from a Stargazer's Notebook}

I sit here writing this final chapter on the eve of the rise of Makali'i (Pleiades) into the night skies of Hawai'i. It is the coming of Makahiki with the celebrations, games, feasts, and competitions that accompanied this time for the indigenous peoples of the 'aina. I cannot help but shake my head and smile realizing that I come to close this dissertation as the very stars upon which I reflected for my opening chapter ascend. Has this journey been part of a cosmic plan?

Just as so many have done before me, I have put my eyes towards the night sky to discover what beauty might lie there. Constellations, solar systems, stars, planets, and black holes have, in this extended metaphor, served us as all heavenly bodies have for ages. They became guides on a journey. And this leg of the journey is quickly coming to a close. But before we draw our eyes downward, I wish for us to take a moment of gratitude to contemplate in a moment all that we have come to discover from these lights that burn so brightly in the midst of a sky that can seem lonely and dark.

\section{Inner Transformations}

In my Introduction to LGBTQ Studies course, one of my students, Nichole Young, reflected very profoundly as she noted that "We are mostly made up of stardust" (personal communication, October, 2015). I love this quote for a number of reasons. One reason is that it's a sparkly way of understanding ourselves as human beings and I wish for all my students to walk out shimmering with the joy of personal authenticity. Primarily I love the quote because, without knowing it, my student had revealed to me the value of being a stargazer. When we look into the universe from our tiny vantage point on the edge of a spinning, hurling, water enveloped, planetary rock, we might like 
to imagine that we are discovering something new about the other parts of the great abyss. If we can look up on the right night, using a strong enough telescope, we believe that we can touch the stars and bring them down to us. We imagine that we have come to understand them because that is what we do as human beings. This isn't really what is happening at all, as much as our objective minds wish to believe it. What my student revealed to me is that when I look up at the stars, when I learn about the patterns of their shimmering, their clustered locations, and even their inverse existence as black holes, I am truly taking a journey inward. I do not look alone at the stars but the stars look back at me and it is together that we come to know who we are in this universe.

Dr. Suzanne SooHoo, my professor and mentor, likes to ask a very important question of her students and herself: "Who are you now that you have come through this research?" I want to reflect a bit on this question as I believe that there is much to be revealed about the research through this question. If looking into the lives of queer teachers in Catholic schools is like looking out into the stars, then it is less about objectifying the "other" than it is about subjectifying the self. As Martin Buber (1996) would have us understand, we only come to know the I of our existence through itself intertwining and relational existence with the many you's that share this world. Because of this deep relationship of selfhood and otherness, one in which we must acknowledge that each coexists internally and extrinsic to the other, the question of research ethics becomes something of greater import than what we might have first believed. I have come to see that to honor the agency and intent of the "other" of research is not simply a way to be more just towards them. Rather, since my own identity is inextricably tied up with theirs, the call to be ethical is equally as important in dealing with one's own self as 
it is in dealing with the other. If we do not answer this question about selfhood in tandem to the concept of otherness and community, then our work will be artificial and extracted from the human condition. It is for this reason that Culturally Responsive Methodologies urge us to place greatest import on the presence of relationship (Berryman et al., 2013). I am a new kind of academic and researcher because I have allowed relationship to be the source and compass of my work.

I began to conceive of this research immersed in the best of intentions and illuminated by the guiding lights of wisdom figures from the realms of queer studies, liberation theology, and critical pedagogy. I was sure that I needed to construct a work that would be as true as possible to the theoretical and methodological frames that I embraced. Ethics were about safety keeping and honoring a space that would be secure vessels for the voicing of authentic experiences and stories. I knew that my processes might change in unknown ways, as the readings had prepared me for this (Campbell \& Farrier, 2015). My relationship to my participants was but an imaginary reality lying across an unknown horizon as I presented my proposal.

Once I entered the work of gaining participants, I began to engage in the sentience of epistemology. Yet it was not until I stopped to examine my own experiences as the process unfolded that I came to realize that relationship would become the measure and guide of the research and its development. What do I mean by the sentience of epistemology? Manulani Meyer (2001) spoke of a mode of Hawaiian knowing that is centered in the gut. It is a knowing that is felt. I do not claim that my own way of knowing is Hawaiian per se, but I find resonance through this research with a felt epistemology. Perhaps this should not be surprising as we are discussing in this research 
an identity tied to one's sexuality, sex, and gender. If knowledge of these psychophysical realities were not themselves manifested bodily, it would be disingenuous. As I entered into the efforts of gathering participants, I felt the joy, fear, and isolation of the women and men to whom I was talking. My frustration, which I chalked up to a lack of patience, was really the first inklings of a knowledge about queer-teacher existence in Cathoilc schools. This difficulty to sustain the early relationships and the resistance to a meeting of teachers from a single school site started to manifest in me as feelings of despair. I was sure the work would not be accomplished. Yet, I was also sharing in the feelings of isolation that these teachers had in their own locations, for once one seeks authentic relationship they discover that transference of knowing can happen through emotional realms.

As the research continued, I found that I was beginning to move beyond an intellectualized ethical framework whose verification was founded on the writings of distant scholars. Rather, my approach was becoming more rich as I placed actual relationship with my participants as the primary concern. Safety and risk were determined, not so much by the ideas of academics but from the sense of security that arose in me and others as we walked into the waters of research. Where relationship was most authentic, such was the path that the research needed to take. It was for this reason that I handed all information about my analysis to my participants before even whispering my first thoughts to my academic mentors. It was through this lens that we together determined a means of sharing stories that could advance the mission of the work, while not threatening the jobs of the teachers. In this work, I learned to more 
earnestly honor the value of building and sustaining relationships, not simply as a means to accessing a community but as the goal and measure of validity in working with others.

I came to the work convinced that authentic humility sought to negate the self so as to minimize the bias I might give the research. While I never expected that my work would be objective, I longed to honor the space of community for the queer teachers in a way that made little sense of my own self. I could see myself as insider and outsider in regards to my intellectual and experiential contributions, but I failed to realize that I was not aware of the ways that my humanity would come to engage and enhance the work. Adopting an action research strategy that sought to be culturally responsive, I was bound to discover that relationships cannot be taken on "for the benefit of another" alone but truly do require mutuality (Berryman et al., 2013). I had thought that I was performing mutuality well in the research retreat when I would dare to clarify an idea that the participants were making. Yet, Mateo was quick to show me that I had more to do if I was to be a co-researcher with the new community that was being formed. When we went to dinner on Saturday night, the group was chatting about the ideas that were floating in the teacher minds as I sat back and smiled like a third-party observer. All was going well during the retreat and in a somewhat predictable way, even as messy as the time schedule had been. Then, out of nowhere, Mateo took control of the conversation and directed it to me and asked: "So, Kevin, we have all shared our stories and had a wonderful time of it but we haven't had a chance to hear yours. Tell us your story." I was silent for a moment and felt the rise of three distinct emotions. First, I was confused because I felt that I had been transparent about the major parts of my life in talking to each of the participants and didn't know that they felt like I wasn't contributing. Second, 
I was fearful because I had not prepared for the question at all. The retreat direction was swiftly taken out of my hands and embraced by the new leadership of the retreatants leaving me vulnerable. Finally, I felt excitement because as I watched the community begin to grow among the teachers, I felt a longing to be part of it but I was hesitant to assert myself. As SooHoo (2013) reminded us, the good practitioner of CRM embraces humility by waiting for an invitation to be with the community in question. This was my invitation.

Taking the risk to respond to this invitation to share my story served to dramatically change the ethos and conceptualization of the retreat work itself. I began to share my own story about growing up in Catholic schools and discovering that I was different. I talked about my efforts to understand myself through submission to a God bigger than myself: through prayer, through innumerable deliverances and minor exorcism, through acceptance of priesthood in place of seeking love, and finally through emotionally and financially crippling processes of reparative therapy. I have told my story so many times that it has been a while since I have gotten emotional about it. Yet, as I told these teachers my story, I began to cry and they did the same. Then Mateo asked: "How did you get here in your life, then?" What I said next was something I had never fully comprehended about my story of coming out and pursuing personal authenticity. With tear-filled eyes, I looked at Mateo and I told him that I walked into a Church at some point, so worn out by trying to make myself fit into the standard of holiness that plagued me all my life. I was particularly tired of going to confession multiple times a day in an unhealthy desire to wash out my soul while knowing that my "objectively disorderd" soul was unwashable. I was tired of the same ghosts of being 
unlovable in the eyes of God that led me to fight with bulimic tendencies which urge me to purge my inner self of all the inner blackness I embodied. In that Church I was exhausted and I saw no hope for happiness in my life. So I looked up at the Crucifix and said the most earnest prayer I have ever uttered to this day: "Fuck You!" At this point, I was really crying. I told the group that what I have learned since then was that if I was ever going to find peace, that God in my head who hated me had to die. And what's more, I had to be the one to kill him for I had constructed him from all the lies that had been given to me from years in Catholic education and ministry. The last four years, I have been killing/dismantling/deconstructing this "god image" and have found the greatest freedom ever. I then told the group that I never really understood that this was what I had been doing since I came out until I told them at that moment. Then, one at a time, starting with Jae, each man acknowledged that freedom has been about dismantling lies in their lives.

This study changed me in a profound way. The relationships that developed in the work and my participation in the action of the research has given me a totally new way of understanding my own queer self in the Church. I never knew that I was part of a process that was so visceral and hopeful. My years of reading queer theorists and the work of gay activists were far too disembodied for me to understand my full flesh, blood, and souled self in relationship with a real human community. All that I was aware of before speaking and listening to this community was that I was a survivor, though what surviving meant required my telling of the story in the community. Only through this was I able to understand that I was not alone and that there was a rhythm to my own story that was like the rhythm of others I had never met before. This alone would have been a 
substantial revelation, but it was only enhanced by a statement made by Mateo at the dinner table after my story was told. He thanked me for sharing with the group about my story, one with which he particularly found resonance. Then he told me that he understood the purpose of the research better. I asked him to explain what that meant. He said, hearing my story he realized that it was as if this whole retreat were a process of me, reaching back to queer teachers and walking them through the same process of the death of a false god together so that they could find freedom on the other side. I was shocked, not because he had discovered some secret intention but because he unveiled for me the ways that my story was at work in the process. I knew that he was right and I learned something about the value of mutuality in the deepest way possible. When I was with the others, the benefit became ours and the knowledge that was revealed was more authentic, more vetted, and more trustworthy because of the transparency that only genuine relationships can bring. These findings that surfaced were no longer discoveries about them but revelations about us, realities that have led me down unexpected pathways which I learned to navigate through the ethical compass of authentic, vulnerable, and rigorous relationality.

Peter McLaren (1988) wrote that the authentic critical pedagogue might be described as a "liminal servant" (p. 174). He looks to the teacher to be a facilitator who helps the classroom to be a place of profound possibility because it is a place where the roles of teachers' and students', knowing and learning, action and meditation are held in set of relational positions which question our traditional binaries so as to reimagine the outside world. Here I cannot help but call to mind the concept of Nita Freire's (2014) "untested feasibility" which sustains the hope for a better tomorrow if only we push 
beyond the essentialism of a particular construction of social existence. Having passed through this work and coming to understand this research process as both liturgical and revolutionary, I have developed a more expansive sense of my researcher positionality. I came to understand that it is not only teachers who are liminal servants, but researchers as well. My role was less about directing the investigation and more about holding a space in "kairos" that was authentically liminal in relationship to the daily expectations of queer-teacher lives. As facilitator, it was my role to ensure that there was safety from the fears of repercussions. At the same time, I knew that I was embracing Kevin Kumashiro's $(2002,2009)$ work in pressing teachers into uncomfortable spaces where formally dislocated identities were made to embrace and common sense meanings failed to satisfy a process of meaning making. Like a critical teacher, who opens their classroom to become a laboratory (or indeed a sacred space) of contextually and experientially informed knowledge production, I learned that the critical researcher, particularly one with an eye to queering the world, must be a master at the art of facilitating, following, leading, and becoming personally uncomfortable for the sake of the unknown social transformation which may flow forth. Felicitously tainted by this experience of academic research aimed towards social transformation, I have learned that my commitment to scholarship can best be authenticated when it is geared towards a movement towards justice.

My final reflection upon the question of the effect of this research on who I am and how my life will unfold from this point onward, draws me back to the realization that looking at the stars teaches us a lot about ourselves as composite and animated collections of stardust. My time with this community significantly impacted my 
existence for I came to new knowledge of these stars of the Catholic school universe and in so doing, I saw reflected back at me, their own revelations of who I am. At the second retreat that this group conducted as the first of many action steps that are flowing from this living action research, I shared a story about growing up as a student in a Catholic school:

I knew deep within myself that I was different and had said to only one very close friend that I "might possibly be gay." (It is very telling that I told my friend this heavy secret upstairs in the closet of a guest room in her home where I demanded that both the closet and room door be closed and lights turned off. Such shame!) I didn't think there was anyone else like me in the whole school (and years have proven that I am the only queer alumnus for several classes above and below my class). Being queer was a feeling and a reality that I could only play out in my head through reflection, sadness, fantasy, and prayer. What makes this so different from the experience of so many other youth was that queerness had no flesh or physicality. That is, until my senior year, when one of my favorite teachers came to the school to teach us English. He was brilliant, he was very well-groomed, and he was GAY... a fact that we all knew by way of the rumor mill. Mr. English (pseudonym) meant so much more to me than he did to the rest of my peers, not because of some romantic or sexualized teenage feelings, but because he was the first time I could hear what a gay person sounded like, see what real life gay hair looked like, touch gay skin when he shook our hands at the classroom door, and see what a gay smile looked like when he laughed at his own puns. Mr. English was the first time that I could imagine knowledge of my sexuality and knowledge of my body to come together in a real way, 
breaking down the binary good/bad of body/soul of a queer kid in Tennessee. Then, in early December, Mr. English informed us that he was not going to return to the school (holding back anger as much as he could) due to some issues that arose with administration. The rumor mill was alive again with the "real story" that he was asked to leave because he was queer and had a life partner. (I have since learned the names of the teachers who leaked this true information to the student body to ensure that his leaving would not be rumored to be about any misconduct. These teachers told me that, though they were not able to share this information directly, they found it important that students who loved him knew about the injustice of the administrative decision.) When Mr. English was asked to leave, every fear that I had about being out as Catholic were proven true... his body wasn't welcome in this Church, and my queer body wasn't going to be either.

Telling this story in the queer-teacher retreat was the antithesis of the experience that I was describing. It has been an enfleshment of knowing what it means to be queer in the Church, a connection between the years of mental imaginings I have worked up for myself and the reality of others on the same path. Through this research I have spent hours texting, talking, eating, laughing, drinking, crying, hugging, celebrating, dancing, and being human with a group of queers who are part of the Church. Spending time looking into their lives was an opportunity for me to see my own life in context. I am now part of a community, one that is able to challenge me and support me in ways that even well-intentioned non-queers or those outside of the structures of the Church cannot. I have come to learn that critical research will always lead us back to ourselves, moving us to grasp new ideas and concepts, inciting us to action in the world, and in this case, 
humanizing us as it dismantles the oppression we may have all-too-easily internalized. I am a co-learner, a member of community, an advocate for queer reality, and the practitioner of a new spirituality which has been brought to life in me because I dared to take on this research.

\section{Sketching What We Saw ...}

We started this research asking two specific questions. First, we wanted to know how queerness was understood to be constructed in Catholic schools for queer teachers. The answer that we received from our data was much more complex than we might have first expected, though it finds a happy home in the already existing literature. First, we learned that much of what determines the queer experience in Catholic school is related to a sense of fear. Like Foucault's (1977) understanding of the pan-optics of discipline, the mechanism of fear operates in the lives of queer teachers daily. This is not simply a sense of fear of the queer person, which might manifest itself in hatred, but an emotional marker that indicates the finite boundaries of what is considered normal in this particular context. Note, the operation of fear is specific to the location of the queer teacher, meaning that the limits of queerness in Catholic schooling alter the boundaries of personal and institutional existence. The finding of a particular experience of fear that was so deeply tied to the specific realities of Catholic schools aligns with the realization that we made in our literature review, that context is highly important. Evans' (2002) reflection on identity returns to us with new vigor: "I am positing that identities are not static but are an effect of interacting with others and with larger concepts that are conveyed through the circulating discourses" (p. 4). Fear is a psycho-emotional indicator which makes clear the lines of normative being in a particular circumstance. In relation 
to this, we found three ways that queerness came to be constructed in the Catholic school in the push/pull dialectic of power and resistance (Foucault, 1978). These are by performance, ontology, and agency.

The three themes: Doing Queer, Being Queer, and Enforcing Queer give us a triple-lensed approach to understanding the construction of queerness. Performativity has been a part of the discussion of queerness and gender studies from early in the conceptualization of these fields of study (Butler, 1990; Pinar, 1998b; Sullivan, 2003). In this study we discovered that a large part of performing queerness in Catholic schools means being silent. Much like the "closet" of Sedgwick's (1990) work, the life of the queer teacher is caught in a space of hidden presence. This reaffirms the lessons learned from the research, in which teachers felt that negotiating private and public lives was a tedious burden. Here we see that this burden is that of closing off certain aspects of the self while allowing the school to utilize the gifts one brings for the sake of the advancement of its mission. Under the theme of being queer, we find the struggle of identity as it is created in the Catholic school for the queer teacher. The literature spoke of the feeling of isolation and the power of a dominant narrative which impressed themselves on the lives of queer teachers in all schools. In many ways, this is enhanced by our research as we see that isolation and discourse can come together in the art of negatively identifying a population. These teachers bare certain identities given them by others in the schools. Yet, they are also able to find inner identities which more positively inform their lives. This contributes to ideas of queer-teacher resiliency. Finally, under the theme of enforcing queer, we begin to see the specific ways that power is employed in a Catholic school to ensure that queerness maintains a specific meaning 
and service to the school. Morality clauses, parental oversight, and hierarchical claims to orthodoxy are some ways that the power of the heterosexual and cisgender norm is maintained in private Catholic schools. This research thus enhances the literature by answering further the question of the importance of contextuality for the experiences of queer teachers. In particular, since queerness is rarely examined in US Catholic school research, the dissertation contributes to what could be a growing discussion about this intersection.

The second question of the research asked what queer teachers will do about the knowledge they gained above. I have described the decision of the participants to take leadership in creating a second retreat which they facilitated. Additionally, they have established a queer-teacher community. Yet, what has been most revealing is that active social justice work has been a part of queer-teacher experience in a very nuanced way from before the time of the research. By uncovering the spirituality of being an Easter People, the queer teachers have offered us a new way of understanding social justice action. Rather than pushing against the forces of the school, they have embraced a paschal victimhood, slowly dismantling the power of fear over their lives by dying and rising in small ways every day. The radical solidarity they hold with all in these institutions, including those whom they find most oppressive, allows them to subject the institution itself to the crushing blow of its own hegemony as enacted in their lives. Once the norm has come to embrace the queer as part of itself, then it is helpless to maintain its boundaries for queerness will forever make the impermeable walls of normalcy fabulously porous. This discovery of queer-teacher spirituality is a significant contribution to the ways that we look at this population. 


\section{The Catholic Cosmos}

Having reviewed this briefly, we might ask what if any effect this might have on Catholic schools. I would like to say that as a system of education, Catholic schools are invited to consider the priority of human thriving in light of a dedication to strict orthodoxy. Will queer teachers remain in the halls of these school undergoing the crushing stress of self-monitoring and hyper-vigilance in order to serve a norm that negates part of their existence? I believe that it is time for Catholic schools to engage in the difficult examination of ways in which their structures may unintentionally harm the very people who serve in them. This is particularly important for the hierarchy who, rather than becoming the model of the good shepherds they are called to be, play the role of hunter and enemy. Catholic school practices must be more firmly grounded in the ethic of love. This begins with a careful listening to those who find themselves on the margins of these institutions. Are schools and church leaders aware that queer teachers: feel like they are seen as less than others, are unwilling to seek promotion, suffer in a sense of isolation, bare grief and joy about their lives under a veil of silence? Never had they been asked to share their authentic experience of life with the safety of knowing that it will not be prejudged and threaten their employment. I will not prescribe a next step as that must be collaboratively decided in the specific context of the school and church. Nonetheless, discussions had in Catholic schools must ultimately move into action in some way.

This research may speak most loudly to queer teachers in Catholic schools across the nation. As practitioners of the art of pedagogy, this work reveals that you are simultaneously struggling to make space to be authentically yourself. The work of this 
research study is an invitation for you to push beyond the boundaries of fear and isolation to find community. It is important for you to share your stories with others who understand. These stories are more than venting sessions, they can hold within them the key to understanding the weight that is felt in the daily routine of your job. Creating connections with others and establishing communities of authentic dialogue is proven in this study to transform Catholic educational experience for the teachers who are involved. I recommend that such communities take shape in the specific contexts of your lives so that it might bring good for you.

Finally, and perhaps most hopefully, this research has unearthed something quite beautiful laying quietly in the heart of the Catholic school. That is, it has shown us a spiritual existence which takes inspiration from the Catholic faith. This Easter People spirituality allows Catholic schools to reimagine the ways in which justice can take shape. The Catechism of the Catholic church reminds us that:

many and varied spiritualities have been developed throughout the history of the churches. The personal charism of some witnesses to God's love for men has been handed on, like 'the spirit' of Elijah to Elisha and John the Baptist, so that their followers may have a share in this spirit. A distinct spirituality can also arise at the point of convergence of liturgical and theological currents, bearing witness to the integration of the faith into a particular human environment and its history. The different schools of Christian spirituality share in the living tradition of prayer and are essential guides for the faithful. In their rich diversity, they are refractions of the one pure light of the Holy Spirit. (Sacred Congregation for the Doctrine of the Faith, 1994, para. 2683) 
This research welcomes schools to become attuned to the multiple ways that the Spirit is active within its own ranks. By listening to the experiences of these queer teachers when they speak about spiritual realities in light of justice and grace, the school may find new pathways for honoring the marginalized. Rather than favoring a singular charism, it might behoove schools to be open to a living bricolage (much like we did in constructing this research) of spiritualties that can make greater sense of the world inside and outside of the school walls. The polyphonic reverberations of diverse spiritual understanding have always been a part of our Catholic schools, we are now being invited to retreat from a single-narrative stance to many ideas coexist under the same umbrella of Catholic schooling.

\section{Notes for Future Stargazers}

As much as we wish that our looking into the skies could grasp all that there is to know about the cosmos, we will always return to our earthly project with lessons and questions. This research project was not flawless. The research, while it was extended to any and all queer identified teachers for attendance, the population of the first retreat was a group of four gay, identified cisgender men. Though there was diversity in age, race, and even religion, the study is much in need of further work to include voices of queer populations not yet heard. This research did not explore the intersections of race and queerness as I had originally hoped that it would. During the retreat, I asked leading questions about the role that race played in the experiences of being queer in a Catholic school and the participants were uninterested in exploring that topic. Rather, the group focused on queerness as a culture common to all. Further research exploring this intersection would be very valuable. Other questions still remain. What could we learn 
from lesbian voices? What do those who center their queerness in gender rather than sexuality reveal to us? Are there people who feel queer-identified in the public sphere but have no sense of being queer in the Catholic school because of the social construction of their selves? What can we learn about queerness and its construction from speaking with non-queer faculty and administrators? I believe that the large amount of emphasis that was placed by the community on the role of administration, hierarchy, and parents in the ways that they experienced life demands that further research be done on the insights and perceptions of these groups regarding queerness. Do the perceptions match the beliefs of the queer teachers? Are there new actions that develop from such a study?

The research also finds itself contextualized on the west Coast of the United States. This is only one context of Catholic schooling. Having grown up in the South, I know that Catholic school takes on its own tenor when surrounded by a Protestant majority. Likewise, after the recent Presidential election of 2016, our country has been revealed to be much more divided than may have first been believed. This political revelation of two Americas, often divided between urban and rural locations, calls into question the fullness of a study that centers itself in one part of the country. Thus, such work needs to continue in Catholic schools across the United States, revealing the nuanced ways that local and ecclesial contexts construct queerness and inform movements for justice. Continuing to follow up on invitations to do these research retreats with groups of queer teachers who are showing interest in different parts of the nation will be a way of remaining true to the question at hand.

Meanwhile, this research has given birth to a community of queer teachers who are regularly meeting to share stories and discuss lives in Catholic schools with a hope 
for justice. I have become a welcome member of this group, and as I sit with them, acting as participant and archivist, I find new questions emerging. I am reminded of the statement from Gary that this community is a culture in itself. The second retreat and the discussions of organizing a meeting with others bring me to new questions. I have come to understand the deep resonance that indigenous epistemologies and scholarship have made in my own life due to this revelation of Gary (a man who is does not identify as the same race as myself). In some way, the wisdom of a people written in language that is authentic to their experience and shared existence in this world was harkening me to seek to understand my own community. I do not claim that being queer is an indigenous existence. But I acknowledge that it was the work of indigenous scholars and communities that have pushed against the imposed identification and oppression that has made this research fruitful for the queer community. I begin to wonder what value might be had in creating spaces for communities and scholars working in these areas to come together to share story, practice, and wisdom. Could the shared and honored multiplicity of voices, particularly those which have known oppression, give rise to a transformation in educational practice for social justice?

In looking at this queer-teacher community as it collects itself out of the darkness of individualized isolation, I begin to see the rise of a new process. I watch as the community comes to understand itself in the liminal spaces in which the power of Catholic school hegemony does not pertain. What is the language that speaks to the queer world view? What does it mean to know and be known as a queer teacher? What is the meaning of faith and spirituality? How do we construct an ethic of life and activity which is not only informed by the pain of the past but develops from the core of our 
authentic beings? While the queer community has been growing over the last several decades and may be considered to have its own history, it lacks the deep cultural roots that other communities have. We have seen a generation wiped out by HIV/AIDS that started the process of self-understanding. Subsequent generations have continued to deal with the art of survival as homelessness, suicide, and murder still plague parts of the community. Hardly able to collect itself as a group to ask "who are we?," the queer community lacks the ability to have structures to mentor and parent generations about their ontology. Having carved the space to understand themselves as queer teachers in Catholic schools, this growing group is undertaking a process that I have termed "autopedagogy.” Peter McLaren (Personal Communication, October 10, 2016) pointed out that this term is similar to that of autodidacticism and we spoke about the ways that these processes are different. Autodidactic is defined by the Merriam-Webster's (n.d.) dictionary as "having skills or knowledge acquired through one's own efforts without formal training." Unlike this more individual term in which epistemological gains comes through the singular work of person towards the specific end of arriving at some commonly held "truth" not previously revealed to the learner, auto-pedagogy requires community and its terminous cannot be validated by anyone outside of the knowing group itself. That is, auto-pedagogy is the art of a community coming to know its ontology and epistemological reality through internal self-discovery without the benefit of an authoritative voice. The result of auto-pedagogy is authenticity, though what this may look like cannot be known before. This action study begs the research to follow the community along its path of understanding and action to see what more may be revealed. 


\section{In Closing}

I close this dissertation with an invitation to the reader. Having been welcomed by these queer teachers to hear their stories and see their lives, how have you been altered? Remember that we are stardust and every heavenly body that we gaze at, or every human reality that we contemplate, reveals back to us something about ourselves and our lives. These teachers chose to take the lessons that they learned and put them into action. They did not let their stories be without meaning. Rather, they embraced them with a dynamism of spirituality and have moved beyond the event horizon of their own world into the unknown possibilities of a better tomorrow. They turn with me to you, whatever your relationship to them or the Catholic Church or schooling, and ask you the same question that is evidenced by their untiring lives: "Now that you have learned all this, what will what will you DO?"

Twinkle, twinkle little star! How I wonder what you are going to do now.... 


\section{References}

Achieng-Evensen, S. C. (2016). Young, Urban, Professional, and Kenyan?:

Conversations Surrounding Tribal Identity and Nationhood (Doctoral dissertation). Retrieved from College of Educational Studies

Dissertations. (Paper 9).

http://digitalcommons.chapman.edu/ces_dissertations/9

Adler, S. M. (2004). Multiple layers of a researcher's identity: Uncovering Asian

American voices. In K. Mutua \& B. B. Swadener (Eds.), Decolonizing

research in cross-cultural contexts: Critical personal narratives (pp. 107-

121). Albany, NY: State University of New York Press.

Allman, P. (2001). Revolutionary social transformation: Democratic hopes, political possibilities and critical education. Westport, CT: Bergin \& Garvey.

Anderson G. L., \& Herr, K. (1999). The new paradigm wars: Is there room for rigorous practioner knowledge in schools and universities? Educational

Researcher, 28(5), 12-21+40.

Asher, N. (2002). Engaging difference: Towards a pedagogy of interbeing. Teaching Education, 14(3), 235-247.

Ashworth, G. J. (2011). Heritage in ritual and identity. In C. Brosius, \& K. M. Polit (Eds.), Ritual, identity and heritage: The politics of culture and performance in a globalised world. New Dehli: Routledge

Barnard, I. (2004). Queer race: Cultural interventions in the racial politics of queer theory. New York, NY: Lang. 
Bartolomé, L. I. (2009). Beyond the methods fetish: Towards a humanizing pedagogy. In A. Darder, M. P. Baltodano, \& R. D. Torres (Eds.), The critical pedagogy reader (2nd ed; pp.338-55). New York, NY: Routledge.

Baum, G. (1975). Religion and alientation: a theological reading of sociology. Mahwah, NJ: Paulist Press.

Berryman, M., SooHoo, S., \& Nevin, A. (2013). Culturally responsive research from the margins. In M. Berryman, S. SooHoo, \& A. Nevin, (Eds.), Culturally responsive methodologies. Bingley, UK: Emerald Group.

Boff, L. (2013). Christianity in a nutshell. Maryknoll, NY: Orbis Books.

Boff, L., \& Boff, C. (2012). Introducing liberation theology, (P. Burns, Trans.). Maryknoll, NY: Orbis Books.

Boyle, G. (2010). Tattoos on the heart: The power of boundless compassion. New York, NY: Free Press.

Brueggemann, W. (2015). Performance as liminality: Between reality and possibility. Theology Today, 72(3), 262-275.

Buber, M. (1996). I and thou. New York, NY: Simon \& Schuster.

Butler, J. (1990). Gender trouble. New York, NY: Routledge.

Cahill, C. (2007). Repositioning ethical commitments: Participatory action research as relational praxis of social change. Acme: An International E-journal for Critical Geographies, 6(3), 360-373.

Campbell, A. \& Farrier, S. (2015). Queer practice as research: A fabulously messy business. Theater Research International, 40(1), 83-87. 
Canadian Conference of Catholic Bishops. (2011). Pastoral ministry to young people with same-sex attraction. Conocan Inc. Retrieved from http://www.cccb.ca/site/images/stories/pdf/ministry-ssa_en.pdf

Carlson, D. (1998). Who am I? Gay identity and a politics of the self. In W. Pinar. (Ed.) Queer theory in education. (pp. 107-121). Mahwah, NJ: Lawrence Erlbaum.

Cheng, P. (2012). From sin to amazing grace: Discovering the queer Christ. New York, NY: Seabury Books.

Cheng, P. (2013). Rainbow theology: Bridging race, sexuality and spirit. NewYork, NY: Church Publishing.

Cone, J. H. (1975). God of the oppressed. Maryknoll, NY: Orbis.

Corber, R. (1998). Lesbian and gay studies in today's academy. Academe, 84(5), 46-49.

Cummings, M. C., (2009). Someday this will be useful to you: Self-disclosure and lesbian and gay identity in the ESL writing classroom. Journal of basic writing, 28(1), 71-89.

Dallavis, C. (2011). Qualifying sociopolitical consciousness: Complicating culturally responsive pedagogy for faith-based schools. Education and urban society, 45(2), 266-284.

Darder, A. (2015). Freire and education. New York, NY: Routledge.

Davies, E. (2015). Meanings and mess in collaborative participatory research. Literacy, 49(1), 28-36.

DeJean, W. (2010). Courageous conversations: Reflections on a queer life narrative model. The teacher educator, 45, 233-243. 
Doll, M. A. (1998). Queering the gaze. In W. Pinar (Ed.), Queer theory in education. (pp. 287-298). Mahwah, NJ: Lawrence Erlbaum.

Driscoll, J. F. (1910). Paschal Lamb. In The Catholic Encyclopedia. New York: Robert Appleton Company. Retrieved November, 2016 from http://www.newadvent.org/cathen/08755a.htm

Endo, H., Reece-Miller, P. C., \& Santavicca, N. (2010). Surviving in the trenches: A narrative inquiry into queer teachers' experiences and identity. Teaching and Teacher Education, 26, 1023-1030.

Evans, K. (2002). Negotiating the self: Identity, sexuality, and emotion in learning to teach. New York, NY: RoutledgeFalmer.

Everitt, J. B. (2010). The experience of Catholic, gay and lesbian, Catholic secondary school teachers within northern. California: A participatory action research study. (Doctoral dissertation). Retrieved from ProQuest (3411411).

Fals-Borda, O. (2001). Participatory (action) research in social theory: Origins and challenges. In P. Reason \& H. Bradbury (Eds.). Handbook of action research: participative inquiry and practice (pp. 27-37). London: Sage Publishing.

Feldmeier, P. (2016). What is spirituality? Interview with U.S. Catholic. Retrieved from http://www.uscatholic.org/articles/201604/what-spirituality-30626

Ferfolja, T. (2005). Institutional silence: Experience of Australian lesbian teachers working in Catholic high schools. Journal of Gay \& Lesbian Issues in Education, 2(3), 51-66. 
Ferfolja, T. (2014). Reframing queer teacher subjects: Neither in nor out but present. In

A. Harris \& E. M. Gray (Eds.). Queer teachers, identity and performativity (pp. 29-44). New York, NY: Palgrave Macmillan .

Ferguson, D. L., \& Ferguson, P. M. (2000). Qualitative research in special education: toward an open inquiry instead of a new orthodoxy? Journal of the Association for Persons with Severe Handicaps, 25(3), 180-185.

Ferguson, J. M. (2013). Queering methodologies: Challenging scientific constraint in the appreciation of queer and trans subjects. The Qualitative Report, 18(25), $1-13$.

Fine, M. (2009). Sexuality, schooling, and adolescent females: The missing discourse of desire. In A. Darder, M. P. Baltodano, \& R. D. Torres (Eds.), The critical pedagogy reader (2nd ed; pp. 240-261). New York, NY: Routledge.

Fine, M. Torre, M. E., Boudin, K., Bowen, I., Clark, J., Hylton, D., Martinez, M., “Missy”, Rivera, M., Roberts, R. A., Smart, P., \& Upegui, D. (2003a). Participatory action research: within and beyond bars. In P. Camic, J. E. Rhodes, \& L. Yardley (Eds.), Qualitative research in psychology: Expanding perspctives in methodology and design. (pp. 173-198). Washington, DC: APA.

Fine, M., Weis, L. Weseen, S., \& Wong, L. (2003b). For whom? Qualitative research, representations, and social responsibilities. In N. K. Denzin \& Y. S. Lincoln (Eds.), The landscape of qualitative research (2nd ed., pp. 167207). Thosand Oaks, CA: Sage Publications. 
Ford, T. (2103). My research journey: Contributing to a new education story for Maori. In M. Berryman, S. SooHoo, \& A. Nevin (Eds.), Culturally responsive methodologies (pp. 245-261). Bingly, UK: Emerald Group.

Foucault, M. (1977). Discipline and punish: The birth of the prison, (A. Sheridan, trans.). New York, NY: Pantheon Books.

Foucault, M. (1978). The history of sexuality. Volume I: An introduction, (R. Hurley, trans.). New York, NY:Vantage. E-book version.

Freire, N. (2014, October 25). The presence of Paulo Freire at Chapman University. Paper presented at the Critical Scholars Symposium: Teaching Critically and Democratically in Times of Crisis, at Chapman University in Orange, California.

Freire, P. (2000). Pedagogy of the oppressed. New York, NY: Continuum.

Freire, P. (2001). Pedagogy of freedom. New York, NY: Continuum.

Freire, P. (2007). Pedagogy of the heart. New York, NY: Continuum.

Getz, C., \& Kirkley, E. (2006). Shaking up the status quo: Challenging intolerance of the lesbian, gay and bisexual at a private Roman Catholic university. College Student Journal, 40(4), 857-869.

Giroux, H. G. (2009a). Critical theory and educational practice. In A. Darder, M. P. Baltodano, and R. D. Torres (Eds.), The critical pedagogy reader (2nd ed; pp. 27-51). New York, NY: Routledge.

Giroux, H. G. (2009b). Teacher education and democratic schooling. In A. Darder, M. P. Baltodano, and R. D. Torres (Eds.), The critical pedagogy reader (2nd ed; pp. 438-59). New York, NY: Routledge. 
Glassman, M., \& Erdem, G. (2014). Participatory action research and its meanings: Vivencia, praxis, and conscientization. Adult Education Quarterly, 64(3), 206-221.

Glynn, T. (2013). Me Nohotahi, mahitahi, haeretahi, tātou: Collaborative partnerships between indigenous and non-indigenous researchers (Māori and Pākehā). In M. Berryman, S. SooHoo, \& A. Nevin, (Eds.), Culturally responsive methodologies (pp. 35-52). Bingly, UK: Emerald Group.

Graves, K. L. (2009). And they were wonderful teachers: Florida's purge of gay and lesbian teachers. Chicago, IL: University of Illinois Press.

Gray, E. M. (2013). Coming out as a lesbian, gay or bisexual teacher: Negotiating private and professional worlds. Sex Education, 13(6), 702-714.

Gray, E. M. (2014). LGBTQ teachers and the location of difference in English schools. In A. Harris \& E. M. Gray (Eds.). Queer teachers, identity and performativity (pp.75-89). New York, NY: Palgrave Macmillan .

Gray, E. M., \& Harris, A. (2014). Introduction: Marked presence/unremarkable absence: Queer teachers, 'identity' and performativity. In A. Harris \& E. M. Gray (Eds.), Queer teachers, identity and performativity (pp.1-10). New York, NY: Palgrave Macmillan .

Greene, M. (2009). In search of a critical pedagogy. In A. Darder, M. P. Baltodano, \&

R. D. Torres (Eds.), The critical pedagogy reader (2nd ed; pp. 84-96). New York, NY: Routledge.

Griffin, P. (1991). From hiding out to coming out: Empowering lesbian and gay educators. In K. M. Harbeck (Ed.). Coming out of the classroom closet: 
Gay and lesbian students, teachers, and curricula (pp. 167-196).

Binghamton, NY: Harrington Park Press.

Gust, S. W. (2007). Look out for the football players and the frat boys":

Autoethnographic reflections of a gay teacher in a gay curricular experience. Educational Studies, 41(1), 43-60.

Gutierrez, G. (1973). A theology of liberation (15th ed.). Maryknoll, NY: Orbis Books. Harbeck, K. M. (1991a). Introduction. In K. M. Harbeck (Ed.), Coming out of the classroom closet: Gay and lesbian students, teachers, and curricula (pp.17). New York: Harrington Park Press.

Harbeck, K. M. (1991b). Gay and lesbian educators: Past history/future prospects. In K. M. Harbeck (Ed.). Coming out of the classroom closet: Gay and lesbian students, teachers, and curricula. (pp. 121-140). New York: Harrington Park Press.

Harris, A., \& Jones, T. (2014). Trans teacher experiences and failure of visibility. In A. Harris \& E. M. Gray (Eds.). Queer teachers, identity and performativity (pp.11-28). New York, NY: Palgrave Macmillan .

Harrison, J., MacGibbon, L., \& Morton, M. (2001). Regimes of trustworthiness in qualitative research: The rigors of reciprocity. Qualitative Inquiry, 7(3), 323-345.

Hawking, S. W. (1975). Particle creation by black holes. Communications in Mathematical Physics 43, 199-220. (The original paper.)

Herr, K., \& Anderson, G. L. (2005). The action research dissertation: A guide for students and faculty. Thousand Oaks, CA: Sage Publications. 
Holland, J., \& Henriot, P. (1983). Social analysis: Linking faith and justice. Maryknoll, NY: Orbis.

hooks, b. (1994). Teaching to transgress: Education as the practice of freedom. New York, NY: Routledge.

hooks, b. (2009). Confronting class in the classroom. In A. Darder, M. P. Baltodano, \& R. D. Torres (Eds.), The critical pedagogy reader (2nd ed; pp. 135-41). New York, NY: Routledge.

Jackson, J. (2010). “How do you spell homosexual?” Naturally queer moments in K-12 classrooms. InternationalJjournal of Critical Pedagogy, 3(1),36-51.

Jackson, J. M., (2007). Reclaiming queerness: Self identity, and the research process. Journal of Research Practice, 3(1), 1-8.

Jagose, A. (1996). Queer theory: An introduction. New York, NY: New York University Press.

Jankie, D. (2011). “Tell me who you are": Problematizing the construction and positionalities of "insider"/"outsider" of a "native" ethnographer in a postcolonial context. In K. Mutua \& B. B. Swadener (Eds.) Decolonizing research in cross-cultural contexts: Critical personal narratives. New York, NY: State University of New York.

John Paul II. (1991, May 1). Centesimus annus. Vatican City: Liberia Editrice Vaticana. John Paul II. (1984, December 2). Reconciliatio et paenitencia. Vatican City: Liberia Editrice Vaticana.

John Paul II. (1998, September 4). Fides et Ratio. Vatican City: Liberia Editrice Vaticana. 
John Paul II. (2006). Man and woman he created them: A theology of the body. (M. Waldstein, trans.). Boston, MA: Pauline.

Juul, T. P. (1995). Community and conformity: A national survey contrasting rural, suburban, and urban lesbian, gay male, and bisexual public school teachers. Paper presented at the annual meeting of the American Educational Research Association, San Francisco, CA.

Kahn, R. (2009).Towards ecopedagogy: Weaving a broad-based pedagogy of liberation for animals, nature, and the oppressed people of the earth. In A. Darder, M. P. Baltodano, \& R. D. Torres (Eds.), The critical pedagogy reader (2nd ed; pp. 522-40). New York, NY: Routledge.

Kelly, M. B. (2007). Seduced by grace: Contemporary spirituality, gay experience and Christian faith. Melbourne: Clouds of Magellan.

Khayatt, D. (1999). Sex and pedagogy: Performing sexualities in the classroom. GLQ: A Journal of Lesbian and Gay Studies, 5(1), 107-113.

King, M. L. (1958/2010). The power of nonviolent action. In C. Lemert (Ed.) Social theory: The multicultural and classic readings (4th ed., 351-353). Boulder, CO: Westview.

Kosciw, J. G., Greytak, E. A., Palmer, N. A., \& Boesen, M. J. (2014). The 2013 national school climate survey: The experiences of lesbian, gay, bisexual and transgender youth in our nation's schools. New York, NY: GLSEN.

Kumashiro, K. K. (2002). Troubling education: queer activism and antioppressive pedagogy. New York, NY: Routledge. 
Kumashiro, K. K. (2009). Against common sense: Teaching and learning toward social justice. New York, NY: Routledge.

LeMatser, B. (2011). Queer imang(in)ing: Liminality as resistance in Lindqvist's "Let the Right One In." Communication and Critical/Cultural Studies, 8(2), 103123.

Leo XIII. (1891). Rerum Novarum. Vatican City: Liberia Editrice Vaticana.

Lepherd, L. (2015). Spirituality: Everyone has it, but what is it?. International Journal of Nursing Practice, 21(5), 566-574.

Litton, E. F. (1999, April). Stories of courage and hope: Gay and lesbian catholic school teachers. Paper presented at the annual meeting of the American Educational Research Association, Montreal, Canada.

Luhmann, S. (1998). Queering/querying pedagogy? Or, pedagogy is a pretty queer thing. In W. Pinar. (Ed.) Queer theory in education (pp. 141-156). Mahwah, NJ:Lawrence Erlbaum.

Macey, D. (2000). Dictionary of critical theory. London: Penguin.

Macfarlane, S. (2013). To acquiesce and to coalesce: Achieving alignment and unity for Māori through culturally responsive and socially responsible research. In M. Berryman, S. SooHoo, \& MacGillivray, I. K., (2008). My former students' reflections on having an openly gay teacher in high school. Journal of LGBT Youth, 5(4), 72-91.

Maher, M. J. (2007). Gay and lesbian students in Catholic high schools: A qualitative study of alumni narratives. A journal of inquiry \& practice, 10(4), 449472. 
Martin, S. P. \& Litton, E. F. (2004). Equity, advocacy and diversity:Nnew directions for

Cathoilc schools. Washington, DC: National Catholic Education

Association.

McCarthy, L. (2010). Wearing my identity: A transgender teacher in the classroom.

Equity \& Excellence in Education, 36(2), 170-183.

McLaren, P. (1988). The liminal servant and the ritual roots of critical pedagogy.

Language Arts, 65(2), 164-180.

McLaren, P. (1999). Schooling as a ritual performance: Towards a political economy of educational symbols and gestures (3rd ed.). New York, NY: Rowman and Littlefield.

McLaren, P. (2003). Life in schools: An introduction to critical pedagogy in the foundations of education (4th ed.). San Francisco, CA: Allyn and Bacon. McLaren, P. (2009). Critical pedagogy: A look at the major concepts. In A. Darder, M. P. Baltodano, \& R. D. Torres (Eds.), The critical pedagogy reader (2nd ed; pp. 61-83). New York, NY: Routledge.

Merriam-Webster Dictionay. (n.d.). Autodidactic. Retreived from http://www.merriamwebster.com/dictionary/autodidactic

Meyer, M. A. (2001). Our own liberation: Reflections on Hawaiian epistemology. The Contemporary Pacific, 13(1), 123-198.

Milne, A. (2013). Colouring in the white spaces: Cultural-identity and learning in schools (Doctoral dissertation, University of Waikato). Retreieved from: http://www.academia.edu/4425445/Colouring_in_the_White_Spaces_Recl aiming_Cultural_Identity_in_Whitestream_Schools_Ph_D_Thesis 
Morris, V. W. (2013). A river connects us: Crossing the waters on the foundation of culturally responsive and socially responsible research. In M. Berryman, S. SooHoo, \& A. Nevin (Eds.), Culturally responsive methodologies (pp. 53-68). Bingly, UK: Emerald Group.

Moss, G. (2004). Provisions of trustworthiness in critical narrative research: Bridging intersubjectivity and fidelity. The qualitative report, 9(2), 359-374.

National Conference of Catholic Bishops. (1997). Always our children: A pastoral message to homosexual children and suggestions for pastoral ministers. Washington DC: USCCB Publishing.

Neary, A., (2014). Teachers and civil partnership: (Re)producing legitimate subjectivities in the straight spaces of schools. In A. Harris \& E. M. Gray (Eds.), Queer teachers, identity and performativity (pp.45-59). New York, NY: Palgrave Macmillan .

Nevin, A. (Eds.), Culturally responsive methodologies (pp. 129-148). Bingly, UK: Emerald Group.

Nevin, A. (2013). Deconstructing my positivist paradigm: Making room for culturally responsive methodology. In M. Berryman, S. SooHoo, \& A. Nevin (Eds.), Culturally responsive methodologies (pp. 107-127). Bingly, UK: Emerald Group.

New Advent. (n.d.). Liturgy. Retrieved from http://www.newadvent.org/cathen/09306a.htm

Nicolosi, J. (2009). Shame and attachment loss: The practical work of reparative therapy. Downers Grove, IL: Intervarsity. 
Nixon, D., \& Givens, N. (2004). 'Miss, you're so gay.' Queer stories from trainee teachers. Sex Education, 4(3), 217-237.

Nygreen, K. (2010). Critical delimmas in PAR: Toward a new theory of engaged research for social change. Social Justice, 36 (4), 14-35.

Oldenski, T. (1997). Liberation theology and critical pedagogy in today's Catholic schools: Social justice in action. New York, NY: Garland Publishing.

Park, P. (1999). People, knowledge, and change in participatory research. Management Learning, 30(2),141-157.

Park, P. (2001). Knowledge and participatory research. In P. Reason \& H. Bradbury. (Eds.) Handbook of action research: Participative inquiry and practice (pp. 81-90). London:Sage.

Paul VI. (1972, January 1). If you want peace, work for justice. Vatican City: Liberia Editrice Vaticana.

Pinar, W. (1998a). Introduction. In W. Pinar. (Ed.) Queer theory in education (pp. 1-39). Mahwah, NJ:Lawrence Erlbaum.

Pinar, W. (1998b). Undertsanding curriculum as gender text: Notes on reproduction, ressistance, and male-male relations. In W. Pinar. (Ed.) Queer theory in education (pp. 1837-202). Mahwah, NJ:Lawrence Erlbaum.

Pope Benedict XVI. (2009). Caritas in veritate. Vatican City: Liberia Editrice Vaticana. Pope Francis. (2013a). General Audience. Video presented in Saint Peter's Square. Available from https://w2.vatican.va/content/francesco/en/audiences/2013/documents/pap a-francesco_20131002_udienza-generale.html 
Pope Francis. (2013b, October 9). General Audience. Retrieved from

http://w2.vatican.va/content/francesco/en/audiences/2013/documents/papa -francesco_20131009_udienza-generale.html

Pope Francis. (2015). Laudato si'. Vatican City: Liberia Editrice Vaticana.

Pope John Paul II. (1981). Familiaris consortio. Vatican City: Liberia Editrice Vaticana.

Rasmussen, M. L., (2004). Wounded identities: Sex and pleasure: "Doing it" at school. Not! Discourse: Studies in the Cultural Politics of Education, 25(4), 445458.

Ratzinger, J. (1984, August 6). Instructions on certain aspects of the "theology of liberation." Vatican City: Liberia Editrice Vaticana.

Rofes, E. (2000). Young adult reflections on having an openly gay teacher during early adolescence. Education \& urban society, 32(3), 399-412.

Rogers, M. (2012). Contextualizing theories and practices of bricolage research. The qualitative report, 17(7), 1-17.

Rohr, R. (2002, March 15). The tomb as liminal space: Some contemporary versions.

National Catholic Reporter, p. 11. (Also found at https://www.highbeam.com/doc/1G1-84307016.html)

Romero, O. (2003). The violence of love (J. R. Brockman, trans.). Bruderhof Foundation. E-book version retrieved from http://servicioskoinonia.org/biblioteca/pastoral/RomeroBrockmanViolence OfLove.pdf

Rudoe, N. (2010). Lesbian teachers' identity, power and the public/private boundary. Sex education, 10(1), 23-36. 
Rudoe, N. (2014). Out in Britain: The politics of sexuality, education, and lesbian and gay teachers in schools. In A. Harris \& E. M. Gray (Eds.), Queer teachers, identity and performativity (pp.60-74). New York, NY: Palgrave Macmillan .

Sacred Congregation for the Doctrine of the Faith. (1994). Catechism of the Catholic

Church. Vatican City: Liberia Editrice Vaticana.

Sears, J. T. (1998). A generational and theoretical analysis of culture and male (homo)sexuality. In W. Pinar (Ed.), Queer theory in education (pp. 73106). Mahwah, NJ: Lawrence Erlbaum.

Second Vatican Council. (1965a). Gaudium et Spes. In N. Tanner, S. J. (Ed.), Vatican II: The essential texts (pp. 189-298). New York, NY: First Image. Second Vatican Council. (1965b). Nostra Aetate. In N. Tanner, S. J. (Ed.), Vatican II: The essential texts (pp. 319-328). New York, NY: First Image.

Sedgwick, E. K. (1990). Epistemology of the closet. Los Angeles, CA: University of California Press.

Siope, A. (2013). 'A culturally responsive pedagogy of relations': Coming to understand. Waikato Journal of Education: Te Hautaka Mātauranga o Waikato, 18(2), $37-49$.

Skjoldager-Nielsen, K., \& Edelman, J. (2014). Liminality. Ecumenica, 7(1-2). 1-6. Smith, L. T. (1999). Decolonizing methodologies: Research and indigenous peoples. Dunedin, New Zealand.

Sobrino, J. (1993). Jesus the liberator: A historical, theological reading of Jesus of Nazareth. Maryknoll, NY: Orbis. 
SooHoo, S. (2013). Humility within culturally responsive methodologies. In M. Berryman, S. SooHoo, \& A. Nevin, (Eds.), Culturally responsive methodologies (pp. 199-220). Bingly, UK: Emerald Group.

Stonebanks, C. D. (2008). An Islamic perspective on knowledge, knowing and methodology. In N. Denzin, Y. Lincoln, \& L. Smith (Eds.), Handbook of critical and indigenous methodologies. Los Angeles, CA: Sage Publications.

Sullivan, N. (2003). A critical introduction to queer theory. New York: NY: University Press.

Taylor, D. M. (2011). Identity negotiation: An intergenerational examination of lesbian and gay band directors. Research \& Issues in Music Education, 9(1), 1-14.

Tierney, W. G., \& Dilley, P. (1998). Constructing knowledge, educational research, and gay and lesbian studies. In W. Pinar. (Ed.) Queer theory in education (pp. 49-72). Mahwah, NJ:Lawrence Erlbaum.

Tillich, P. (2014). The courage to be (3rd ed.). New Haven, CT: Yale Univerity Press. Trebilcock, M. (2016). Theology in context: Liminality. Colloquium, 48(1), 74-85. Tutu, D. (1994). The rainbow people of God: The making of a peaceful revolution. New York, NY: Doubleday.

United States Conference of Catholic Bishops. (2006). Ministry to persons with a homosexual inclination: Guidelines for pastoral care. Washington DC: USCCB Publishing.

Vatican II. Gaudium et Spes. (1965, December 7). Retrieved December 5, 2014. 
Wilson, A. (2013). Errant wanderings amongst the voices on the margins. In M. Berryman, S. SooHoo, \& A. Nevin (Eds.), Culturally responsive methodologies (pp. 245-261). Bingly, UK: Emerald Group.

Wimberly, G. L. (Ed.). (2015). LGBTQ issues in education: Advancing a research agenda. Washington, DC: AERA

Wojtyla, K. (1960). Love and responsibility (H. T. Willetts, trans.). San Francisco, CA: Ignatius.

Woods, S. E., \& Harbeck, K. M. (2012). Living in two worlds: The identity management strategies used by lesbian physical educators. In K. M. Harbeck (Ed.), Coming out of the classroom closet: Gay and lesbian students, teachers, and curricula (pp. 141-166). Binghamton, NY: Harrington Park Press.

Yadegari, M. (1986). Liberation theology and Islamic revivalism. Journal of religious thought, 43(2), 38-50.

Yoshino, K. (2006). Covering: the hidden assault on our civil rights. New York, NY: Random House. 
Appendix A: Consent Letter

\section{CHAPMAN UNIVERSITY \\ ONE UNIVERSITY DR. \\ ORANGE, CA 92866}

$\begin{array}{ll}\text { FACULTY ADVISOR: } & \begin{array}{l}\text { Suzanne SooHoo, PhD } \\ \text { College of Educational Studies } \\ 714-997-6781 \\ \text { soohoo@chapman.edu }\end{array} \\ & \text { Kevin Stockbridge } \\ \text { STUDENT } & \text { College of Educational Studies } \\ \text { 213-800-3064 } \\ \text { Stock124@mail.chapman.edu }\end{array}$

You are being invited to participate in a research study. Participation in this study is completely voluntary. Please read the information below and ask questions about anything that you do not understand.

PURPOSE:

The purpose of this study is to explore the meaning of queerness in Catholic schools as understood by queer-identified teachers employed by these institutions.

NUMBER OF PARTICIPANTS \& STUDY LOCATION:

This study will include up to six participants who will meet at a location agreeable and accessible to all the participants.

\section{QUALIFICATION(S) TO PARTICIPATE:}

You may participate in this study if you are over the age of 18 , currently employed as a teacher by a Catholic elementary or high school, and identify as queer.

\section{PROCEDURES:}

The study will involve six group meetings for 60-90 minutes in which experiences of queer teachers in Catholic schools will be shared and analyzed by the participants.

\section{BENEFITS:}

This study has no direct benefit to the participants involved. It is possible that participation may benefit your well-being through the sharing of personal stories with others who have similar experiences. The benefit of the study to society is a better 
understanding of the experiences of queer persons in Catholic institutions providing potential insight into issues of justice and educational equity.

RISKS:

Participants engaging in the study may experience the following: anxiety and discomfort in sharing personal stories with others.

PRIVACY \& CONFIDENTIALITY:

No personally identifiable information will be recorded in the data collected for this study. No video or audio recording will take place.

COMPENSATION, REIMBURSEMENT, COSTS:

You will not be compensated for your participation in this study.

CONTACT INFORMATION:

Kevin Stockbridge, Student Investigator

Stock124@mail.chapman.edu

QUESTIONS OR COMMENTS RELATED TO STUDY:

If you have any comments or questions regarding the conduct of this research, your participation in the study, or about the consent form, contact a member from the research team listed above.

TO REPORT A CONCERN:

If you would like to report a concern about the study or the informed consent process, you may contact Chapman University's Institutional Review Board, Office of Research and Sponsored Programs Administration by phone (714)-628-7392 or (714) 628-2805, by email at irb@chapman.edu, or by mail at Chapman University, ORSPA, One University Dr., Orange, CA 92866.

You should not sign this consent form until all of your questions about this study have been answered. You will be given a copy of this signed and dated consent form to keep. Participation in this study is completely voluntary. You may refuse to answer any questions or discontinue your involvement at any time without penalty or loss of benefits to which you might otherwise be entitled. Your decision will not affect your future relationship with Chapman University, student status or employment.

If I agree to participate in the study, I will receive a signed copy of this form and a copy of the Research Participant's Bill of Rights.

\section{By signing this document I am indicating that I have read the above information and consent to participate in the research.}


Printed Name of Participant

Signature of Participant

Date

Signature of Investigator

Date 
Appendix B: Retreat Outline

\title{
PeculiarPresences in Sacred Halls Retreat April 22-24 $4^{\text {th }}, 2016$
}

\author{
FRIDAY \\ 9:30- Snacks, Introductions, and Social Time \\ Return Home \\ Sleep \\ SATURDAY \\ 9am-Breakfast \\ loam-Research /ntroduction \\ 10:30-1 $1 \mathrm{pm}-$ What is My Story? \\ 11-12am Examen One \\ 12-12:30pm-Break/Personal Time \\ 12:30pm - Working Lunch \\ 1:30-2:30pm-Examen Two \\ 2:30-3 pm-Break/Personal Time \\ 2:30-3:30pm - Examen Three \\ 3:30-4:30pm-Break/Personal Time \\ 4:30- 5:30pm- Examen Four \\ 5:30-6pm-Break/Personal Time \\ 6-9pm- Dinner, Chill Time and Community Building! \\ Wrap Up Thoughts \\ SUINDAY \\ 8 am- Working Breakfast \\ Where Do We Go From Here? \\ 9:30am-Depart to Airport \\ 11:30am-Goodbye Lunch
}


Appendix C: Coded Statements

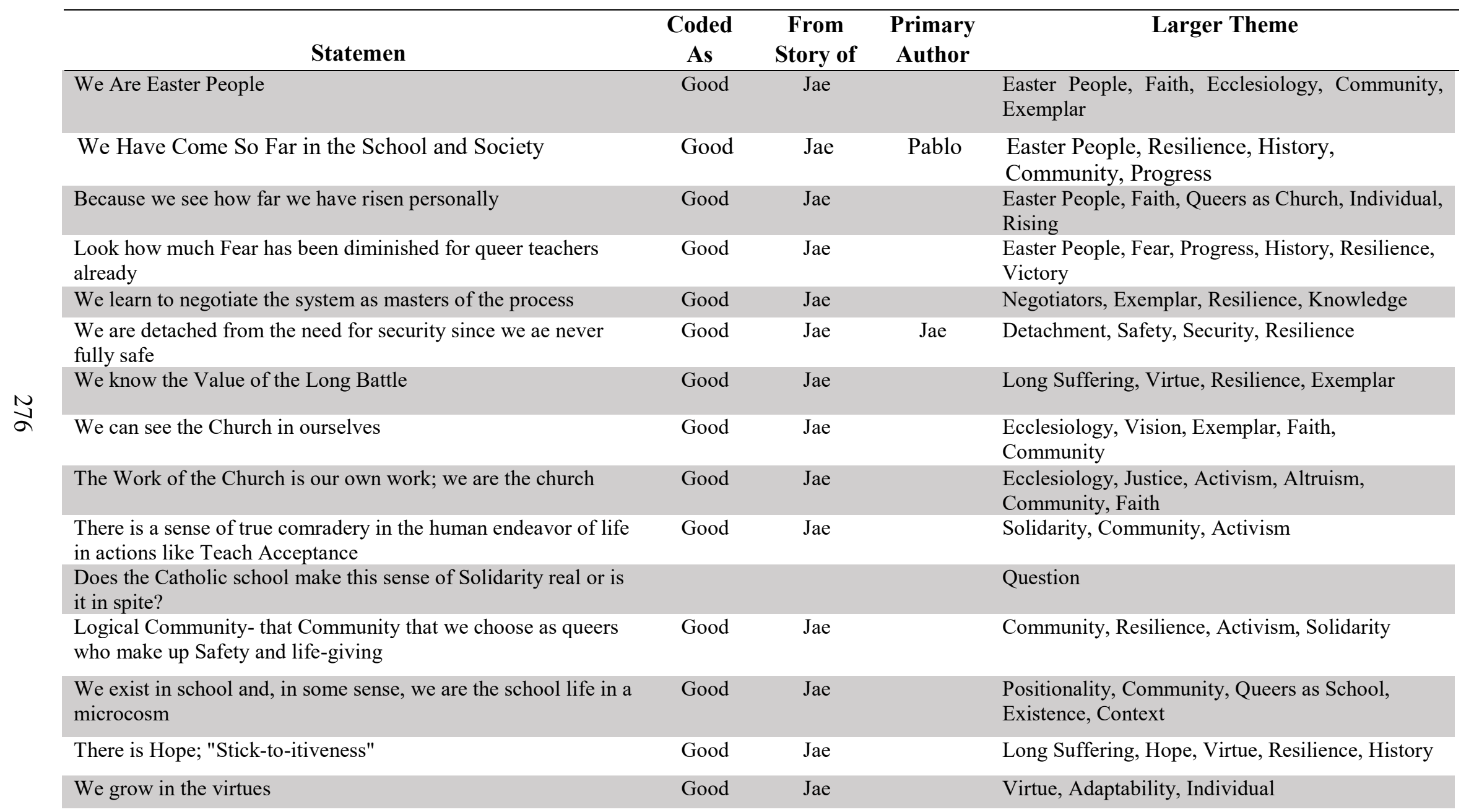


We build love in our school Community by creating Relationships with youth an adults in things like Teach

Acceptance

We build love by being there for students in a way that we never

had in schools

We are healed by making the school a better place for the queer

youth coming up after us

Building resiliency comes through learning how to deal with the

obstacles in our life in schools

We represent an alternate lifestyle

We show that there are different paths for moving through life

We are a safe spece for those who don't fit into the norm because of the pressures of school, expected life timelines, due to sexual phobias, or any number of non-normative experiences.

We show that there is no one way to be a man or woman

Our lives call into question the gendered school "tag lines" of ou schools

We work against the "Macho Watcho" vibe that can permeate a

school Community

By being in personal Relationships with others in our schools we transform the sense of justice and Solidarity in our Community

When we make friends and share our sexuality with others we put a face on the issue at hand with queer teachers and students

We call people to Stand for Justice (Catalyst)

We harken the Church to be attentive to the sensus fidelium

We show that the locus of Solidarity is in the work of justice in our current cry for right treatment

We can validate the lived reality of people by being authentic

(with ourselves, relatives, and friends) ????

Our struggles can gather a Community of support in our schools

We can witness to love in a new way through our lives

We become the exceptions to the rules, especially when the leadership is non-Catholic
Good Jae

Virtue, Solidarity, Love, Teach Acceptance

ove, Solidarity, Students, Future, Activism

Healing, School, Students, Future, Activism

Good Jae

Resiliency, Obstacles

Good

Jae

Alternatives, Exemplar

Good Pablo

Alternatives, Students, Exemplar, Activism, Future

Good Pablo

Safety, School, Norm, Pressure, Phobia, Exemplar

Good Pablo Alternatives, Gender, Exemplar, Students

Good Pablo

Pablo

Good

Pablo

Matteo

Gention, Activism, Exemplar, School,

Norms, Mantras

Discerning Presence

Solidarity, Relationships, Activism, Justice,

Exemplar, Students, Community

Good Pablo Community, Relationships, Exemplar, School, Faculty, Students

Good Pablo Catalyst, Justice, Activism, School

Good Pablo

Reformers, Activism, Faith, Justice, Challenge

Good Pablo

Solidarity, Justice, Activism, Demand

Good Pablo Validation, Exemplar, Justice, Queer, Relationship

Good Pablo

Good Pablo

Good Pablo

Pablo

Community, Activism, Struggle, Relationship, School, Students

Love, Faith, Witness, Exemplar

Exception, Faith, Exemplar, Leadership 


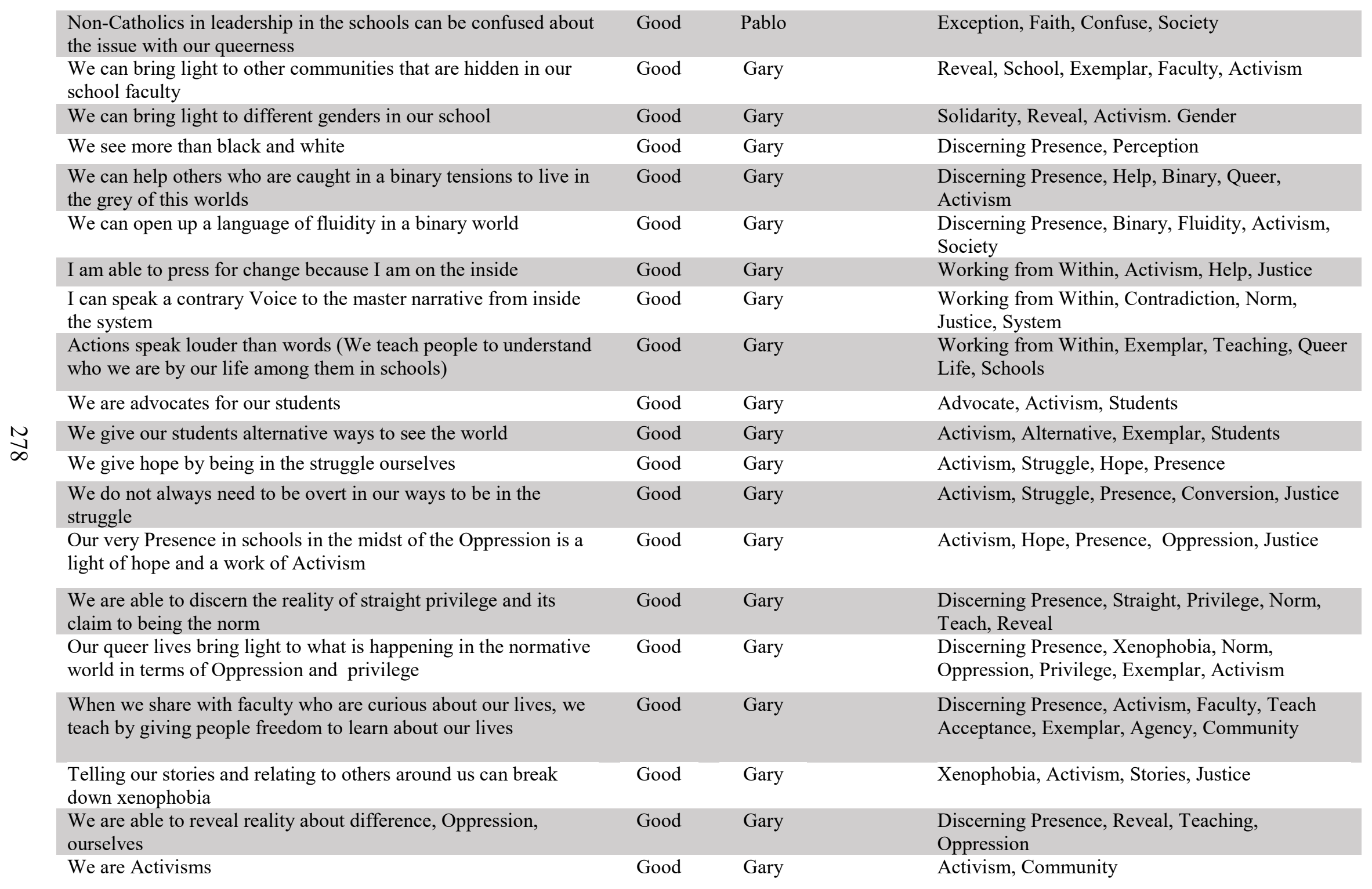




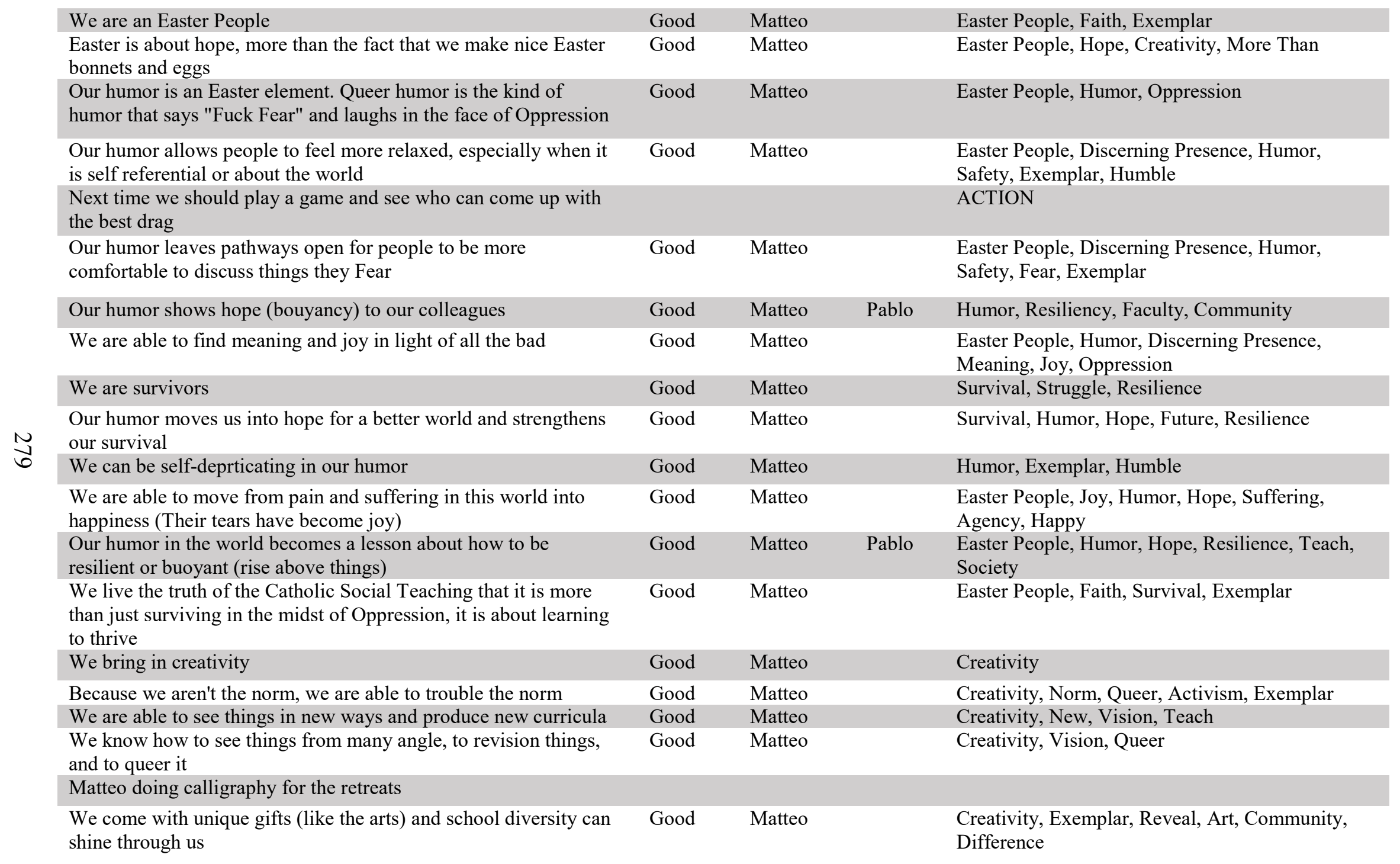




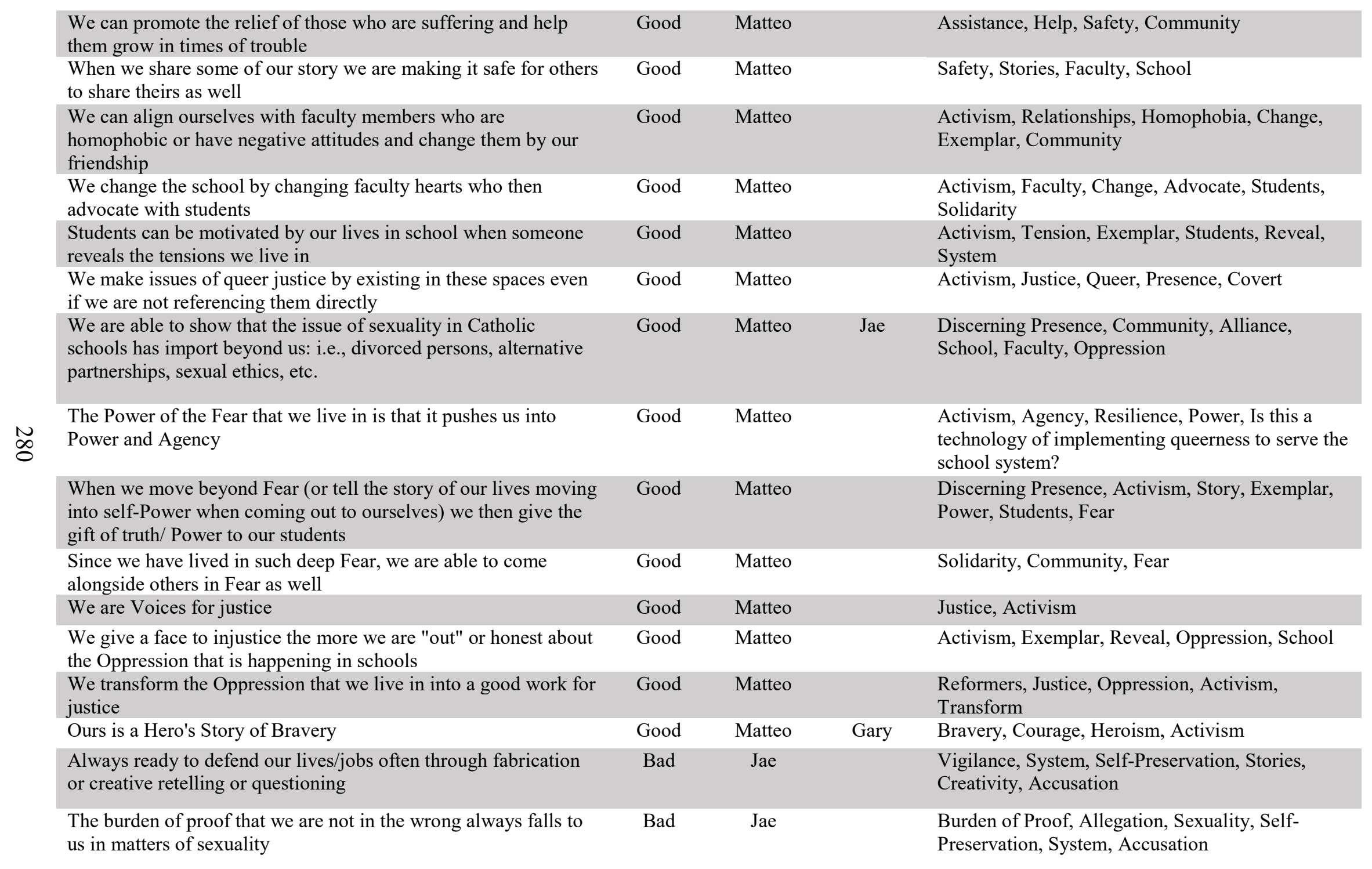




\begin{tabular}{|c|c|c|c|}
\hline Continual sense of Insecurity & Bad & $\mathrm{Jae}$ & Insecurity, Safety \\
\hline Administration cannot offer us security in our jobs & $\mathrm{Bad}$ & Jae & Administration, Safety, Insecurity, School \\
\hline $\begin{array}{l}\text { We experience bullying from our students and they get no } \\
\text { repercussions sometimes }\end{array}$ & $\mathrm{Bad}$ & Jae & Bullying, Administration, Student, Inequality \\
\hline We are the objects of bullying & $\mathrm{Bad}$ & $\mathrm{Jae}$ & Bullying, Administration, Exemplar \\
\hline We live in paranoia & Bad & Jae & Insecurity, Safety, Fear \\
\hline $\begin{array}{l}\text { Our students become a potential Threat to us, even as we are } \\
\text { trying to care for them }\end{array}$ & $\mathrm{Bad}$ & Jae & $\begin{array}{l}\text { Insecurity, Double Bind, Safety, Students, Help, } \\
\text { Expectation, Threat }\end{array}$ \\
\hline Our Shepherds become our enemies & $\mathrm{Bad}$ & Jae & $\begin{array}{l}\text { Insecurity, Double Bind, Safety, Faith, Enemies, } \\
\text { Expectation, Threat }\end{array}$ \\
\hline There is no sense of security & Bad & Jae & Insecurity, Safety \\
\hline $\begin{array}{l}\text { Small victories are typical for us rather than large wins in our } \\
\text { efforts }\end{array}$ & $\mathrm{Bad}$ & Jae & Struggle, Victory, Activism, Small \\
\hline $\begin{array}{l}\text { Others do not understand that the struggle is often a forward and } \\
\text { back kind of process, we take two steps forward but then take a } \\
\text { few steps back }\end{array}$ & $\mathrm{Bad}$ & Jae & $\begin{array}{l}\text { Struggle, Insecurity, Process, Activism, Not } \\
\text { Understood }\end{array}$ \\
\hline $\begin{array}{l}\text { We find that we must be constantly on alert in order to learn } \\
\text { resiliency }\end{array}$ & $\mathrm{Bad}$ & Jae & $\begin{array}{l}\text { Struggle, Insecurity, Resilience, Vigilance, } \\
\text { Learning, Expectation }\end{array}$ \\
\hline $\begin{array}{l}\text { The life of the school never gives us a chance to be on break } \\
\text { from the Vigilance }\end{array}$ & $\mathrm{Bad}$ & Jae & $\begin{array}{l}\text { Struggle, Insecurity, Vigilance, Safety, School, } \\
\text { Expectation }\end{array}$ \\
\hline $\begin{array}{l}\text { Ours is a resiliency above and beyond the normal load of } \\
\text { pressure dealt with by the norm }\end{array}$ & $\mathrm{Bad}$ & Jae & $\begin{array}{l}\text { Struggle, Resilience, Norm, Exemplar, } \\
\text { Expectation }\end{array}$ \\
\hline $\begin{array}{l}\text { We keep "taking it" until we learn to get used to it (when do we } \\
\text { fight back?) }\end{array}$ & $\mathrm{Bad}$ & Jae & Oppression, Struggle, Activism, Abuse \\
\hline $\begin{array}{l}\text { We know that the things in life that bring us joy (marriage, } \\
\text { Relationships, our identity) can and are read by others in school } \\
\text { in a negative light }\end{array}$ & $\mathrm{Bad}$ & Pablo & $\begin{array}{l}\text { Life, Relationships, School, Negative, } \\
\text { Interpretation, Exemplar, Love }\end{array}$ \\
\hline $\begin{array}{l}\text { We need to constantly monitor ourselves in school, not to share } \\
\text { our joys lest they become negative images of us }\end{array}$ & $\mathrm{Bad}$ & Pablo & $\begin{array}{l}\text { Vigilance, Negative, Interpretation, Safety, } \\
\text { Relationships, School, Fear }\end{array}$ \\
\hline $\begin{array}{l}\text { Our own Community of friends is Threatened by their association } \\
\text { with us (Can the people who love us even support us?) }\end{array}$ & $\mathrm{Bad}$ & Pablo & $\begin{array}{l}\text { Community, Isolation, Threat, Love, Safety, } \\
\text { Relationships }\end{array}$ \\
\hline $\begin{array}{l}\text { "Catholic Identity" has been employed as a catch } \\
\text { phrase/movement that is a Risk to queer teachers in schools }\end{array}$ & Bad & Pablo & Faith, Mantra, Safety, Insecurity, Threat \\
\hline
\end{tabular}




\begin{tabular}{|c|c|c|c|}
\hline $\begin{array}{l}\text { We have no say in the final analysis...the decisins about our lives } \\
\text { are made beyond us and often without full consultation...the } \\
\text { choice to fire us has been made based on accusations before we } \\
\text { get a chance to talk }\end{array}$ & $\mathrm{Bad}$ & Pablo & $\begin{array}{l}\text { Voice, Agency, Administration, Employment, } \\
\text { Accusation, Insecurity, Power }\end{array}$ \\
\hline $\begin{array}{l}\text { We know what is really going on because we have seen the } \\
\text { hidden lives of others (esp. clergy) }\end{array}$ & $\begin{array}{c}\text { Good/ } \\
\text { Bad }\end{array}$ & Pablo & Secrets, Vision, Knowledge, Power, Faith \\
\hline We hold Power when we know the secret queer lives of others & Good & Matteo & Power, Secrets, Queers, Relationships \\
\hline $\begin{array}{l}\text { We are made to live with hypocracy on the issue which Threatens } \\
\text { our security the most }\end{array}$ & $\mathrm{Bad}$ & Pablo & Insecurity, School, Faith, Lies, Safety \\
\hline $\begin{array}{l}\text { Ministerial exception to legal protections for teachers has been } \\
\text { extended to all teachers in Catholic schools or is being tried to in } \\
\text { order to make firing easier }\end{array}$ & $\mathrm{Bad}$ & Pablo & $\begin{array}{l}\text { Faith, Safety, Administration, School, Society, } \\
\text { Employment, Law, Exemplar }\end{array}$ \\
\hline $\begin{array}{l}\text { To be seen as a minister in the work of education was once } \\
\text { positive but now becomes a Threat to queer teachers }\end{array}$ & Bad & Pablo & Double Bind, Faith, Threat, Employment, Law \\
\hline $\begin{array}{l}\text { Firings remind us that the Church is looking at two real issues in } \\
\text { their decisions: one is the question of poverty as when a teacher } \\
\text { loses their position and struggles to be employed, the other is the } \\
\text { question of moral acceptability as in the case of queer lives going } \\
\text { against teaching of the Faith...in the end it is the morality issue } \\
\text { that wins out, it is ultimately about the teachings and not the } \\
\text { person }\end{array}$ & $\mathrm{Bad}$ & Pablo & $\begin{array}{l}\text { Faith, Discerning Presence, Administration, } \\
\text { School, Worth }\end{array}$ \\
\hline $\begin{array}{l}\text { We must live with Power being manipulated in ways that always } \\
\text { protect the school and Church }\end{array}$ & Bad & Pablo & Safety, Power, Faith, School \\
\hline We are not able to trust others to look out for our best interest & Bad & Pablo & Trust, Relationships, Safety \\
\hline $\begin{array}{l}\text { We have to condition ourselves that we don't want public } \\
\text { recognition for our lives because of the constraints we live in }\end{array}$ & Bad & Pablo & Hidden, Life, Safety, Threat, System, Recognition \\
\hline $\begin{array}{l}\text { Recognition for others in the school can be a moment of } \\
\text { Community building but for us it can become a Threat }\end{array}$ & $\mathrm{Bad}$ & Pablo & $\begin{array}{l}\text { Community, Relationships, Activism, School, } \\
\text { Threat }\end{array}$ \\
\hline $\begin{array}{l}\text { Recognition that is given to us can become a space for } \\
\text { Community for the queer Community if it is present }\end{array}$ & Good & Pablo & $\begin{array}{l}\text { Community, Recognition, Presence, Queer, } \\
\text { Exemplar, Activism }\end{array}$ \\
\hline We live in a limbo & $\mathrm{Bad}$ & Pablo & Insecurity, Safety \\
\hline $\begin{array}{l}\text { We find ourselves assisting the queer, questioning, and struggling } \\
\text { students while we must remain silent ourselves }\end{array}$ & Bad & Pablo & Voice, Agency, Help, Students, Activism \\
\hline $\begin{array}{l}\text { We must play a dance between how public we can be in our lives } \\
\text { in our school and how much we can share }\end{array}$ & $\mathrm{Bad}$ & Pablo & Public, School, Agency, Limitations, Safety \\
\hline
\end{tabular}


If we marry, it must be secret (you can choose secret marriages in California) so that we can work

Our choice is to hide our love or be open about our joys

Queer love is limited in its expression because I cannot bring my

full loving self to the table

I must be reminded that I am intrinsically Disordered

Queer teachers are stuck in the cycling thoughts of "how can this be wrong or seen as evil?"

We are not able to bring stories of love for Fear of the

consequence

Queer students need mentors in the life ahead of them but our

forced silence does not allow us to help them to negotiate the

LGBTQ world

Our depression can enable us to be able to help students who go through the same (this is the redemption of suffering)

Pregnancy and lesbian identity is especially difficult because if a lesbian woman wants to be pregnant she must disappear because

of the questions that come about the pregnancy

\section{Queer people must often pretend that they do not have children at} all

When a gay man has a child, no one questions how the child

came to be because he can hide behind the assumed

heteronormative discourse...lesbian women cannot

Our discussion was limited by lack of gender representation

Even as gay men we can see the kind of Power and privelge that

we can wield that our lesbian counterparts cannot simply because of gender

Queer men are measured against gendered norms... we see this in

the kinds of language that is used to shame or negate a person

(you talk like girls, etc.)

Queer existence is always seen as a problem- administration always see us from a problematic viewpoint and speak in that way
Bad Pablo Relationships, Secrets, Employment, Safety, School Happiness, Hidden, Love, Safety, Agency

Love, Queer, Voice, Hidden, Division, Presence

Disorder, Told, Learn, Exemplar

Questioning, Doubt, Confusion

Bad Pablo

ablo

Story, Love, Fear, Presence, School, Silence

Bad Pablo

Pablo

Students, Help, Exemplar, Silence, Activism

Bad Pablo Students, Help, Exemplar, Silence, Activism

\section{Good Final Day Pablo Struggle, Redemption, Faith, Students, Help,} Activism

Bad Gary Gender, Relationships, Safety, Hidden, Pregnancy,

Children, Secrets

Secrets, Hidden, Children, Employment

Bad Gary Children, Gender, Hidden, Covering, Exemplar

$\mathrm{Bad}$

ary

Children, Gender, Hidden, Covering, Exemplar

$\begin{array}{lll}\text { Bad } & \text { Gary } & \text { Gender, Limitations } \\ \text { Bad } & \text { Gary } & \text { Power, Gender, School }\end{array}$

Norms, Gender, Queer, Life, Assumption,
Expectation

Bad Gary

Presence, Problem, School, Safety,

Administration, Stories 
We rarely get acknowledged for the gifts that our queerness

$\mathrm{Bad}$

Gary

Recognition, Gifts, Presence, Forgotten, Gratitude

brings (Could there be thankfulness for the queer Presence?)

Relationships among same sex are limited in their expression in a Bad Gelationships, Binary, Limitation, Norms, Gender

way that brings everything into a binary

While students may express a very fluid manner in which they

$\mathrm{Bad}$

Gary

Relationships, Fluidity, Norm, Students, Adults,

relate (touch, romance, talk) we find that our institutions make

sense of them in a way that moves towards the normative...this is

a phase and not acceptable for adult relating

Queer teachers are unprotected $\quad$ Bad Gary Insecurity, Safety, School

In our dioceses we see that in the hierarchy there are those who Bad Gary Faith, Threat, Morals, School, Church, Enemy,

are Threats to us because of their positions to oversee morality in

schools (aka: anti-queer) [Bishops and Superintendents]

Our principals are disempowered, even if they are in support of $\quad$ Bad Gary Sower, Administration, Church, System, Safety, us

Parents are given total Power (as stakeholders) to call us out on our queerness to the highest Powers and Threaten our jobs

$\infty$ Queer teachers rarely have a chance to authentically defend ourselves, once the stakeholder has pushed for our dismissal

Insecurity

When we are fired it comes swiftly and silences our rebuttal so as

to protect the administration from being called into question for our Presence

Administrators have their jobs on the line in places in which unions may protect teachers but the school leadership fall directly underneath the oversight of the hierarchy

\begin{tabular}{|c|c|c|c|}
\hline In dealing with queerness, there is no gray area or dialogue & $\mathrm{Bad}$ & Gary & $\begin{array}{l}\text { Queer, Morality, Discerning Presence, Voice, } \\
\text { Agency }\end{array}$ \\
\hline $\begin{array}{l}\text { We find ourselves afraid of possible parental attacks against us } \\
\text { for moral reasons }\end{array}$ & Bad & Gary & Parents, School, Safety, Morality \\
\hline $\begin{array}{l}\text { There is a sense of a story that we are child molestors that is } \\
\text { stirred up in the conversations of the sex scandal which blames } \\
\text { sex abuse on gay identity }\end{array}$ & $\mathrm{Bad}$ & Gary & Dangerous, Queerness, Stories, Faith, Exemplar \\
\hline
\end{tabular}

There is a sense that parents will think that we are trying to indoctrinate children "I don't want them to turn my kid gay"

Bad Gary

Employment, Power, Agency, Safety, Self-

Preservation, Protection, Voice

Bad Gary Employment, Silence, Protection, Administration, Presence, Firing

Administration, Protection, Faith, Hierarchy, Safety, System

Bad Gary 


\begin{tabular}{|c|c|c|c|}
\hline $\begin{array}{l}\text { Uber conservative parents hold to moral orthodoxy and are adept } \\
\text { at dismantling progressive theology by putting it in a frame of } \\
\text { Faithful v unFaithful teachings...it becomes a kind of neo- } \\
\text { inquisition which is happening in the Church today }\end{array}$ & Bad & Gary & $\begin{array}{l}\text { Conservatism, Morality, Reframing, Insecurity, } \\
\text { Safety, Inquisition }\end{array}$ \\
\hline $\begin{array}{l}\text { When we work within the system, there is a danger that we might } \\
\text { be seen as advocating the very oppressive system we are a part of }\end{array}$ & $\mathrm{Bad}$ & Gary & $\begin{array}{l}\text { Within, System, Advocating, Oppression, Norm, } \\
\text { Contradiction }\end{array}$ \\
\hline $\begin{array}{l}\text { There is a real economic need that I am dealing with and the } \\
\text { Power to have an income is squarely in the hands of the school, } \\
\text { so I can only work from within to a certain extent }\end{array}$ & $\mathrm{Bad}$ & Gary & $\begin{array}{l}\text { Employment, Insecurity, Limitation, Within, } \\
\text { Power, School }\end{array}$ \\
\hline $\begin{array}{l}\text { I internalize myself as dangerous and so I keep safe by: not } \\
\text { seeking promotion, working harder than others, and hold off on } \\
\text { having children }\end{array}$ & $\mathrm{Bad}$ & Gary & $\begin{array}{l}\text { Oppression, Danger, Safety, Limitations, Children, } \\
\text { Power }\end{array}$ \\
\hline $\begin{array}{l}\text { Queers have to work harder just to prove that they are as good as } \\
\text { any other worker... we see this in careers across our society }\end{array}$ & Bad & Gary & Expectation, Queer, Burden of Proof, Exemplar \\
\hline We are on constant Vigilance & Bad & Gary & Vigilance, Constant, Safety, Insecurity \\
\hline $\begin{array}{l}\text { There must be care taken to know what is brought into the public } \\
\text { and what remains private; you speak a code of your "roommate } \\
\text { and dog" instead of partner and child }\end{array}$ & $\mathrm{Bad}$ & Gary & $\begin{array}{l}\text { Public and Private, Hidden, Code, Stories, } \\
\text { Vigilance, Relationships }\end{array}$ \\
\hline $\begin{array}{l}\text { Queers must always ask who they can be comfortable with in the } \\
\text { school and share a bit about their life }\end{array}$ & $\mathrm{Bad}$ & Gary & $\begin{array}{l}\text { Queer, Discerning Presence, Safety, Comfort, } \\
\text { School }\end{array}$ \\
\hline Heterosexual lives are the strict norm & $\mathrm{Bad}$ & Gary & Norms, Heterosexuality \\
\hline Xenophobia, more than homophobia is the problem & Bad & Gary & Xenophobia, Queer, Fear \\
\hline $\begin{array}{l}\text { Fears of may kinds of difference exist in the Catholic school } \\
\text { (race, gender, sexuality, etc.) }\end{array}$ & Bad & Gary & Fear, Xenophobia, Race, Gender \\
\hline $\begin{array}{l}\text { We can more easily teach against xenophobia than teaching } \\
\text { against homophobia because it embrace others that are not seen } \\
\text { as morally objectionable }\end{array}$ & Good & Gary & Activism, Xenophobia, Morals, Teaching \\
\hline $\begin{array}{l}\text { There is a sexuality double standard; while heterosexual people } \\
\text { can talk about wife and children we cannot mention } \\
\text { partnerships...it is said that it is about not bringing sexuality into } \\
\text { the dialogue of school but you cannot have a child without } \\
\text { sex...HR becomes the overseeing Powers }\end{array}$ & $\mathrm{Bad}$ & Gary & $\begin{array}{l}\text { Double Bind, Children, Relationships, HR, Stories, } \\
\text { Sex }\end{array}$ \\
\hline We have a target on us & Bad & Matteo & Safety, Insecurity, Hunting \\
\hline $\begin{array}{l}\text { If we do certain things or speak on issues that connect to } \\
\text { queerness it becomes a Threat to us }\end{array}$ & $\mathrm{Bad}$ & Matteo & Threat, Hidden, Norm, Acting \\
\hline
\end{tabular}


Queers are both an object of interest while also being the locus of conflict in schools

We are scapegoats for other issues and thus feel more pressure

than others to comply (divorce, pedagogy, religious difference,

etc.)

Our effect on improving our lives in schools is indirect because

we need allies to speak on our behalf

The burden is on us to convince others that this issue is something they must fight for as well

The issues and psychoses of the writers of theology gets passed along with the teachings themselves (Augustine, Aquinas,

Luther, Puritans...) as the general milieu of sexuality

Homosexuality is focal point for the internalized shame present in our theology

Unrefined theology is lived and perpetuates the self-hatred of the

fathers of the teachings

There is an insistence that we are silent about the issue which

means that we are unable to re-story and transform theologies

through our lived experience (orthodoxy as norm)

\section{Queer live in Fear}

We know that there are real Risks that we experience as possibility (harm, rejection, loss of employment, etc.)

Our own Fear keeps us from being able to speak against the internalized Fears of our queer students because it is a Threat to us to help them

Queer Fears exist beyond the school but the Threats of the institution call to mind daily the Threats that we expeirnce on the streets (We encounter this violence in homilies as well)

Our institutions are very binary, teaching an "us and them" mentality

Queers feel the internal divide of "Love the sinner but hate the sin"

All issues are painted in the stark "good and bad" narrative
$\mathrm{Bac}$

$\mathrm{Bad}$

Matteo

Exemplar

Exemplar, Scapegoat, Relationships, Hidden

Bad Matteo Solidarity, Isolation, Limitation, Within,

Activism

Bad Matteo Burden of Proof, Activism, Solidarity

Bad Matteo Faith, Morals, Sexuality, Tradition, Milieu,

Teaching

$\begin{array}{ccl}\text { Bad } & \text { Matteo } & \begin{array}{l}\text { Exemplar. Shame, Morals, Oppression, Teaching, } \\ \text { Faith } \\ \text { Teaching, Stories, Self-Hatred, Oppression, } \\ \text { System, Students, Faith }\end{array} \\ \text { Faith, Stories, Voice, Norm, Silence, Activism } \\ \text { Matteo } & \text { Matteo } & \text { School, Fear, Queer } \\ \text { Bad } & \text { Matteo } & \text { Agency, Risk, Threat, Fear, Employment } \\ \text { Madteo } & \text { Matteo } & \text { Fear, Voice, Oppression, Students, Help, Advocate }\end{array}$

$\mathrm{Bad}$

Matteo

Fear, School, Threat, Society, Vigilance

Bad

Matteo

Matteo

Binary, Teaching, School, Us v. Them, Division,

Mentality

Bad Matteo Faith, Division, Binary, Mantra

Bad Matteo

Binary, Morals, Discerning Presence, Stories 


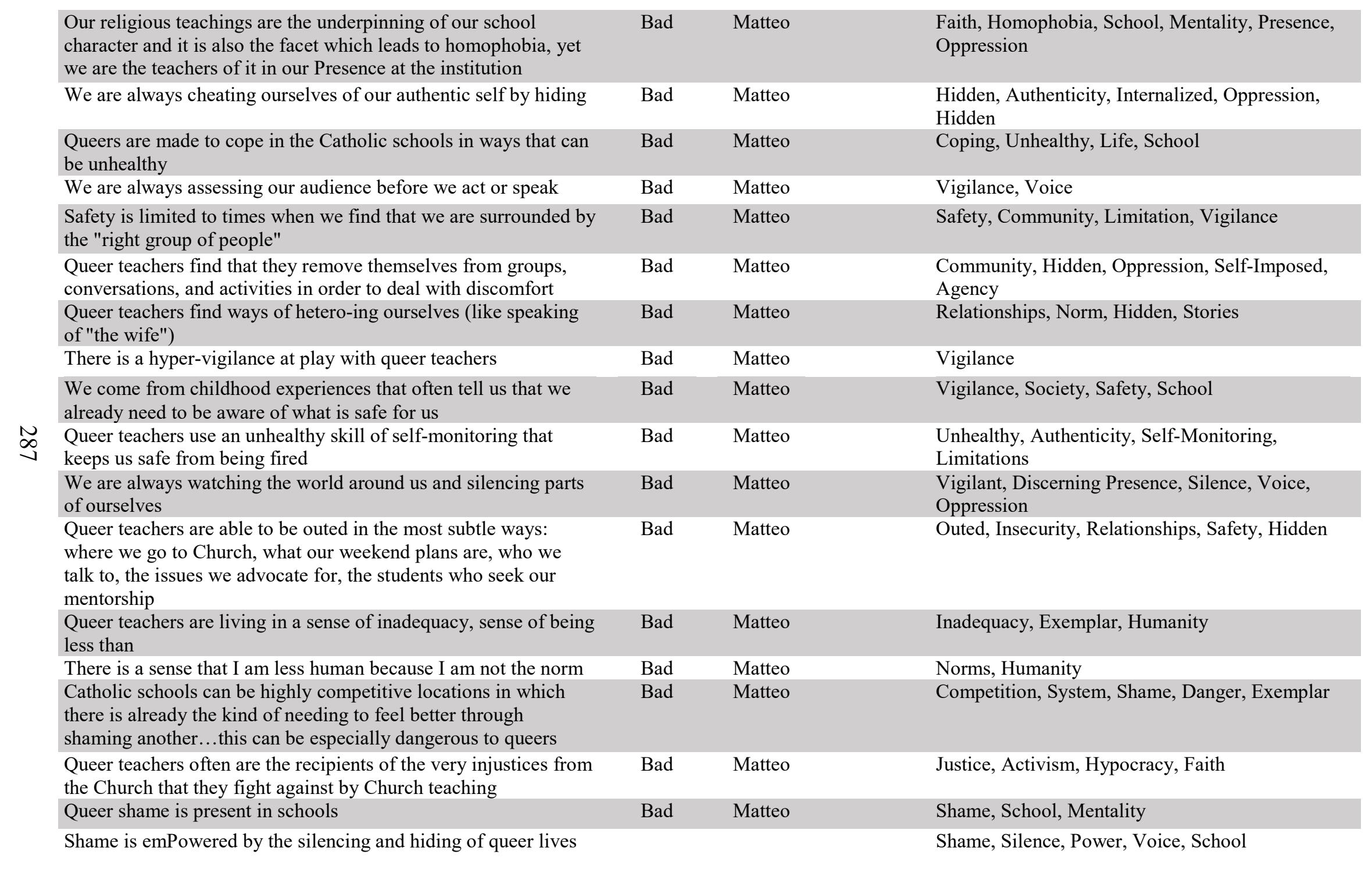


Shame is redoubled by means of the negative light put on queer teachers in : contracts, consequences, rumor mills in schools

which often seek to point out immorality, and the deferred shame that others don't want to feel and therefore can be placed on us as

scapegoats

Queer teachers must wrestle with the question "Am I good?"

We teach that all are made in the image and likeness of God and,

so, wish to show to our students that we are all good; yet the

shame placed upon us and lived in our hiding speaks against the teaching and hurts the students in believing this truth

We constantly find ourselves questioning our bravery

We are brave for even being in a Catholic school

There are real stakes at play that limit our struggle for justice

(job, family, promotion, student response, student benefit, etc.)
Bad

Matteo

Stories, System, Double Bind, Scapegoat

Bad Matteo

Matteo

Question, Self, Goodness, Stories, Queer, Faith

Bad Matteo

Faith, Students, Goodness, Shame

Bad

Matteo

Good

Matteo

Matteo

Courage, Doubt, Question

Presence, Faith, Activism

Struggle, Employment, Limitation, Safety 


\section{Appendix D: Theme Families}

\section{Unique Role}

We Are Easter People

We know the Value of the Long Battle

We can see the Church in ourselves

We represent an alternant lifestyle

We are a safe space for those who don't fit into the norm because of the pressures of school, expected life timelines, due to sexual phobias, or any number of nonnormative experiences.

We show that there is no one way to be a man or woman

Our lives call into question the gendered nature of school "tag lines" of our schools (Ex: "Being real men")

By being in personal Relationships with others in our schools we transform the sense of justice and Solidarity in our Community

When we make friends and share our sexuality with others we put a face on the issue at hand with queer teachers and students

We can validate the lived reality of people by being authentic (with ourselves, relatives, and friends)

We can witness to love in a new way through our lives

We become the exceptions to the rules, especially when the leadership is non-Catholic We can bring light to other communities that are hidden in our school faculty

Actions speak louder than words (We teach people to understand who we are by our life among them in schools)

We give our students alternative ways to see the world

Our queer lives bring light to what is happening in the normative world in terms of Oppression and privilege

When we share with faculty who are curious about our lives, we teach by giving people freedom to learn about our lives

We are an Easter People

Our humor allows people to feel more relaxed, especially when it is self referential or about the world

Our humor leaves pathways open for people to be more comfortable to discuss things they Fear

We can be self-deprecating in our humor

We live the truth of the Catholic Social Teaching that it is more than just surviving in the midst of Oppression, it is about learning to thrive

Because we aren't the norm, we are able to trouble the norm

We come with unique gifts (like the arts) and school diversity can shine through us 


\section{Community}

We Are Easter People

We Have Come So Far in the School and Society

We can see the Church in ourselves

The Work of the Church is our own work; we are the church

There is a sense of true comradery in the human endeavor of life in actions like Teach

Acceptance

Logical Community- that Community that we choose as queers who make up Safety and life-giving

We exist in school and, in some sense, we are the school life in a microcosm

By being in personal Relationships with others in our schools we transform the sense of justice and Solidarity in our Community

When we make friends and share our sexuality with others we put a face on the issue at hand with queer teachers and students

Our struggles can gather a Community of support in our schools

When we share with faculty who are curious about our lives, we teach by giving people freedom to learn about our lives

We are Activisms

Our humor shows hope (buoyancy) to our colleagues

We come with unique gifts (like the arts) and school diversity can shine through us

We can promote the relief of those who are suffering and help them grow in times of trouble

We can align ourselves with faculty members who are homophobic or have negative attitudes and change them by our friendship

We are able to show that the issue of sexuality in Catholic schools has import beyond us: i.e., divorced persons, alternative partnerships, sexual ethics, etc.

Since we have lived in such deep Fear, we are able to come alongside others in Fear as well

Our own Community of friends is Threatened by their association with us (Can the people who love us even support us?)

Recognition for others in the school can be a moment of Community building but for us it can become a Threat

Recognition that is given to us can become a space for Community for the queer Community if it is present

Safety is limited to times when we find that we are surrounded by the "right group of people"

Queer teachers find that they remove themselves from groups, conversations, and activities in order to deal with discomfort

Desire to build community between teachers in schools (queer)

Desire to have connections with queer teachers in schools beyond our own (like a union)... a fabu Union 
Gay teachers can have positive in coming together but, if one is not careful about who is brought into the collective it can go wrong

Not everyone gets along in the queer community and not all have a sense of trust/trustworthiness

Desire for a relief from the sense of Isolation

Teachers are afraid to come out to one another

Two schools exist that have a semi-community of queer teachers as represented in the participants

Desire for more of these meetings

There is a sadness of the loss of the gay culture and the gay locations (coffee shops, restaurants, bars, etc.)

Desire for a place for us to hear from our elders

It enables us to mentor each other and know how to mentor (we come to know our brothers and sisters)

Stories remind us that we are not alone

Relationship is the necessary element in drawing people together for a study of this kind (by the participants)

\section{Easter People/ Resilience}

We Are Easter People

We Have Come So Far in the School and Society

Because we see how far we have risen personally

Look how much Fear has been diminished for queer teachers already

We learn to negotiate the system as masters of the process

We are detached from the need for security since we ae never fully safe

We know the Value of the Long Battle

Logical Community- that Community that we choose as queers who make up Safety and life-giving

There is Hope; "Stick-to-itiveness"

We are an Easter People

Easter is about hope, more than the fact that we make nice Easter bonnets and eggs

Our humor is an Easter element. Queer humor is the kind of humor that says "Fuck

Fear" and laughs in the face of Oppression

Our humor allows people to feel more relaxed, especially when it is self referential or about the world

Our humor leaves pathways open for people to be more comfortable to discuss things they Fear

We are able to find meaning and joy in light of all the bad

We are survivors

Our humor moves us into hope for a better world and strengthens our survival

Our humor in the world becomes a lesson about how to be resilient or buoyant (rise above things)

We are able to move from pain and suffering in this world into happiness (Their tears have become joy) 
We live the truth of the Catholic Social Teaching that it is more than just surviving in the midst of Oppression, it is about learning to thrive

The Power of the Fear that we live in is that it pushes us into Power and Agency

We find that we must be constantly on alert in order to learn resiliency

The life of the school never gives us a chance to be on break from the Vigilance

Ours is a resiliency above and beyond the normal load of pressure dealt with by the norm

Building resiliency comes through learning how to deal with the obstacles in our life in schools

\section{Threat/Danger/Vigilance}

We live in paranoia

Our students become a potential Threat to us, even as we are trying to care for them

Our own Community of friends is Threatened by their association with us (Can the people who love us even support us?)

"Catholic Identity" has been employed as a catch phrase/movement that is a Risk to queer teachers in schools

We are made to live with hypocracy on the issue which Threatens our security the most

To be seen as a minister in the work of education was once positive but now becomes a Threat to queer teachers

We have to condition ourselves that we don't want public recognition for our lives because of the constraints we live in

Recognition for others in the school can be a moment of Community building but for us it can become a Threat

In our dioceses we see that in the hierarchy there are those who are Threats to us because of their positions to oversee morality in schools (aka: anti-queer) [Bishops and Superintendents]

Parents are given total Power (as stakeholders) to call us out on our queerness to the highest Powers and Threaten our jobs

There is a sense of a story that we are child molestors that is stirred up in the conversations of the sex scandal which blames sex abuse on gay identity

There is a sense that parents will think that we are trying to indoctrinate children "I don't want them to turn my kid gay"

When we work within the system, there is a Danger that we might be seen as advocating the very oppressive system we are a part of

I internalize myself as Dangerous and so I keep safe by: not seeking promotion, working harder than others, and hold off on having children

If we do certain things or speak on issues that connect to queerness it becomes a Threat to us

We know that there are real Risks that we experience as possibility (harm, rejection, loss of employment, etc.) 
Our own Fear keeps us from being able to speak against the internalized Fears of our queer students because it is a Threat to us to help them

Queer Fears exist beyond the school but the Threats of the institution call to mind daily the Threats that we expeirnce on the streets (We encounter this violence in homilies as well)

Catholic schools can be highly competitive locations in which there is already the kind of needing to feel better through shaming another...this can be especially Dangerous to queers

Gay teachers can have positive in coming together but, if one is not careful about who is brought into the collective it can go wrong

\section{Power}

We have no say in the final analysis...the decisins about our lives are made beyond us and often without full consultation... the choice to fire us has been made based on accusations before we get a chance to talk

We know what is really going on because we have seen the hidden lives of others (esp. clergy)

We hold Power when we know the secret queer lives of others

We must live with Power being manipulated in ways that always protect the school and Church

Even as gay men we can see the kind of Power and privelge that we can wield that our lesbian counterparts cannot simply because of gender

Our principals are disemPowered, even if they are in support of us

Parents are given total Power (as stakeholders) to call us out on our queerness to the highest Powers and Threaten our jobs

Queer teachers rarely have a chance to authentically defend ourselves, once the stakeholder has pushed for our dismissal

There is a real economic need that I am dealing with and the Power to have an income is squarely in the hands of the school, so I can only work from within to a certain extent

I internalize myself as Dangerous and so I keep safe by: not seeking promotion, working harder than others, and hold off on having children

There is a sexuality double standard; while heterosexual people can talk about wife and children we cannot mention partnerships... it is said that it is about not bringing sexuality into the dialogue of school but you cannot have a child without sex...HR becomes the overseeing Powers

Shame is emPowered by the silencing and hiding of queer lives

Schools should have better labor organization

Teachers should have more of a voice (in the decisions being made about them)

There should be a plurality of voices (in the decisions made in schools and teachers lives)

Desire to have connections with queer teachers in schools beyond our own (like a union).... a fabu Union

They stated that this is also a huge risk in trying to make this possible. 


\section{Oppression}

We are always watching the world around us and silencing parts of ourselves

Queer teachers find that they remove themselves from groups, conversations, and activities in order to deal with discomfort

We are always cheating ourselves of our authentic self by hiding

Our religious teachings are the underpinning of our school character and it is also the facet which leads to homophobia, yet we are the teachers of it in our Presence at the institution

Our own Fear keeps us from being able to speak against the internalized Fears of our queer students because it is a Threat to us to help them

Unrefined theology is lived and perpetuates the self-hatred of the fathers of the teachings

I internalize myself as Dangerous and so I keep safe by: not seeking promotion, working harder than others, and hold off on having children

When we work within the system, there is a Danger that we might be seen as advocating the very oppressive system we are a part of

We keep "taking it" until we learn to get used to it (when do we fight back?)

We transform the Oppression that we live in into a good work for justice

We give a face to injustice the more we are "out" or honest about the Oppression that is happening in schools

We are able to show that the issue of sexuality in Catholic schools has import beyond us: i.e., divorced persons, alternative partnerships, sexual ethics, etc.

We live the truth of the Catholic Social Teaching that it is more than just surviving in the midst of Oppression, it is about learning to thrive

We are able to find meaning and joy in light of all the bad

Our humor is an Easter element. Queer humor is the kind of humor that says "Fuck Fear" and laughs in the face of Oppression

We are able to reveal reality about difference, Oppression, ourselves

Our queer lives bring light to what is happening in the normative world in terms of Oppression and privilege

Our very Presence in schools in the midst of the Oppression is a light of hope and a work of Activism

\section{School/Faculty/Students}

We Have Come So Far in the SCHOOL and Society

We exist in SCHOOL and, in some sense, we are the SCHOOL life in a microcosm We build love by being there for Students in a way that we never had in SCHOOLs

We are healed by making the SCHOOL a better place for the queer youth coming up after us

We show that there are different paths for moving through life

We are a safe space for those who don't fit into the norm because of the pressures of SCHOOL, expected life timelines, due to sexual phobias, or any number of nonnormative experiences.

We show that there is no one way to be a man or woman 
Our lives call into question the gendered SCHOOL "tag lines" of our SCHOOLs

We work against the "Macho Watcho" vibe that can permeate a SCHOOL Community

By being in personal Relationships with others in our SCHOOLs we transform the sense of justice and Solidarity in our Community

When we make friends and share our sexuality with others we put a face on the issue at hand with queer teachers and Students

We call people to Stand for Justice (Catalyst)

Our struggles can gather a Community of support in our SCHOOLs

We can bring light to other communities that are hidden in our SCHOOL Faculty

We are advocates for our Students

We give our Students alternative ways to see the world

When we share with Faculty who are curious about our lives, we teach by giving people freedom to learn about our lives

Our humor shows hope (buoyancy) to our colleagues

When we share some of our story we are making it safe for others to share theirs as well

We change the SCHOOL by changing Faculty hearts who then advocate with Students

We can align ourselves with Faculty members who are homophobic or have negative attitudes and change them by our friendship

Students can be motivated by our lives in SCHOOL when someone reveals the tensions we live in

We are able to show that the issue of sexuality in Catholic SCHOOLs has import beyond us: i.e., divorced persons, alternative partnerships, sexual ethics, etc.

When we move beyond Fear (or tell the story of our lives moving into self-Power when coming out to ourselves) we then give the gift of truth/ Power to our Students administrationistration cannot offer us security in our jobs

We experience bullying from our Students and they get no repercussions sometimes We are the objects of bullying

Our Students become a potential Threat to us, even as we are trying to care for them We need to constantly monitor ourselves in SCHOOL, not to share our joys lest they become negative images of us

We know that the things in life that bring us joy (marriage, Relationships, our identity) can and are read by others in SCHOOL in a negative light

We have no say in the final analysis...the decisins about our lives are made beyond us and often without full consultation... the choice to fire us has been made based on accusations before we get a chance to talk

Ministerial exception to legal protections for teachers has been extended to all teachers in Catholic SCHOOLs or is being tried to in order to make firing easier

Firings remind us that the Church is looking at two real issues in their decisions: one is the question of poverty as when a teacher loses their position and struggles to be employed, the other is the question of moral acceptability as in the case of queer lives going against teaching of the Faith...in the end it is the morality issue that wins out, it is ultimately about the teachings and not the person

We must live with Power being manipulated in ways that always protect the SCHOOL and Church 
Recognition for others in the SCHOOL can be a moment of Community building but for us it can become a Threat

We find ourselves assisting the queer, questioning, and struggling Students while we must remain silent ourselves

We must play a dance between how public we can be in our lives in our SCHOOL and how much we can share

If we marry, it must be secret (you can choose secret marriages in California) so that we can work

We are not able to bring stories of love for Fear of the consequence

Queer Students need mentors in the life ahead of them but our forced Silence does not allow us to help them to negotiate the LGBTQ world

Our depression can enable us to be able to help Students who go through the same (this is the redemption of suffering)

Even as gay men we can see the kind of Power and privelge that we can wield that our lesbian counterparts cannot simply because of gender

Queer existence is always seen as a problem-administration - always see us from a problematic viewpoint and speak in that way

While Students may express a very fluid manner in which they relate (touch, romance, talk) we find that our institutions make sense of them in a way that moves towards the normative...this is a phase and not acceptable for adult relating

Queer teachers are unprotected

In our dioceses we see that in the hierarchy there are those who are Threats to us because of their positions to oversee morality in SCHOOLs (aka: anti-queer) [Bishops and Superintendents]

Our principals are disemPowered, even if they are in support of us

When we are fired it comes swiftly and Silences our rebuttal so as to protect the administration from being called into question for our Presence

Administrators have their jobs on the line in places in which unions may protect teachers but the SCHOOL leadership fall directly underneath the oversight of the hierarchy

We find ourselves afraid of possible parental attacks against us for moral reasons

There is a real economic need that I am dealing with and the Power to have an income is squarely in the hands of the SCHOOL, so I can only work from within to a certain extent

Queers must always ask who they can be comfortable with in the SCHOOL and share a bit about their life

Unrefined theology is lived and perpetuates the self-hatred of the fathers of the teachings

Our own Fear keeps us from being able to speak against the internalized Fears of our queer Students because it is a Threat to us to help them

Queer Fears exist beyond the SCHOOL but the Threats of the institution call to mind daily the Threats that we expeirnce on the streets (We encounter this violence in homilies as well)

Our institutions are very binary, teaching an "us and them" mentality 
Our religious teachings are the underpinning of our SCHOOL character and it is also the facet which leads to homophobia, yet we are the teachers of it in our Presence at the institution

Queers are made to cope in the Catholic SCHOOLs in ways that can be unhealthy

We come from childhood experiences that often tell us that we already need to be aware of what is safe for us

Queer shame is present in SCHOOLs

Shame is emPowered by the Silencing and hiding of queer lives

We teach that all are made in the image and likeness of God and, so, wish to show to our Students that we are all good; yet the shame placed upon us and lived in our hiding speaks against the teaching and hurts the Students in believing this truth

Schools should have better labor organization

Don't ask, don't tell culture is super strong in the Catholic schools

\section{Relationships/Children}

When we make friends and share our sexuality with others we put a face on the issue at hand with queer teachers and Students

We can validate the lived reality of people by being authentic (with ourselves, relatives, and friends)

Our struggles can gather a Community of support in our SCHOOLs

We can align ourselves with Faculty members who are homophobic or have negative attitudes and change them by our friendship

We know that the things in life that bring us joy (marriage, Relationships, our identity) can and are read by others in SCHOOL in a negative light

We need to constantly monitor ourselves in SCHOOL, not to share our joys lest they become negative images of us

Our own Community of friends is Threatened by their association with us (Can the people who love us even support us?)

We hold Power when we know the secret queer lives of others

We are not able to trust others to look out for our best interest

Recognition for others in the SCHOOL can be a moment of Community building but for us it can become a Threat

Pregnancy and lesbian identity is especially difficult because if a lesbian woman wants to be pregnant she must disappear because of the questions that come about the pregnancy

Relationships among same sex are limited in their expression in a way that brings everything into a binary

While Students may express a very fluid manner in which they relate (touch, romance, talk) we find that our institutions make sense of them in a way that moves towards the normative...this is a phase and not acceptable for adult relating 
There must be care taken to know what is brought into the public and what remains private; you speak a code of your "roommate and dog" instead of partner and child

There is a sexuality double standard; while heterosexual people can talk about wife and children we cannot mention partnerships... it is said that it is about not bringing sexuality into the dialogue of SCHOOL but you cannot have a child without sex...HR becomes the overseeing Powers

We are scapegoats for other issues and thus feel more pressure than others to comply (divorce, pedagogy, religious difference, etc.)

Queer teachers find ways of hetero-ing ourselves (like speaking of "the wife")

Queer teachers are able to be outed in the most subtle ways: where we go to Church, what our weekend plans are, who we talk to, the issues we advocate for, the Students who seek our mentorship

I internalize myself as Dangerous and so I keep safe by: not seeking promotion, working harder than others, and hold off on having Children

There is a sense that parents will think that we are trying to indoctrinate Children "I don't want them to turn my kid gay"

When a gay man has a child, no one questions how the child came to be because he can hide behind the assumed heteronormative discourse...lesbian women cannot Queer people must often pretend that they do not have Children at all

\section{Activism}

The Work of the Church is our own work; we are the church

There is a sense of true comradery in the human endeavor of life in actions like Teach Acceptance

Logical Community- that Community that we choose as queers who make up Safety and life-giving

We build love by being there for students in a way that we never had in schools

We are healed by making the school a better place for the queer youth coming up after us

We show that there are different paths for moving through life

Our lives call into question the gendered school "tag lines" of our schools

We work against the "Macho Watcho" vibe that can permeate a school Community

By being in personal Relationships with others in our schools we transform the sense of justice and Solidarity in our Community

We call people to Stand for Justice (Catalyst)

We harken the Church to be attentive to the sensus fidelium

We show that the locus of Solidarity is in the work of justice in our current cry for right treatment

Our struggles can gather a Community of support in our schools

We can bring light to other communities that are hidden in our school faculty

We can bring light to different genders in our school 
We can help others who are caught in a binary tensions to live in the grey of this worlds

We can open up a language of fluidity in a binary world

I am able to press for change because I am on the inside

I can speak a contrary Voice to the master narrative from inside the system

We are advocates for our students

We give our students alternative ways to see the world

We give hope by being in the struggle ourselves

We do not always need to be overt in our ways to be in the struggle

Our very Presence in schools in the midst of the Oppression is a light of hope and a work of Activism

Our queer lives bring light to what is happening in the normative world in terms of Oppression and privilege

When we share with faculty who are curious about our lives, we teach by giving people freedom to learn about our lives

Telling our stories and relating to others around us can break down xenophobia

We are Activisms

Because we aren't the norm, we are able to trouble the norm

We can align ourselves with faculty members who are homophobic or have negative attitudes and change them by our friendship

We change the school by changing faculty hearts who then advocate with students

Students can be motivated by our lives in school when someone reveals the tensions we live in

We make issues of queer justice by existing in these spaces even if we are not referencing them directly

The Power of the Fear that we live in is that it pushes us into Power and Agency

When we move beyond Fear (or tell the story of our lives moving into self-Power

when coming out to ourselves) we then give the gift of truth/ Power to our students

We are Voices for justice

We give a face to injustice the more we are "out" or honest about the Oppression that is happening in schools

We transform the Oppression that we live in into a good work for justice

Ours is a Hero's Story of Bravery

Small victories are typical for us rather than large wins in our efforts

Others do not understand that the struggle is often a forward and back kind of process, we take two steps forward but then take a few steps back

We keep "taking it" until we learn to get used to it (when do we fight back?)

Recognition for others in the school can be a moment of Community building but for us it can become a Threat

Recognition that is given to us can become a space for Community for the queer Community if it is present

We find ourselves assisting the queer, questioning, and struggling students while we must remain silent ourselves

Queer students need mentors in the life ahead of them but our forced silence does not allow us to help them to negotiate the LGBTQ world 
Our depression can enable us to be able to help students who go through the same (this is the redemption of suffering)

We can more easily teach against xenophobia than teaching against homophobia because it embrace others that are not seen as morally objectionable

Our affect on improving our lives in schools is indirect because we need allies to speak on our behalf

The burden is on us to convince others that this issue is something they must fight for as well

There is an insistence that we are silent about the issue which means that we are unable to re-story and transform theologies through our lived experience (orthodoxy as norm)

Queer teachers often are the recipients of the very injustices from the Church that they fight against by Church teaching

We are brave for even being in a Catholic school

\section{Voice/Silence}

Shame is emPowered by the silencing and hiding of queer lives

We are always watching the world around us and Silencing parts of ourselves

We are always assessing our audience before we act or speak

Our own Fear keeps us from being able to speak against the internalized Fears of our queer students because it is a Threat to us to help them

There is an insistence that we are silent about the issue which means that we are unable to re-story and transform theologies through our lived experience (orthodoxy as norm)

In dealing with queerness, there is no gray area or dialogue

When we are fired it comes swiftly and Silences our rebuttal so as to protect the administration from being called into question for our Presence

Queer teachers rarely have a chance to authentically defend ourselves, once the stakeholder has pushed for our dismissal

Queer love is limited in its expression because I cannot bring my full loving self to the table

We find ourselves assisting the queer, questioning, and struggling students while we must remain silent ourselves

We have no say in the final analysis...the decisins about our lives are made beyond us and often without full consultation... the choice to fire us has been made based on accusations before we get a chance to talk 
Agency

Queer teachers find that they remove themselves from groups, conversations, and activities in order to deal with discomfort

We know that there are real Risks that we experience as possibility (harm, rejection, loss of employment, etc.)

In dealing with queerness, there is no gray area or dialogue

Queer teachers rarely have a chance to authentically defend ourselves, once the stakeholder has pushed for our dismissal

Our choice is to hide our love or be open about our joys

We must play a dance between how public we can be in our lives in our school and how much we can share

We find ourselves assisting the queer, questioning, and struggling students while we must remain silent ourselves

We have no say in the final analysis...the decisins about our lives are made beyond us and often without full consultation... the choice to fire us has been made based on accusations before we get a chance to talk

The Power of the Fear that we live in is that it pushes us into Power and Agency

We are able to move from pain and suffering in this world into happiness (Their tears have become joy)

When we share with faculty who are curious about our lives, we teach by giving people freedom to learn about our lives

\section{Safety/Insecurity/Security}

There are real stakes at play that limit our struggle for justice (job, family, promotion, student response, student benefit, etc.)

Queer teachers are able to be outed in the most subtle ways: where we go to Church, what our weekend plans are, who we talk to, the issues we advocate for, the students who seek our mentorship

We come from childhood experiences that often tell us that we already need to be aware of what is safe for us

Safety is limited to times when we find that we are surrounded by the "right group of people"

We have a target on us

Queers must always ask who they can be comfortable with in the school and share a bit about their life

We are on constant Vigilance

I internalize myself as Dangerous and so I keep safe by: not seeking promotion, working harder than others, and hold off on having children

There is a real economic need that I am dealing with and the Power to have an income is squarely in the hands of the school, so I can only work from within to a certain extent 
Uber conservative parents hold to moral orthodoxy and are adept at dismantling progressive theology by putting it in a frame of Faithful $v$ unFaithful teachings... it becomes a kind of neo-inquisition which is happening in the Church today

We find ourselves afraid of possible parental attacks against us for moral reasons

Administrators have their jobs on the line in places in which unions may protect teachers but the school leadership fall directly underneath the oversight of the hierarchy

Queer teachers rarely have a chance to authentically defend ourselves, once the stakeholder has pushed for our dismissal

Our principals are disemPowered, even if they are in support of us

Queer teachers are unprotected

Queer existence is always seen as a problem- administration always see us from a problematic viewpoint and speak in that way

Pregnancy and lesbian identity is especially difficult because if a lesbian woman wants to be pregnant she must disappear because of the questions that come about the pregnancy

Our choice is to hide our love or be open about our joys

If we marry, it must be secret (you can choose secret marriages in California) so that we can work

We must play a dance between how public we can be in our lives in our school and how much we can share

We live in a limbo

We have to condition ourselves that we don't want public recognition for our lives because of the constraints we live in

We must live with Power being manipulated in ways that always protect the school and Church

Ministerial exception to legal protections for teachers has been extended to all teachers in Catholic schools or is being tried to in order to make firing easier

We are made to live with hypocracy on the issue which Threatens our security the most

We have no say in the final analysis...the decisins about our lives are made beyond us and often without full consultation... the choice to fire us has been made based on accusations before we get a chance to talk

"Catholic Identity" has been employed as a catch phrase/movement that is a Risk to queer teachers in schools

Our own Community of friends is Threatened by their association with us (Can the people who love us even support us?)

We need to constantly monitor ourselves in school, not to share our joys lest they become negative images of us

The life of the school never gives us a chance to be on break from the Vigilance

We find that we must be constantly on alert in order to learn resiliency

Others do not understand that the struggle is often a forward and back kind of process, we take two steps forward but then take a few steps back

There is no sense of security

Our Shepherds become our enemies

Our students become a potential Threat to us, even as we are trying to care for them 
We live in paranoia

Administration cannot offer us security in our jobs

Continual sense of Insecurity

When we share some of our story we are making it safe for others to share theirs as well

We can promote the relief of those who are suffering and help them grow in times of trouble

Our humor leaves pathways open for people to be more comfortable to discuss things they Fear

Our humor allows people to feel more relaxed, especially when it is self referential or about the world

We are a safe spece for those who don't fit into the norm because of the pressures of school, expected life timelines, due to sexual phobias, or any number of nonnormative experiences.

We are detached from the need for security since we ae never fully safe

\section{Faith}

We Are Easter People

Because we see how far we have risen personally

We can see the Church in ourselves

The Work of the Church is our own work; we are the church

We can witness to love in a new way through our lives

We become the exceptions to the rules, especially when the leadership is non-Catholic

Non-Catholics in leadership in the schools can be confused about the issue with our queerness

We are an Easter People

We live the truth of the Catholic Social Teaching that it is more than just surviving in the midst of Oppression, it is about learning to thrive

"Catholic Identity" has been employed as a catch phrase/movement that is a Risk to queer teachers in schools

We know what is really going on because we have seen the hidden lives of others (esp. clergy)

We are made to live with hypocracy on the issue which Threatens our security the most

Ministerial exception to legal protections for teachers has been extended to all teachers in Catholic schools or is being tried to in order to make firing easier

To be seen as a minister in the work of education was once positive but now becomes a Threat to queer teachers

Firings remind us that the Church is looking at two real issues in their decisions: one is the question of poverty as when a teacher loses their position and struggles to be employed, the other is the question of moral acceptability as in the case of queer lives going against teaching of the Faith...in the end it is the morality issue that wins out, it is ultimately about the teachings and not the person

We must live with Power being manipulated in ways that always protect the school and Church 
Our depression can enable us to be able to help students who go through the same (this is the redemption of suffering)

In our dioceses we see that in the hierarchy there are those who are Threats to us because of their positions to oversee morality in schools (aka: anti-queer) [Bishops and Superintendents]

Administrators have their jobs on the line in places in which unions may protect teachers but the school leadership fall directly underneath the oversight of the hierarchy

There is a sense of a story that we are child molestors that is stirred up in the conversations of the sex scandal which blames sex abuse on gay identity

There is a sense that parents will think that we are trying to indoctrinate children "I don't want them to turn my kid gay"

Uber conservative parents hold to moral orthodoxy and are adept at dismantling progressive theology by putting it in a frame of Faithful $v$ unFaithful teachings... it becomes a kind of neo-inquisition which is happening in the Church today

The issues and psychoses of the writers of theology gets passed along with the teachings themselves (Augustine, Aquinas, Luther, Puritans...) as the general milieu of sexuality

Homosexuality is focal point for the internalized shame present in our theology

Unrefined theology is lived and perpetuates the self-hatred of the fathers of the teachings

There is an insistence that we are silent about the issue which means that we are unable to re-story and transform theologies through our lived experience (orthodoxy as norm)

Queers feel the internal divide of "Love the sinner but hate the sin"

Our religious teachings are the underpinning of our school character and it is also the facet which leads to homophobia, yet we are the teachers of it in our Presence at the institution

Queer teachers often are the recipients of the very injustices from the Church that they fight against by Church teaching

Queer teachers must wrestle with the question "Am I good?"

We teach that all are made in the image and likeness of God and, so, wish to show to our students that we are all good; yet the shame placed upon us and lived in our hiding speaks against the teaching and hurts the students in believing this truth

We are brave for even being in a Catholic school

We grow in the virtues

I must be reminded that I am intrinsically Disordered

Queer teachers are stuck in the cycling thoughts of "how can this be wrong or seen as evil?"

\section{Fear}

Look how much Fear has been diminished for queer teachers already

Our humor leaves pathways open for people to be more comfortable to discuss things they Fear

The Power of the Fear that we live in is that it pushes us into Power and Agency 
When we move beyond Fear (or tell the story of our lives moving into self-Power when coming out to ourselves) we then give the gift of truth/ Power to our students

Since we have lived in such deep Fear, we are able to come alongside others in Fear as well

We live in paranoia

We need to constantly monitor ourselves in school, not to share our joys lest they become negative images of us

We are not able to bring stories of love for Fear of the consequence

Xenophobia, more than homophobia is the problem

Fears of may kinds of difference exist in the Catholic school (race, gender, sexuality, etc.)

We know that there are real Risks that we experience as possibility (harm, rejection, loss of employment, etc.)

Queer live in Fear

Our own Fear keeps us from being able to speak against the internalized Fears of our queer students because it is a Threat to us to help them

Queer Fears exist beyond the school but the Threats of the institution call to mind daily the Threats that we expeirnce on the streets (We encounter this violence in homilies as well)

\section{Solidarity}

There is a sense of true comradery in the human endeavor of life in actions like Teach Acceptance

Does the Catholic school make this sense of Solidarity real or is it in spite?

Logical Community-that Community that we choose as queers who make up Safety and life-giving

We build love in our school Community by creating Relationships with youth an adults in things like Teach Acceptance

We build love by being there for students in a way that we never had in schools

By being in personal Relationships with others in our schools we transform the sense of justice and Solidarity in our Community

We show that the locus of Solidarity is in the work of justice in our current cry for right treatment

We change the school by changing faculty hearts who then advocate with students

Since we have lived in such deep Fear, we are able to come alongside others in Fear as well

Our affect on improving our lives in schools is indirect because we need allies to speak on our behalf

The burden is on us to convince others that this issue is something they must fight for as well 


\section{Discerning Presence}

We are always watching the world around us and Silencing parts of ourselves

All issues are painted in the stark "good and bad" narrative

Queers must always ask who they can be comfortable with in the school and share a bit about their life

In dealing with queerness, there is no gray area or dialogue

Firings remind us that the Church is looking at two real issues in their decisions: one is the question of poverty as when a teacher loses their position and struggles to be employed, the other is the question of moral acceptability as in the case of queer lives going against teaching of the Faith...in the end it is the morality issue that wins out, it is ultimately about the teachings and not the person

When we move beyond Fear (or tell the story of our lives moving into self-Power when coming out to ourselves) we then give the gift of truth/ Power to our students

We are able to show that the issue of sexuality in Catholic schools has import beyond us: i.e., divorced persons, alternative partnerships, sexual ethics, etc.

We are able to find meaning and joy in light of all the bad

Our humor leaves pathways open for people to be more comfortable to discuss things they Fear

Our humor allows people to feel more relaxed, especially when it is self referential or about the world

We are able to reveal reality about difference, Oppression, ourselves

When we share with faculty who are curious about our lives, we teach by giving people freedom to learn about our lives

Our queer lives bring light to what is happening in the normative world in terms of Oppression and privilege

We are able to discern the reality of straight privilege and its claim to being the norm We can open up a language of fluidity in a binary world

We can help others who are caught in a binary tensions to live in the grey of this worlds

We see more than black and white

We work against the "Macho Watcho" vibe that can permeate a school Community

\section{Presence}

We give hope by being in the struggle ourselves

We do not always need to be overt in our ways to be in the struggle

Our very Presence in schools in the midst of the Oppression is a light of hope and a work of Activism

We make issues of queer justice by existing in these spaces even if we are not referencing them directly 
Recognition that is given to us can become a space for Community for the queer Community if it is present

Queer love is limited in its expression because I cannot bring my full loving self to the table

We are not able to bring stories of love for Fear of the consequence

Queer existence is always seen as a problem- administration always see us from a problematic viewpoint and speak in that way

We rarely get acknowledged for the gifts that our queerness brings (Could there be thankfulness for the queer Presence?)

When we are fired it comes swiftly and Silences our rebuttal so as to protect the administration from being called into question for our Presence

Our religious teachings are the underpinning of our school character and it is also the facet which leads to homophobia, yet we are the teachers of it in our Presence at the institution

We are brave for even being in a Catholic school

\section{Other}

We constantly find ourselves questioning our bravery

Shame is redoubled by means of the negative light put on queer teachers in : contracts, consequences, rumor mills in schools which often seek to point out immorality, and the deferred shame that others don't want to feel and therefore can be placed on us as scapegoats

There is a sense that I am less human because I am not the norm

Queer teachers use an unhealthy skill of self-monitoring that keeps us safe from being fired

Queers are made to cope in the Catholic schools in ways that can be unhealthy

Heterosexual lives are the strict norm

Queer men are measured against gendered norms...we see this in the kinds of language that is used to shame or negate a person (you talk like girls, etc.)

Our discussion was limited by lack of gender representation

The burden of proof that we are not in the wrong always falls to us in matters of sexuality

We know how to see things from many angle, to revision things, and to queer it We are able to see things in new ways and produce new curricula

We bring in creativity 
